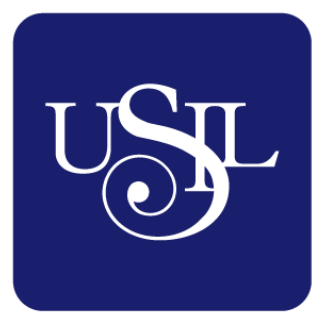

UNIVERSIDAD

SAN IGNACIO

DE LOYOLA

ESCUELA DE POSTGRADO

Maestría en Administración de Negocios - Executive MBA

\title{
IMPLEMENTACIÓN DE UN CENTRO DE BENEFICIO AVÍCOLA CON BUENAS PRÁCTICAS DE MANUFACTURA
}

Tesis para optar el grado de Maestro en Administración de

Negocios - Executive MBA

\author{
CHRISTIAN GAGO SILVA \\ VIOLETA FERNÁNDEZ LOCATELLI
}

Asesor

Miguel Solano Morales

Lima - Perú

2018 


\section{RESUMEN EJECUTIVO}

El presente plan de negocio propone ofrecer el servicio de beneficio y peladuría de pollos que opere con un modelo de gestión certificado con buenas prácticas de manufactura (BPM) cuya certificación la otorga el ente regulador (SENASA) siempre que se cumplan los requisitos de procesos inocuos que aseguren alimentos saludables, con procesos automatizados que disminuyan los riesgos de contaminación y con capacidad para cubrir una ventana horaria de 4 horas. Este servicio está diseñado para satisfacer la demanda de clientes que cuentan con servicios similares pero informales y sin las condiciones de higiene e inocuidad que exige el tipo de producto con el que se trabaja como es el pollo fresco. Esto permite además que el cliente compare rápidamente este servicio con los de la competencia y pueda optar por el ofrecido en este negocio.

El plan de negocio contempla la constitución de una empresa del modelo Sociedad Anónima Cerrada con la razón social: CBA Doña Viole S.A.C. la cual estará ubicado en la ciudad de Lima, distrito de San Juan de Lurigancho y estará soportada por una pequeña estructura organizativa lo suficientemente ágil y dinámica de acuerdo a las características del negocio.

El factor de diferenciación que permitirá diferenciar al CBA Doña Viole del resto de peladurías es la garantía de inocuidad e higiene, evidenciada a través de la certificación BPM. Para los clientes usuarios del servicio la propuesta de valor estará expresada en "Asegurar el negocio con un proceso de pelado de calidad, que entregue 
un pollo saludable, en el tiempo adecuado, que alargue su tiempo de vida y que el consumidor final lo prefiera".

Para el consumidor final la propuesta de valor estará expresada en el slogan: "Pollo saludable para tu familia, pelado con la mejor calidad" ya que el posicionamiento deseado para este negocio es que el consumidor termine solicitando al cliente usuario del servicio pollos beneficiados en la peladuría Doña Viole, como la mejor alternativa para el pelado del pollo.

Teniendo en cuenta la alta demanda actual y potencial de este servicio y además las consideraciones legales, sanitarias y técnicas que implica esta propuesta, se ha realizado la evaluación económica y financiera con una proyección a cinco años concluyendo que se trata de un plan de negocio rentable y factible de implementar.

Se ha estimado una inversión total de S/ 617,072 la que considera únicamente aporte de capital a través de los socios, inversión que genera un VANE positivo de S/ 133,917 y con flujos de caja positivos desde el primer año de operación por tratarse de un modelo con pago al contado. La inversión realizada por los accionistas será recuperada en un periodo de 4 años y 7 meses.

Se trata de una propuesta de negocio única e innovadora ya que hasta la fecha no existen modelos similares implementados y se encuentra en medio de una oportunidad también única donde la coyuntura gubernamental, los temas vinculados a la salud e inocuidad de los productos, las cada vez más rigurosas políticas de cuidado al medio ambiente entre otros aspectos son cubiertas en este plan de negocio. 


\section{ÍNDICE}

CAPÍTULO I

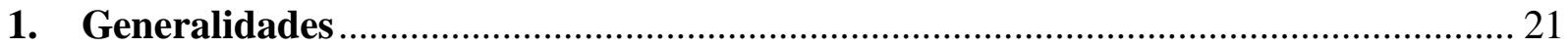

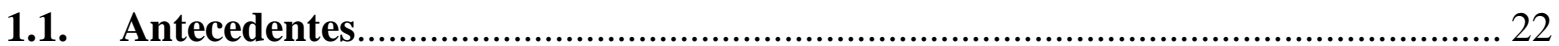

1.2. Determinación del problema u oportunidad ............................................ 24

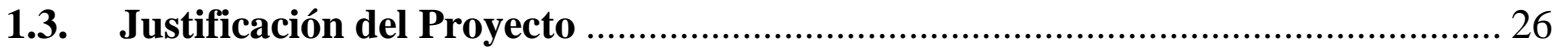

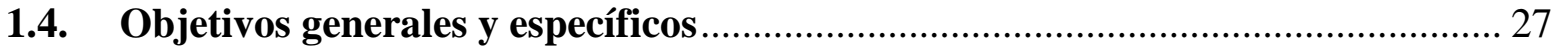

1.5. Alcances y limitaciones de la investigación ..................................................... 29

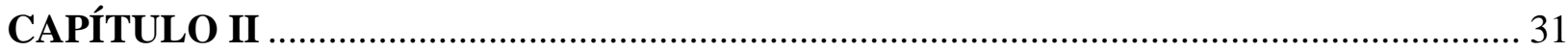

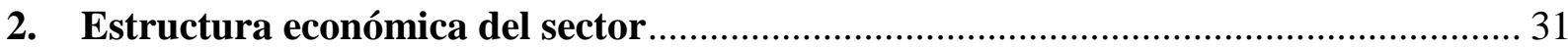

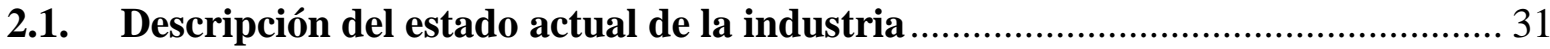

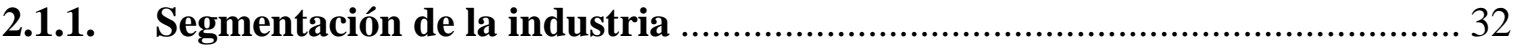

2.1.2. Empresas que la conforman (ubicación, volumen de ventas, empleados, etc.) 34

2.2. Tendencias de la industria (crecimiento, inversiones) .................................. 37

2.3. Análisis Estructural del Sector Industrial ...................................................... 38

2.4. Análisis de la Competencia .................................................................... 50

2.4.1. Empresas que ofrecen el mismo producto o servicio, indicando las semejanzas y diferencias que tienen con el proyecto de empresa ........................... 50 
2.4.2. Participación de mercado de cada uno de ellos ........................................ 51

2.4.3. Matriz de perfil competitivo .............................................................. 53

2.5. Análisis del Contexto Actual y Esperado ..................................................... 57

2.5.1. Análisis Político-Gubernamental ......................................................... 57

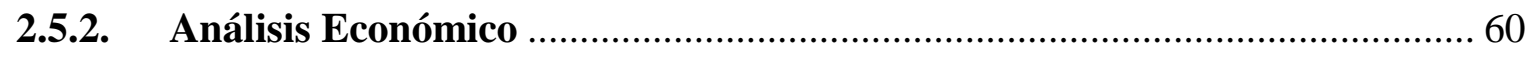

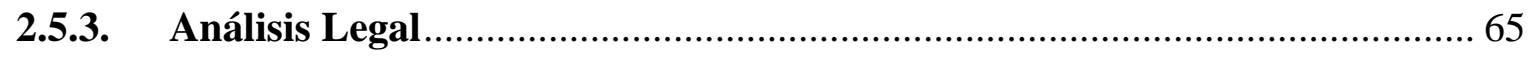

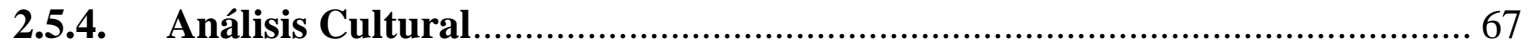

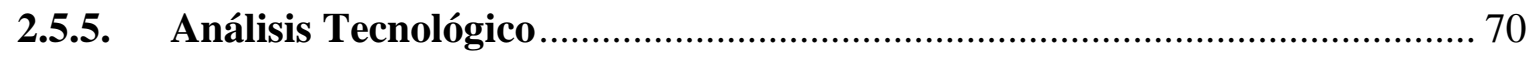

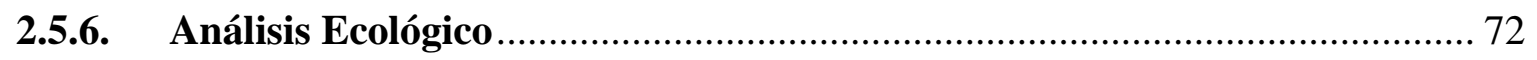

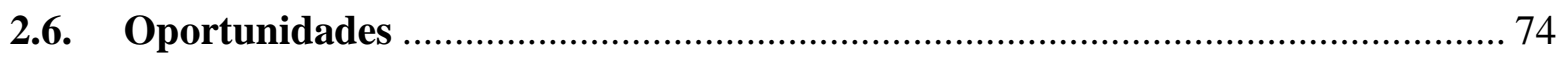

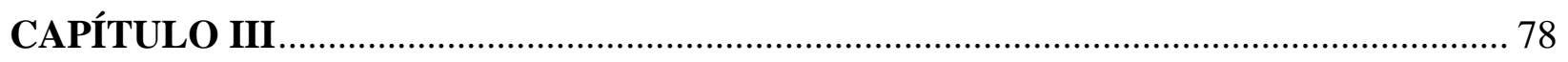

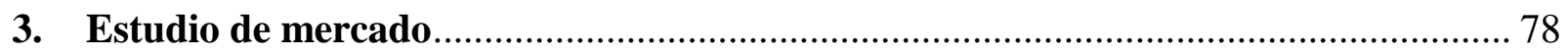

3.1. Descripción del servicio o producto ........................................................... 78

3.2. Selección del segmento de mercado .......................................................... 80

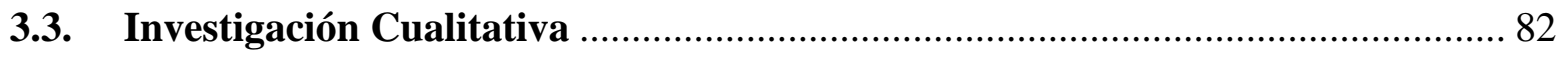

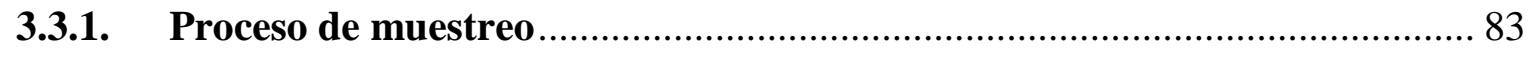

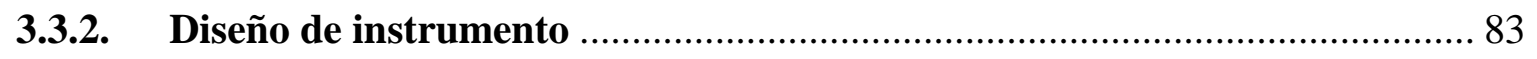

3.3.3. Análisis y procesamiento de datos ................................................. 84

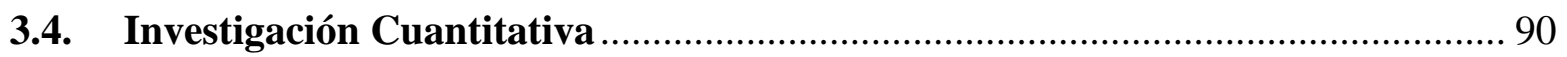

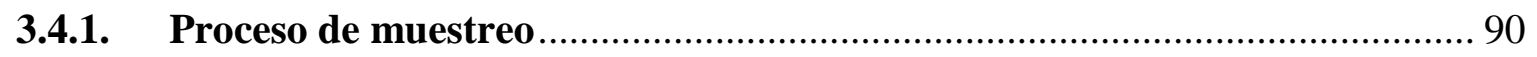




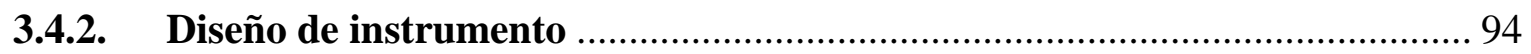

3.4.3. Análisis y procesamiento de datos ...................................................... 95

3.5. Conclusiones y recomendaciones del Estudio Cualitativo y Cuantitativo......... 105

3.6. Perfil del consumidor tipo y sus variantes................................................ 110

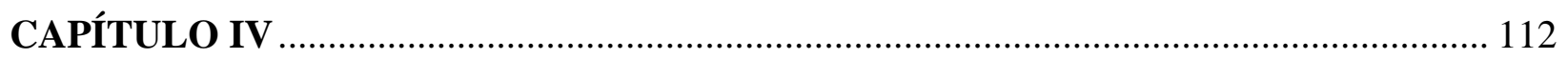

4. Proyección del mercado objetivo ..................................................................... 112

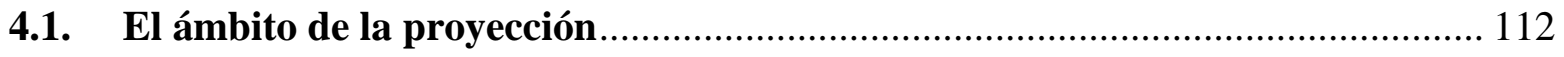

4.2. Selección del método de proyección .............................................................. 115

4.2.1. Mercado Potencial ................................................................................ 116

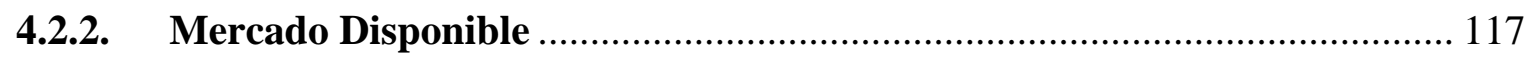

4.2.3. Mercado Efectivo................................................................................. 118

4.2.4. Mercado Objetivo............................................................................ 120

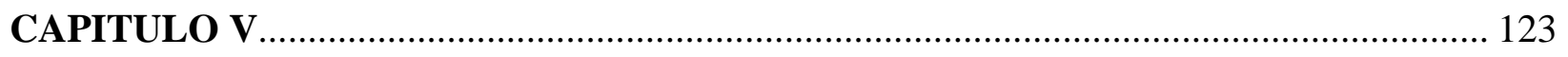

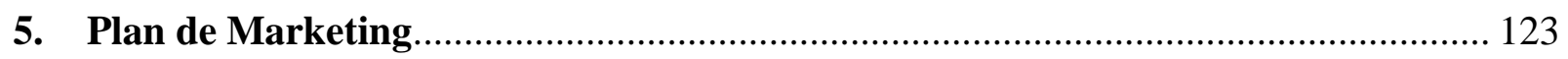

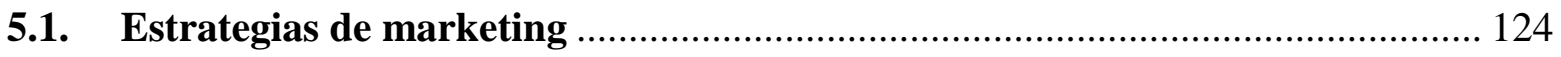

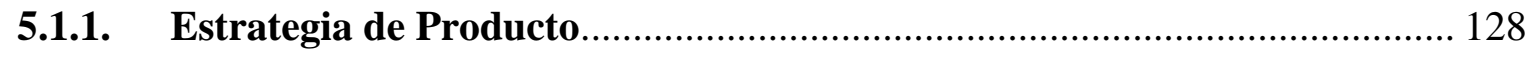

5.1.2. Estrategia de Precio .................................................................... 133

5.1.3. Estrategia de Plaza y Distribución.................................................. 136

5.1.4. Estrategia de promoción y publicidad................................................ 137

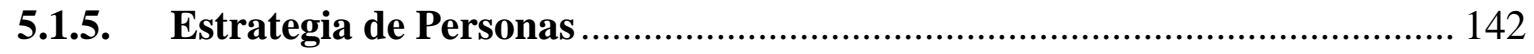


5.1.6. Estrategia de Procesos .................................................................. 143

5.1.7. Estrategia de Presencia Física ............................................................ 144

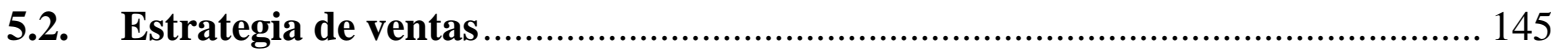

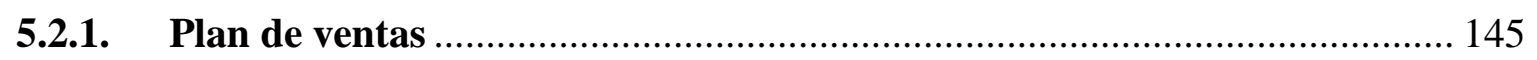

5.2.2. Políticas de servicios y garantías....................................................... 146

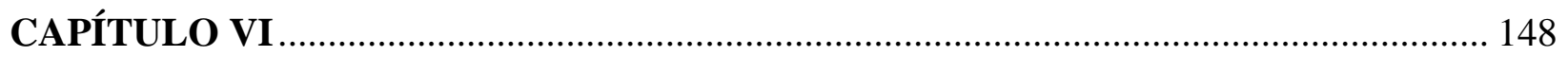

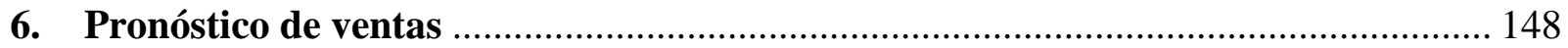

6.1. Fundamentos y supuestos .................................................................... 148

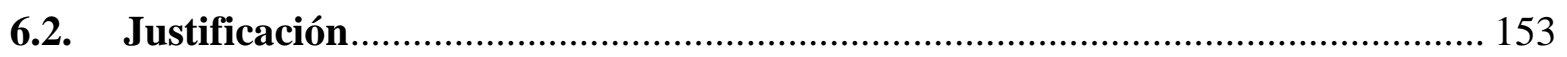

6.3. Análisis de los riesgos y aspectos críticos que impactan en el pronóstico ......... 155

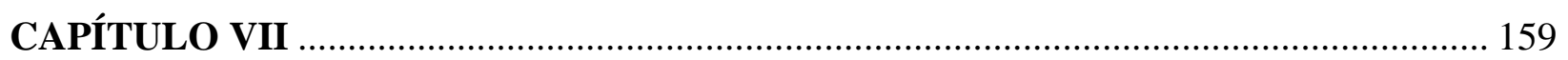

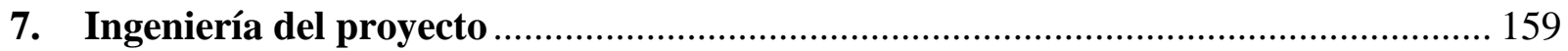

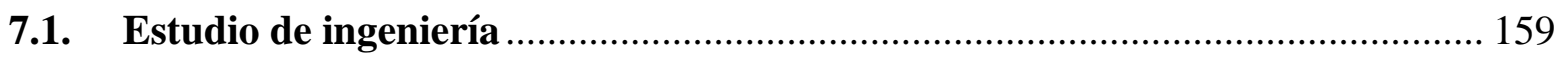

7.1.1. Modelamiento y selección de procesos productivos ............................... 159

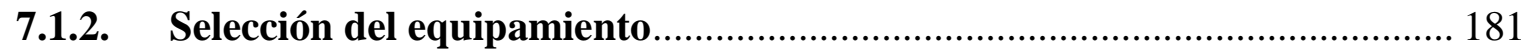

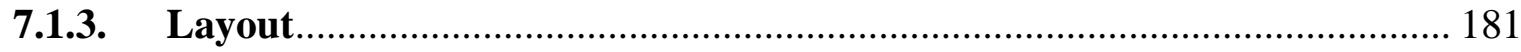

7.1.4. Distribución de equipos y maquinarias .............................................. 182

7.2. Determinación del Tamaño..................................................................... 183

7.2.1. Proyección de crecimiento ................................................................ 183

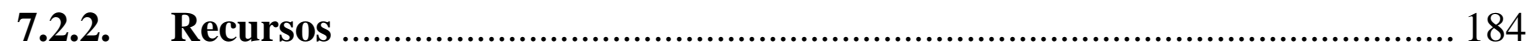




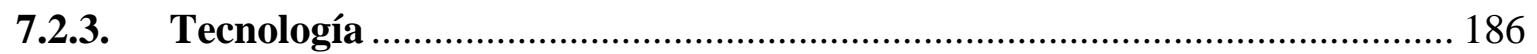

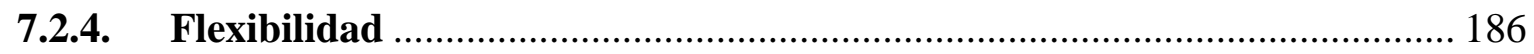

7.2.5. Selección del tamaño ideal....................................................................... 187

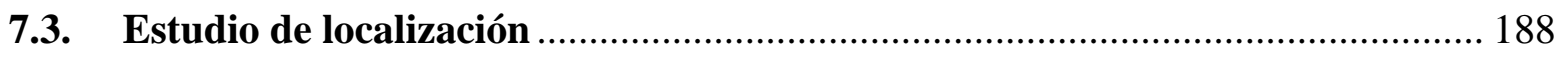

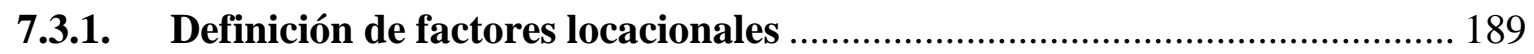

7.3.2. Consideraciones legales........................................................................... 193

7.3.2.1. Identificación del marco legal................................................................... 193

7.3.2.2. Ordenamiento jurídico de la empresa ………………………………...... 199

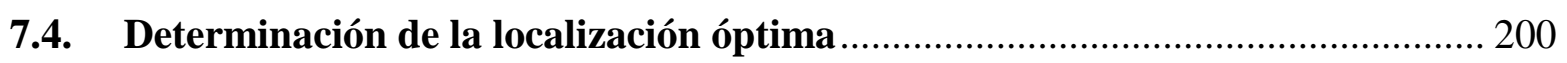

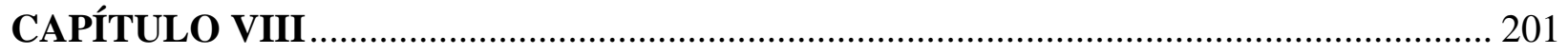

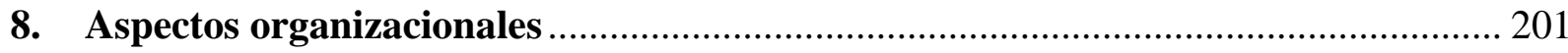

8.1. Caracterización de la cultura organizacional deseada .................................... 201

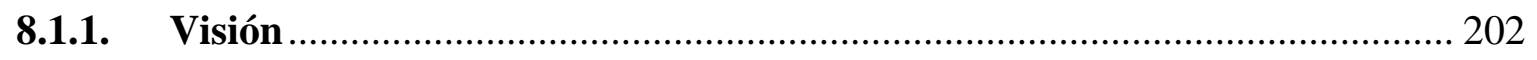

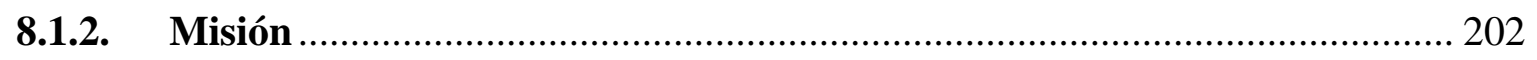

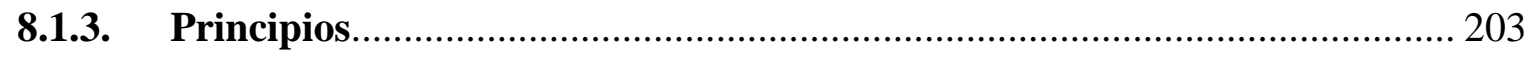

8.2. Formulación de Estrategias del Negocio ……………...................................... 204

8.3. Determinación de las ventajas competitivas críticas ………………………........ 206

8.4. Diseño de la estructura organizacional deseada ............................................. 207

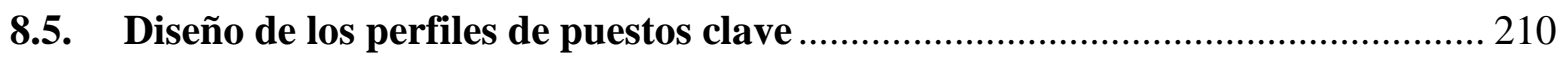

8.6. Remuneraciones, compensaciones e incentivos................................................. 216 
8.7. Política de recursos humanos ............................................................... 217

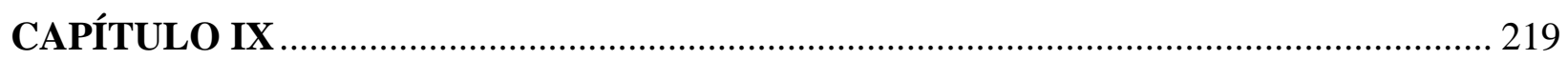

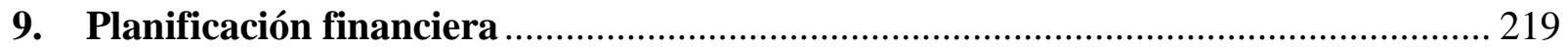

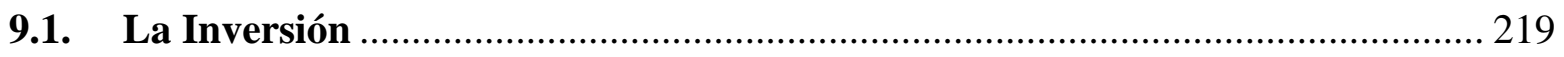

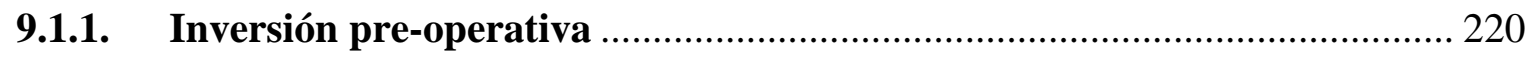

9.1.2. Inversión en capital de trabajo ......................................................... 221

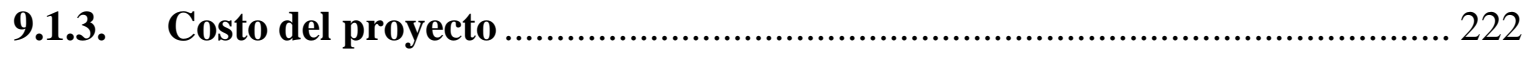

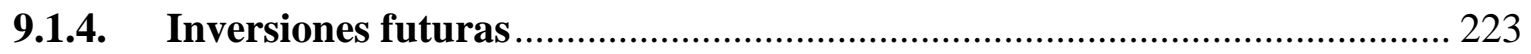

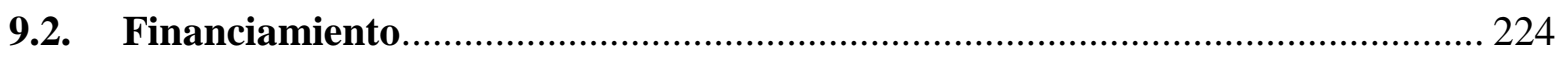

9.2.1. Endeudamiento y condiciones ............................................................. 224

9.2.2. Capital y costo de oportunidad ...................................................... 224

9.2.3. Costo de capital promedio ponderado............................................... 227

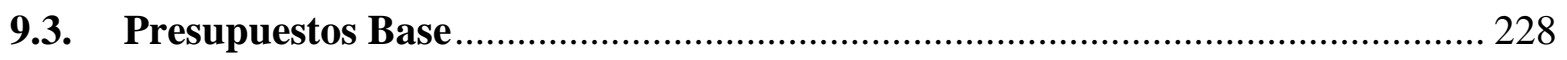

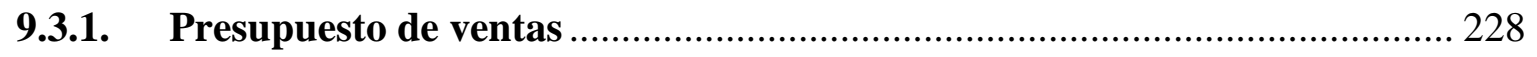

9.3.2. Presupuesto de costos de producción ................................................... 229

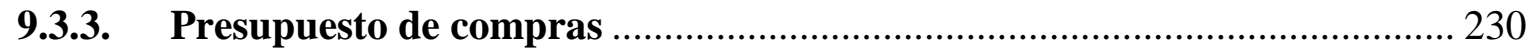

9.3.4. Presupuesto de costo de ventas ........................................................ 231

9.3.5. Presupuesto de gastos administrativos .............................................. 231

9.3.6. Presupuesto de marketing y ventas .................................................. 232

9.3.7. Presupuesto de gastos financieros.................................................... 233 
9.4. Presupuestos de Resultados

9.4.1. Estado de ganancias y pérdidas proyectado .......................................... 234

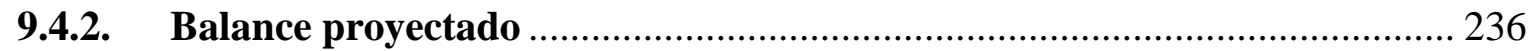

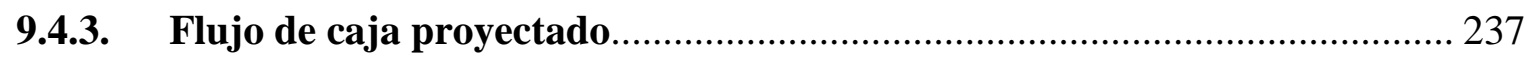

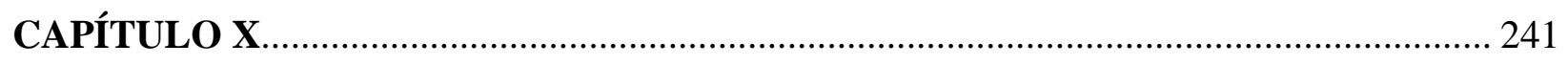

10. Evaluación económico financiera …........................................................... 241

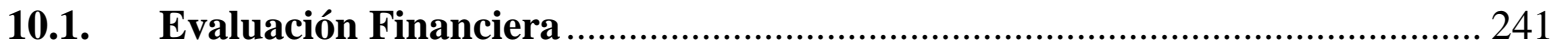

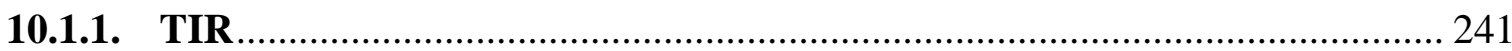

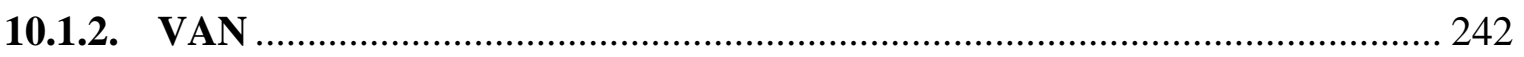

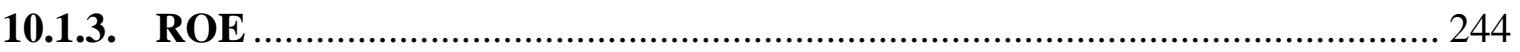

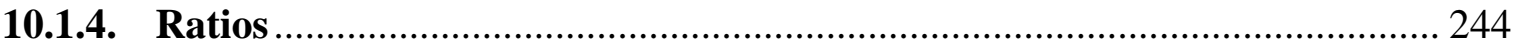

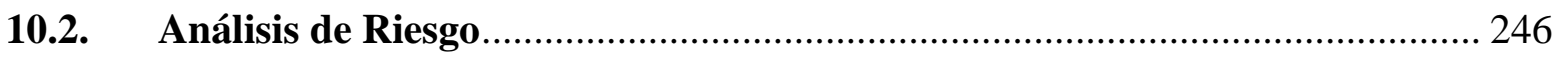

10.2.1. Análisis del punto de equilibrio ..................................................... 247

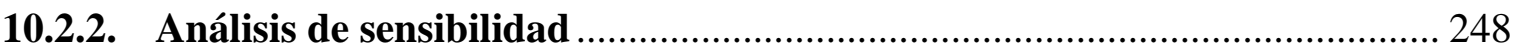

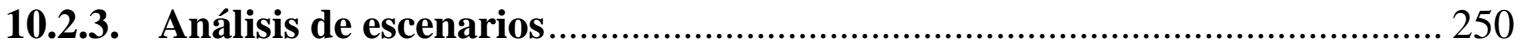

CONCLUSIONES Y RECOMENDACIONES …......................................................... 253

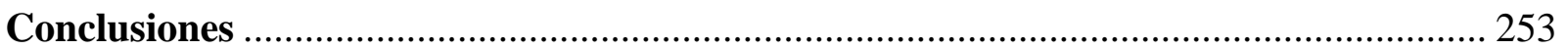

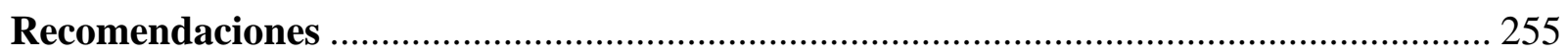

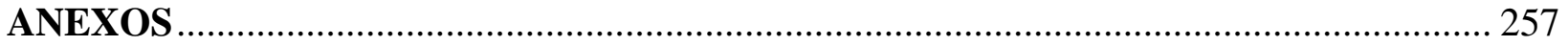

Anexo $\mathbf{N}^{\circ}$ 1: Entrevista a profundidad $\mathbf{N}^{\circ} 01$ - Especialista del sector........................ 257 
Anexo $\mathrm{N}^{\circ}$ 2: Entrevista a profundidad $\mathrm{N}^{\circ} 02$ - Especialista del sector.

Anexo $N^{\circ}$ 3: Entrevista a profundidad $N^{\circ} 03$ - Cliente potencial. 269

Anexo $N^{\circ}$ 4: Entrevista a profundidad $N^{\circ} 04$ - Cliente Actual. 273

Anexo $N^{\circ}$ 5: Entrevista a profundidad $N^{\circ} 05$ - Competidor Relacionado. 278

Anexo $N^{\circ}$ 6: Ficha técnica de la Encuesta 283

Anexo $\mathrm{N}^{\circ}$ 7: Modelo de encuesta para avícolas y picadores 284

Anexo $\mathbf{N}^{\circ}$ 8: Selección de equipamiento. 285

Anexo $\mathrm{N}^{\circ}$ 9: Autorización sanitaria de apertura y funcionamiento de centros de

faenamiento. 292

Anexo $\mathrm{N}^{\circ}$ 10: Detalle de la inversión inicial. 294

Anexo $N^{\circ}$ 11: Detalle de depreciaciones y amortizaciones. 297

Anexo $\mathrm{N}^{\circ}$ 12: Detalle de la reinversión. 299

Anexo $\mathrm{N}^{\circ}$ 13: Tabulación de la encuesta. 300

Anexo $N^{\circ}$ 14: Detalle de costos y gastos. 302

BIBLIOGRAFÍA. 304 


\section{ÍNDICE DE FIGURAS}

Figura $\mathrm{N}^{\circ}$ 1: Participación de mercado en Lima Metropolitana y Callao de empresas productoras

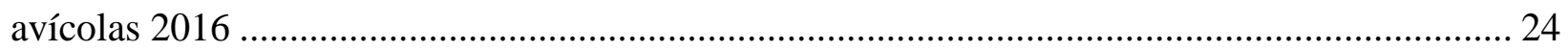

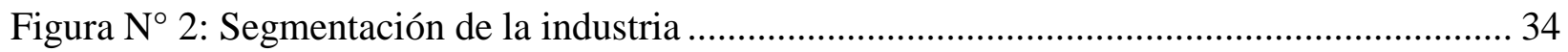

Figura $\mathrm{N}^{\circ}$ 3: Cadena de distribución desde la granja hasta el consumidor final ........................... 39

Figura $N^{\circ}$ 4: Aplicación de Cinco Fuerzas de Porter - Estructura de la Industria ........................ 40

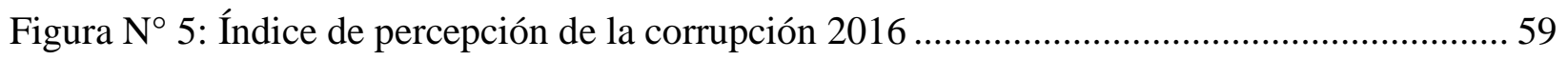

Figura $\mathrm{N}^{\circ}$ 6: Daños generados por el Fenómeno del Niño ………………………….................. 62

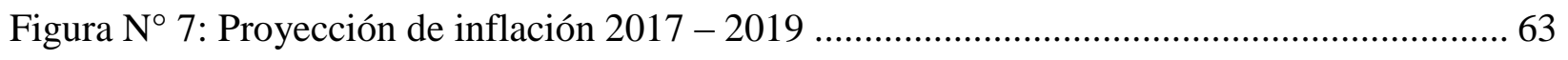

Figura $\mathrm{N}^{\circ}$ 8: Evolución y proyección del tipo de cambio............................................................ 64

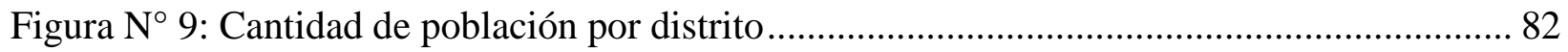

Figura $\mathrm{N}^{\circ}$ 10: Atributos más valorados por las avícolas y picadores …………………………... 102

Figura $\mathrm{N}^{\circ}$ 11: Determinación del mercado potencial ............................................................ 116

Figura $\mathrm{N}^{\circ}$ 12: Determinación del mercado disponible …………........................................... 118

Figura $\mathrm{N}^{\circ}$ 13: Determinación del mercado efectivo ……......................................................... 120

Figura $\mathrm{N}^{\circ}$ 14: Determinación del mercado objetivo …………….............................................. 121

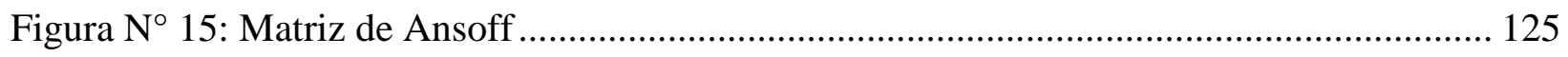

Figura $\mathrm{N}^{\circ}$ 16: Producto inicial y final del servicio del CBA Doña Viole ................................... 129

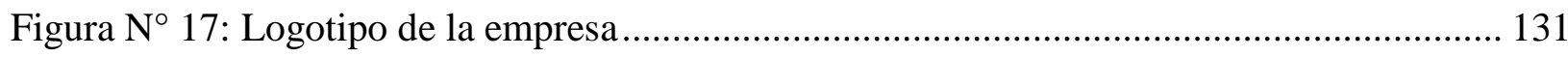

Figura $\mathrm{N}^{\circ}$ 18: Modelo de empaque para clientes usuarios ....................................................... 132

Figura $\mathrm{N}^{\circ}$ 19: Modelo de empaque para consumidor final..................................................... 133

Figura $\mathrm{N}^{\circ}$ 20: Canal de distribución mayorista …….............................................................. 137 
Figura $\mathrm{N}^{\circ} 21$ : Modelo de publicidad en puesto de mercado................................................. 138

Figura $\mathrm{N}^{\circ}$ 22: Cronograma de actividades del plan de ventas - año 2018 ............................. 146

Figura $\mathrm{N}^{\circ}$ 23: Macro Proceso, procesos y sub procesos de beneficio de pollo ........................ 160

Figura $\mathrm{N}^{\circ} 24$ : Macro proceso beneficio de pollo ........................................................... 161

Figura $\mathrm{N}^{\circ}$ 25: Fotografía del colgado de pollo vivo ..................................................... 163

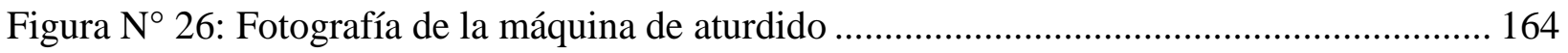

Figura $\mathrm{N}^{\circ}$ 27: Fotografía del proceso de sangrado ...................................................... 166

Figura $\mathrm{N}^{\circ}$ 28: Fotografía de la máquina del proceso de escaldado ...................................... 167

Figura $N^{\circ}$ 29: Fotografía exterior de la máquina del proceso de desplumado.......................... 168

Figura $\mathrm{N}^{\circ}$ 30: Fotografía de la salida del pollo ya pelado ............................................... 169

Figura $\mathrm{N}^{\circ}$ 31: Fotografía maquinaria para el requemado ................................................ 170

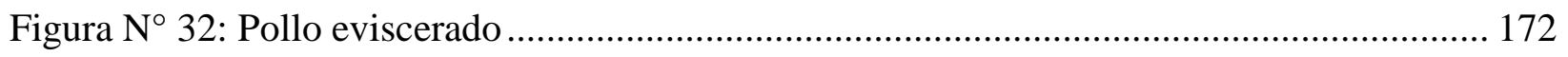

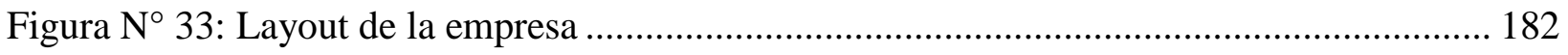

Figura $N^{\circ}$ 34: Distribución de equipos en el área de operaciones ........................................ 183

Figura $\mathrm{N}^{\circ}$ 35: Plano de la macro localización de la empresa .............................................. 191

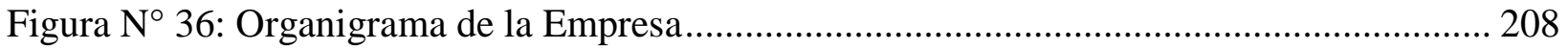




\section{ÍNDICE DE TABLAS}

Tabla $\mathrm{N}^{\circ}$ 1: Proyección de crecimiento de producción de pollo en Lima Metropolitana..... 37

Tabla $\mathrm{N}^{\circ}$ 2: Matriz de atractividad - Ingreso de nuevos competidores .................................. 43

Tabla $\mathrm{N}^{\circ}$ 3: Matriz de atractividad - Poder de negociación con proveedores............................ 44

Tabla $N^{\circ} 4$ : Matriz de atractividad - Poder de negociación de los clientes .............................. 46

Tabla $\mathrm{N}^{\circ}$ 5: Matriz de atractividad - Amenaza de productos sustitutos................................... 47

Tabla $N^{\circ}$ 6: Matriz de atractividad - Rivalidad entre los competidores actuales ...................... 48

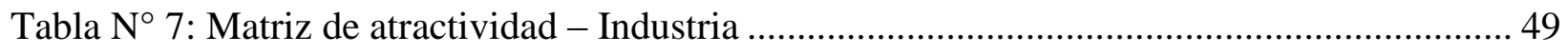

Tabla $\mathrm{N}^{\circ}$ 8: Participación de mercado por tipo de empresa................................................... 52

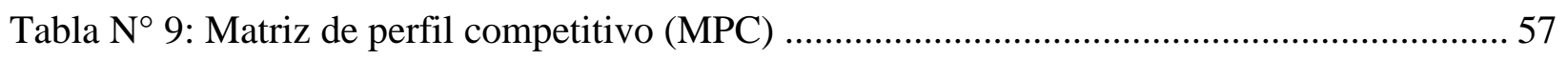

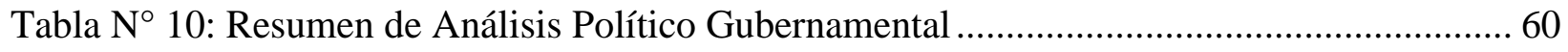

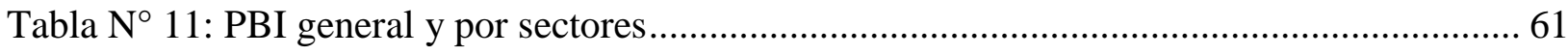

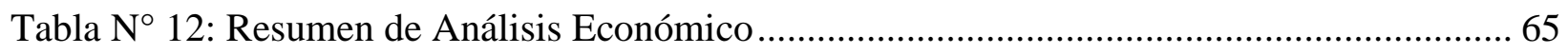

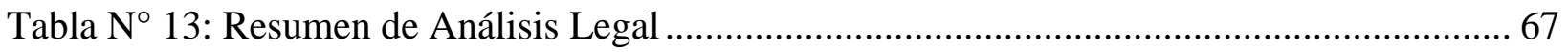

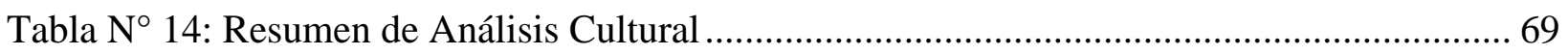

Tabla N 15: Resumen de Análisis Tecnológico .............................................................. 72

Tabla $N^{\circ} 16:$ Resumen de Análisis Ecológico ................................................................... 74

Tabla $N^{\circ}$ 17: Matriz de Evaluación de Factores Externos (EFE) ........................................... 75

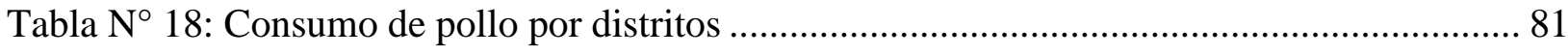

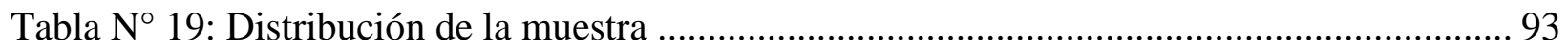

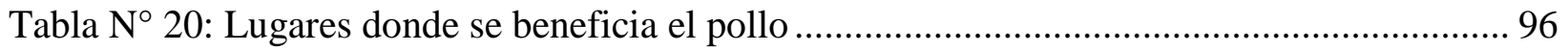

Tabla $\mathrm{N}^{\circ} 21$ : Centros de beneficio con suministro de agua potable ...................................... 97 
Tabla $\mathrm{N}^{\circ}$ 22: Cantidad de Trabajadores (peladores) necesarios .............................................. 98

Tabla $\mathrm{N}^{\circ}$ 23: Rango de cantidad de pollo beneficiado ....................................................... 99

Tabla $\mathrm{N}^{\circ}$ 24: Frecuencia de utilización del servicio de beneficio del pollo ............................. 100

Tabla $\mathrm{N}^{\circ}$ 25: Proveedores de pollo vivo para las avícolas y picadores …............................... 100

Tabla $\mathrm{N}^{\circ}$ 26: Costo promedio unitario para el beneficio del pollo ...................................... 101

Tabla $N^{\circ}$ 27: Porcentaje de aceptación de un CBA con BPM............................................... 103

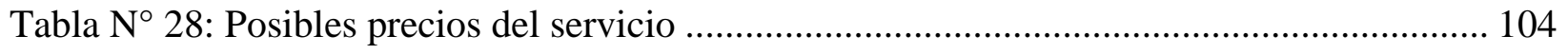

Tabla $\mathrm{N}^{\circ}$ 29: Perfil de cliente usuario del servicio ........................................................... 110

Tabla $\mathrm{N}^{\circ}$ 30: Perfil de cliente final o consumidor ........................................................... 111

Tabla $\mathrm{N}^{\circ}$ 31: Participación de mercado y variación anual................................................... 122

Tabla $\mathrm{N}^{\circ}$ 32: Comparativa de precio actual, precio que están dispuestos los clientes a realizar y

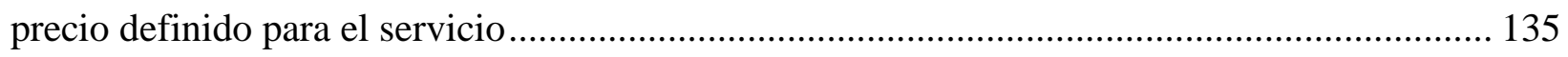

Tabla $N^{\circ}$ 33: Evolución del mercado objetivo en años 2018 - 2022 ................................... 149

Tabla $\mathrm{N}^{\circ}$ 34: Cálculo de la frecuencia de utilización del servicio ........................................ 150

Tabla $N^{\circ}$ 35: Cálculo de la cantidad de pollo que se beneficia al utilizar el servicio................ 151

Tabla $N^{\circ}$ 36: Evolución de la demanda 2016-2022 …...................................................... 152

Tabla $N^{\circ}$ 37: Porcentaje promedio de variación anual de la demanda del servicio 2016-2022 . 152

Tabla $N^{\circ}$ 38: Cantidad de pollo beneficiado por cliente 2017-2022 ..................................... 153

Tabla $\mathrm{N}^{\circ}$ 39: Pronóstico de ventas anuales ................................................................... 153

Tabla $\mathrm{N}^{\circ}$ 40: Tabla de distribución de ventas ................................................................... 154

Tabla N 41: Pronóstico de ventas mensual año 2018....................................................... 155

Tabla $\mathrm{N}^{\circ} 42$ : Especificaciones técnicas por proceso ..................................................... 174

Tabla $\mathrm{N}^{\circ} 43$ : Detalle de capacidad de planta ............................................................... 175 


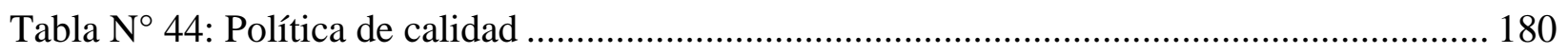

Tabla $N^{\circ}$ 45: Detalle de recursos para la operación................................................................... 184

Tabla $\mathrm{N}^{\circ}$ 46: Detalle de recursos para el despacho................................................................. 185

Tabla N ${ }^{\circ}$ 47: Detalle de recursos para la limpieza..................................................................... 185

Tabla $N^{\circ}$ 48: Demanda diaria del servicio y nivel de utilización .................................................. 188

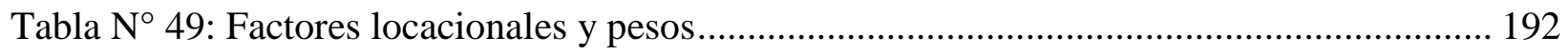

Tabla Nº 50: Alternativas micro localización......................................................................... 192

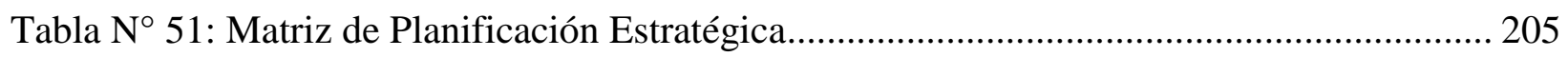

Tabla $\mathrm{N}^{\circ}$ 52: Número de trabajadores de la empresa ……...................................................... 209

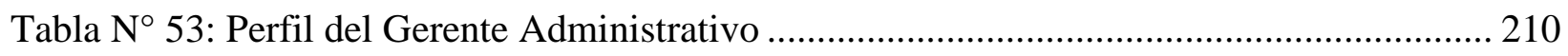

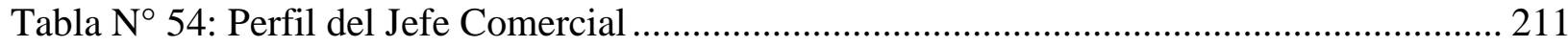

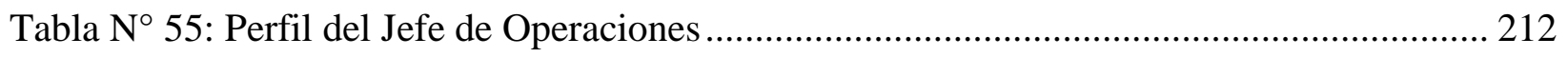

Tabla N $N^{\circ}$ 56: Perfil del Asistente Administrativo y GGHH ........................................................ 214

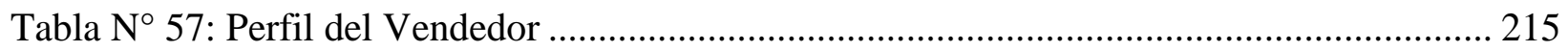

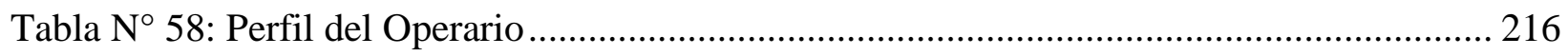

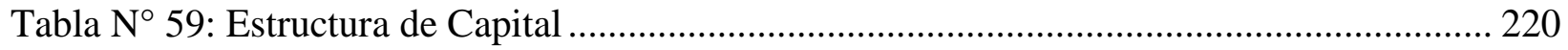

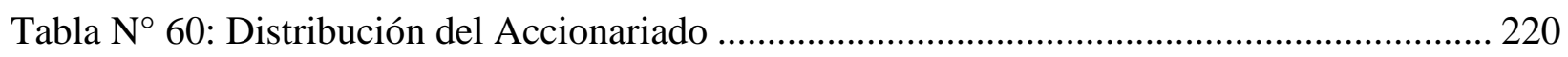

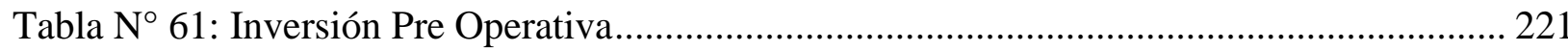

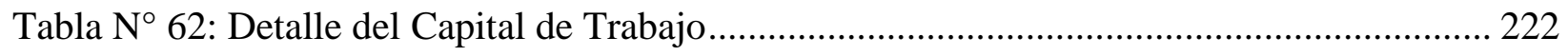

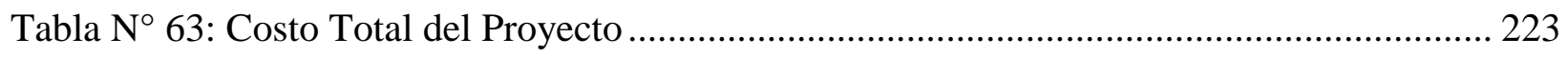

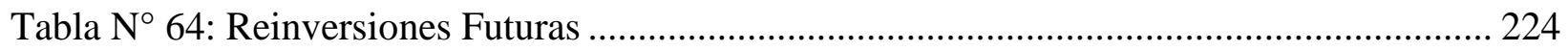

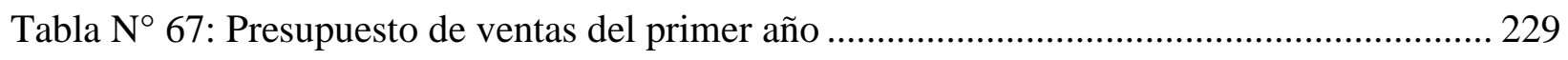

Tabla N ${ }^{\circ}$ 68: Presupuesto de Costos de Producción........................................................................ 230 
Tabla $N^{\circ}$ 69: Presupuesto de Compras .............................................................................. 231

Tabla $N^{\circ}$ 70: Presupuesto de Gastos Administrativos ......................................................... 232

Tabla $N^{\circ} 71$ : Presupuesto de Marketing y Ventas .............................................................. 233

Tabla N ${ }^{\circ}$ 72: Estado de Ganancias y Pérdidas Proyectado.................................................... 235

Tabla $N^{\circ} 73$ : Balance General Proyectado .................................................................... 237

Tabla N ${ }^{\circ}$ 74: Flujo de Caja Proyectado Para el Balance General ........................................... 238

Tabla N ${ }^{\circ}$ 75: Flujo de Caja Proyectado Para Ratios de Rentabilidad ..................................... 239

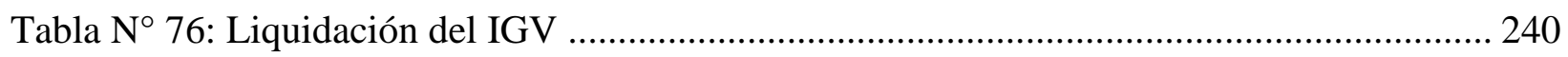

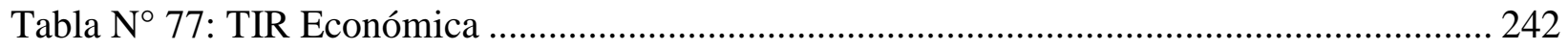

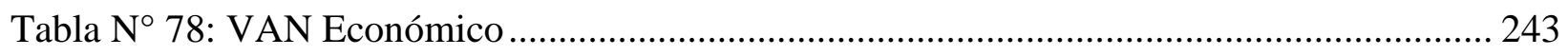

Tabla N 79: Periodo de Recuperación................................................................................. 243

Tabla $\mathrm{N}^{\circ}$ 80: Tabla de ROE del Proyecto ........................................................................ 244

Tabla $N^{\circ}$ 81: Ratio de Liquidez ................................................................................ 245

Tabla N 82: Razón de Endeudamiento............................................................................ 245

Tabla $N^{\circ}$ 83: Ratios de Rentabilidad ............................................................................ 246

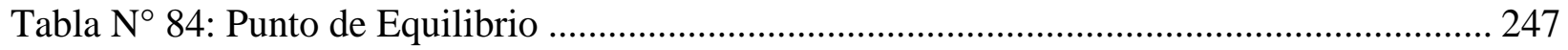

Tabla $\mathrm{N}^{\circ}$ 85: Flujos y TIR con $-10 \%$ de Ingresos........................................................... 248

Tabla $N^{\circ}$ 86: Flujos y TIR con $-5 \%$ de Ingresos.............................................................. 249

Tabla N ${ }^{\circ}$ 87: Flujos y TIR con $+10 \%$ de Costos de Operación ............................................. 249

Tabla $N^{\circ} 88$ : Flujos y TIR con $-15 \%$ del Precio del Servicio.............................................. 250

Tabla $\mathrm{N}^{\circ}$ 89: Análisis de Escenarios.............................................................................. 252 


\section{INTRODUCCIÓN}

La publicación en junio del 2003 de la resolución ministerial para la comercialización de pollos que prohíbe que las aves vivas compradas por los dueños de los puestos del mercado de abasto (picadores) sean beneficiadas dentro de los centros de acopio o de los mercados de abasto, ha significado que las operaciones de beneficio deban ejecutarse en centros de beneficio formales que cumplan con las condiciones exigidas por las normas vigentes. Ante este escenario, y a pesar de las leyes que posteriormente fueron promulgadas en apoyo, han proliferado peladurías informales alrededor de los mercados que atienden esta nueva demanda sin las condiciones básicas que aseguren un producto saludable. El presente plan de negocio tiene como objetivo implementar un centro de beneficio avícola formalmente constituido y con procesos que garanticen la calidad e inocuidad del producto final aprovechando las oportunidades generadas en este entorno, creando así una alternativa de pelado de los pollos cumpliendo con las normas sanitarias y dando solución a la situación de informalidad existente, proporcionando una oferta de valor para los picadores que será reconocida y preferida por el consumidor final.

En el capítulo I se definen los antecedentes en cuanto a la comercialización de pollos en Lima Metropolitana determinando así el problema y las oportunidades que representan las políticas gubernamentales en este negocio, complementándolo con la descripción de los objetivos generales y específicos que se buscan en el proyecto, así como el alcance y limitaciones que se han considerado en la investigación. 
En el capítulo II se desarrolla el análisis del sector avícola, sus proyecciones y tendencias de mercado en torno a los volúmenes de crianza. Con esa información se segmenta el mercado ubicando al negocio de la peladuría analizando las oportunidades que harían viable el negocio.

En el capítulo III se describe la definición comercial del servicio de beneficio de pollos, sus características y donde estará ubicado geográficamente. Asimismo, se resumen las conclusiones de la investigación cualitativa y cuantitativa realizadas. Estas son utilizadas para entender cuál es el público objetivo, las propuestas de precios que están dispuestos a pagar por el servicio, entre otros.

El capítulo IV resume el análisis para cuantificar el mercado objetivo que se considerará en el plan de negocio y realizar las proyecciones en base a ello.

En el capítulo V se ha definido el mix de marketing y las estrategias de ventas que permitan el ingreso al mercado objetivo de este servicio.

El Capítulo VI calcula los pronósticos de ventas esperados desde el inicio de la operación del negocio y analiza los riesgos potenciales críticos que pueden impactar en éste.

En el Capítulo VII se analizan los equipos e infraestructura que se requieren para poner en marcha la Peladuría Doña Viole. Además considera los recursos, ubicación entre otros.

El Capítulo VIII detalla los aspectos organizacionales que ayudan a estructurar y gestionar la empresa incluyendo definiciones de misión, visión, principios operativos y políticas que sustenten el modelo. 
El Capítulo IX trata lo concerniente a la inversión requerida para implementar el plan de negocio, la fuente de financiamiento y el presupuesto. Con esa información se elaboran los presupuestos de resultados proyectados a cinco años para que sean utilizados en la evaluación del proyecto.

Finalmente, en el Capítulo X se realiza la evaluación económica financiera para analizar la factibilidad del plan de negocio.

Asimismo, se incorporan cálculos de los ratios financieros más relevantes así como riesgos en base a escenarios dando así un panorama completo del plan de negocio sobre todo por el tipo de industria en la que se desarrolla. 


\section{CAPÍTULO I}

\section{Generalidades}

El proyecto para la implementación de un Centro de beneficio avícola (CBA) operada con altos estándares de calidad y con buenas prácticas de manufactura, encuentra un entorno favorable como consecuencia de las normas de salubridad impuestas por el gobierno y distritos que exigen llegar a los consumidores con productos que no pongan en riesgo su salud al momento de su consumo. Este modelo de negocio es atractivo para una industria que se encuentra en constante crecimiento, con prácticas de crianza cada vez más exigentes en calidad pero que terminan perdiendo esa oferta de valor al momento del beneficio de las aves ya que en la actualidad no existen centros de beneficio de pollos que se preocupen por asegurar la preservación de los procesos hasta la llegada al cliente.

\section{Definiciones:}

- CBA: Centro de beneficio avícola que opera formalmente y cuenta con procesos sanitarios autorizados por los entes reguladores (municipalidad, SENASA entre otros).

- Avícolas: También llamadas minoristas son clientes que compran a mayoristas o distribuidores pollo vivo, los pelan en peladurías y los venden a los picadores.

- Peladurías: Lugares donde se benefician y pelan los pollos para luego ser comercializados en los puestos de mercado. Para realizar esta actividad es necesario contar con las licencias municipales y de SENASA que es el organismo regulador. 
- Picadores: Son clientes que tienen puestos en los mercados y compran pollos vivos que son beneficiados en las peladurías, en sus propios puestos (actividad realizada incluso estando prohibida) o en otros lugares. El pollo puede ser vendido entero o en cortes.

- Consumidor final: Clientes finales que compran el pollo en los puestos de mercado. Específicamente el ama de casa.

\subsection{Antecedentes}

En la actualidad, la producción avícola para carne de pollo se encuentra en constante crecimiento, en el periodo 2015 se generó un incremento del $7.9 \%$ con respecto al año anterior, según boletín estadístico mensual del sector avícola, diciembre 2015, disponible en http://www.minagri.gob.pe/portal/boletin-estadistico-mensual-de-laproduccion-y-comercializacion-avicola/sector-avicola-2015?download=8773: diciembre2015 y en el periodo 2016 se generó un incremento del 4.6\% con respecto al año 2015, según boletín estadístico mensual del sector avícola, diciembre 2016, disponible en http://www.minagri.gob.pe/portal/boletin-estadistico-mensual-de-la-produccion-y$\underline{\text { comercializacion-avicola/sector-avicola-2016?download=10599:sector-avicola- }}$

$\underline{\text { diciembre-2016 }}$ esto debido a que dicho producto (pollo) forma parte importante de la canasta familiar de una población que crece en Lima y al interior del país en forma sostenida durante los últimos años, la tasa de crecimiento de la población estimada para los años 2017 y 2018 es del 1.07\% y $1.06 \%$ respectivamente, según el INEI, disponible en http://www.inei.gob.pe/media/MenuRecursivo/Cap03020.xls. 
Esto conduce a que cada vez más comercializadoras de pollos se incorporen a este negocio buscando ser más competitivos en precios ofreciendo a sus clientes productos de mejor calidad como oferta de valor.

El cambio en las normas sanitarias, cuyas restricciones son detalladas en el reglamento del sistema sanitario avícola, para la comercialización de pollos en los mercados (relacionado a la prohibición del beneficio de pollo en el mismo puesto del mercado) cuyo objetivo es asegurar la calidad del producto final que va directamente a los consumidores, encuentra en la actualidad a avícolas y picadores que no están preparados para cumplir con dichas normas y con los estándares de calidad necesarios, teniendo en cuenta que las aves hasta hace muy poco tiempo les han sido vendidas vivas por parte de mayoristas y distribuidores. Esto ha originado la proliferación de distintos modelos de peladurías informales donde se benefician y pelan pollos pero con muchas deficiencias y riesgos pero sobre todo con pobres condiciones sanitarias y de higiene.

Un proceso de beneficio que cumpla con las normas estándares vigentes requiere de una mayor automatización y buenas prácticas de manufactura que garanticen la calidad e inocuidad del producto final, creando así ventajas competitivas y comparativas en los picadores puesto que, terminará cerrando la cadena de calidad que se inicia desde los procesos internos de las empresas productoras, hasta su colocación en el puesto del mercado.

La comercialización de pollos en Lima metropolitana y Callao ha tenido un comportamiento ascendente los últimos años con una expectativa de crecimiento en volumen para el 2025 de 1,038 millones de $\mathrm{Kg}$. de pollos, esta información será profundizada en el segundo capítulo del presente plan de negocio. 
En el mercado existen más de 70 empresas que participan en la crianza de pollo a nivel de Lima metropolitana y Callao de las cuales las más importantes son San Fernando, Redondos, Santa Elena y Agro inversiones los Abedules concentrando el 85\% de la oferta y dejando el $15 \%$ restante a medianas y pequeñas empresas productoras así como a empresas informales.

Figura $\mathrm{N}^{\circ}$ 1: Participación de mercado en Lima Metropolitana y Callao de empresas productoras avícolas 2016

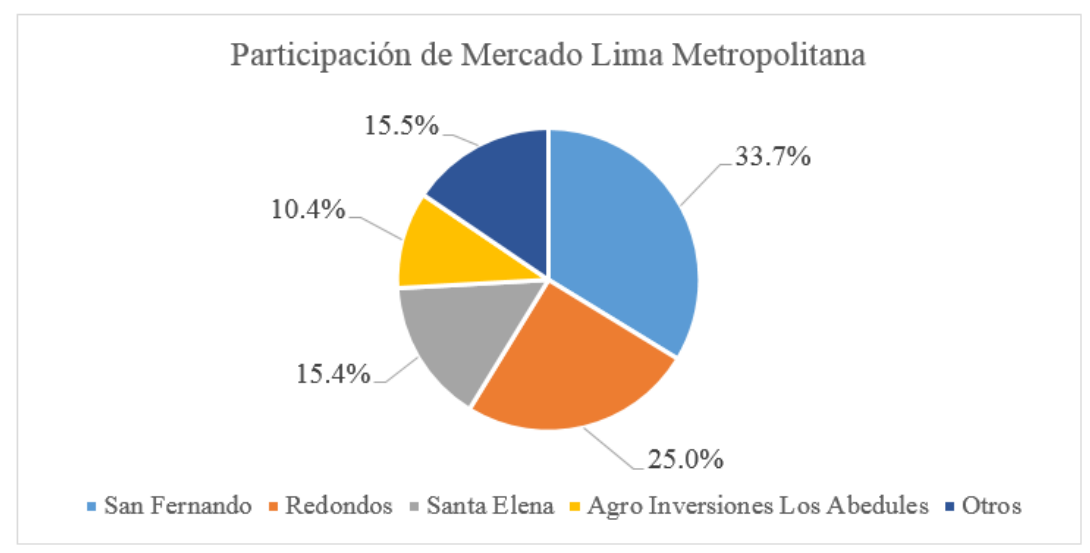

Fuente: Adaptado de Bases a datos del MINAGRI.

\subsection{Determinación del problema u oportunidad}

El 27 de junio del 2003 se publicó en el Diario El Peruano la Resolución Ministerial N²82- 2003-SA/DM referente al Reglamento Sanitario de Funcionamiento de Mercados de Abasto donde se menciona en el Capítulo IV de la comercialización según el tipo de alimento el Artículo 26.- Comercialización de carnes y menudencias de animales de abasto que hace referencia textual a lo siguiente: "Las carnes y menudencias de animales de abasto procederán de camales o de centros de beneficio autorizados. 
Queda prohibido el beneficio y eviscerado de cualquier animal de abasto en los puestos de venta de los mercados de abasto".

Esta política gubernamental continuó siendo apoyada por leyes posteriores (reglamento del sistema sanitario avícola publicado en el Diario El Peruano el primero de noviembre del 2017), las cuales tenían como objetivo la implementación de centros de beneficio y pelado de aves que se ocupen de esta necesidad. Como era de esperarse esto condujo a que emergieran peladurías informales para atender este nuevo requerimiento.

La presencia de estas peladurías han venido generando impactos negativos en la calidad del producto final que llevan los clientes al mercado ya que sus procesos son muy precarios, no cuentan con un control de calidad y no cumplen con las normas regulatorias para productos de consumo humano. Esto pone en riesgo a una población que puede estar adquiriendo productos contaminados con bacterias las cuales generan impactos muy graves en la salud de niños, adultos, ancianos y personas que basan sus dietas en el pollo como principal insumo.

Por otro lado, los distribuidores, mayoristas y picadores ven afectados sus ingresos y rentabilidad cuando las peladurías son intervenidos o clausuradas por instituciones como SENASA, DIGESA, Municipalidades, etc. por no cumplir con las medidas exigidas para el desarrollo de esta actividad ya que todas las aves son decomisadas. Esto se viene informando a la población en los diversos medios de comunicación del país (p.e. http://larepublica.pe/sociedad/809519-comerciantesvendian-pollos-malogrados-en-sjm). 
Se identifica que el pollo beneficiado en estas peladurías presenta un menor tiempo de conservación en el puesto de mercado, por debajo de lo requerido por el picador para lograr la venta total de su producto. Esto conlleva a que el pollo sufra un proceso de descomposición muy rápido debido a que estos lugares no cuentan con procesos certificados (p.e. uso de agua limpia, mesas de trabajo sin contaminantes, personal con sus implementos de trabajo reglamentarios etc.) y además no cuentan con sistemas de enfriamiento que controle su deterioro. Finalmente dado que se trata de un proceso manual, la carne sufre mucha manipulación, elevando los niveles de contaminación del producto hacia los consumidores.

Se ha identificado la oportunidad de desarrollar una propuesta alternativa con procesos estandarizados y únicos, con una oferta de valor que pueda ser reconocida y preferido por el cliente, cumpliendo con todas las normas legales y estándares de calidad exigidos.

\subsection{Justificación del Proyecto}

El cambio en las normas sanitarias para la comercialización de pollos en los mercados de abasto relacionado a la prohibición del beneficio de pollo en el mismo puesto del mercado brinda la oportunidad de presentar un plan de negocio que propone invertir en la implementación de un centro de beneficio Avícola (CBA) que cuente con un modelo de gestión certificado con buenas prácticas de manufactura (BPM), con una operación que se desarrolle con procesos automatizados, con capacidad para atender la demanda actual y potencial con una ventana horaria de 4 horas, y asegurando las normas de salubridad impuestas por los organismos estatales y/o municipales las cuales son cada 
vez más exigentes y tienden a erradicar en el mediano plazo a los locales que no cumplan con los requisitos mínimos. El negocio está dirigido a las avícolas y picadores que compran pollo vivo a mayoristas y/o distribuidores y que actualmente los benefician informalmente y con pobres condiciones.

La elaboración del plan de negocio permitirá aplicar los conocimientos adquiridos durante el desarrollo de los cursos de Marketing, Investigación de Mercados, Finanzas y Costos entre otros llevados en la maestría para definir conceptos, métodos y herramientas relacionados a: análisis de la industria, estudio del mercado, definición del servicio propuesto, clientes potenciales, planes estratégicos y comerciales, ingeniería del proyecto y evaluación de la viabilidad del plan de negocio.

\subsection{Objetivos generales y específicos}

Los objetivos generales y específicos han sido formulados para marcar claramente las prioridades de investigación que tiene el presente plan de negocios, considerando que dentro del marco académico es importante identificar factores que determinen la viabilidad del proyecto.

\subsubsection{Objetivo general}

El objetivo general es determinar la viabilidad técnica y económica de la implementación del CBA Doña Viole, como una alternativa diferenciada y que genere valor a los clientes directos y consumidores finales. 


\subsubsection{Objetivos específicos}

\section{Objetivos Comerciales}

- Realizar una investigación de mercado cuya finalidad es identificar las necesidades de los clientes directos y consumidores finales.

- Estudiar la estructura del mercado, la situación actual del sector y conocer cómo opera la competencia.

- Identificar el mercado objetivo y proyectar las ventas que se realizaran a lo largo de la evaluación del proyecto.

- Diseñar las estrategias de marketing en función a la demanda del servicio, que permitan posicionar la marca y conseguir los objetivos de ventas necesarios para la operación.

\section{Objetivos Económicos}

- Identificar la viabilidad económica y financiera del proyecto analizando los flujos de caja, los ratios de rentabilidad y el periodo de recuperación de la inversión.

\section{Objetivos Operacionales}

- Diseñar el proceso operativo que detalle las actividades a realizar en el CBA Doña Viole y que transforme el pollo vivo en pollo beneficiado. 
- Diseñar el modelo de estructura organizacional que más se ajuste a las necesidades de la empresa y definir las funciones de cada puesto de trabajo.

- Identificar y estudiar el marco legal que es necesario cumplir para asegurar el funcionamiento del negocio.

\subsection{Alcances y limitaciones de la investigación}

\subsubsection{Alcance}

Los alcances para el desarrollo del plan de negocio son:

- A nivel geográfico, considera ubicarse en San Juan de Lurigancho debido a que es el distrito en donde se comercializa la mayor cantidad de pollo vivo.

- El servicio estará dirigido a personas naturales o jurídicas cuya actividad principal sea la comercialización de pollo beneficiado y que utilicen los servicios de las peladurías.

- Los datos que se proyectarán y analizaran corresponderán a un periodo de evaluación de cinco años.

\subsubsection{Limitaciones}

Las limitaciones encontradas en el desarrollo del plan de negocio son:

- La escasa información estadística, información secundaria, relacionada al sector de peladurías de pollo hace necesario recurrir a fuentes primarias como encuestas y especialistas del sector. 
- No existen censos oficiales relacionados a las peladurías de pollo que permitan realizar un análisis exacto de los competidores del sector. 


\section{CAPÍTULO II}

\section{Estructura económica del sector}

En este capítulo se desarrollará un análisis completo de la industria de las peladurías de pollo para los mercados de abasto, además cómo se comportan en relación al sector avícola en general. Cuáles son las tendencias del mercado en el que se implementará el negocio propuesto y con esa información analizar las oportunidades que harían viable el negocio.

\subsection{Descripción del estado actual de la industria}

En Lima Metropolitana los pollos vivos usualmente han sido beneficiados en los puestos de los mercados. Debido a las exigencias de las regulaciones y políticas gubernamentales los dueños de los puestos de mercado y las avícolas han empezado a migrar a la utilización de peladurías de pollo, lugares para el beneficio y pelado los cuales se han convertido en un agente importante de la cadena de comercialización de pollo vivo ya que las normativas actuales así lo contemplan.

Hoy la industria de beneficio de pollo se encuentra ante un escenario donde por un lado existe una alta demanda del servicio producto del crecimiento anual que viene dándose en la demanda de pollo y por otro lado sin la capacidad de poder responder ante esta necesidad ya que el operar de una manera formal tal como lo exige la regulación actual es prácticamente imposible de asumir básicamente porque no se cuenta con el 
conocimiento de las mejores prácticas que se requiere para operar cumpliendo con dichas exigencias.

Esto ha hecho que proliferen peladurías informales, con procesos $100 \%$ manuales, que no se preocupan por cuidar las normas de salubridad exigidas atendiendo a una necesidad urgente que se presentó. Ante esta situación el gobierno ha comenzado a lanzar operativos e intervenciones por parte de los entes regulatorios (SENASA, municipalidades) quienes viendo la pobre calidad de los procesos y la informalidad en la que se desarrollan proceden a decomisar las carcasas de pollo ocasionando pérdidas en toda la cadena de valor.

Para las avícolas y picadores esta situación se exacerba con las clausuras de locales ya sean propios o alquilados que utilizan para prestar sus servicios. A nivel de consumidores finales, las peladurías no están garantizando la inocuidad del producto final poniendo en riesgo la salud pública.

\subsubsection{Segmentación de la industria}

La industria del pelado de pollo se encuentra segmentada según el tipo de mercado que atiende. En relación a ello se encuentra el pollo que es destinado para la elaboración de productos terminados y el pollo que es destinado a los mercados de abasto.

\section{a) Pollo para la elaboración de productos terminados}

Aproximadamente el $30 \%$ de la producción de pollo de Lima Metropolitana y Callao es destinada para la elaboración de producto 
terminado (hamburguesas, pollo trozado, pollo congelado, etc.). El beneficio y transformación del pollo vivo se realiza en plantas industriales y el producto final es comercializado en autoservicios, hoteles, cadenas de pollerías entre otros. Se cumplen con las políticas de salubridad exigidas por los entes reguladores.

\section{b) Pollo destinado para los mercados de abasto}

El $70 \%$ restante de la producción de pollo que es destinada a Lima Metropolitana y Callao ingresa a los mercados de abasto beneficiado en peladurías informales que no cumplen con las normas básicas de salubridad exigidas por los entes reguladores. Estas peladurías son categorizadas como pequeñas, medianas y grandes dependiendo de su capacidad.

En la siguiente figura se puede observar la segmentación de la industria. El plan de negocio pretende atender parte del $70 \%$ del pollo que ingresa a los mercados de abasto. 
Figura $\mathrm{N}^{\circ}$ 2: Segmentación de la industria

\begin{tabular}{|c|c|c|c|}
\hline Productos terminados & \multicolumn{3}{|c|}{ Mercados de abasto } \\
\hline $\begin{array}{c}\text { Plantas de beneficio } \\
\text { industriales }\end{array}$ & 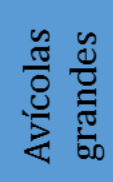 & 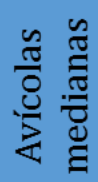 & $\begin{array}{l}\mathscr{D} \\
\frac{0}{0} \\
\frac{0}{0} \\
0 \\
0\end{array}$ \\
\hline & Competid & s potencia & \\
\hline
\end{tabular}

Fuente: Elaboración propia.

\subsubsection{Empresas que la conforman (ubicación, volumen de ventas, empleados, etc.)}

Las peladurías que prestan el servicio de beneficio y pelado de pollos para ser llevados a los mercados de abasto las conforman:

\section{Picadores}

Que benefician su propio pollo

- Son empresas familiares pequeñas que tienen puestos en los mercados de abasto, compran pollo a distribuidores, mayoristas y/o avícolas, los pelan y posteriormente lo venden directamente al consumidor final en sus puestos de mercado o a otros picadores. 
- Usan para pelar los pollos, locales pequeños que se encuentran ubicados cerca a los mercados donde tienen sus puestos lo que permite llegar rápidamente a los puntos de atención.

- Cuentan en la operación de pelado con entre 1 y 3 personas que son familiares directos.

- El proceso de beneficio que ofrecen es $100 \%$ manual.

- Pueden pelar hasta 400 pollos diarios.

- El negocio de pelado es operado en la informalidad ya que no cuentan con permisos ni licencias para operar.

\section{Avícolas medianas}

Que venden pollos a picadores y ofrecen el servicio de beneficio de pollo

- Son por lo general empresas pequeñas o medianas que compran pollo a distribuidores y mayoristas, los venden a los picadores $\mathrm{y}$ antes de entregarlos los pelan. Finalmente los entregan en el puesto del picador. También pueden ser recogidos por el propio picador en el local donde se ha beneficiado el pollo.

- Usan para pelar los pollos, locales propios o alquilados que se encuentran ubicados cerca a los mercados donde se encuentran sus clientes.

- Cuentan en la operación de pelado con personas contratadas por horas que pueden ser de 3 a 8 . Pueden ser familiares directos.

- El proceso de beneficio que ofrecen es $100 \%$ manual. 
- Pueden pelar hasta 800 pollos diarios.

- El negocio de pelado es operado en la informalidad ya que no cuentan con permisos ni licencias para operar.

\section{Avícolas grandes}

Que venden pollos a picadores y avícolas medianas y ofrecen el servicio de beneficio de pollo

- Son empresas grandes que compran pollo a distribuidores y mayoristas, los venden a las avícolas medianas y picadores y antes de entregarlos los pelan. Los pollos siempre son recogidos por la propia avícola o picador en el local donde se ha beneficiado el pollo con su propia movilidad.

- Usan para pelar los pollos, locales con gran infraestructura que pueden ser propios o alquilados y que se encuentran ubicados cerca a los mercados o locales donde se encuentran sus clientes.

- Cuentan en la operación de pelado con personas contratadas por horas que pueden ser más de 10 .

- El proceso de beneficio que ofrecen es $100 \%$ manual.

- Pueden pelar hasta 1600 pollos diarios.

- El negocio de pelado es operado en la informalidad ya que no cuentan con permisos ni licencias para operar. 
Son estas empresas las que realizan el beneficio y pelado de los 78,000 pollos que ingresan aproximadamente al distrito de San Juan de Lurigancho de forma diaria.

\subsection{Tendencias de la industria (crecimiento, inversiones)}

Debido a que el proceso de beneficio avícola forma parte obligatoria de la cadena de valor de la comercialización de pollo vivo existe una relación directa con el crecimiento de este sector, es decir la demanda de servicios de peladurías crecerá al ritmo de dicha industria.

$\mathrm{Si}$ analizamos las estadísticas podemos observar que el $53 \%$ de la comercialización de pollos del Perú se realiza en Lima Metropolitana y Callao cuyo comportamiento ha sido ascendente en los últimos años. En el año 2016 la producción avícola ha sido de 272 millones de pollos y la expectativa de crecimiento para el año 2025 de 376 millones, significando una tasa de crecimiento anual del $4.2 \%$ en promedio.

\section{Tabla $\mathrm{N}^{\circ}$ 1: Proyección de crecimiento de producción de pollo en Lima}

\section{Metropolitana}

\begin{tabular}{|c|c|c|c|c|c|c|c|c|c|c|}
\hline & DATOS & 2010 & 2011 & 2012 & 2013 & 2014 & 2015 & 2016 & 2020 & 2025 \\
\hline \multicolumn{11}{|c|}{ LIMA METROPOLITANA Y CALLAO } \\
\hline Demanda de Pollo & MM Kgs. & 519 & 515 & 573 & 609 & 670 & 711 & 747 & 882 & 1,038 \\
\hline Demanda de Pollo & MM Unid. & 197 & 193 & 211 & 222 & 244 & 259 & 272 & 322 & 376 \\
\hline Población & MM Hab. & 9.2 & 9.3 & 9.4 & 9.6 & 9.8 & 9.9 & 10.1 & 10.7 & 11.5 \\
\hline Consumo Per cápita & $\mathrm{Kg}$ /año $\mathrm{Hab}$. & 56.7 & 55.4 & 60.6 & 63.4 & 68.7 & 71.8 & 74.3 & 82.6 & 90.2 \\
\hline Crecimiento anual & $\% \operatorname{Var}$ & $8.0 \%$ & $-2.0 \%$ & $9.5 \%$ & $5.1 \%$ & $10.0 \%$ & $6.2 \%$ & $5.0 \%$ & $4.0 \%$ & $3.0 \%$ \\
\hline
\end{tabular}

Nota: Adaptado de Bases a datos del MINAGRI.

La tendencia del crecimiento en la demanda de pollo vivo identificada anteriormente trae también un crecimiento en la demanda de la utilización del servicio de 
las peladurías, ya que la legislación norma el ingreso de pollos a los mercados ya beneficiados. Esta tendencia mencionada por MINAGRI sustenta el crecimiento del servicio en la misma proporción lo que convierte a este sector en una alternativa atractiva para propuestas de negocio relacionadas a este mercado.

Los organismos reguladores y municipalidades son cada vez más exigentes hacia el cumplimiento de normas de salubridad vigentes y realizan constantes operativos en donde se clausuran de peladurías informales, generando pérdidas económicas para los picadores y avícolas.

\subsection{Análisis Estructural del Sector Industrial}

De acuerdo a las investigaciones realizadas, la estructura del sector de venta de pollo vivo que llega para ser beneficiado y pelado a los puestos en los mercados se encuentra definida, con procesos y actores que a continuación se grafican. 


\section{Figura $\mathrm{N}^{\circ}$ 3: Cadena de distribución desde la granja hasta el consumidor final}

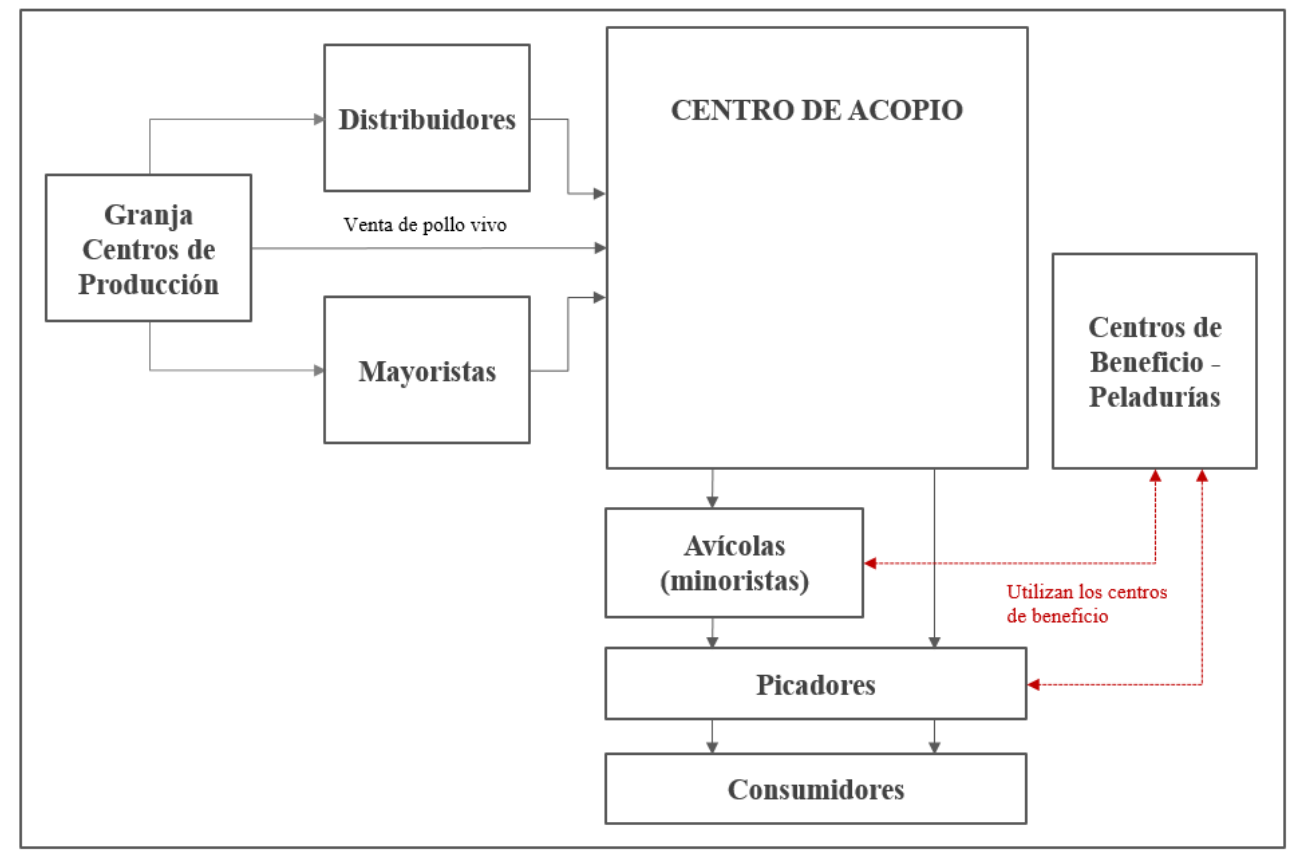

Fuente: Elaboración propia.

Actualmente las peladurías se encuentran dentro de un modelo que opera en la informalidad, con procesos manuales que atienden a distribuidores, mayoristas, avícolas y picadores con bajos estándares de calidad y salubridad, además de no contar con las respectivas licencias de funcionamiento.

Es aquí donde se rompen las políticas de calidad que utilizan las empresas de crianza de pollo, ya que cuando el producto llega al puesto del mercado y por ende a la mesa del consumidor ha perdido la oferta de valor del productor.

Para identificar el potencial real que tiene el negocio de implementar un centro de beneficio avícola es importante analizar las partes que interactúan en esta industria y sobre todo cuál es su capacidad para influir en ella. Este análisis realizado bajo la 
metodología de las 5 fuerzas de Michael Porter ha sido obtenido a través de entrevistas con expertos en el sector de crianza de aves.

Es importante entender que una industria no se encuentra conformada únicamente por los competidores actuales, existen 5 fuerzas que determinan la atractividad de la industria y es necesario conocer las fuerzas de cada una de ellas para poder asegurar el éxito del negocio.

En la Figura $N^{\circ} 4$ podemos identificar las fuerzas que influyen en la industria de centros de beneficio avícola.

\section{Figura $\mathrm{N}^{\circ}$ 4: Aplicación de Cinco Fuerzas de Porter - Estructura de la Industria}

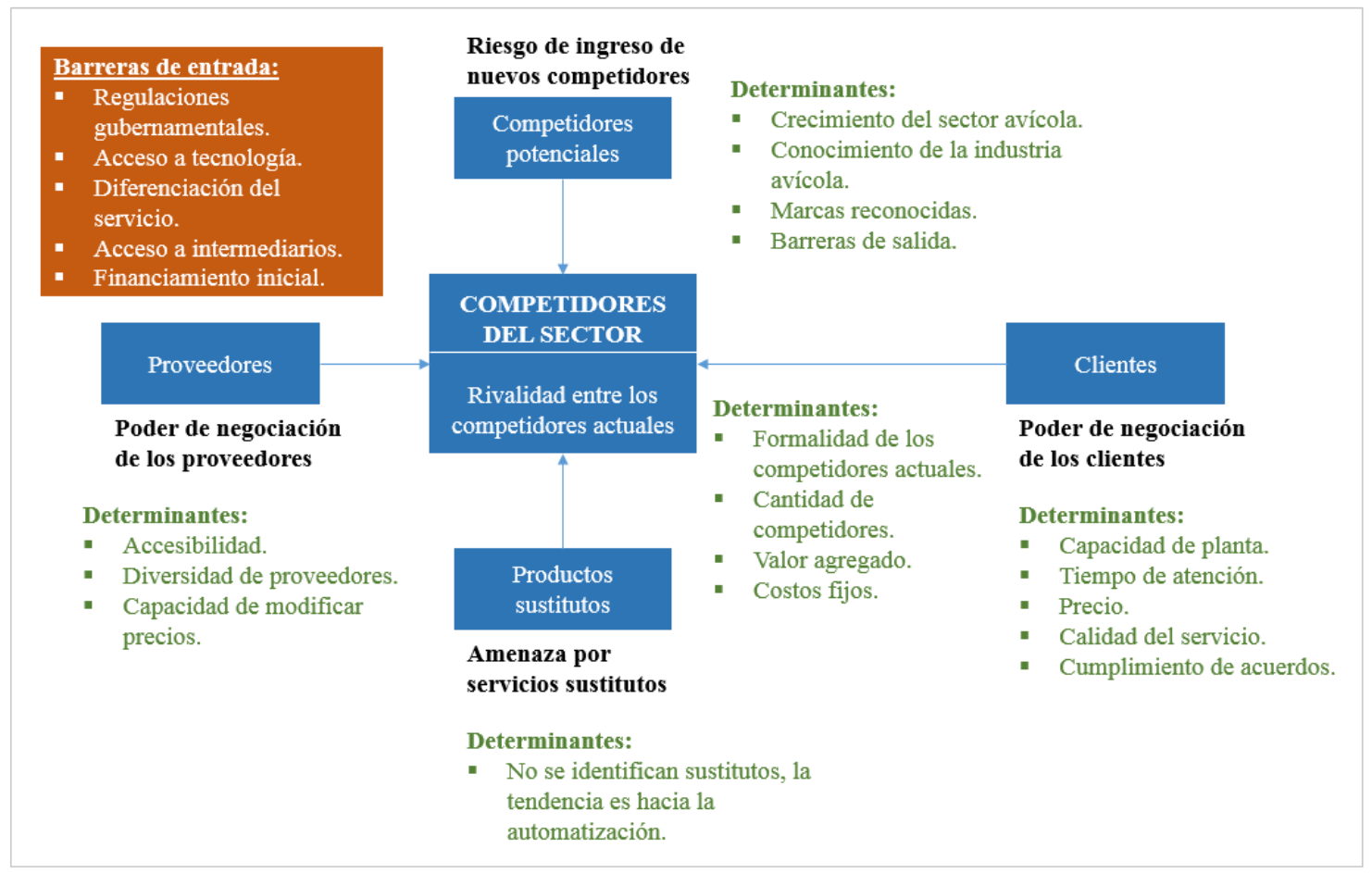

Fuente: Elaboración propia. 
A cada una de las fuerzas de la industria se le ha asignado una calificación en función a la capacidad de influenciar (poder, riesgo o amenaza) en el industria actual y a las tendencias, se ha utilizado la escala de Likert con valores que van desde 1 cuando la fuerza es muy baja y hasta 5 cuando la fuerza es muy alta.

\section{a. Riesgo de ingreso de nuevos competidores}

Para el análisis del riesgo del ingreso de nuevos competidores se han considerado dentro del análisis las barreras de entrada existentes y sus factores determinantes.

- En relación a la inversión inicial esta no significa una fuerte barrera debido a que los costos por inversión inicial, licencias y puesta en marcha no representan importes muy significativos. Desde el enfoque del competidor actual esto significa un riesgo alto puesto que una empresa nueva que ingrese con un modelo de gestión diferenciado puede significar pérdidas en su participación de mercado, por el lado del nuevo competidor el hecho que las barreras no sean significativas representa la oportunidad de incursionar en un negocio que se encuentra en constante crecimiento.

- En relación a las regulaciones gubernamentales y/o distritales se identifica que estás no son muy restrictivas, las normas de salubridad son asequibles siempre que se cumpla con las normas vigentes, la burocracia de los organismos públicos son las barreras que deben de superarse para poner en marcha un negocio. 
- En relación a marcas que dominen el mercado, no se identifica una marca considerada como la líder, la informalidad con la que operan los centros de beneficio avícola hacen que no sean capaces de brindar un servicio diferenciado y que genere valor a los clientes y consumidores. Un centro de beneficio avícola que opere con buenas prácticas de manufactura y con procesos automatizados significaría la oportunidad de brindar un servicio que genere valor y posicionar rápidamente la marca.

- En relación al acceso a tecnología existen dentro del país una serie de empresas que brindan soluciones tecnológicas que permiten la automatización de los procesos claves en un centro de beneficio avícola, sin embargo el sector está dominado por empresas informales que operan de forma manual que no cuentan con flujos de operación definidos ni políticas de calidad.

- En relación al acceso a los intermediarios se identifica una barrera fuerte, para incursionar en el negocio es necesario conocer no solo el funcionamiento de un centro de beneficio avícola sino que también es necesario conocer la industria avícola en general, este aspecto puede significar un escenario desalentador para nuevos inversionistas ya que los costos de aprendizaje son muy elevados.

- En relación a las barreras de salida no se identifican condiciones que dificulten la salida rápida del negocio, las limitantes para la salida estarán orientadas a la recuperación de la inversión inicial, al cumplimiento de las obligaciones económicas con los empleados, el gobierno y con los 
proveedores, por otro lado no se identifica la necesidad de generar contratos de largo plazo con clientes para asegurar la continuidad del negocio.

Nivel de riesgo identificado: ALTO.

A continuación se detalla la matriz atractividad:

Tabla $\mathbf{N}^{\circ}$ 2: Matriz de atractividad - Ingreso de nuevos competidores

\begin{tabular}{lcccc}
\hline \multicolumn{5}{c}{ Matriz de Atractividad para el Ingreso de Nuevos Competidores } \\
\hline \multicolumn{1}{c}{ Elemento de análisis } & $\begin{array}{c}\text { Nivel de } \\
\text { amenaza }\end{array}$ & Ponderación & $\begin{array}{c}\text { Grado de } \\
\text { atractividad }\end{array}$ & $\begin{array}{c}\text { Puntuación } \\
\text { ponderada }\end{array}$ \\
\hline $\begin{array}{l}\text { Inversión inicial } \\
\text { Regulaciones gubernamentales }\end{array}$ & Alto & 0.20 & 4 & 0.80 \\
$\begin{array}{l}\text { y/o distritales } \\
\text { Marcas que dominen el mercado }\end{array}$ & Alto & 0.10 & 4 & 0.40 \\
Acceso a tecnología & Alto & 0.30 & 5 & 1.50 \\
Acceso a los intermediarios & Medio & 0.10 & 4 & 0.40 \\
Barreras de salida & Bajo & 0.20 & 3 & 0.60 \\
\multicolumn{1}{c}{ Totales } & Alto & 0.10 & 4 & 0.40 \\
\hline \multicolumn{4}{c}{} \\
\hline
\end{tabular}

Nota: Elaboración propia.

La matriz de atractividad para el ingreso de nuevos competidores obtiene un valor de 4.1 como resultado ponderado, lo que indica que para los nuevos inversionistas resulta atractivo el mercado actual ya que de los elementos analizados, las marcas que dominan el mercado no existen porque operan en la informalidad y porque son pocos los expertos en negocios de esta naturaleza.

\section{b. Poder de negociación de los proveedores}

- En relación a la diversidad de proveedores, existen una serie de empresas en el mercado que pueden proporcionar los insumos y tecnología necesaria para 
la operación de la empresa, esta situación es favorable ya que no existe el riesgo que los precios suban de forma desproporcionada.

- Los costos por mano de obra, energía eléctrica y agua potable son los costos principales en un centro de beneficio avícola, en relación al agua potable el único proveedor es SEDAPAL y los precios dependen del tipo de consumo (comercial o residencial) y los mismos se encuentran regulados por la SUNASS lo que hace que los precios se mantengan estables en el tiempo, en relación a la energía eléctrica la empresa proveedora depende de la zona de residencia y estas se encuentran reguladas por el OSINERGMIN.

Nivel de Poder de los proveedores: BAJO.

A continuación se detalla la matriz atractividad:

Tabla $\mathbf{N}^{\circ}$ 3: Matriz de atractividad - Poder de negociación con proveedores

\begin{tabular}{lcccc}
\hline \multicolumn{5}{c}{ Matriz de Atractividad para el Poder de Negociación de los Proveedores } \\
\hline \multicolumn{1}{c}{ Elemento de análisis } & $\begin{array}{c}\text { Nivel de } \\
\text { amenaza }\end{array}$ & Ponderación & $\begin{array}{c}\text { Grado de } \\
\text { atractividad }\end{array}$ & $\begin{array}{c}\text { Puntuación } \\
\text { ponderada }\end{array}$ \\
\hline Diversidad de proveedores & Bajo & 0.30 & 4 & 1.20 \\
Costo de mano de obra & Bajo & 0.30 & 3 & 0.90 \\
Costo de energía eléctrica & Bajo & 0.20 & 4 & 0.80 \\
Costo de agua potable & Bajo & 0.20 & 4 & 0.80 \\
\hline \multicolumn{1}{c}{ Totales } & - & $\mathbf{1 . 0 0}$ & & $\mathbf{3 . 7 0}$ \\
\hline
\end{tabular}

Nota: Elaboración propia.

La matriz de atractividad para el poder de negociación de los proveedores obtiene un valor de 3.7 como resultado ponderado, lo que indica que la situación es favorable para los inversionistas porque en la actualidad existen en el mercado 
empresas que proveen de insumos para operar o la tecnología requerida a precios asequibles, pero ninguno es lo suficientemente grande para poder ejercer algún tipo de monopolio o ejercer presión sobre el costo final del servicio.

\section{c. Poder de negociación de los clientes}

- En relación a la capacidad para poder acceder a servicios similares, los clientes pueden optar por adquirir el servicio de beneficio del pollo con una serie de alternativas informales o ejecutarlos ellos mismos ya que los lugares donde operan se encuentran muy cerca a sus puestos de venta y son de fácil acceso.

- En relación al precio, los clientes no gestionan sus cuentas con contratos a largo plazo lo que imposibilita que pueda asegurarse algún tipo de compromiso con ellos. Esto podría conducir a que el cliente migue a otra empresa que ofrezca mejor precio del servicio de pelado de pollo.

- En relación a la calidad de servicio, las peladurías actuales operan con bajos estándares de calidad, sin embargo los clientes hoy no diferencian aún la oferta de valor de beneficiar las aves con las condiciones de inocuidad requeridas para un producto de consumo masivo y se conforman con el cumplimiento básico.

Nivel de Poder de los clientes: ALTO.

A continuación se detalla la matriz atractividad: 
Tabla $N^{\circ}$ 4: Matriz de atractividad - Poder de negociación de los clientes

\begin{tabular}{lcccc}
\hline \multicolumn{5}{c}{ Matriz de Atractividad para el Poder de Negociación de los Clientes } \\
\hline \multicolumn{1}{c}{ Elemento de análisis } & $\begin{array}{c}\text { Nivel de } \\
\text { amenaza }\end{array}$ & Ponderación & $\begin{array}{c}\text { Grado de } \\
\text { atractividad }\end{array}$ & $\begin{array}{c}\text { Puntuación } \\
\text { ponderada }\end{array}$ \\
\hline $\begin{array}{l}\text { Acceso a otras peladurías } \\
\begin{array}{l}\text { Precios con contratos a largo } \\
\text { plazo }\end{array}\end{array}$ & Alto & 0.50 & 2 & 1.00 \\
$\begin{array}{l}\text { Diferenciación a estándares de } \\
\text { calidad }\end{array}$ & Medio & 0.20 & 3 & 0.60 \\
\hline \multicolumn{1}{c}{ Totales } & Alto & 0.30 & 2 & 0.60 \\
\hline
\end{tabular}

Nota: Elaboración propia.

La matriz de atractividad para el poder de negociación de los clientes obtiene un valor de 2.2 como resultado ponderado, lo que indica que la situación se muestra desfavorable para los inversionistas debido a que los posibles clientes tienen a su alcance una serie de alternativas que pueden utilizar aún sin generarles valor o cayendo en la informalidad porque no identifican la oferta de valor.

\section{d. Amenaza de productos sustitutos}

- No se identifican servicios sustitutos a los centros de beneficio avícola, existe la posibilidad que cada cliente implemente su propia planta, pero esta posibilidad es baja ya que se necesita implementar una serie de condiciones de salubridad difíciles de mantener, además se debe de tener en cuenta que el giro de negocio de los clientes corresponde solo a la comercialización del pollo, la actividad del beneficio del pollo es una actividad de soporte para ellos.

Nivel de amenaza de productos sustitutos: BAJO. 
A continuación se detalla la matriz atractividad:

Tabla $N^{\circ}$ 5: Matriz de atractividad - Amenaza de productos sustitutos

\begin{tabular}{|c|c|c|c|c|}
\hline \multicolumn{5}{|c|}{ Matriz de Atractividad para la Existencia de Productos Sustitutos } \\
\hline Elemento de análisis & $\begin{array}{l}\text { Nivel de } \\
\text { amenaza }\end{array}$ & Ponderación & $\begin{array}{c}\text { Grado de } \\
\text { atractividad }\end{array}$ & $\begin{array}{c}\text { Puntuación } \\
\text { ponderada }\end{array}$ \\
\hline $\begin{array}{l}\text { Existencia de productos } \\
\text { sustitutos }\end{array}$ & Bajo & 1.00 & 5 & 5.00 \\
\hline Totales & - & 1.00 & & 5.00 \\
\hline
\end{tabular}

Nota: Elaboración propia.

La matriz de atractividad para la existencia de productos sustitutos obtiene un valor de 5.0 como resultado ponderado, se le asigna la máxima valoración debido a que no se identifican servicios sustitutos para el proceso de beneficio y pelado de pollo.

\section{e. Rivalidad entre los competidores actuales}

- En el mercado formal se genera una competencia media debido a que existen distribuidores que han implementado peladurías dentro de sus locales propios saliéndose de la formalidad en esta actividad para poder operar, corriéndose el riesgo de ser clausurados.

- En el mercado informal existe una competencia alta. Los clientes muchas veces buscan el mismo día peladores independientes que puedan realizar el pelado de sus pollos, promoviendo de esta manera la informalidad. 
- Los competidores no realizan campañas de marketing que les permita captar nuevos clientes, los clientes son conseguidos a través de referencias personales. Se debe tener en cuenta que las peladurías en la actualidad operan con bajos estándares de calidad y salubridad y no cuentan con variables de diferenciación que generen valor para los clientes.

- Aunque como consecuencia de la informalidad no existen datos estadísticos que permitan cuantificar de forma exacta el número de competidores del sector, existen en la industria una gran cantidad de peladurías informales para atender la demanda del mercado.

Nivel de rivalidad entre los competidores: MEDIA.

A continuación se detalla la matriz atractividad:

Tabla $\mathbf{N}^{\circ}$ 6: Matriz de atractividad - Rivalidad entre los competidores actuales

\begin{tabular}{lcccc}
\hline \multicolumn{5}{c}{ Matriz de Atractividad para Rivalidad con Competidores } \\
\hline \multicolumn{1}{c}{ Elemento de análisis } & $\begin{array}{c}\text { Nivel de } \\
\text { amenaza }\end{array}$ & Ponderación & $\begin{array}{c}\text { Grado de } \\
\text { atractividad }\end{array}$ & $\begin{array}{c}\text { Puntuación } \\
\text { ponderada }\end{array}$ \\
\hline Informalidad del sector & Alta & 0.20 & 4 & 0.80 \\
Campañas de marketing & Bajo & 0.40 & 5 & 2.00 \\
Número de competidores & Alta & 0.40 & 2 & 0.80 \\
\hline \multicolumn{1}{c}{ Totales } & - & $\mathbf{1 . 0 0}$ & & $\mathbf{3 . 6 0}$ \\
\hline
\end{tabular}

Nota: Elaboración propia.

La matriz de atractividad para la rivalidad con competidores obtiene un valor de 3.6 como resultado ponderado, lo que indica que la situación se muestra medianamente favorable para los inversionistas debido a que los competidores 
operan en la informalidad por lo tanto tienen alto riesgo y esta condición no les permite recurrir a estrategias comerciales para el crecimiento de sus empresas.

Tras realizar el análisis de las cinco fuerzas y con la finalidad de identificar el nivel de atractividad del sector se ha consolidado la información en la siguiente matriz:

Tabla $\mathrm{N}^{\circ}$ 7: Matriz de atractividad - Industria

\begin{tabular}{|c|c|c|c|c|}
\hline \multicolumn{5}{|c|}{ Matriz de Atractividad de la Industria } \\
\hline Elemento de análisis & $\begin{array}{l}\text { Nivel de } \\
\text { amenaza }\end{array}$ & Ponderación & $\begin{array}{c}\text { Grado de } \\
\text { atractividad }\end{array}$ & $\begin{array}{l}\text { Puntuación } \\
\text { ponderada }\end{array}$ \\
\hline $\begin{array}{l}\text { Riesgo de ingreso de nuevos } \\
\text { competidores }\end{array}$ & Alto & 0.10 & 4.10 & 0.41 \\
\hline $\begin{array}{l}\text { Poder de negociación de los } \\
\text { proveedores }\end{array}$ & Bajo & 0.20 & 3.70 & 0.74 \\
\hline $\begin{array}{l}\text { Poder de negociación de los } \\
\text { clientes }\end{array}$ & Alto & 0.30 & 2.20 & 0.66 \\
\hline Amenaza de productos sustitutos & Bajo & 0.10 & 5.00 & 0.50 \\
\hline $\begin{array}{l}\text { Rivalidad entre los competidores } \\
\text { actuales }\end{array}$ & Medio & 0.30 & 3.60 & 1.08 \\
\hline $\begin{array}{c}\text { Totales } \\
\end{array}$ & - & 1.00 & & 3.39 \\
\hline
\end{tabular}

Nota: Elaboración propia.

La matriz de atractividad de la industria obtiene un valor de 3.39 como resultado ponderado, esto significa que los inversionistas pueden ver al sector como una oportunidad atractiva para incursionar con un servicio innovador y diferenciado.

Además el CBA Doña Viole se convertiría en el pionero del sector al incursionar con un modelo automatizado y que genere valor tanto a los clientes usuarios como a los consumidores finales. 


\subsection{Análisis de la Competencia}

\subsubsection{Empresas que ofrecen el mismo producto o servicio, indicando las semejanzas $y$ diferencias que tienen con el proyecto de empresa}

Un centro de beneficio avícola automatizado y que cumpla con las buenas prácticas de manufactura no cuenta con competencia directa debido a que los actuales competidores del sector operan en la informalidad, con procesos $100 \%$ manuales e incumpliendo con los estándares de calidad necesarios.

Es así que las peladurías informales se convierten en competencia indirecta del servicio ofrecido por el presente plan de negocio, en donde podemos citar:

- Picadores, que benefician su propio pollo.

- Avícolas medianas, que venden pollos a picadores y ofrecen el servicio de beneficio de pollo.

- Avícolas grandes, que venden pollos a picadores y avícolas medianas y ofrecen el servicio de beneficio de pollo.

Las características de estas empresas han sido mencionadas previamente.

Al realizar el análisis de semejanzas y diferencias entre las peladurías y el modelo de negocio del CBA que se está proponiendo se puede observar lo siguiente: 


\section{Semejanzas}

- Resuelve una necesidad urgente e importante.

- Tienen ventajas competitivas similares en cuanto a cercanía a los mercados, que permite reducir los costos por transporte.

- Presentan la misma ventana horaria de atención.

- Las personas que participan en el negocio tienen experiencia en el sector avícola.

\section{Diferencias}

- Mayor vida útil de los pollos beneficiados en el CBA debido a las mejores condiciones de beneficio y al proceso de enfriamiento de las aves.

- El proceso garantiza la inocuidad del producto final como consecuencia de la operación con buenas prácticas de manufactura.

- Empresa formalmente constituida para operar eliminando el riesgo de decomisos por malas prácticas.

\subsubsection{Participación de mercado de cada uno de ellos}

A través de información del MINAGRI se ha identificado que el promedio diario de pollo vivo que ingresa al distrito de San Juan de Lurigancho es de 78,000 pollos.

Esta cantidad de pollo debe ser beneficiada previamente para que llegue a la mesa del consumidor final. Dicha actividad es realizada por 
empresas que se dedican como actividad adicional a la peladuría de pollo y tal como se han mencionadas anteriormente, son:

- Picadores, que benefician su propio pollo.

- Avícolas medianas, que venden pollos a picadores y ofrecen el servicio de beneficio de pollo.

- Avícolas grandes, que venden pollos a picadores y avícolas medianas y ofrecen el servicio de beneficio de pollo.

Entre estos 3 grupos de peladores se reparten los 78,000 pollos que ingresan al mercado.

Debido a la problemática del sector en cuanto al acceso e información, se han realizado entrevistas con expertos del sector avícola con la finalidad de determinar su participación, resultando lo siguiente:

\section{Tabla $\mathbf{N}^{\circ}$ 8: Participación de mercado por tipo de empresa}

Cantidad de pollo que ingresa a SJL $\quad 78,000$

\begin{tabular}{lccc}
\hline $\begin{array}{l}\text { Empresa que realizan la actividad } \\
\text { de pelado de pollo }\end{array}$ & Picadores & $\begin{array}{c}\text { Avícolas } \\
\text { medianas }\end{array}$ & $\begin{array}{c}\text { Avícolas } \\
\text { grandes }\end{array}$ \\
\hline Participación en beneficio de pollo & $5.5 \%$ & $75.0 \%$ & $19.5 \%$ \\
\hline $\begin{array}{l}\text { Cantidad de pollo beneficiado por estas } \\
\text { empresas }\end{array}$ & 4,290 & 58,500 & 15,210 \\
\hline Capacidad promedio de beneficio diario & $\begin{array}{c}\text { Entre } 100 \mathrm{y} \\
400\end{array}$ & $\begin{array}{c}\text { Entre } 100 \mathrm{y} \\
800\end{array}$ & $\begin{array}{c}\text { Entre } 800 \mathrm{y} \\
1600\end{array}$ \\
\hline
\end{tabular}

Nota: Elaboración propia. 
Como se puede observar en la tabla anterior en proporción la mayor cantidad de pollo es beneficiado por las empresa de tipo avícolas medias, estas empresas benefician el $75 \%$ de pollo que ingresa los mercados de abasto a través de los picadores. En promedio benefician entre 100 y 800 pollos de forma diaria.

\subsubsection{Matriz de perfil competitivo}

Como parte del análisis del plan de negocio deben identificarse aquellos factores de éxito que los competidores del sector tienen en sus operaciones para ser considerados en el plan de negocio y lograr ser competitivos.

Para ello se ha desarrollado la Matriz de perfil Competitivo de la siguiente manera:

- Se han considerado los tres tipos de competidores que tienen participación en el mercado de peladurías de pollo.

- Se han identificado los factores críticos de éxito a través de lo recogido en el estudio cuantitativo (encuestas de opinión) y entrevistas a clientes potenciales y expertos con experiencia de campo en el sector. También se ha considerado las observaciones de campo ejecutadas durante las visitas a los mercados de abasto y centros de distribución. 
Los factores críticos identificados para la evaluación del MPC son:

- Ventana horaria de atención: El tiempo transcurrido en la ejecución de los procesos es crítico para llegar al puesto en igual de oportunidades que el resto y de acuerdo a lo que requiere el cliente.

- Vida útil del producto: El producto debe durar por lo menos 6 horas en el puesto del mercado sin perder sus condiciones organolépticas.

- Ubicación de la peladuría: El local debe estar cerca a los mercados donde abastecerá a sus clientes.

- Pollo sano: El producto es solicitado por el cliente final con características físicas como conformación, rendimiento pero sobre todo con el color característico amarillo.

- Espacio para maniobra de transporte: lugar de fácil acceso y con espacios para recepcionar los camiones que dejan los pollos así como los vehículos que los recogen.

- Calidad de infraestructura: El proceso tiene que ser ejecutado en locales que cumplan con las normas estipuladas tanto para el procesamiento de aves como para la evacuación correcta de las aguas servidas.

- Servicios básicos: En este modelo es imprescindible el uso de agua potable y electricidad por lo que deben estar abastecidos formalmente.

- Acceso de mano de obra: Se requiere disponibilidad diaria de mano de obra. 
- Experiencia en el sector: Es clave conocer la industria para anticiparse a eventos y tomar las mejores decisiones o las más estratégicas.

- Formalidad: contar con licencias de funcionamiento hace que la operación entre en la formalidad asegurando crecimiento sostenible.

- Sistema de tratamiento de residuos: El proceso de beneficio y pelado requiere de sistemas que tengan resueltos los procesos para tratar residuos tales como plumas, vísceras y sangre.

Se ha definido y asignado una ponderación a cada "factor clave de éxito" teniendo en cuenta la opinión de expertos del sector. Los factores con ponderaciones más altos (de 0.20 para la vida útil del pollo y 0.15 para la ubicación del CBA) se han calculado en base a los resultados más altos que se obtuvieron de las encuestas respecto al nivel de preferencia de esas características para los usuarios de las peladurías. Las siguientes ponderaciones utilizadas para el resto de factores se han valorado en función a la operación del servicio y la sanidad de las aves, factores que están relacionados a la ejecución de la venta final.

Las calificaciones se han considerado en una escala del 1 al 4 clasificándolas en 4 tipos y se han formulado en base a los conocimientos de los dos socios del negocio: 
- 1: Debilidad principal, a esta debilidad se le debe prestar la mayor atención posible debido a que representa un riesgo alto para la empresa y de no ser atendida puede generar pérdida en la participación de mercado.

- 2: Debilidad menor, a esta debilidad se le debe prestar atención debido a que representa un riesgo medio/bajo para la empresa pero que no significan perdida de ventaja competitiva.

- 3: Fortaleza menor, esta fortaleza que no genera diferenciación con el resto de competidores ya que los atributos evaluados con esta fortaleza no son los más valorados por los clientes.

- 4: Fortaleza principal, esta fortaleza es la más importante ya que debe de servir para determinar y evidenciar la oferta de valor propuesta al cliente. Esta calificación se asigna cuando las empresas generan ventajas competitivas en los atributos más valorados por los clientes.

En la tabla $\mathrm{N}^{\circ} 9$ se muestra la matriz MPC con las ponderaciones que se recogieron de los expertos, así como los promedios de cada una de ellas. 
Tabla $\mathbf{N}^{\circ}$ 9: Matriz de perfil competitivo (MPC)

\begin{tabular}{|c|c|c|c|c|c|c|c|}
\hline \multirow[b]{2}{*}{$\begin{array}{l}\text { Factores críticos } \\
\text { para el éxito }\end{array}$} & \multirow[b]{2}{*}{ Ponderación } & \multicolumn{2}{|c|}{$\begin{array}{c}\text { Picadores } \\
\text { (benefician su propio } \\
\text { pollo) }\end{array}$} & \multicolumn{2}{|c|}{$\begin{array}{c}\text { Avícolas medianas } \\
\text { (ofrecen el servicio de } \\
\text { beneficio de pollo) }\end{array}$} & \multicolumn{2}{|c|}{$\begin{array}{c}\text { Avícolas grandes } \\
\text { (ofrecen el servicio de } \\
\text { beneficio de pollo) }\end{array}$} \\
\hline & & Calif. & Punt. & Calif. & Punt. & Calif. & Punt. \\
\hline Ventana horaria de atencion & 0.10 & 4 & 0.40 & 4 & 0.40 & 4 & 0.40 \\
\hline Vida útil del pollo & 0.20 & 1 & 0.20 & 1 & 0.20 & 1 & 0.20 \\
\hline Ubicación del CBA & 0.15 & 3 & 0.45 & 4 & 0.60 & 4 & 0.60 \\
\hline Pollo sano & 0.10 & 1 & 0.10 & 2 & 0.20 & 2 & 0.20 \\
\hline Espacio para maniobra del transporte & 0.10 & 1 & 0.10 & 2 & 0.20 & 3 & 0.30 \\
\hline Sistema de tratamiento de residuos & 0.10 & 1 & 0.10 & 1 & 0.10 & 1 & 0.10 \\
\hline Buenas prácticas de manufactura & 0.10 & 1 & 0.10 & 2 & 0.20 & 2 & 0.20 \\
\hline Calidad de infraestructura & 0.03 & 1 & 0.03 & 2 & 0.06 & 2 & 0.06 \\
\hline Servicios básicos & 0.03 & 1 & 0.03 & 3 & 0.09 & 3 & 0.09 \\
\hline Acceso de mano de obra & 0.03 & 3 & 0.09 & 3 & 0.09 & 3 & 0.09 \\
\hline Experiencia en el sector & 0.03 & 3 & 0.09 & 4 & 0.12 & 4 & 0.12 \\
\hline Formalidad (licencias) & 0.03 & 1 & 0.03 & 2 & 0.06 & 2 & 0.06 \\
\hline Total & 1.00 & & 1.72 & & 2.32 & & 2.42 \\
\hline
\end{tabular}

Nota: Adaptado de "Desarrollo de la MPC", por Fred David.

Como resultado de la matriz de Perfil Competitivo las empresas de peladurías obtuvieron puntajes de 1.72, 2.32 y 2.42 de acuerdo a su clasificación.

Se identificaron que los factores de mayor relevancia para tener éxito y que deben ser consideradas al desarrollar el proyecto son: la ubicación de la peladuría, la ventana horaria de atención y la experiencia en el sector de las personas que lideren los procesos.

\subsection{Análisis del Contexto Actual y Esperado}

\subsubsection{Análisis Político-Gubernamental}

En el aspecto político-gubernamental el entorno muestra una tendencia favorable esto como consecuencia de las políticas que mantiene el gobierno actual y las reformas que ha anunciado respecto a su enfoque en el desarrollo 
del país lo cual crea confianza y sensación de estabilidad en los productores avícolas.

Otro aspecto importante es que, después de los desastres naturales que vivió el país, se ha tomado la decisión política de realizar altas inversiones en los próximos dos años destinadas a la reconstrucción país, lo cual se generará más empleo y esto inyectará a la economía más población económicamente activa la cual incrementará la demanda de carne de pollo en la canasta familiar.

Los últimos casos de corrupción generados por empresas extranjeras que operan en el país han involucrado alcaldes, gobernadores, ex presidentes y figuras públicas. Esta situación evidencia la corrupción que envuelve el país y que se ve reflejada en el índice de percepción de la corrupción (CPI) del año 2016 publicado por Transparencia Internacional, donde Perú se encuentra en el puesto 101 en el ranking mundial de corrupción, esto de entre 176 países. Como se observa en la figura $\mathrm{N}^{\circ} 2.4$ Perú ha perdido 3 puntos en el ranking en los últimos 5 años. 
Figura $\mathrm{N}^{\circ}$ 5: Índice de percepción de la corrupción 2016

\section{CORRUPTION PERCEPTIONS INDEX 2016}

\begin{tabular}{|c|c|c|c|c|c|c|c|}
\hline \multirow[b]{2}{*}{$\begin{array}{l}2016 \\
\text { Rank }\end{array}$} & \multirow[b]{2}{*}{ Country } & \multirow[b]{2}{*}{$\begin{array}{l}2016 \\
\text { Score }\end{array}$} & \multirow[b]{2}{*}{$\begin{array}{l}2015 \\
\text { Score }\end{array}$} & \multirow[b]{2}{*}{$\begin{array}{l}2014 \\
\text { Score }\end{array}$} & \multicolumn{3}{|c|}{ Qsearch } \\
\hline & & & & & $\begin{array}{l}2013 \\
\text { Score }\end{array}$ & $\begin{array}{l}2012 \\
\text { Score }\end{array}$ & Region \\
\hline 101 & Peru & 35 & 36 & 38 & 38 & 38 & Americas \\
\hline 101 & Philippines & 35 & 35 & 38 & 36 & 34 & Asia Pacific \\
\hline 101 & Thailand & 35 & 38 & 38 & 35 & 37 & Asia Pacific \\
\hline 101 & Timor-Leste & 35 & 28 & 28 & 30 & 33 & Asia Pacific \\
\hline 101 & Trinidad and Tobago & 35 & 39 & 38 & 38 & 39 & Americas \\
\hline 108 & Algeria & 34 & 36 & 36 & 36 & 34 & $\begin{array}{l}\text { Middle East and North } \\
\text { Africa }\end{array}$ \\
\hline 108 & Cóte d'lvoire & 34 & 32 & 32 & 27 & 29 & Sub Saharan Africa \\
\hline 108 & Egypt & 34 & 36 & 37 & 32 & 32 & $\begin{array}{l}\text { Middle East and North } \\
\text { Africa }\end{array}$ \\
\hline 108 & Ethiopia & 34 & 33 & 33 & 33 & 33 & Sub Saharan Africa \\
\hline 108 & Guyana & 34 & 29 & 30 & 27 & 28 & Americas \\
\hline 113 & Armenia & 33 & 35 & 37 & 36 & 34 & Europe and Central Asia \\
\hline 113 & Bolivia & 33 & 34 & 35 & 34 & 34 & Americas \\
\hline 113 & Vietnam & 33 & 31 & 31 & 31 & 31 & Asia Pacific \\
\hline$\cdots$ & $\cdots \cdot$ & $\omega$ & 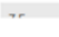 & $\omega$ & $m$ & 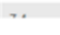 & $\ldots \ldots$ \\
\hline \multicolumn{8}{|c|}{ Visit www.transparency.org/cpi for more information } \\
\hline 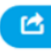 & & & & & & \multicolumn{2}{|c|}{ TIRANSPAREN } \\
\hline
\end{tabular}

Fuente: Transparencia Internacional.

Ante este escenario el gobierno ha tomado de la decisión política de combatir la corrupción conformado una serie de comisiones que tienen por objetivo sancionar a los responsables y promover leyes más rígidas en la gestión gubernamental.

Esto va a influir en el incremento del índice de confianza del inversionista porque claramente se interpreta la intención del gobierno como una posición que genere expectativas.

A continuación se detalla una tabla resumen con las amenazas y oportunidades identificadas: 
Tabla $N^{\circ}$ 10: Resumen de Análisis Político Gubernamental

\begin{tabular}{|c|c|c|}
\hline Factor & Análisis & $\begin{array}{c}\text { Oportunidad } \\
\text { Amenaza - }\end{array}$ \\
\hline \multirow{3}{*}{ Políticos } & $\begin{array}{l}\text { Estabilidad de la política } \\
\text { gubernamental }\end{array}$ & Oportunidad \\
\hline & $\begin{array}{l}\text { Inyección de capital para la } \\
\text { reconstrucción }\end{array}$ & Oportunidad \\
\hline & Lucha frontal contra la corrupción & Oportunidad \\
\hline Inversiones & $\begin{array}{l}\text { Confianza de los inversionistas del } \\
\text { sector privado }\end{array}$ & Oportunidad \\
\hline
\end{tabular}

Nota: Elaboración propia.

\subsubsection{Análisis Económico}

\section{Producto Bruto Interno (PBI) - General y por sectores}

Existe una tendencia positiva en relación a la variación porcentual del PBI del país, en los últimos 2 años se identifica un crecimiento en relación al año 2014 (valor más bajo desde el año 2009 post crisis financiera mundial).

Las proyecciones de crecimiento del PBI para los periodos 2017, 2018 y 2019 son de $2.8 \%, 4.0 \%$ y $4.0 \%$ respectivamente, estos valores se encuentran ajustados considerando la coyuntura generada por el efecto del fenómeno del Niño Costero que experimento el país y la postergación de megaproyectos por los casos de corrupción detectados este año. 
Tabla $\mathbf{N}^{\circ}$ 11: PBI general y por sectores

\begin{tabular}{|c|c|c|c|c|c|c|c|c|}
\hline & $\begin{array}{r}\text { Peso Año } \\
\text { Base } 2007 \\
\end{array}$ & 2016 & 2017 & 2018 & 2019 & 2020 & 2021 & $\begin{array}{c}\text { Prom } \\
2018-2021 \\
\end{array}$ \\
\hline Agropecuario & 6,0 & 2,3 & 0,9 & 4,6 & 4,0 & 4,0 & 4,0 & 4,1 \\
\hline Agrícola & 3,8 & 1,4 & $-0,5$ & 4,9 & 4,0 & 3,9 & 3,9 & 4,2 \\
\hline Pecuario & 2,2 & 3,7 & 3,0 & 4,2 & 4,2 & 4,2 & 4,1 & 4,2 \\
\hline Pesca & 0,7 & $-10,1$ & 34,7 & 5,4 & 3,5 & 3,4 & 3,5 & 4,0 \\
\hline Minería e hidrocarburos & 14,4 & 16,3 & 4,9 & 4,7 & 1,2 & 1,5 & 2,4 & 2,4 \\
\hline Minería metálica & 12,1 & 21,1 & 5,5 & 4,1 & 1,4 & 2,1 & 2,9 & 2,6 \\
\hline Hidrocarburos & 2,2 & $-5,1$ & 2,4 & 7,2 & 0,0 & 0,0 & 0,0 & 1,8 \\
\hline Manufactura & 16,5 & $-1,4$ & 1,4 & 3,4 & 3,6 & 3,6 & 3,6 & 3,6 \\
\hline Primaria & 4,1 & $-0,6$ & 9,7 & 3,6 & 3,3 & 3,2 & 3,2 & 3,3 \\
\hline No primaria & 12,4 & $-1,7$ & $-0,6$ & 3,3 & 3,7 & 3,7 & 3,7 & 3,6 \\
\hline Electricidad y agua & 1,7 & 7,3 & 3,2 & 5,0 & 5,5 & 5,5 & 5,5 & 5,4 \\
\hline Construcción & 5,1 & $-3,1$ & $-0,1$ & 8,8 & 5,4 & 5,4 & 5,0 & 6,2 \\
\hline Comercio & 10,2 & 1,8 & 1,6 & 2,5 & 3,8 & 4,0 & 4,0 & 3,6 \\
\hline Servicios & 37,1 & 4,3 & 3,1 & 3,7 & 4,7 & 4,9 & 4,9 & 4,6 \\
\hline PBI & 100,0 & 4,0 & 2,8 & 4,0 & 4,0 & 4,0 & 4,0 & 4,0 \\
\hline PBI primario & 25,2 & 9,9 & 5,0 & 4,6 & 2,2 & 2,3 & 2,9 & 3,0 \\
\hline PBI no primario ${ }^{1}$ & 66,5 & 2,4 & 2,1 & 4,0 & 4,5 & 4,7 & 4,6 & 4,4 \\
\hline
\end{tabular}

Nota: BCRP. Proyecciones MEF.

Por otro lado, se observa también el crecimiento del sector pecuario de $3.0 \%$ para el 2017 y $4.2 \%$ promedio $2018-2022$, con la misma tendencia que muestra el PBI general, lo que supone que la demanda de pollo vivo se comportará de la misma manera.

\section{La reconstrucción por efecto del Fenómeno del Niño Costero}

Según Macroconsult, los daños y pérdidas generados por el fenómeno del Niño Costero le han significado al Perú una pérdida aproximada de US\$ 3 mil millones, siendo mayores los daños generados en carreteras, seguido de viviendas como se puede visualizar en la siguiente tabla. 
Figura $N^{\circ}$ 6: Daños generados por el Fenómeno del Niño

\begin{tabular}{lrr}
\hline \multicolumn{1}{c}{ Rubro dañado } & \multicolumn{1}{c}{$\begin{array}{c}\text { US\$ } \\
\text { millones }\end{array}$} & \% part. \\
\hline Carreteras & 1,259 & $40 \%$ \\
Viviendas & 1,123 & $36 \%$ \\
\hline Puentes & 253 & $8 \%$ \\
Áreas de cultivo & 243 & $8 \%$ \\
Instituciones educativas & 171 & $5 \%$ \\
Canales de riego & 38 & $1 \%$ \\
Caminos rurales & 31 & $1 \%$ \\
Establecimientos de salud & 7 & $0 \%$ \\
\hline Total nacional & $\mathbf{3 , 1 2 4}$ & $\mathbf{1 0 0 \%}$ \\
\hline
\end{tabular}

Fuente: Macroconsult.

Referencia: Indeci.

Existe una alta disposición del gobierno en relación a la inversión pública. A la fecha, el Gobierno Central viene planificando los proyectos a desarrollarse en la próxima etapa de "Reconstrucción", según el director ejecutivo de la ARCC, Pablo de la Flor y publicado en el diario Gestión el día 25 de junio del 2017, el plan de reconstrucción contempla inversiones que superan los S/ 20 millones de soles. Se ha presentado también como iniciativa permitir a las empresas privadas financiar obras públicas a cargo del impuesto a la renta, es decir realizar obras por impuestos.

Esta inyección de capital le permitirá al país recuperar las pérdidas generadas en el año 2017 impactado en un fuerte crecimiento del PBI en los periodos 2018 y 2019, según lo indica el BCRP en sus encuestas de expectativas macro económicas. 


\section{Inflación}

La inflación anual muestra una tendencia estable, en el año 2016 cerró en un 3.2\%, porcentaje menor con respecto al año 2015 que fue de 4.4\% esto gracias a las políticas monetarias implementadas por el BCRP.

Para el año 2017 se proyecta un 3.0\% de inflación y para el año 2018 se proyecta un $2.8 \%$ de inflación según el BCRP.

\section{Figura $N^{\circ}$ 7: Proyección de inflación 2017 - 2019}

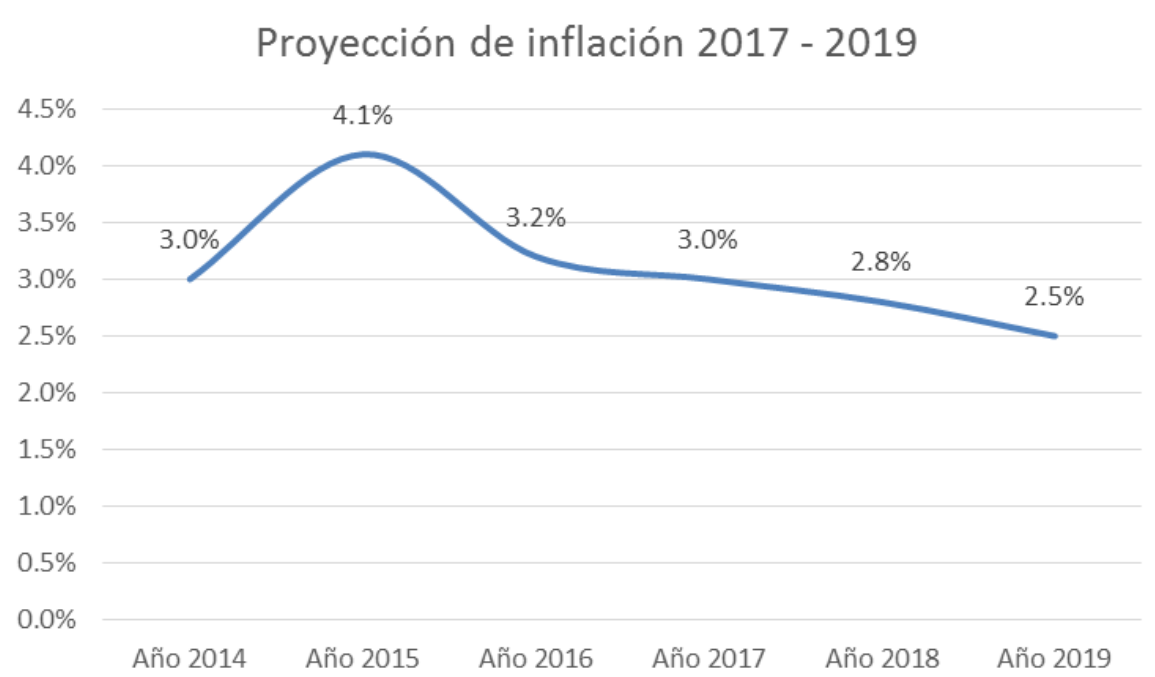

Fuente: Adaptado de "Encuesta de expectativas macro económicas", por BCRP.

\section{Tipo de cambio}

El tipo de cambio muestra un comportamiento estable, en el año 2016 el tipo de cambio promedio fue de 3.38 soles por cada dólar y en el año 2017 el tipo de cambio promedio asciende a 3.24 soles por cada dólar. 
Para los años 2018 y 2019 se realizan las siguientes estimaciones, esto según la encuesta de expectativas macroeconómicas realizada y publicada por el Banco Central de Reservas del Perú

Figura $N^{\circ}$ 8: Evolución y proyección del tipo de cambio

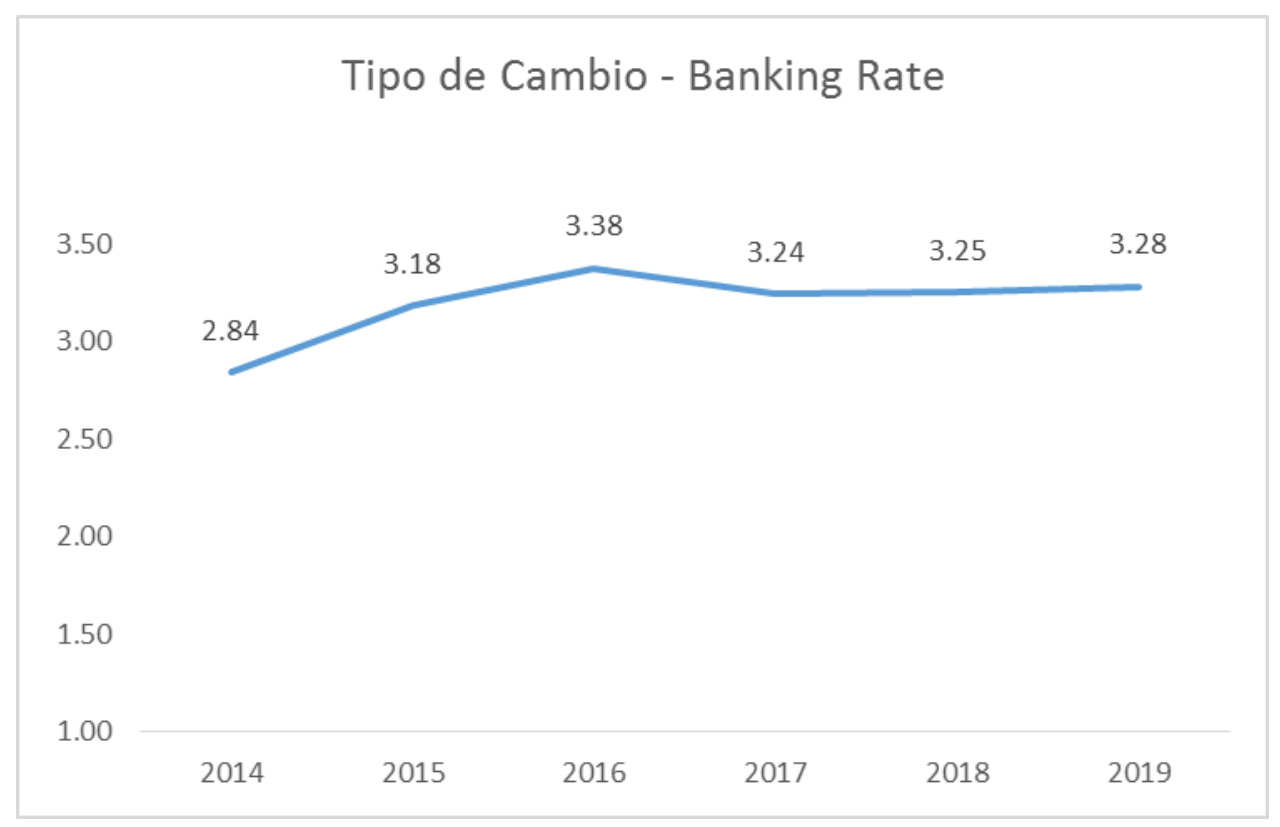

Fuente: Adaptado de BCRP.

A continuación se detalla una tabla resumen con las amenazas y oportunidades identificadas: 


\section{Tabla $\mathbf{N}^{\circ}$ 12: Resumen de Análisis Económico}

\begin{tabular}{lll}
\hline \multicolumn{1}{c}{ Factor } & \multicolumn{1}{c}{ Análisis } & $\begin{array}{c}\text { Oportunidad } \\
\text { Amenaza - }\end{array}$ \\
\hline PBI & $\begin{array}{l}\text { Tendencia del crecimiento en los } \\
\text { próximos años } \\
\text { Estable y con proyección a } \\
\text { mantenerse }\end{array}$ & Oportunidad \\
Inflación & Oportunidad \\
$\begin{array}{l}\text { Reconstrucción } \\
\text { por efectos del } \\
\text { niño costero }\end{array}$ & Inyección de inversión pública & Oportunidad \\
Tipo de cambio & $\begin{array}{l}\text { Estable y con proyección a } \\
\text { mantenerse }\end{array}$ & Oportunidad \\
\hline
\end{tabular}

Nota: Elaboración propia.

\subsubsection{Análisis Legal}

Para poder aperturar un centro de beneficio avícola formal es necesario conseguir previamente la licencia de funcionamiento expedida por el SENASA - Servicio Nacional de Sanidad Agraria, según lo comentado por un especialista del sector es esta una de las dificultades principales por superar debido a los requisitos que conlleva dicha licencia. Para la construcción y funcionamiento de una planta de beneficio de pollos, es necesario cumplir con las normas establecidas en el reglamento del sistema sanitario avícola detallado según decreto supremo $\mathrm{N}^{\circ}$ 0292007-AG y publicado en el diario el peruano con fecha 01 de noviembre del 2007.

El SENASA y las municipalidades han intensificado en los últimos años sus políticas de lucha contra la informalidad e insalubridad realizando operativos que finalizan en la clausura de los centros de beneficios 
clandestinos, aplicándose las multas correspondientes y realizando la incineración del pollo decomisado.

Existe mucha burocracia para la gestión de las respectivas licencias de funcionamiento y sanitarias, ya que son los organismos públicos quienes otorgan las licencias, los cuales tienen una serie de trámites administrativos que cumplir por exigencias del estado.

Es necesario contar con la licencia de funcionamiento expedida por la municipalidad donde se ubique el CBA, así como también con la licencia de INDECI, en la actualidad se vienen generando inspecciones para asegurar que las empresas cuenten con las respectivas licencias de acuerdo al giro de negocio.

Es necesario atender la ley de Seguridad y Salud en el Trabajo 29783 la cual estipula que el empleador debe garantizar en su centro de trabajo las condiciones de seguridad que protejan su salud y bienestar. Las empresas deben de implementar los comités de seguridad y salud en el trabajo según lo exige la ley generándose costos que generalmente no son contemplados en su estructura.

A continuación se detalla una tabla resumen con las amenazas y oportunidades identificadas: 
Tabla $N^{\circ}$ 13: Resumen de Análisis Legal

\begin{tabular}{llc}
\hline \multicolumn{1}{c}{ Factor } & \multicolumn{1}{c}{ Análisis } & $\begin{array}{c}\text { Oportunidad } \\
\text { Amenaza - }\end{array}$ \\
\hline \multirow{2}{*}{ Licencias } & $\begin{array}{l}\text { Burocracia para obtener las licencias } \\
\text { de funcionamiento }\end{array}$ & Amenaza \\
& Exigencias de las normas regulatorias & Amenaza \\
& Operativos contra la informalidad & Oportunidad \\
Regulaciones & $\begin{array}{l}\text { Inspecciones de los organismos } \\
\text { gubernamentales y municipales (SST, }\end{array}$ & Oportunidad \\
& INDECI, SENASA, SUNAT) & \\
\hline
\end{tabular}

Nota: Elaboración propia.

\subsubsection{Análisis Cultural}

\section{En relación a la industria}

Las peladurías de pollo en la actualidad se caracterizan por su informalidad, es habitual ver en los diferentes medios de comunicación noticias relacionadas a la clausura de camales clandestinos debido a que no cuentan con las licencias necesarias. Las pobres condiciones en el proceso de beneficio en cuanto al cumplimiento de las normas de salubridad hacen que el producto final que llega a la mesa del consumidor no cuente con los estándares básicos.

Las empresas del sector en general se han acostumbrado a que esta parte de la industria (el pelado) se realice con bajos estándares de calidad, incluso cuando esta rompe la cadena de valor que inicia en las empresas que se dedican a la crianza de pollo. 


\section{En relación a los consumidores finales}

Los consumidores finales cada vez se preocupan más en temas relacionados a la salud familiar y en mejorar los hábitos alimenticios, sin embargo estos no toman conciencia aún de los problemas reales que existen en la industria del pelado de pollo y como esto va en contra de la salud propia y familiar.

La carne de pollo es la más consumida en Lima Metropolitana y Callao, sin embargo esta preferencia lleva consigo algunas características que deben ser resueltas por el presente plan de negocio. En cuanto al color, las amas de casa se encuentran acostumbradas al color amarillo del pollo asociándolo a la entrega de un pollo sano, además no es habitual encontrar en los puestos de los mercados pollo congelado ya que lo asocian a pollo, esto debido a que la textura del pollo una vez descongelada no es la preferida la preferida y no es aceptada.

\section{En relación a los canales de comunicación}

El Internet y Facebook, en la actualidad existe una fuerte tendencia en la utilización del internet para las diversas actividades de las personas y empresas, es así que se puede ver como empresas tradicionales se encuentran migrando sus canales de comunicación y marketing a esta nueva tendencia.

Las empresas en general crean páginas web y perfiles de Facebook para comunicar sus ventajas competitivas y crear fidelidad de sus clientes. 
En la actualidad existen una serie de páginas de internet en donde se publican on-line las noticias más actuales y las campañas de ventas vigentes.

Facebook se sigue manteniendo como la red social más utilizada en el mundo. En el Perú año a año el número de usuarios crece de forma acelerada, es así que hemos pasado de 9 millones de usuarios en el año 2012 a 17 millones de usuarios en el año 2016, esto según el diario La República.

A continuación se detalla una tabla resumen con las amenazas y oportunidades identificadas:

Tabla $N^{\circ}$ 14: Resumen de Análisis Cultural

\begin{tabular}{llc}
\hline \multicolumn{1}{c}{ Factor } & \multicolumn{1}{c}{ Análisis } & $\begin{array}{c}\text { Oportunidad } \\
\text { Amenaza - }\end{array}$ \\
\hline $\begin{array}{l}\text { Informalidad del } \\
\text { sector }\end{array}$ & $\begin{array}{l}\text { Las peladurías operan con bajos } \\
\text { estándares de calidad e inocuidad } \\
\text { Las avícolas y picadores se han } \\
\text { adaptado a la informalidad } \\
\text { servicio }\end{array}$ & Oportunidad \\
& $\begin{array}{l}\text { No reconocen la oferta de valor } \\
\text { Mayor preocupación en temas de } \\
\text { salud y alimentación } \\
\text { Poca educación en temas de } \\
\text { inocuidad } \\
\text { Cambio en los hábitos de } \\
\text { fonsumidor }\end{array}$ & Amenaza \\
& $\begin{array}{l}\text { comunicación con tendencia al canal } \\
\text { digital }\end{array}$ & Oportunidad \\
\hline
\end{tabular}

Nota: Elaboración propia. 


\subsubsection{Análisis Tecnológico}

\section{Automatización y tecnología}

En la actualidad el sector de las peladurías opera con procesos $100 \%$ manuales dada la naturaleza del negocio avícola cuyo desarrollo en esta parte del proceso ha sido incipiente apoyado en las pocas exigencias de los usuarios de este servicio. Hoy existe una fuerte tendencia hacia la utilización de tecnología en la automatización de los procesos productivos en general y en todas las industrias. El termino automatización es utilizado para describir tipos de maquinarias o sistemas que operan de forma automática sin necesidad de la mano del hombre o en su defecto tener una necesidad mínima.

El proceso de pelado de pollo requiere de avances tecnológicos que puedan generarles beneficios en relación a:

- La velocidad de sus ciclos productivos los cuales pueden volverse más cortos generando menos mano de obra y logrando cumplir con las ventanas horarias de atención a los clientes.

- La calidad final del producto obtenido del servicio de pelado el cual mejora significativamente en aspectos de inocuidad y conservación.

- Los costos del servicio de pelado por efecto de la automatización se reducen considerablemente no solo como consecuencia de la reducción de la mano de obra sino que también por una 
disminución de las mermas de no calidad, reducción de los espacios de trabajo, reducción de los accidentes entre otros.

Sin embargo se tienen problemas en la aceptación del pollo beneficiado con procesos automatizados por parte del consumidor final porque algunas peladurías, en su intento de incursionar aisladamente con automatizaciones básicas no logran concluir con un producto final similar a uno procesado en forma manual en acabado y color. Esto sucede por la falta de experiencia en temas industriales por parte de los peladores.

El acceso por parte de la industria de beneficio de pollos a procesos automatizados, innovadores y con tecnologías que aseguren su calidad, se encuentra hoy en el Perú disponible ya que existen empresas dedicadas a estos procesos industriales que iniciaron sus operaciones en plantas de beneficio de pollos para clientes retail y que hoy están en capacidad de atender a este sector de peladurías de pollo vivo.

A continuación se detalla una tabla resumen con las amenazas y oportunidades identificadas: 
Tabla $N^{\circ}$ 15: Resumen de Análisis Tecnológico

\begin{tabular}{clc}
\hline \multicolumn{1}{c}{ Factor } & \multicolumn{1}{c}{ Análisis } & $\begin{array}{c}\text { Oportunidad } \\
\text { Amenaza - }\end{array}$ \\
\hline \multirow{4}{*}{ Automatización } & $\begin{array}{l}\text { Mayor accesibilidad a la reconversión } \\
\text { tecnológica } \\
\text { macabado (textura y color) del } \\
\text { producto final similar al procesado en } \\
\text { forma manual }\end{array}$ & Oportunidad \\
Eficiencia en los procesos & Amenaza \\
& $\begin{array}{l}\text { relacionados a mano de obra, } \\
\text { reducción de mermas y optimización } \\
\text { de tiempos }\end{array}$ & Oportunidad \\
\hline
\end{tabular}

Nota: Elaboración propia.

\subsubsection{Análisis Ecológico}

La actividad misma de beneficiar pollo produce un gran volumen de residuos de forma diaria, tales como plumas, sangre y agua residual, lo cual exige a las empresas del rubro avícola y a los CBA a desarrollar una adecuada gestión del manejo de residuos, con la finalidad de mitigar el impacto ambiental y cumplir con el reglamento del sistema sanitario avícola en su artículo $34^{\circ}$ Buenas prácticas en el manejo de plumas, vísceras, sangre, guano o productos de desecho, antes de salir de un establecimiento avícola con o sin ocurrencia de enfermedad notificable.

El Sr. Víctor Carabalí Ocoró menciona en su tesis denominada "Producción de proteína para consumo animal mediante hidrólisis de plumas de pollo en agua sub crítica" que las plumas están compuestas por 91\% proteína (queratina), $1 \%$ lípidos y $8 \%$ agua, debido a este alto valor proteico, la demanda de estos residuos aumenta para la fabricación de 
harina de plumas, la cual en la actualidad es usada para la producción de alimentos para animales.

Es así que se genera en el Perú un mercado alternativo o un sub sector como consecuencia del beneficio de pollo, por lo que muchas de las empresas del rubro avícola (mayoristas, distribuidores y peladores) por lo general venden este residuo, logrando obtener ingresos y descartando así su eliminación por incineración o entrega a los recolectores municipales. Entre las empresas que elaboran harina de plumas en el Perú, podemos encontrar a Coinsa, Alternativas Proteicas del Pacífico, Negocios Agroindustriales Los Ferroles y Agroindustrias Intiquilla entre otras.

En cuanto a la sangre, ésta también contiene una gran fuente de proteínas, por lo que también puede ser usada para la producción de alimentos para animales, la tendencia actual orienta a los CBA a implementar adecuados dispositivos y/o infraestructura de retención de la sangre, con la finalidad de evitar que este residuo se descargue en el alcantarillado.

A continuación se detalla una tabla resumen con las amenazas y oportunidades identificadas: 
Tabla $N^{\circ}$ 16: Resumen de Análisis Ecológico

\begin{tabular}{llc}
\hline \multicolumn{1}{c}{ Factor } & \multicolumn{1}{c}{ Análisis } & $\begin{array}{c}\text { Oportunidad } \\
\text { Amenaza - }\end{array}$ \\
\hline Impacto & $\begin{array}{l}\text { Adecuada gestión del manejo de } \\
\text { residuos }\end{array}$ & Amenaza \\
Ambiental & $\begin{array}{l}\text { Empresas relacionadas para el } \\
\text { tratamiento de residuos avícolas }\end{array}$ & Oportunidad \\
\hline
\end{tabular}

Nota: Elaboración propia.

\subsection{Oportunidades}

Habiendo identificado las oportunidades y amenazas que se encuentran inmersas para el presente plan de negocio se desarrollará una herramienta de la dirección estratégica denominada Matriz de Evaluación de Factores Externos (EFE) la que permite realizar una evaluación del macroentorno y sus componentes.

En esta matriz se presentaran las oportunidades y amenazas que forman parte de los factores críticos del éxito y se le asignaran valores o pesos que serán asignados en relación a la contribución de éxito que le signifique a la empresa.

Como principal objetivo para la elaboración de la siguiente matriz identificamos la posibilidad de conocer la forma en que influyen en el éxito del negocio las oportunidades y amenazas para que de este modo la empresa pueda enfocarse en las oportunidades que debe aprovechar y potenciar con estrategias, y también cuales son las amenazas que debe abordar para reducir el riesgo de la empresa. 
Tabla $\mathbf{N}^{\circ}$ 17: Matriz de Evaluación de Factores Externos (EFE)

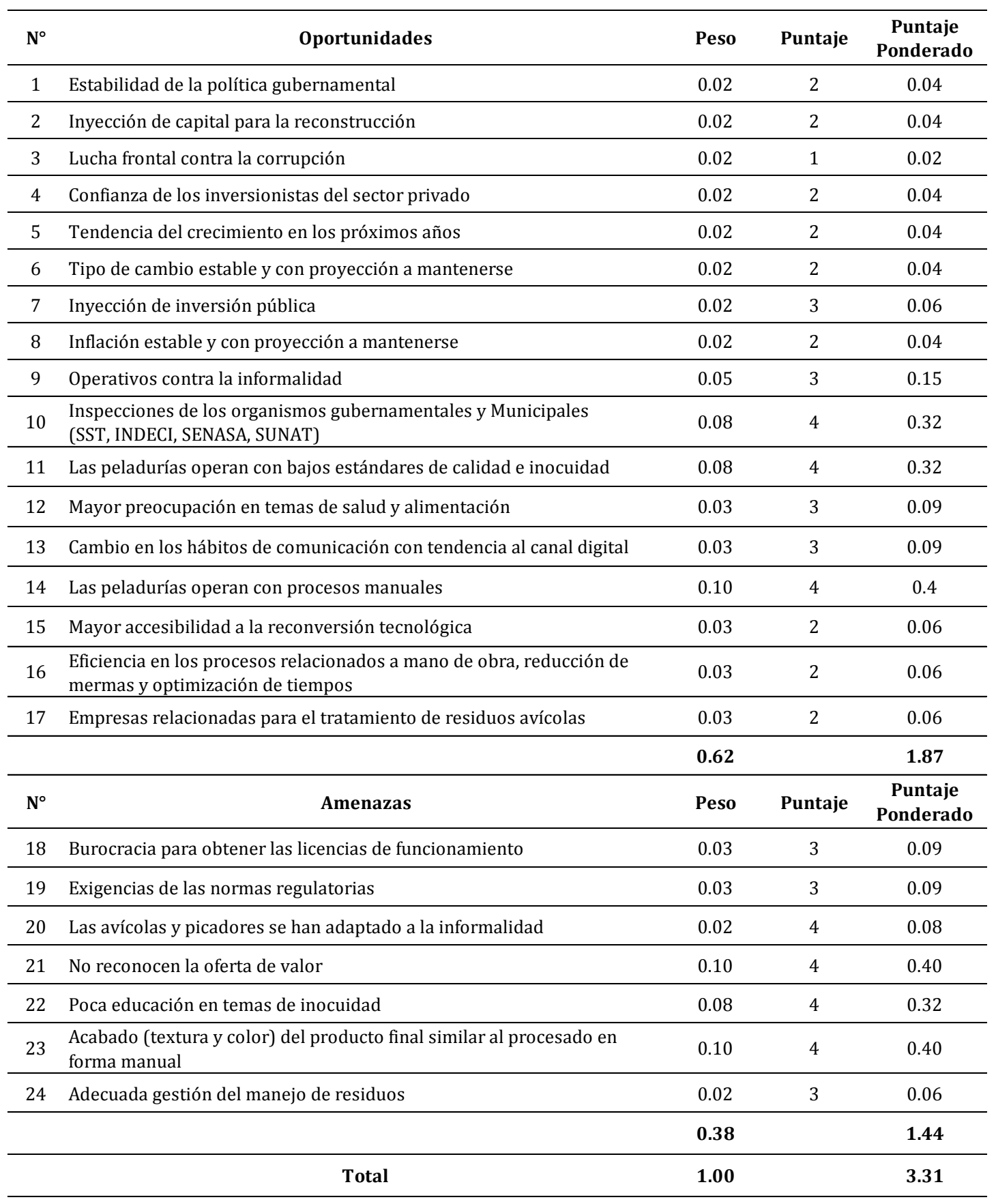

\section{Nota: Elaboración propia.}


Como se puede observar en la tabla anterior el peso de las oportunidades es mayor a las amenazas con valores de 0.62 y 0.38 respectivamente, entendiéndose que es importante aprovechar las oportunidades para lograr el éxito.

En relación a las oportunidades se identifican a los siguientes factores con mayor ponderación. Las peladurías operan con procesos manuales con un ponderado de 0.10, las peladurías operan con bajos estándares de calidad e inocuidad con un ponderado de 0.08 y las inspecciones de los organismos gubernamentales y municipales con un ponderado de 0.08 , debido a que impactan directamente al éxito del negocio y que se encuentran alineados a las exigencias que realiza el mercado y los organismos supervisores. Estos mismos factores presentan la más altas calificación con un valor de cuatro en cada uno de ellos, debido a ello y de forma estratégica serán abordados por la empresa para el desarrollo del negocio. Además de pueden observar como algunos de los criterios con mayor calificación a operativos contra la informalidad, mayor preocupación en temas de salud y alimentación y cambio en los hábitos de comunicación con tendencia al canal digital con una valoración de tres en cada uno de ellos.

Los factores con ponderación baja se encuentran enfocados en los aspectos políticos y económicos con valores de que fluctúan entre 0.01 y 0.02 y ello debido a que estos factores se muestran estables y con tendencias favorables, además no generan un impacto significativo en el desarrollo del presente negocio.

En relación a las amenazas se identifican a los siguientes factores con mayor ponderación. No reconocen la oferta de valor con un ponderado de 0.10 , poca educación en temas de inocuidad con un ponderado de 0.08 y acabado (textura y color) del producto final similar al procesado en forma manual con un ponderado de 0.10 , estas 
amenazas son relevantes para el negocio y se encuentran directamente relacionadas a las preferencias y hábitos de los usuarios del servicio y de los consumidores finales, la aceptación de ellos es un tema que será priorizado por la empresa y se abordaran con suma importancia. Así mismo estos tres factores presentan la más altas calificación con un valor de cuatro en cada uno de ellos considerando que un centro de beneficio automatizado y con que cumpla con buenas prácticas de manufactura representa la mejor manera de abordar estas amenazas.

Se puede identificar también a los factores que muestran una baja ponderación, encontrándose a las avícolas y picadores se han adaptado a la informalidad con un ponderado de 0.02 pero esta tendencia se encuentra en proceso de cambio debido a los operativos que realizan las municipalidades y el SENASA, y una adecuada gestión del manejo de residuos con un ponderado de 0.02 y que forma parte de los requisitos para la implementación de un centro de beneficio. Ambos factores muestran altas calificaciones con valores de 4 y 3 respectivamente por tratarse de amenazas que son abordadas directamente por el presente negocio con un servicio diferenciado y que cumpla con los estándares de inocuidad que el producto final necesita.

El valor promedio ponderado en una matriz EFE es de 2.5 debido a que el total ponderado más alto obtenible es de 4.0 y el total ponderado más bajo obtenible es de 1.0.

Habiéndose identificado un valor final ponderado de 3.31 para la matriz EFE se indica que el proyecto está por encima de la media y que será importante implementar estrategias que aprovechen las oportunidades y contrarresten las amenazas. El análisis de entorno externo en general es favorable para el proyecto lo que lo convierte en una excelente alternativa dentro del sector avícola. 


\section{CAPÍTULO III}

\section{Estudio de mercado}

El presente capitulo describe los aspectos generales que incluyen la definición comercial del servicio, las principales características y la determinación del área geográfica para la implementación del centro de beneficio de pollos. Asimismo, a través de las investigaciones cualitativas y cuantitativas realizadas se conocerá la cantidad de consumidores que aceptarán el servicio a ofrecer, el precio al que están dispuestos a obtenerlo, entre otros.

El desarrollo de este estudio es el paso inicial para determinar la factibilidad comercial del proyecto.

\subsection{Descripción del servicio o producto}

El plan de negocio consiste en la implementación del CBA el cual brindará el servicio de beneficio avícola, operando con una licencia de funcionamiento formal, autorizado por SENASA y certificado con buenas prácticas de manufactura (BPM) que permitan ofrecer un producto de alta calidad, en el tiempo que lo requiere el cliente y con una mayor vida útil como oferta de valor.

El local del CBA se encontrará diseñado para que opere con procesos automatizados para brindar el servicio de beneficio de una manera eficiente dándole velocidad al proceso y con estrictas normas de salubridad que aseguren el cumplimiento de los requisitos solicitados por los organismos estatales y/o municipales, logrando que 
el proceso sea limpio dentro de todas las etapas de beneficio hasta la llegada a los consumidores finales.

El proyecto contempla el tratamiento de los residuos generados durante el proceso del día (plumas, vísceras y sangre) a través del acopio y recolección diaria por parte de pequeños empresarios terceros quienes no realizan ningún cobro por esta actividad ya que la tienen implementada en forma habitual.

El personal que labore será formal, capacitado y debidamente equipado con los EPP exigidos por el reglamento de Seguridad y salud en el trabajo.

\section{Producto Básico}

Se le ofrecerá al cliente el servicio de pelado de pollo operado con buenas prácticas de manufactura.

\section{Producto Real}

El servicio de pelado de pollo contará con la certificación de BPM que asegure la correcta elaboración y prevención de los factores contaminantes que puedan comprometer al producto.

\section{Producto Aumentado}

\section{Para Avícolas y Picadores}

El pollo beneficiado será empacado antes de la entrega en bolsas polipropilenos, las cuales tendrán impresa la oferta de valor prometida a este segmento de clientes y 
permitirá reconocer que el pollo ha sido pelado en un centro autorizado y con BPM que garantice la inocuidad del producto.

\section{Para el consumidor final}

Por cada servicio se entregarán paquetes de bolsas dirigidas a los consumidores finales donde este encontrará el link del perfil de Facebook y la página web de la empresa en donde los consumidores accederán para conocer la cadena de operación del proceso de pelado, las prácticas sanitarias que aseguran la inocuidad del producto y las evidencias tanto de la inscripción municipal como de la certificación de BPM otorgada por la entidad pertinente.

Se considera importante mostrar en la red videos de las intervenciones municipales a las peladurías informales. Se mostrarán también videos tutoriales sobre los cortes de pollo que pueden rendir más a las amas de casa y se contará con recetarios interactivos para preparaciones novedosas.

\subsection{Selección del segmento de mercado}

En relación al segmento meta este estará compuesto por lo siguiente:

- Personas naturales o jurídicas.

- Sector de desempeño pecuario.

- Actividad económica, comercialización de pollo vivo, avícolas y picadores.

- Que cuenten con la necesidad de utilizar centros de beneficio de aves o peladurías. 
- Que cuenten con cobertura geográfica en el distrito de San Juan de Lurigancho.

Los criterios de identificación utilizados para la selección de la zona geográfica son: a) El consumo de pollos por distrito y b) La cantidad de población del distrito.

Por la naturaleza del servicio a ofrecer, esta información servirá para poder identificar el público objetivo al que será dirigido el negocio, público que será estudiado en los análisis cuantitativo y cualitativo.

Tabla $N^{\circ}$ 18: Consumo de pollo por distritos

\begin{tabular}{lrr}
\hline \multicolumn{1}{c}{ Mercado Mayorista } & Unidades & \% Participación \\
\hline CALLAO & 62,454 & $10 \%$ \\
SAN JUAN DE LURIGANCHO & 78,016 & $13 \%$ \\
CAQUETA & 71,963 & $12 \%$ \\
CHORRILLOS & 47,386 & $8 \%$ \\
COMAS & 55,889 & $9 \%$ \\
LA VICTORIA & 30,430 & $5 \%$ \\
PUENTE PIEDRA & 42,491 & $7 \%$ \\
RIMAC & 11,936 & $2 \%$ \\
SAN LUIS & 25,550 & $4 \%$ \\
SAN MARTIN DE PORRES & 24,931 & $4 \%$ \\
SAN MIGUEL & 15,830 & $3 \%$ \\
SANTA ANITA & 68,110 & $11 \%$ \\
VILLA EL SALVADOR & 62,431 & $10 \%$ \\
\hline TOTAL & 597,418 & $\mathbf{1 0 0 \%}$ \\
\hline
\end{tabular}

Nota: Adaptado de "Información Estadística", por Ministerio de Agricultura y Riego.

Como se observa en el cuadro anterior es el distrito de San Juan de Lurigancho el que concentra una mayor participación con un $13 \%$ además es el que presenta una mayor 
población. Esto convierte a este distrito como el más atractivo para la instalación del negocio.

En relación a la cantidad de población por distrito, San Juan de Lurigancho es el que concentra la mayor cantidad de población con una participación del $12 \%$ como se puede observar en la siguiente figura.

\section{Figura $\mathbf{N}^{\circ}$ 9: Cantidad de población por distrito}

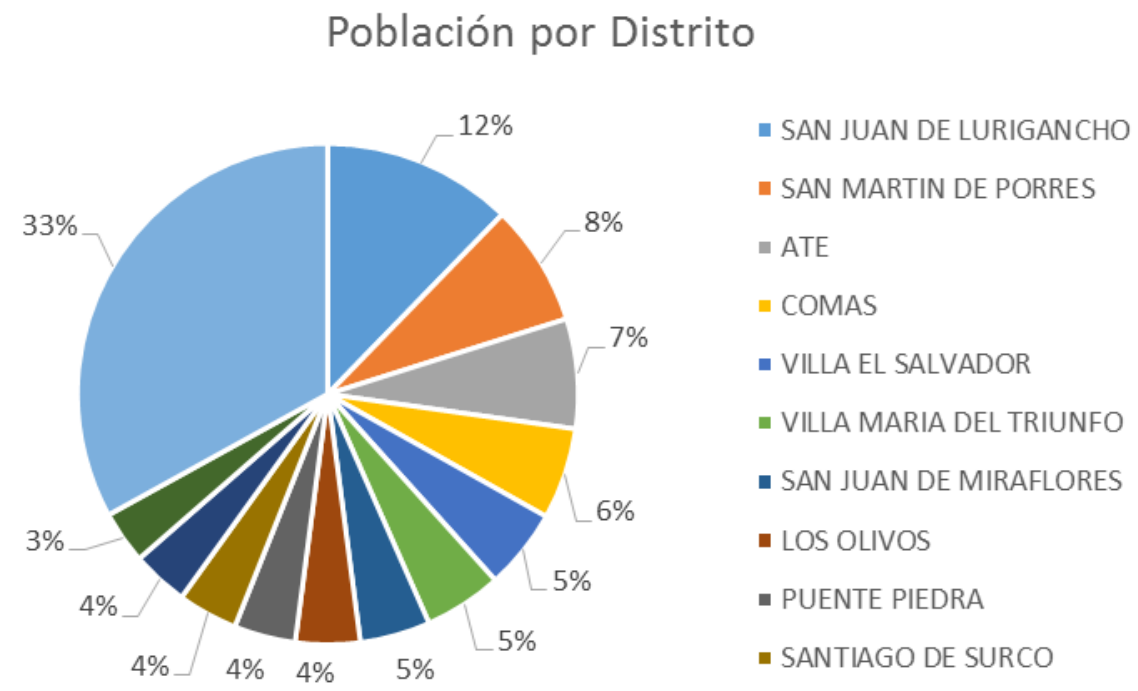

Fuente: Adaptado "Estimaciones y proyecciones de población”, por INEI.

\subsection{Investigación Cualitativa}

A través de la investigación cualitativa se identificará como opera el negocio en cuanto a volúmenes ofertados, precios de venta, ofertas de valor, ubicación y comportamientos desde el punto de vista de los clientes actuales (avícolas y picadores), clientes potenciales (picadores con peladeros en sus casas o puestos del mercado), 
competidores relacionados (distribuidores con peladurías dentro de su local), especialistas del sector y consumidor final (amas de casa)

\subsubsection{Proceso de muestreo}

Se ejecutarán Entrevistas a profundidad de acuerdo al público mencionado anteriormente como técnica cualitativa para poder, a través de sus respuestas, comprender a profundidad como piensan respecto al modelo de negocio planteado e interpretar sus posiciones y modelarlo de acuerdo a ello. Se ejecutarán considerando la disponibilidad en relación con la cadena de valor de la venta de pollo vivo y buscando la información más relevante a incorporar en el proyecto.

\subsubsection{Diseño de instrumento}

El instrumento utilizado para la Entrevista a Profundidad es un guión de entrevista con preguntas y repreguntas en base a los supuestos utilizados y los objetivos de la investigación. Se busca conocer la parte subjetiva en forma individual y se realizan en función a la experiencia de la persona entrevistada. En anexos $\mathrm{N}^{\circ} 1, \mathrm{~N}^{\circ} 2, \mathrm{~N}^{\circ} 3, \mathrm{~N}^{\circ} 4$ y $\mathrm{N}^{\circ} 5$ se encuentran entrevistas a detalle. 


\subsubsection{Análisis y procesamiento de datos}

\section{Resumen de las entrevistas a profundidad:}

\section{a. Especialistas del sector (dos expertos en temas de demanda y mercado} objetivo)

El objetivo de estas entrevistas fue conocer, desde el punto de vista de dos expertos cuales son los comportamientos de la demanda que deben servir de base para enfocar el negocio, los riesgos a los que se deben enfrentar, recoger las sugerencias que ayuden a afinar la propuesta de negocio y algunos alcances acerca de la propuesta de valor presentada.

Ambos entrevistados coinciden en que el sector avícola en los últimos años se encuentra en proceso de formalización, indican que la comercialización hace 10 años se caracterizaba en que las aves llegaban vivas al mismo puesto del picador. Hoy las aves tienen que llegar ya beneficiadas lo que ha ocasionado que se incluya en la cadena de comercialización un proceso adicional antes de llegar al puesto del picador.

Uno de los entrevistados señaló que un integrante más de la cadena de valor hace que se abran posibilidades para negocios como el planteado en el presente plan de negocio.

Respecto a las acciones que actualmente viene implementando el gobierno peruano en referencia a las leyes de comercialización en mercados de abasto indicaron que irán aumentando, presentándose una gran oportunidad para las empresas o personas que identifiquen la necesidad que se tiene de 
entregar un producto de calidad y con la salubridad que hoy exige el consumidor.

Los especialistas ven con potencial la propuesta de negocio porque adicionalmente a generar ingresos se proporciona un producto saludable para el consumidor. Sin embargo uno de los especialistas mencionó que un tema a considerar es conseguir la intervención de los organismos reguladores para impedir que las peladurías informales puedan seguir trabajando sin las autorizaciones respectivas incumpliendo las normas de buenas prácticas de manufactura.

Uno de los expertos mencionó que Perú es uno de los pocos países a nivel latinoamericano donde aún el pollo llega vivo a la ciudad donde es beneficiado antes de ser vendido en los puestos de mercado, esto obedece a la cultura de Peruanos y que no se evidencia una tendencia al cambio.

Ante la pregunta de cómo se debería enfocar la oferta de valor uno de ellos indicó que el mayor valor deberá estar enfocado en el consumidor final, es decir, las ama de casa quienes al lograr identificar la oferta de valor, serían ellas mismas las que exigirán esas prácticas.

Los expertos indican que este proceso de formalización tiene el éxito garantizado ya que sin duda tendrá el apoyo de los consumidores que hoy está muy interesado en consumir alimentos que no se conviertan en un riesgo para su salud.

Uno de los expertos menciona que en las periferias de los mercados se pueden ubicar las avícolas y peladores que benefician pollos. En el distrito de 
San Juan de Lurigancho existen 160 pero indica que aproximadamente el 93\% son avícolas.

Ambos coincidieron en que existen riesgos que pueden presentarse con este negocio como la ubicación del centro de beneficio de aves considerando que no se encuentre en zonas urbanas pero sí cerca del mercado para facilitar que las avícolas y picadores recojan el producto para su comercialización.

También indican que no debe descuidarse el tema del tratamiento de las aguas residuales, esto tiene que ser bien manejado de lo contrario se convierte en un problema, de igual forma con los otros restos que deja el proceso de beneficio.

Finalmente mencionan que una oferta de valor bien direccionada en donde se comunique las condiciones en las que el pollo fue beneficiado, conseguirá una rápida aceptación por parte de las avícolas y picadores ya que a su vez será apreciado por el consumidor final.

Como recomendaciones adicionales uno de los expertos indica que un alimento tan importante como el pollo necesita ser ofrecido al consumidor en las mejores condiciones de salubridad y este negocio además de generar un ingreso interesante contribuye a garantizar al consumidor productos saludables. Indica que se trata de una excelente oportunidad para mejorar la calidad de vida de los peruanos.

Uno de los expertos indica que la participación de mercado de pelado de pollo por tipo de empresa se muestra como sigue: $5.5 \%$ de las empresas que realizan la actividad de pelado son picadores y la diferencia son avícolas entre 
medianas y grandes (75\% avícolas medianas y $19.5 \%$ avícolas grandes). Sustentando este cálculo en proporción a la cantidad de pollo que benefician.

\section{b. Competidor relacionado (Distribuidor que haya incorporado dentro de su} modelo de negocio principal un CBA como parte de su cadena de valor.

El objetivo de esta entrevista fue conocer, en base a sus experiencias desarrolladas durante la puesta en marcha del CBA, cuales son los factores de éxito que considera relevantes para tomarlos en cuenta durante el desarrollo del proyecto.

El entrevistado indica que haber colocado un CBA dentro de su cadena de valor reduce la intermediación y reduce la dependencia del mayorista. Indica que este proceso le da un valor agregado que asegura mayor rentabilidad. El Distribuidor indica que se le abren las puertas a distintos negocios anexos de la cadena de valor como los pollos trozados además le dan la oportunidad de contar con un espacio controlado a un precio adecuado.

Por otro lado, indica que la regulación de los locales corresponde a SENASA que tiene requisitos muy estrictos para obtener los permisos, los cuales demoran en gestionarse de 2 a 3 meses. Estos trámites son largos porque indica que SENASA, dentro de su modelo de operación sigue las referencias de las certificaciones de BPM. Y añade que son difíciles de implementar si no se tiene considerado como objetivo estratégico. Indica que constantemente está siendo visitado por entidades del estado auditando los 
procesos lo cual encarece el servicio por los gastos en los que deben incurrir para subsanar las observaciones.

Una experiencia que ha recogido del mercado es que la automatización ha tenido bastante aceptación en los clientes sin embargo deben considerarse temas de calidad para que el producto final tenga los colores y acabados necesarios.

c. Cliente (persona que compra pollo vivo y utiliza el servicio de una peladuría)

El objetivo de esta entrevistas fue conocer cuáles son los factores que influyen en el cliente para elegir una peladuría sobre otra para el beneficio del pollo. También se buscó conocer la oferta de valor y el nivel de aceptación.

El entrevistado al ser una persona que compra pollo todos los días manifiesta que existen horarios establecidos que deben cumplirse para poder llegar a tiempo a sus clientes. Considera que el proceso de pelado es una actividad complicada y muy sacrificada. Prefiere pagar por el servicio aun cuando a veces no vienen beneficiados con procesos de calidad. Como los clientes no identifican de donde vienen esos pollos beneficiados, negocia con el precio.

El entrevistado considera que la demora en el beneficio es clave para elegir un servicio. En promedio indica que un buen ratio es de 200 pollos en 15 minutos porque él mismo tiene que trasladarlo en su vehículo al mercado. 
En cuanto a las características más importantes de beneficio, identifica los mismos atributos que los expertos, es decir, que tenga un buen sangrado, que no estén remojados en agua estancada y que no huela feo porque cuando le sobra producto, él lo guarda para el día siguiente en una conservadora. De igual manera coincide en la importancia de tener una ventana horaria adecuada a su proceso (3 a 4 horas como máximo) puede marcar la diferencia.

Actualmente incurre en un gasto adicional que es la compra de bolsas para traslado de pollo pero no tiene problemas con los desechos porque son las propias peladurías que se encargan de ellos. Piensa que el consumidor final podría preferir la recompra allí si identifica la oferta de valor.

\section{d. Cliente potencial (persona que no usa el servicio de peladuría de terceros}

\section{porque esa actividad la realiza él mismo}

El objetivo de esta entrevistas fue entender cuáles son las oportunidades que se presentan y como deberían ser enfocadas para formular la oferta de valor del negocio.

El entrevistado tomó la decisión de pelar él mismo sus pollos porque los locales son muy sucios, no tienen agua potable y muchas veces no hay iluminación correcta. Indica que es por eso que los locales son cerrados de sorpresa y siempre está en riesgo de perder la venta del día.

Indicó las características negativas que se presentan en el proceso de pelado como, pollo grasoso, muy sancochado o con piel desgarrada producto de un mal pelado, indico también que esto es identificado por el consumidor 
final y lo rechaza. Igual cuando toma mal olor por efecto de haber sido enjuagado con agua sucia y luego embolsado. Siente que le convendría tener un local cercano para beneficiar pero por ahora el que tiene es limpio. El entrevistado indica que de identificar en el servicio propuesto beneficios en la duración del pollo en su mesa o que mejore el acabado, de seguro se cambiaría.

En cuanto al pago por el servicio indicó que en promedio el paga 0.30 centavos por pollo y que dependiendo de la oferta y aceptación del cliente podría pagar hasta 0.35 centavos. Indica que el volumen de pollo vivo que ingresa al mercado es alto con lo cual la actividad del pelado se vuelve necesaria.

\subsection{Investigación Cuantitativa}

A través de la investigación cuantitativa se estudiará a los clientes usuarios del CBA mediante la elaboración de una encuesta dirigida a las avícolas y picadores. Se identificarán las condiciones actuales del beneficio de pollo, los factores más valorados por los clientes usuarios, el nivel de aceptación que tendría el CBA así como también el nivel de pollo que benefician y la frecuencia de utilización de las peladurías.

\subsubsection{Proceso de muestreo}

El proceso de generación de la muestra se ha realizado considerando un modelo no probabilístico por conveniencia como consecuencia que las avícolas y picadores que operan en el distrito de San Juan de Lurigancho no se encuentran 
plenamente identificados, lo que imposibilita realizar un muestreo aleatorio priorizándose la accesibilidad a las empresas. En la ficha técnica incluida en el anexo $\mathrm{N}^{\circ} 6$ se encuentran detallados todos los aspectos relevantes para el proceso de muestro.

Como ya se ha mencionado en el apartado selección del segmento del mercado, el plan de negocio materia de estudio ha seleccionado al distrito de San Juan de Lurigancho como el mercado en donde se introducirá el servicio debido a que este mercado es el más grande de Lima, concentrando el 13\% de participación de venta de pollo vivo con aproximadamente 78,000 pollos vendidos de forma diaria.

En base a esta información la muestra estará compuesta por avícolas que comercialicen pollos vivos y que necesiten el beneficio de estas para que el producto llegue al puesto del picador, y algunos picadores que compran pollo vivo y los benefician por cualquiera de las formas antes mencionadas cuya operación se encuentre ubicada en el distrito de San Juan de Lurigancho.

Como consecuencia de la informalidad no existen datos estadísticos que permita la identificación de la cantidad de posibles clientes de los CBA, sin embargo hemos tomado como las entrevistas a profundidad en donde se menciona que existen aproximadamente 160 avícolas y picadores que se dedican a la venta de pollo beneficiado en el distrito de San Juan de Lurigancho, son estas empresas las que se deben estudiar y sobre ellas se realizará el cálculo de la muestra.

Como es difícil concentrar a este tipo de empresas se ha decidido y ejecutado la encuesta en el centro de acopio del distrito de San Juan de 
Lurigancho ubicado en Av. El Sol 309 Canto Grande - SJL como primer punto de contacto, un segundo contacto serían las instalaciones de las empresas antes mencionadas.

Para el cálculo de la muestra y considerando que la población es finita se utilizará la siguiente formula estadística:

$$
\text { Muestra }=\frac{N * Z^{2} * p * q}{e^{2} *(N-1)+Z^{2} * p * q}
$$

Donde:

Z, es el nivel de confianza con un valor de 1.645 en la distribución normal que corresponde a un $90 \%$ de nivel de confianza.

p, es la probabilidad a favor, generalmente un 0.50 .

q, es la probabilidad en contra (1-p).

e, es el margen de error aceptable para el estudio, para este efecto un $7 \%$.

N, es la población objetivo materia de estudio, para este efecto 160 empresas.

\section{Nota:}

Los valores de $\mathrm{Z}$ y e han sido ajustados a $90 \%$ y $7 \%$ respectivamente, según lo indicado por Jeffrey L. Pope es importante considerar ciertos criterios al momento de cuantificar el tamaño muestral, criterios como el costo asociado, el tiempo y acceso son factores que influyen la investigación, además considerando lo indicado por los expertos en la entrevistas a profundidad en relación a la muy poca disposición para contestar encuestas por parte de los dueños de las avícolas y 
picadores se ajustaron los valores antes mencionados. Con este ajuste se genera un tamaño de muestra que aborda al $46.25 \%$ del total de avícolas y picadores que operan en el distrito, considerándose así como una muestra con un alto nivel de precisión sobre la población a estudiar.

Aplicando la formula se identifica que la muestra es la siguiente:

$$
\text { Muestra }=\frac{160 * 1.645^{2} * 0.5 * 0.5}{0.07^{2} *(160-1)+1.645^{2} * 0.5 * 0.5} \approx 74
$$

Tamaño de muestra $=74$ empresas.

\section{Distribución de la muestra:}

Dado que la población total de avícolas y peladurías es de 160 y conociendo por información de los expertos en el rubro que el 93\% de ellas son avícolas, se ha distribuido la muestra de 74 entrevistas de manera proporcional a la población total tal como se observa en la siguiente tabla:

A continuación se detalla la tabla de distribución de muestra por tipo de cliente:

Tabla $\mathbf{N}^{\circ}$ 19: Distribución de la muestra

\begin{tabular}{rccc}
\hline \multicolumn{1}{c}{ Tipo de cliente } & $\begin{array}{c}\text { Poblacion } \\
\text { total }\end{array}$ & $\begin{array}{c}\% \\
\text { Participación }\end{array}$ & $\begin{array}{c}\mathbf{N}^{\circ} \text { de } \\
\text { Encuestas } \\
\text { (distribución) }\end{array}$ \\
\hline Picadores & 11 & $7 \%$ & 5 \\
Avícolas & 149 & $93 \%$ & 69 \\
\hline Total & $\mathbf{1 6 0}$ & $\mathbf{1 0 0 \%}$ & $\mathbf{7 4}$ \\
\hline
\end{tabular}

Nota: Elaboración propia. 


\subsubsection{Diseño de instrumento}

Para el diseño del instrumento y tomando en cuenta la poca accesibilidad de las empresas a contestar este tipo de cuestionarios, basando ello en lo indicado por los expertos en las entrevistas a profundidad la herramienta utilizada es un cuestionario simple de 10 preguntas, en el anexo $\mathrm{N}^{\circ} 7$ se puede ver el detalle, la encuesta deberá ser respondida por las personas que representan a las empresas seleccionadas; el tipo de preguntas utilizadas son estructuradas, múltiples y escala de Likert. Es importante mencionar que el cuestionario no puede tener un alto número de preguntas ya que los dueños de los negocios no son muy asequibles a este tipo de iniciativas por lo mismo que la gran mayoría convive con la informalidad.

Las encuestas fueron realizadas de forma presencial con las personas responsables de las empresas seleccionadas de entre todas las empresas que interactúan en la cadena de valor del sector, las empresas encuestadas son de tipo 1) Avícolas y 2) Picadores que compran pollo vivo y los benefician en peladurías diversas, esto debido a que son estas empresas las que utilizarían los servicios de los CBA.

En el contacto se realizó una breve descripción del servicio que se desea implementar mencionado cuales son las fortalezas y los beneficios de gestionar en un CBA con BPM.

La encuesta en mención se aplicó con la finalidad de validar de una manera cuantitativa los siguientes factores:

- El porcentaje de posibles clientes diferenciados de avícolas y picadores. 
- Identificar qué tipo de centro de beneficio utilizan para beneficiar su pollo en la actualidad.

- Identificar las condiciones y procedencia del agua que utilizan los lugares en donde benefician el pollo y la cantidad de peladores (trabajadores) que se dedican a esta actividad.

- Identificar la media ponderada de pollo que beneficia cada posible usuario del CBA.

- Identificar la frecuencia de utilización que tendrá el CBA.

- Identificar cuáles son los precios relativos en la actualidad.

- Cuantificar cuales son los factores que tienen mayor relevancia al momento de valorar al CBA, y escoger donde beneficiarían el pollo.

- Cuantificar cual es el nivel de aceptación que tendrá el CBA, sobre este indicador se podrán planificar las siguientes actividades del plan de negocio, sobre todo estimar la demanda del servicio.

- Identificar cuáles son los precios que están dispuestos a pagar por el nuevo servicio.

\subsubsection{Análisis y procesamiento de datos}

Se han realizado 74 encuestas (cumplimiento del $100 \%$ del tamaño muestral) las mismas que han sido tabuladas en una hoja de Excel con la finalidad de cuantificar los resultados y evaluar cuales son los aspectos más representativos, las tabla que dan origen a los gráficos que presentan los resultados de la encuesta pueden ser consultados en el anexo $\mathrm{N}^{\circ}$ 13: Tabulación de la encuesta. 
En los siguientes párrafos analizaremos los resultados de cada una de las preguntas y haremos hincapié en los aspectos más relevantes.

\section{En relación a la pregunta $\mathrm{N}^{\circ} 1$ : ¿En qué lugar beneficia el pollo?}

\section{Tabla $\mathbf{N}^{\circ}$ 20: Lugares donde se beneficia el pollo}

\begin{tabular}{|l|c|c|}
\hline \multicolumn{1}{|c|}{ Ítem } & $\begin{array}{c}\mathbf{N}^{\circ} \\
\text { Respuestas }\end{array}$ & $\%$ \\
\hline Espacio alquilado & 34 & $46 \%$ \\
\hline Local propio & 20 & $27 \%$ \\
\hline Puesto de mercado & 17 & $23 \%$ \\
\hline Local acondicionado fuera de su casa & 3 & $4 \%$ \\
\hline \multicolumn{1}{|c|}{ Total } & $\mathbf{7 4}$ & $\mathbf{1 0 0 \%}$ \\
\hline
\end{tabular}

Nota: Elaboración propia.

Interpretación: Esta pregunta nace de la necesidad de poder identificar el lugar en donde benefician el pollo en la actualidad las avícolas y los picadores, esta pregunta es importante porque permitirá identificar la oportunidad de llevar nuestra CBA a las avícolas y picadores. El resultado indica que el 27\% de las 74 empresas encuestadas cuentan con un local propio, este porcentaje deberá ser descontado al momento de identificar el mercado objetivo ya que a estas empresas les costará más deshacerse de esta actividad por la inversión inicial realizada.

En relación a la pregunta $\mathrm{N}^{\circ} 2:$ ¿El lugar donde beneficia el pollo cuenta con suministro de agua potable? 


\section{Tabla $\mathbf{N}^{\circ}$ 21: Centros de beneficio con suministro de agua potable}

\begin{tabular}{|l|c|c|c|}
\hline & Ítem & $\begin{array}{c}\mathbf{N}^{\circ} \\
\text { Respuestas }\end{array}$ & $\%$ \\
\hline SI & & 55 & $74 \%$ \\
\hline NO & & 19 & $26 \%$ \\
\hline
\end{tabular}

Nota: Elaboración propia.

Interpretación: Esta pregunta se ha realizado con la finalidad de identificar los niveles de insalubridad con la que operan las avícolas y los picadores al momento de beneficiar el pollo, esto debido a que el insumo básico para el proceso de beneficio es el agua potable. El resultado muestra que el 26\% de las 74 empresas encuestadas realizan el proceso de beneficio del pollo con agua que no proviene de un suministro directo, este aspecto es importante ya que la propuesta de valor de este servicio estará enfocada contar buenas prácticas de manufactura que garanticen la salubridad e inocuidad del producto.

En relación a la pregunta $\mathrm{N}^{\circ}$ 3: ¿Cuántos peladores son necesarios para beneficiar su pollo? 
Tabla $\mathbf{N}^{\circ}$ 22: Cantidad de Trabajadores (peladores) necesarios

\begin{tabular}{|c|c|c|}
\hline Ítem & $\begin{array}{c}\mathbf{N}^{\circ} \\
\text { Respuestas }\end{array}$ & $\%$ \\
\hline 3 TRAB. & 26 & $35 \%$ \\
\hline 2 TRAB. & 22 & $30 \%$ \\
\hline 4 TRAB. & 14 & $19 \%$ \\
\hline 6 TRAB. & 6 & $8 \%$ \\
\hline 7 TRAB. & 6 & $8 \%$ \\
\hline Total & 74 & $100 \%$ \\
\hline
\end{tabular}

Nota: Elaboración propia.

Interpretación: Esta pregunta nace de la necesidad de identificar el número de trabajadores que se dedican a la actividad del beneficio de los pollos, dentro de la propuesta de valor estará incluido que toda la parte operativa y de gestión de personas estará gestionada por el CBA con la finalidad de liberar de este proceso a las avícolas y picadores, actividad que es realizada en horario nocturno con las dificultades que esta conlleva. Como dato relevante se identifica que el $65 \%$ de las 74 empresas encuestadas utilizan entre 2 y 3 personas para el desarrollo de esta actividad.

En relación a la pregunta $\mathrm{N}^{\circ}$ 4: ¿Qué cantidad de pollo beneficia aproximadamente cada vez que utiliza el servicio? 
Tabla $N^{\circ}$ 23: Rango de cantidad de pollo beneficiado

\begin{tabular}{|c|c|c|}
\hline Ítem & $\begin{array}{c}\mathbf{N}^{\circ} \\
\text { Respuestas }\end{array}$ & $\%$ \\
\hline $100-199$ & 14 & $19 \%$ \\
\hline $200-299$ & 3 & $4 \%$ \\
\hline 300 - 399 & 10 & $14 \%$ \\
\hline $400-499$ & 17 & $23 \%$ \\
\hline $500-599$ & 2 & $3 \%$ \\
\hline $600-699$ & 7 & $9 \%$ \\
\hline 700 - 799 & 6 & $8 \%$ \\
\hline $800-899$ & 2 & $3 \%$ \\
\hline 900 - 999 & 4 & $5 \%$ \\
\hline 1000 - 1099 & 0 & $0 \%$ \\
\hline $1100-1199$ & 0 & $0 \%$ \\
\hline $1200-1299$ & 9 & $12 \%$ \\
\hline Total & 74 & $100 \%$ \\
\hline
\end{tabular}

Nota: Elaboración propia.

Interpretación: Es importante conocer los volúmenes de pollos que benefician las avícolas y picadores ya que este input será importante al momento de planificar el tamaño de la planta que pondremos en marcha, además de identificar los posibles compradores ya que un CBA automatizado tiene por finalidad procesar volúmenes medios/altos de pollo, nuestro enfoque estará orientado a los posibles clientes que beneficien más de 400 forma diaria sin que esto sea restrictivo para los clientes. El promedio de pollo beneficiado por las 74 avícolas y picadores encuestados asciende a 547 unidades.

En relación a la pregunta $N^{\circ}$ 5: ¿Con qué frecuencia utiliza el servicio de beneficio de pollo? 
Tabla $\mathbf{N}^{\circ}$ 24: Frecuencia de utilización del servicio de beneficio del pollo

\begin{tabular}{|l|c|c|c|}
\hline \multicolumn{1}{|c|}{ Ítem } & $\begin{array}{c}\mathbf{N}^{\circ} \\
\text { Respuestas }\end{array}$ & $\%$ \\
\hline Diaria & & 74 & $100 \%$ \\
\hline Semanal & & 0 & $0 \%$ \\
\hline Quincenal & & 0 & $0 \%$ \\
\hline Mensual & Total & 0 & $0 \%$ \\
\hline & & $\mathbf{7 4}$ & $\mathbf{1 0 0 \%}$ \\
\hline
\end{tabular}

Nota: Elaboración propia.

Interpretación: $\mathrm{Al}$ igual que la pregunta $\mathrm{N}^{\circ} 4$ esta pregunta es importante ya que nos permite identificar la demanda del servicio del presente plan de negocio, así como identificar el tamaño de planta ideal que debemos de poner en marcha que haga viable el negocio y que maximice la utilización de la misma. Como aspecto relevante se identifica que el $100 \%$ de las empresas encuestadas realizan su actividad de forma diaria.

En relación a la pregunta $\mathrm{N}^{\circ}$ 6: ¿Quién es su proveedor de pollo vivo más recurrente?

Tabla $\mathbf{N}^{\circ}$ 25: Proveedores de pollo vivo para las avícolas y picadores

\begin{tabular}{|l|c|c|}
\hline \multicolumn{1}{|c|}{ Ítem } & $\begin{array}{c}\mathbf{N}^{\circ} \\
\text { Respuestas }\end{array}$ & $\%$ \\
\hline SAN FERNANDO & 29 & $39 \%$ \\
\hline REDONDOS & 21 & $28 \%$ \\
\hline OTROS & 11 & $15 \%$ \\
\hline SANTA ELENA & 7 & $9 \%$ \\
\hline AGRO. INVER. LOS ABEDULES & 6 & $\mathbf{8} \%$ \\
\hline \multicolumn{1}{|c|}{ Total } & $\mathbf{7 4}$ & $\mathbf{1 0 0 \%}$ \\
\hline
\end{tabular}

Nota: Elaboración propia. 
Interpretación: De acuerdo a la figura adjunta se identifica que en San Juan de Lurigancho los 2 proveedores de pollo vivo más representativos son San Fernando y Redondos con una participación del $39 \%$ y $28 \%$ respectivamente, conocer esta información es importante de cara a buscar generar alianzas con estas empresas para dar a conocer nuestra propuesta de valor no solo para los consumidores finales sino que también los picadores de los puestos de mercado.

En relación a la pregunta $N^{\circ} 7$ : ¿Cuál es el costo promedio unitario que le representa cada pollo beneficiado o cuál es el precio que paga por el servicio de forma unitaria?

Tabla $N^{\circ}$ 26: Costo promedio unitario para el beneficio del pollo

\begin{tabular}{|c|c|c|}
\hline Ítem & $\begin{array}{c}\mathbf{N}^{\circ} \\
\text { Respuestas }\end{array}$ & $\%$ \\
\hline S/ 0.30 & 3 & $4 \%$ \\
\hline$S / 0.35$ & 39 & $53 \%$ \\
\hline$S / 0.40$ & 6 & $8 \%$ \\
\hline$S / 0.45$ & 2 & $3 \%$ \\
\hline$S / 0.50$ & 20 & $27 \%$ \\
\hline S/ 0.60 & 4 & $5 \%$ \\
\hline Total & 74 & $100 \%$ \\
\hline
\end{tabular}

Nota: Elaboración propia.

Interpretación: Tras revisar los resultados obtenidos en la encuesta se identifican 2 bloques importantes y los siguientes aspectos, el $57 \%$ de los encuestados indican que su costo por el beneficio de los pollos se encuentra en un rango de entre S/ 0.30 y S/ 0.35 siendo el promedio de estos un importe de S/ 0.346 y encontrándose concentrado en los clientes que benefician en pollo en locales 
propios, en el puesto del mercado y en lugares acondicionados fuera de casa, por otro lado el $43 \%$ de los encuestados indican que su costo por el beneficio de los pollos se encuentra en un rango de entre S/ 0.40 y S/ 0.60 siendo el promedio de estos un importe de S/ 0.491 y encontrándose concentrado en los clientes que benefician el pollo en locales alquilados, por último el costo promedio de todos los encuestados es de S/ 0.41. Estos aspectos identificados son importantes ya que si bien es cierto no nos queremos diferenciar como un servicio económico, es importante tener en cuenta estos rangos de precios actuales con la finalidad de competir con precios acordes al mercado actual.

En relación a la pregunta $\mathrm{N}^{\circ}$ 8: ¿Cuáles son los aspectos que más valora en el proceso de beneficio del pollo?

Figura $\mathrm{N}^{\circ}$ 10: Atributos más valorados por las avícolas y picadores

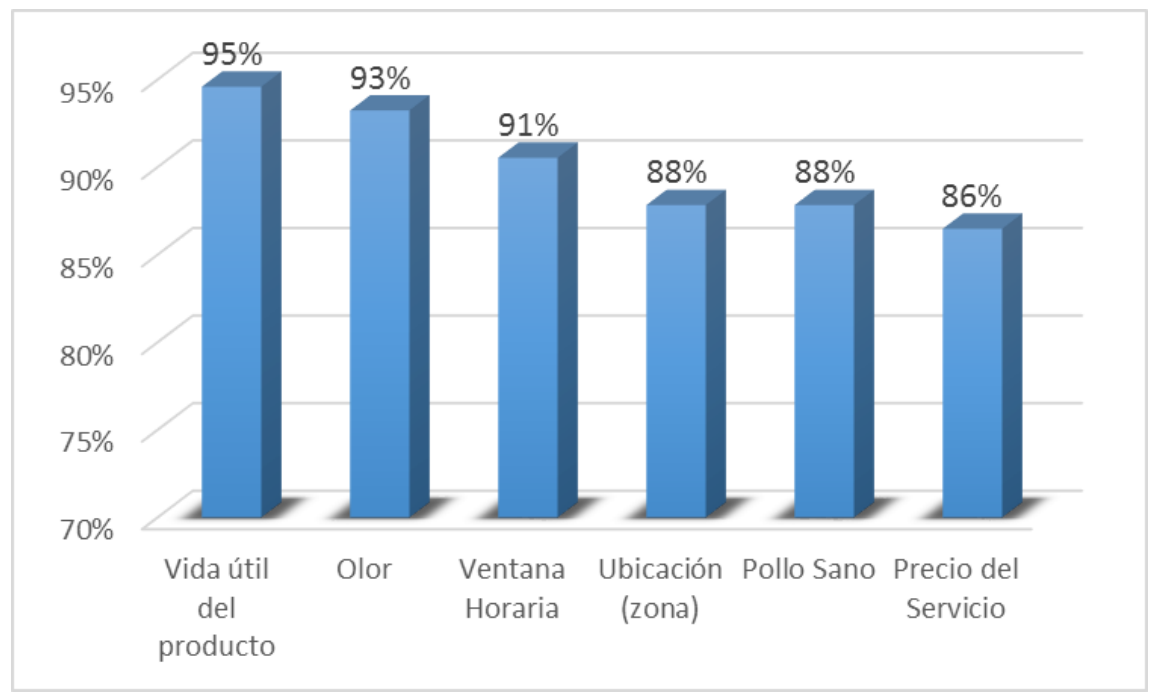

Fuente: Elaboración propia. 
Interpretación: Como se puede identificar en la gráfica adjunta, los atributos que más valoran las avícolas y picadores en el proceso de beneficio del pollo son: 1) Vida útil del producto y 2) Olor, con un $95 \%$ y $93 \%$ de respuestas positivas respectivamente, siendo el precio del servicio el ítem menos valorado con un $86 \%$ de respuestas positivas. Estos resultados son importantes y relevantes al momento de identificar los factores de diferenciación a ofrecer con la finalidad de captar a los clientes.

En relación a la pregunta $\mathrm{N}^{\circ}$ 9: ¿Con qué probabilidad utilizaría nuestros servicios, una planta de beneficio avícola con BPM que opere dentro de la formalidad garantizando la continuidad de sus ventas?

Tabla $\mathrm{N}^{\circ}$ 27: Porcentaje de aceptación de un CBA con BPM

\begin{tabular}{|c|c|c|}
\hline Ítem & $\begin{array}{c}\mathbf{N}^{\circ} \\
\text { Respuestas }\end{array}$ & $\%$ \\
\hline MUY ALTA & 21 & $28.4 \%$ \\
\hline ALTA & 18 & $24.3 \%$ \\
\hline MEDIANA & 16 & $21.6 \%$ \\
\hline BAJA & 8 & $10.8 \%$ \\
\hline MUY BAJA & 11 & $14.9 \%$ \\
\hline Total & 74 & $100.0 \%$ \\
\hline
\end{tabular}

Nota: Elaboración propia.

Interpretación: Esta pregunta es importante porque permite identificar el nivel de aceptación que tendrá un CBA operado con buenas prácticas de manufactura, como se puede identificar en la Tabla $\mathrm{N}^{\circ} 27$ un $28.4 \%$ de los encuestados indican 
que existe una probabilidad muy alta que adquieran el servicio. Este indicador será utilizado también para cuantificar el volumen de demanda, esto de forma conjunta con los volúmenes de pollo beneficiado y la frecuencia del mismo.

En relación a la pregunta $N^{\circ} 10:$ ¿Cuánto estaría dispuesto a pagar por cada unidad de pollo beneficiado por este nuevo servicio?

\section{Tabla $\mathbf{N}^{\circ}$ 28: Posibles precios del servicio}

\begin{tabular}{|c|c|c|}
\hline Ítem & $\begin{array}{c}\mathbf{N}^{\circ} \\
\text { Respuestas }\end{array}$ & $\%$ \\
\hline$S / 0.40$ & 2 & $2.7 \%$ \\
\hline$S / 0.50$ & 35 & $47.3 \%$ \\
\hline S/ 0.55 & 13 & $17.6 \%$ \\
\hline$S / 0.60$ & 5 & $6.8 \%$ \\
\hline S/ 0.65 & 14 & $18.9 \%$ \\
\hline S/ 0.70 & 5 & $6.8 \%$ \\
\hline Total & 74 & $100.0 \%$ \\
\hline
\end{tabular}

Nota: Elaboración propia.

Interpretación: Esta pregunta es importante porque permite identificar cual es el precio que están dispuestos los clientes a pagar por el servicio, como se puede identificar en la Tabla $\mathrm{N}^{\circ} 28$ un $50 \%$ de los encuestados indican que están dispuestos a pagar menos del precio propuesto. Por otro lado, el otro $50 \%$ de los encuestados indican que estarían dispuestos a pagar por el servicio entre $\mathrm{S} / 0.55 \mathrm{y}$ S/ 0.70, siendo el $25.7 \%$ de los encuestados los que estarían dispuestos a pagar un valor promedio de S/ 0.66. Este valor será tomado en cuenta para determinar el precio del servicio. 


\subsection{Conclusiones y recomendaciones del Estudio Cualitativo y Cuantitativo}

\section{Conclusiones de la entrevista a profundidad:}

\section{a. Especialistas del sector (expertos en temas de demanda y mercado objetivo)}

- La idea de negocio de implementar un CBA con buenas prácticas de manufactura y automatizado es una alternativa que encuentra al sector en un proceso de formalización y que abre la posibilidad de llegar hasta la mesa del consumidor a quienes les interesa comer de manera saludable.

- Las prácticas de manufactura planteadas permitirán ofrecer la oferta de valor que son claves en este negocio, además debe estudiarse cuáles serían las estrategias para que el producto sea identificado y sobre todo preferido por los consumidores ya que ellos lo adquieren directo de los picadores.

- La campaña deberá ser impulsada hacia todo proceso que señale las bondades del producto en comparación de los otros y resaltar los beneficios.

- Existen riesgos que deben ser considerados cuando se decida la ubicación del centro de pelado ya que no puede estar muy cercano a las zonas pobladas, además deben tener dentro del diseño, las características claves para el manejo de aguas residuales y otros subproductos como plumas, vísceras etc.

- Los expertos indican que entre el $5.5 \%$ de las empresas que realizan la actividad de pelado son picadores y la diferencia son avícolas entre medianas y grandes (75\% avícolas medianas y $19.5 \%$ avícolas grandes). Esta información en función a la cantidad de pollo beneficiado por estas empresas. 
b. Competidor relacionado (Distribuidor que haya incorporado dentro de su modelo de negocio principal un CBA como parte de su cadena de valor.

- Colocar un CBA dentro de la cadena de valor del pollo vivo reduce la intermediación y dependencia del mayorista. Le da una oferta de valor diferenciada que se traduce en una ventaja competitiva sobre el resto.

- Adicionalmente se abren las puertas a distintos negocios anexos que puedan surgir producto de este modelo tales como los pollos trozados y los subproductos.

- Como temas muy importantes a considerar son la adecuación del CBA a las exigencias municipales y de SENASA, la demora en la tramitación de los permisos de funcionamiento así como la decisión política del país para erradicar estos procesos informales y las malas prácticas.

- La automatización de procesos se presenta como otra ventaja competitiva que puede pasar por un proceso de adecuación para que el producto final cuente con los requisitos necesarios para el consumidor final.

\section{c. Cliente (persona que compra pollo vivo y utiliza el servicio de una peladuría)}

- Los factores que influyen en el cliente para elegir una peladuría sobre otra para el beneficio del pollo son: los horarios de atención para poder llegar a tiempo a los consumidores finales, los atributos tales como un buen sangrado, que no estén remojados en agua estancada, una ventana horaria adecuada a su proceso es de entre 3 y 4 horas como máximo. 
- El consumidor final percibe atributos que hacen la diferencia en la decisión de compra en un picador u otro: Que el pollo no tenga mal olor significa que no está malogrado ni contaminado. Esto es considerado como sinónimo de saludable.

- Otras características que consideran importante y se detienen a evaluar es la piel del pollo: su color amarillo neutro característico, que no debe estar desgarrada ni grasosa, que sea lisa y flexible y que no contengan restos de plumas ni cañones.

En cuanto a su conformación, las amas de casa palpan al pollo evaluando si la carne es firme y los muslos musculosos. Además revisan si existen moretones verdosos.

\section{d. Cliente potencial (persona que no usa el servicio de peladuría de terceros porque esa actividad la realiza él mismo}

- Otro punto importante que debe considerarse es la disponibilidad de agua potable e iluminación.

- Se ha determinado que algunas características tales como pollo grasoso, muy sancochado o con piel desgarrada producto de un mal pelado son factores relevantes para tomar la decisión de usar una peladuría u otra. Igual cuando toma mal olor por efecto de haber sido enjuagado con agua sucia y luego embolsado afecta la colocación del pollo al consumidor final. 
- El promedio de pago por este servicio es de 0.30 centavos por pollo pero dependiendo de la oferta de valor y aceptación del cliente el cliente podría estar dispuesto a pagar hasta 0.35 centavos.

\section{Conclusiones de la encuesta:}

A continuación se realiza un resumen de las conclusiones identificadas tras las encuestas realizadas:

- Se identifica condiciones favorables para la puesta en marcha de un CBA con buenas prácticas de manufactura, por el lado del lugar donde se benefician en la actualidad los pollos, solo un $27 \%$ de los clientes lo realizan en locales propios, además solo un $74 \%$ de los lugares en donde se beneficia el pollo cuenta con suministro de agua potable, asociándose esto último al hecho no de cumplir con las condiciones de salubridad exigidas.

- En relación a la aceptación del servicio, se identifica una alta aceptación por parte de las avícolas y las picadores con un 52.7\% de clientes que indican que existe una alta y muy alta probabilidad de acceder al servicio.

- En relación a la cantidad de pollo que benefician los clientes y su respectiva frecuencia, se ha identificado que los clientes en promedio benefician 547 pollos con una frecuencia diaria, siendo este insumo importante para poder elaborar los pronósticos de ventas e ingresos de la empresa.

- En relación a los aspectos más valorados por las avícolas y picadores en el proceso de beneficio del pollo, se han identificado que los siguientes factores más importantes son: a) vida útil del producto $(95 \%)$, b) olor (93\%) y c) 
ventana horaria (91\%), estos resultados son importantes y sirven de insumo para elaborar los factores de diferenciación y la ventaja competitiva de la empresa.

- En relación a la decisión de compra de consumidor final en un picador u otro, los atributos determinantes son: Que el pollo no presente mal olor, ya que esta característica les indica que están comprando un pollo saludable. Que la piel tenga el color amarillo neutro característico, sin desgarros ni grasosa y sin plumas notorias. Deben tener la carne firme, musculosa y sin moretones verdosos.

- En relación al costo que representa para las avícolas y picadores el proceso de beneficio del pollo, se han identificado los rangos de pago actuales los mismos que han sido detallados en el análisis y procesamiento de la pregunta número $\mathrm{N}^{\circ} 7$ de la encuesta y cuyo promedio es $\mathrm{S} / \mathrm{0.41}$, esta información sirve como base para la identificación del precio que tendrá el servicio y que será detallado en el capítulo 5.

- En relación al nuevo precio que estarían dispuestos a pagar las avícolas y los picadores por un CBA con BPM, se han identificado los rangos mediante la pregunta número $\mathrm{N}^{\circ} 10$ de la encuesta y cuyo promedio es de $\mathrm{S} / 0.55$, esta información sirve como base para la identificación del precio que tendrá el servicio y que será detallado en el capítulo 5. 


\subsection{Perfil del consumidor tipo y sus variantes}

Para la propuesta de este modelo de CBA, se han identificado dos tipos de clientes, por un lado se encuentran los clientes usuarios del servicio que son para el caso las avícolas y los picadores, y por otro lado se encuentran los clientes finales o consumidores del pollo beneficiado, que son para el caso las amas de casa que acuden a los mercados para adquirir el pollo para su alimentación diaria; en las tablas : $\mathrm{N}^{\circ} 29$ y $\mathrm{N}^{\circ} 30$ se encuentra en detalle el perfil de cada uno de los clientes del CBA.

Es importante identificar y definir a cada uno de estos clientes puesto que sus necesidades no son las mismas y por tanto los esfuerzos en marketing que se aplicarán estarán enfocados a captar a atención de cada uno de ellos.

Tabla $\mathbf{N}^{\circ}$ 29: Perfil de cliente usuario del servicio

\begin{tabular}{|c|l|l|}
\hline \multirow{4}{*}{$\begin{array}{c}\text { Característica de } \\
\text { cliente }\end{array}$} & Tipo de persona & Natural o jurídica \\
\cline { 2 - 3 } & Sector & Pecuario \\
\cline { 2 - 3 } & Rubro & Avícolas o picadores \\
\cline { 2 - 3 } & $\begin{array}{l}\text { Aenidad } \\
\text { Comportamiento } \\
\text { de demanda }\end{array}$ & $\begin{array}{l}\text { Empresas que utilizan centros de beneficio } \\
\text { de pollo }\end{array}$ \\
\cline { 2 - 3 } & $\begin{array}{l}\text { Fo cantidad de pollo beneficiado fluctúa } \\
\text { entre 100 y 1,300 aves de forma diaria }\end{array}$ \\
\hline \multirow{2}{*}{$\begin{array}{c}\text { Variable } \\
\text { geográfica }\end{array}$} & $\begin{array}{l}\text { Cobertura } \\
\text { geográfica }\end{array}$ & San Juan de Lurigancho \\
\hline
\end{tabular}

Nota: Elaboración propia. 
Tabla $N^{\circ}$ 30: Perfil de cliente final o consumidor

\begin{tabular}{|c|c|c|}
\hline \multirow{5}{*}{$\begin{array}{c}\text { Variables } \\
\text { demográficas }\end{array}$} & Edad & $24-55$ años \\
\hline & Sexo & Femenino \\
\hline & $\begin{array}{l}\text { Nivel de } \\
\text { instrucción }\end{array}$ & Indiferente \\
\hline & Ocupación & $\begin{array}{l}\text { Ama de casa, con o sin actividad laboral } \\
\text { complementaria }\end{array}$ \\
\hline & $\begin{array}{l}\text { Nivel socio- } \\
\text { económico }\end{array}$ & $B, C$ y D \\
\hline $\begin{array}{c}\text { Variable } \\
\text { geográfica }\end{array}$ & $\begin{array}{l}\text { Distrito de } \\
\text { residencia }\end{array}$ & San Juan de Lurigancho \\
\hline \multirow[b]{2}{*}{$\begin{array}{c}\text { Variables } \\
\text { psicográficas }\end{array}$} & Estilo de vida & Conservadoras \\
\hline & $\begin{array}{l}\text { Comportamiento } \\
\text { habitual }\end{array}$ & $\begin{array}{l}\text { Amas de casa que se preocupen por la } \\
\text { alimentación de la familia en general y que } \\
\text { acuden de forma diaria a los mercados a } \\
\text { comprar los alimentos }\end{array}$ \\
\hline
\end{tabular}

Nota: Elaboración propia. 


\section{CAPÍTULO IV}

\section{Proyección del mercado objetivo}

Este capítulo tiene como finalidad principal definir el mercado objetivo para el plan de negocio que se está desarrollando, evaluando previamente el mercado efectivo, disponible y potencial.

En la actualidad no existen datos estadísticos que permitan identificar cual ha sido el comportamiento del negocio, es importante tener en cuenta que este plan de negocio desarrolla un centro de beneficio avícola (CBA), negocio que en la actualidad convive con un alto nivel de informalidad.

Conociendo estas limitaciones se ha decido utilizar la información obtenida en el proceso de investigación de mercado y el análisis de los capítulos previos, con la finalidad de definir claramente el mercado objetivo, que para efectos de este proyecto no son los consumidores finales que compran el pollo en los puestos de mercado, sino que son los clientes que utilizan los centros de beneficio de pollo para conseguir su producto final, pollo pelado, y este sea llevado al consumidor.

\subsection{El ámbito de la proyección}

La operación del CBA estará ubicada en Lima Metropolitana, específicamente en el distrito de San Juan de Lurigancho, se ha escogido este distrito por 2 motivos principalmente: 
a) La demanda de pollo vivo, como se mencionó en el capítulo anterior y se detalló en la Tabla $\mathrm{N}^{\circ}$ 29, en el distrito de San Juan de Lurigancho se concentra el $13 \%$ de comercialización de pollo vivo de Lima Metropolitana, convirtiéndose en el distrito con mayor participación con un promedio diario de 78,000 pollos.

b) Tamaño de población, según información estadística del INEI con la última actualización al año 2015 el distrito de San Juan de Lurigancho tiene un total de 1'091,303 habitantes, convirtiéndose así en el distrito de Lima Metropolitana que concentra mayor población con un $12.3 \%$ de representatividad.

En el capítulo anterior, en la Tabla $\mathrm{N}^{\circ} 29$ se definió el perfil del cliente usuario del servicio. La proyección del mercado objetivo se realizará sobre este perfil ya que son estos clientes quienes accederán al servicio ofrecido por el CBA y serán quienes generarán los ingresos económicos de este plan de negocio. A través de las entrevistas a profundidad con expertos del sector avícola y con los conocimientos propios de uno de los integrantes del grupo se ha determinado que en la actualidad existen aproximadamente 160 empresas que utilizarían el servicio de un CBA en el distrito de San Juan de Lurigancho.

En un proyecto de inversión la incertidumbre es un aspecto relevante al momento de realizar las proyecciones, para este proyecto la falta de información 
estadística dificulta la toma de decisión, sin embargo se considera importante gestionar tres aspectos que permitirán reducir o mitigar dicha incertidumbre:

a) En relación a la precisión, la información con la que se realizarán las proyecciones ha sido obtenida de forma puntual para este proyecto y tiene una antigüedad no mayor a dos meses, esta información es de fuente primaria principalmente, y la información secundaria que se estaría utilizando corresponde a organismos públicos como MINAGI, INEI entre otros.

b) En relación a la sensibilidad, la demanda del pollo vivo como industria presenta una demanda inelástica en condiciones normales, a nivel empresa sí existe una fuerte competencia por el precio, pero la demanda de los consumidores en general solo se puede ver afectada ante incrementos demasiado elevados, por ejemplo en alguna situación de crisis en donde el precio experimente una fuerte subida y los consumidores deciden cambiar su preferencia por otras carnes, con lo cual todos los factores que puedan significar un incremento del precio deberán ser evaluados. Aunque una reducción en la demanda de pollo vivo significaría también una reducción en la demanda del servicio brindado por un CBA, es importante mencionar que el sector avícola es uno de los sectores más estables y presentada incrementos en los últimos años en Lima Metropolitana y el país, siendo incluso la carne de pollo la preferida por los peruanos. 
c) En relación a la objetividad, la información con la que se realizará la proyección de los distintos mercados ha sido obtenida a través de entrevistas a expertos y encuestas a los clientes usuarios del servicio, las mismas que han sido realizadas con responsabilidad y objetividad ya que han sido ejecutadas y supervisadas por los integrantes del proyecto.

\subsection{Selección del método de proyección}

Tomando como referencia el libro PROYECTOS DE INVERSIÓN - Formulación y Evaluación del autor Nassir Sapag Chain, en su capítulo tres técnicas de predicción; para este plan de negocios se ha tomado como referencia la utilización del método Delphi y el método de Investigación de Mercado (encuestas), ambos métodos se encuentran dentro de la categoría de técnicas cualitativas y se ha tomado dicha referencia debido a que no existen series estadísticas que permitan utilizar técnicas cuantitativas, como consecuencia de la informalidad que prima en el sector.

En relación al método Delphi, dentro del proceso de Investigación de Mercados se han realizado una serie de entrevistas de profundidad con expertos en el sector, en estas entrevistas se les consulto cuál es la estimación aproximada de la demanda de un CBA tomando como referencia el distrito de San Juan de Lurigancho, esto bajo su propia experiencia y tomando como referencia el crecimiento que viene experimentando el sector avícola año a año.

En relación al método de investigación de mercado, se han realizado encuestas a los posibles clientes del CBA. Para determinar a los encuestados se ha calculado el tamaño muestral en función a las empresas y personas naturales con negocio que tienen 
la categoría de avícolas y picadores, y que operan en el distrito de San Juan de Lurigancho.

\subsubsection{Mercado Potencial}

Para el presente plan de negocio ya se encuentra identificado el mercado potencial, se trata de las avícolas y picadores que tienen la necesidad de utilizar los servicios de un CBA como parte de sus actividades para poder comercializar el pollo y que este llegue al puesto de mercado. Las características de los clientes de este mercado potencial ya han sido definidas en la Tabla $\mathrm{N}^{\circ} 30$ : Perfil de cliente usuario del servicio.

En la Figura $\mathrm{N}^{\circ} 11$ se puede identificar el mercado potencial, son 160 clientes aproximadamente los que han sido identificados con las técnicas mencionadas previamente.

Figura $\mathbf{N}^{\circ}$ 11: Determinación del mercado potencial

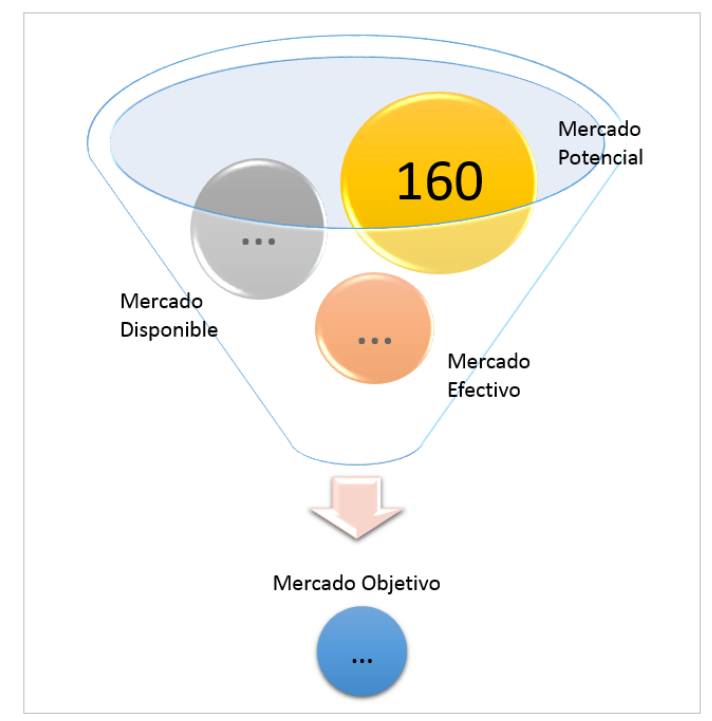

Fuente: Elaboración propia 


\subsubsection{Mercado Disponible}

Para cuantificar la cantidad de clientes que se encuentran dentro del mercado disponible se ha utilizado la encuesta realizada a las avícolas y picadores, en la pregunta número $\mathrm{N}^{\circ} 1$ : "En qué lugar beneficia el pollo", se identifica que el $27 \%$ de los encuestados cuenta con un lugar propio para realizar el proceso de beneficio del pollo.

Con la finalidad de ser más exigentes al momento de cuantificar este mercado se ha decidido retirar a este $27 \%$ de los clientes ya que posiblemente han realizado una inversión en implementar su propio modelo de pelado, siendo la diferencia un $73 \%$ que será el mercado que quedaría disponible.

Los clientes que pelan pollos en el puesto del mercado se están considerando dentro del mercado disponible dado que las regulaciones prohíben esta actividad la cual es constantemente controlada por la municipalidad. Así, cada vez son más los picadores que se encuentran en proceso de migración hacia el beneficio de pollo fuera del mercado de abasto lo cual los convierte en parte del mercado disponible para el plan de negocio.

Mercado disponible $=$ Mercado potencial $(160)$ multiplicado por el $73 \%$ de clientes que benefician el pollo en lugares alquilados, puestos de mercados y locales acondicionados fuera de casa.

En la figura $\mathrm{N}^{\circ} 12$ se puede identificar el mercado disponible, son 117 clientes aproximadamente los que han sido identificados con formula mencionada. 


\section{Figura $\mathrm{N}^{\circ}$ 12: Determinación del mercado disponible}

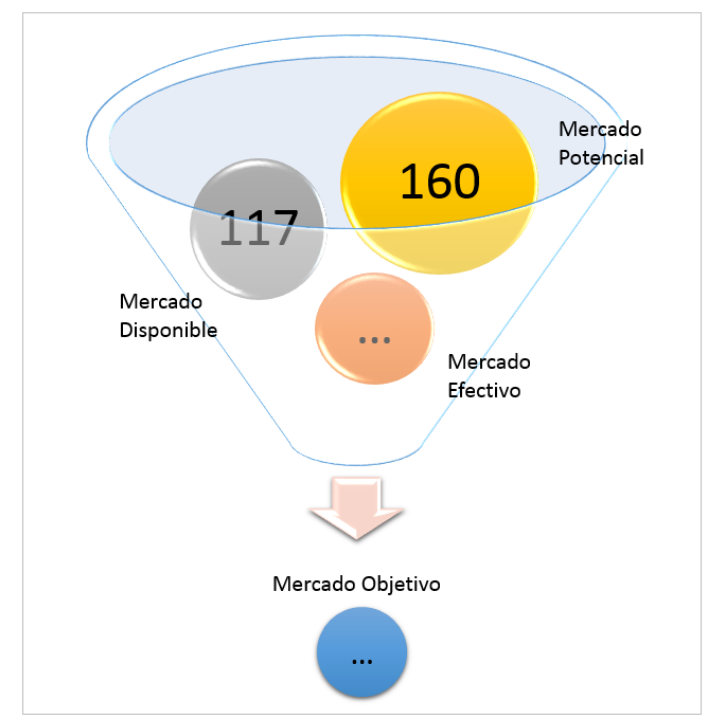

Fuente: Elaboración propia.

\subsubsection{Mercado Efectivo}

Para cuantificar la cantidad de clientes que se encuentran dentro del mercado efectivo se ha utilizado la encuesta realizada a las avícolas y picadores, en la pregunta número $\mathrm{N}^{\circ}$ 9: "Con qué probabilidad utilizaría nuestros servicios, una planta de beneficio avícola con BPM que opere dentro de la formalidad garantizando la continuidad de sus ventas", se identifica que el $52.7 \%$ de los encuestados responden de forma satisfactoria e indican utilizarían el servicio con una muy alta y alta probabilidad, siendo una muy alta probabilidad un $28.4 \%$ y un $24.3 \%$ con alta probabilidad.

Sin embargo, con la finalidad de compensar las desviaciones que podrían generarse al momento de realizar el cálculo del tamaño muestral dado que se han 
considerado las variables de nivel de confianza y margen de error por debajo de lo recomendado (explicado en el capítulo 3), se ha decidido considerar únicamente a los clientes que han respondido que utilizarían el servicio con una muy alta probabilidad que representan al $28.4 \%$. De esta forma al momento de realizar la proyección de las ventas se tendrá una medición más ácida que permita ajustar cualquier desviación producto de las variables que se han utilizado en el cálculo del tamaño muestral para la evaluación.

Solo como referencia, aplicando el criterio de Jeffrey L. Pope que propone realizar una ponderación de todos los resultados de intención de compra asignando porcentajes pre definidos, resulta en un tamaño de mercado efectivo de $30.14 \%$ siendo este resultado $1.6 \%$ menos exigente que el calculado con el cuadro superior (muy alta probabilidad).

Se ha realizado un filtro adicional considerando la pregunta número $\mathrm{N}^{\circ} 10$ : "Cuanto estaría dispuesto a pagar por cada unidad de pollo beneficiado por este nuevo servicio", y se identifica que el $50.1 \%$ de los encuestados responden de forma satisfactoria e indican que su disposición de pago se encuentra sobre S/. 0.55, valor que corresponde a la media de intención de pago.

Mercado efectivo = Mercado disponible (117) multiplicado por el $28.4 \%$ de clientes que han indicado en la encuesta que existe una muy alta probabilidad de que adquieran el servicio y multiplicado también por el $50.1 \%$ de disposición de pago. 
En la figura $\mathrm{N}^{\circ} 13$ se puede identificar el mercado efectivo, son 16 clientes aproximadamente los que han sido identificados con formula mencionada.

\section{Figura $\mathbf{N}^{\circ}$ 13: Determinación del mercado efectivo}

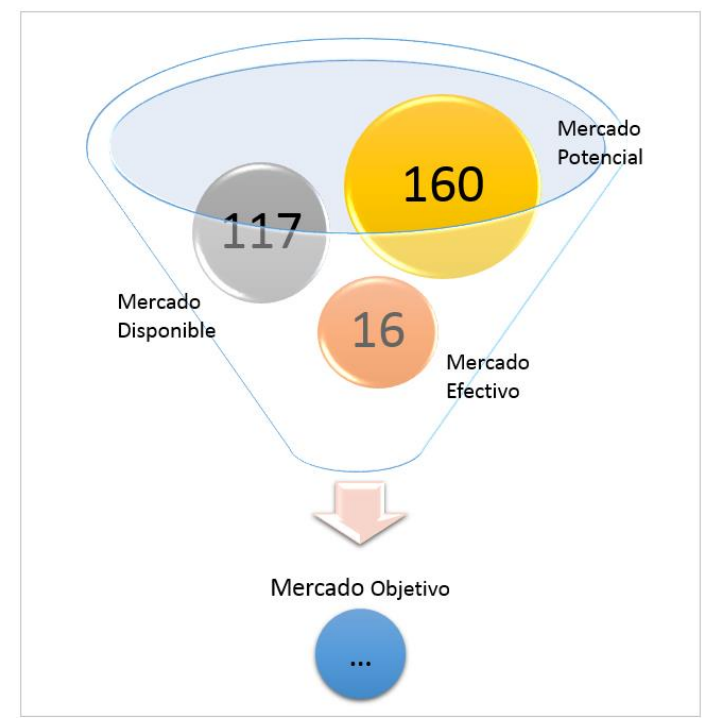

Fuente: Elaboración propia.

\subsubsection{Mercado Objetivo}

El mercado objetivo se determina como parte del mercado efectivo que para el caso del presente plan de negocios se han determinado a 16 clientes.

Un centro de beneficio avícola automatizado y que opere con buenas prácticas de manufactura no cuenta con competidores directos con los cuales compararse por tratarse de una nueva propuesta de negocio, bajo esta premisa se va a considerar como meta empresarial captar en el primer año el $50 \%$ del mercado efectivo. Este escenario es conservador considerando que la presente propuesta cuenta con características diferenciadoras y de alta aceptación por parte 
de los clientes contratantes esto sustentado en las entrevistas a profundidad y en las encuestas realizadas.

Mercado objetivo = Mercado efectivo (16) multiplicado por el $50 \%$ de meta empresarial y capacidad. En la Figura $\mathrm{N}^{\circ} 14$ se puede identificar el mercado objetivo, son 8 clientes los que han sido identificados con formula mencionada.

\section{Figura $N^{\circ}$ 14: Determinación del mercado objetivo}

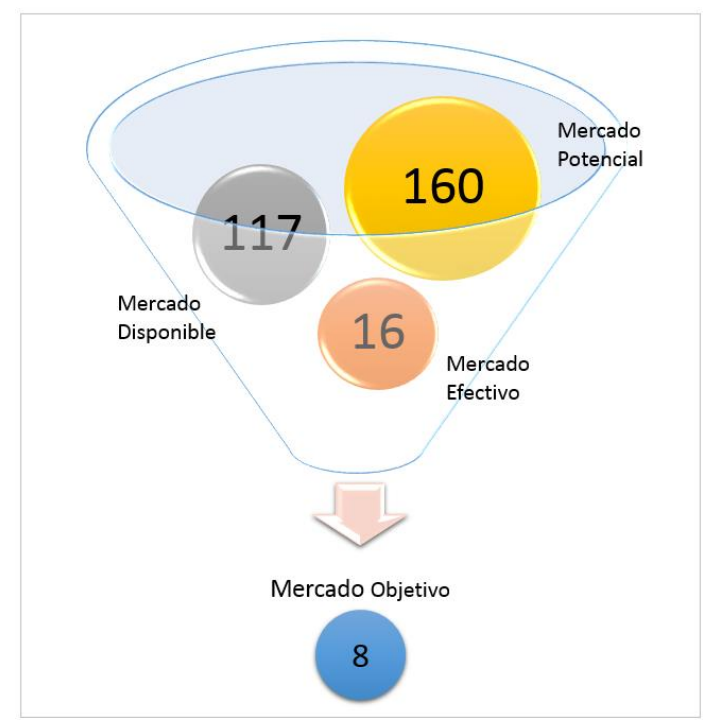

Fuente: Elaboración propia.

Se busca con ello lograr una participación del mercado de $6.84 \%$ para el año 2018. Para los dos años posteriores, es decir los años 2019 y 2020, el CBA Doña Viole proyecta crecer en participación de $0.86 \%$ anual y los años 2021 y 2022, 1.71\% anual hasta llegar a $11.97 \%$ de participación de mercado para el año 2022. Es importante mencionar que esta proyección de crecimiento debe apoyarse por un lado en las políticas restrictivas que vienen aplicando los organismos del estado y las municipalidades las cuales ayudarán a que los usuarios de las 
peladurías vean más atractivo el negocio del CBA Doña Viole. Por otro lado se han planificado estrategias de marketing que se implementarán para lograr la captación, confianza y educación de los clientes las cuales están alineadas a lo estudiado en los capítulos anteriores y cuyo detalle puede ser revisado en el capítulo $\mathrm{N}^{\circ} 5$ del presente plan de negocio.

En la Tabla $\mathrm{N}^{\circ} 31$ se puede identificar la participación de mercado proyectada por año en relación a la demanda de pollo en el distrito en donde se ha considerado una variación anual de $4.2 \%$, este valor corresponde a la expectativa de crecimiento de la demanda de pollo vivo en Lima Metropolitana y ha sido identificada en el capítulo $\mathrm{N}^{\circ} 2$ del presente plan de negocios, y a la captación anual de clientes.

Tabla $N^{\circ}$ 31: Participación de mercado y variación anual

\begin{tabular}{ccrrrrr}
\hline Año & $\begin{array}{c}\text { Demanda de pollo } \\
\text { vivo SJL - Base } \\
\text { mercado } \\
\text { disponible }\end{array}$ & $\begin{array}{c}\mathbf{N}^{\circ} \text { de } \\
\text { clientes }\end{array}$ & $\begin{array}{c}\text { Demanda del } \\
\text { servicio }\end{array}$ & $\begin{array}{c}\text { \% } \\
\text { Participación }\end{array}$ & $\begin{array}{c}\text { \% } \\
\text { Variación }\end{array}$ \\
\hline 2018 & $24,208,470$ & 8 & $1,655,280$ & $6.84 \%$ & - \\
2019 & $25,225,226$ & 9 & $1,940,598$ & $7.69 \%$ & $0.86 \%$ \\
2020 & $26,284,685$ & 10 & $2,246,970$ & $8.55 \%$ & $0.86 \%$ \\
2021 & $27,388,642$ & 12 & $2,809,620$ & $10.26 \%$ & $1.71 \%$ \\
2022 & $28,538,965$ & 14 & $3,415,104$ & $11.97 \%$ & $1.71 \%$ \\
\hline
\end{tabular}

Nota: Adaptado de MINAGRI. 


\section{CAPITULO V}

\section{Plan de Marketing}

En este capítulo se han formulado las estrategias de marketing y ventas que permiten planear el lanzamiento e ingreso al mercado objetivo de este servicio, de acuerdo a los objetivos planteados inicialmente y a las conclusiones extraídas del proceso de investigación de mercado realizado.

El plan está orientado a definir las estrategias del mix de marketing: producto, precio, plaza y distribución, promoción y publicidad, personas, procesos y presencia física para lograr atraer al público objetivo hacia esta nueva propuesta. En el caso de estrategias de ventas, la evaluación está orientada al plan de ventas y las políticas de servicios y garantías que soporten la correcta atención al cliente.

En cada uno de estos puntos se incluyen los atributos que representan las condiciones óptimas de higiene para el beneficio de pollo, reduciendo la exposición a la contaminación y que generan el factor diferenciador como ventaja competitiva.

La captación de los clientes planeada por año se sustenta en un trabajo coordinado para posicionar en la mente, tanto de los clientes usuarios del servicio como de los consumidores finales, la promesa de valor que permitirá satisfacer sus necesidades. Esto se logra a través de la aplicación de las estrategias de marketing. 


\subsection{Estrategias de marketing}

Las estrategias de Marketing están orientadas a captar clientes que puedan identificar las ventajas competitivas con respecto a cualquier tipo de servicio que se presente con un modelo similar.

A continuación se detallan las macro estrategias utilizadas en el presente plan de negocios, las mismas que han permitido identificar aspectos como los factores de diferenciación y posicionamiento del servicio.

\section{a) Estrategia Genérica.}

Se ha considerado que el CBA esté diseñado enfocándose en la estrategia de Diferenciación que de acuerdo a lo indicado por Michael Porter tiene como objetivo crear valor a través de atributos distintos a los ofrecidos en la actualidad y que además estos sean percibidos por el mercado como únicos a través de los diferentes elementos del marketing mix. El servicio ofrecido por este plan de negocios presenta como factor de diferenciación a la garantía de inocuidad e higiene contribuyendo a la salud familiar, el cual se evidencia a través de la obtención de la certificación BPM.

Esto permite además proteger el servicio de competidores que puedan utilizar el precio como poder de negociación ya que si los clientes usuarios y consumidores perciben un servicio distinto y de alto valor estará el cliente usuario dispuesto a pagar un precio más elevado. 


\section{b) Estrategia de Cartera}

Teniendo en cuenta que la propuesta de negocio es un CBA con buenas prácticas de manufactura se han analizado las oportunidades estratégicas del negocio utilizando la Matriz de Ansoff que relaciona los mercados y productos ya sean nuevos o existentes. Al análisis se obtiene como resultado que el CBA se adecúa a la estrategia de desarrollo de un producto nuevo dentro de un mercado existente ya que se está desarrollando un servicio distinto en aspectos tecnológicos, de calidad e inocuidad generando un nuevo modelo de operación. La estrategia es ingresar al mercado ofreciendo este servicio aprovechando la coyuntura gubernamental, el conocimiento del mercado avícola y la forma como operan los clientes.

Figura $N^{\circ}$ 15: Matriz de Ansoff

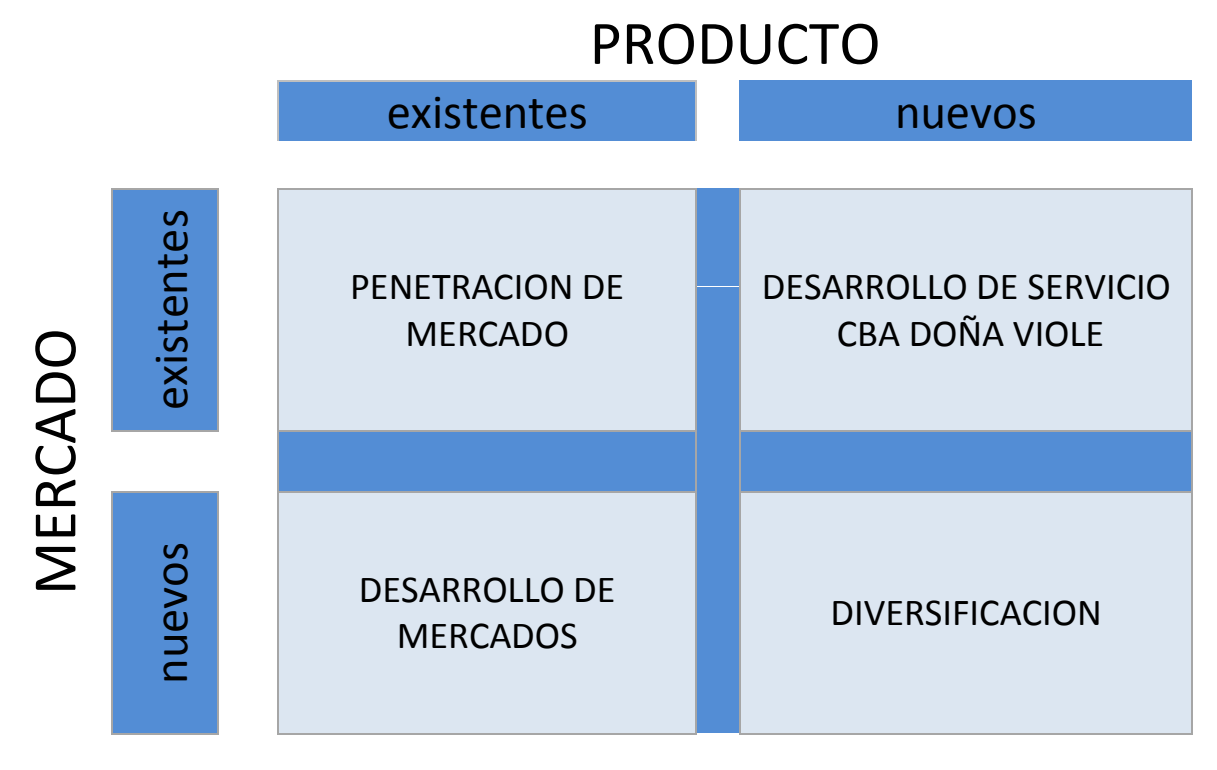

Fuente: Elaboración propia. 


\section{c) Estrategia de Segmentación}

Esta estrategia es importante ya que una adecuada segmentación permite implementar un correcto plan de marketing diferenciado para cada uno de los segmentos, a su vez los esfuerzos en marketing para cada uno de ellos será ejecutado en paralelo con actividades distintas pero bajo un mismo enfoque de calidad de servicio que permita generar mayor eficiencia al plan de marketing. Por lo antes expuesto dentro de las estrategias de segmentación se ha considerado la estrategia diferenciada ya que la oferta comercial estará adaptada a las características de cada segmento.

Dentro de la clasificación, previamente se han determinado dos mercados que tienen distintos tipos de clientes, los mismos que han sido identificados y analizados en el tercer capítulo.

i. Mercado de intermediarios, compuesto por las avícolas y picadores que son usuarios del servicio de un CBA y cuyo detalle se puede identificar en la Tabla $\mathrm{N}^{\circ} 29$.

Se ha identificado para este mercado las siguientes definiciones:

Insight de compra: "Esta es mi empresa, necesito que los clientes compren mi pollo para tener más ingresos y mejorar el nivel de vida de mi familia” Propuesta de valor: "Asegura tu negocio con un proceso de beneficio de calidad que entregue un pollo saludable, en el tiempo adecuado, que alargue su tiempo de vida y que el consumidor final lo prefiera".

ii. Mercado de consumo, compuesto por mujeres amas de casa que son responsables de la alimentación del hogar y cuyo detalle se puede identificar en la Tabla $\mathrm{N}^{\circ} 30$. 
Insight de compra: "Quiero que a mi familia les agrade mi comida y que no les haga daño".

Propuesta de valor: "Cuida tu familia con un pollo saludable pelado con la mejor calidad"

\section{d) Estrategia de Posicionamiento}

El posicionamiento deseado por la Peladuría Doña Viole es ser considerada como una empresa formal y como la mejor alternativa para el pelado del pollo utilizando una planta automatizada con buenas prácticas de manufactura que aseguren la inocuidad del producto.

De acuerdo a la evaluación del sector y la ejecución del proceso de investigación de mercado, se han identificado los atributos o factores que agregan valor para los clientes.

En relación a las avícolas y picadores, se identifican los siguientes atributos:

- Pollo sano.

- Vida útil del pollo en la mesa de picador.

- Ventana horaria de atención.

- Ubicación de la peladuría o CBA

- Formalidad del sector.

En relación a los consumidores finales, se identifican los siguientes atributos:

- Que el pollo no presente mal olor (para el cliente significa que no está malogrado ni contaminado) que sea un pollo saludable. 
- Que el pollo esté fresco.

- Que el pollo no esté golpeado ni con la piel desgarrada

- Que el pollo tenga un color característico amarillo.

- Que esté bien pelado, libre de restos de plumas y cañones

\section{Determinación de la ventaja competitiva}

En función a los atributos identificados se ha establecido la siguiente ventaja competitiva del CBA:

"Servicio accesible, que entrega un producto a tiempo, con la mejor calidad y cumpliendo con las normas de inocuidad vigentes"

\subsubsection{Estrategia de Producto}

\section{Servicio}

El producto a ofrecer es el servicio de peladuría de pollos que opere con un modelo de gestión certificado con buenas prácticas de manufactura (BPM) cuya certificación la otorga SENASA siempre que se cumplan los requisitos de procesos inocuos que aseguren alimentos saludables, con procesos automatizados que disminuyan los riesgos de contaminación y con capacidad para cubrir una ventana horaria de 4 horas. Este servicio está diseñado para satisfacer la demanda de clientes que cuentan con servicios similares pero sin las condiciones de higiene e inocuidad que exige el tipo de producto con el que se trabaja como es el pollo fresco. Esto permite que el cliente compare rápidamente este servicio con los otros ofrecidos y pueda optar por el ofrecido en este negocio. 
El diseño del servicio contempla que el CBA cuente con la certificación de BPM que garantizan inocuidad y calidad.

Nombre Comercial: Peladuría Doña Viole.

Producto Final: Pollo beneficiado con pata y paquete de vísceras

Figura $\mathrm{N}^{\circ}$ 16: Producto inicial y final del servicio del CBA Doña Viole

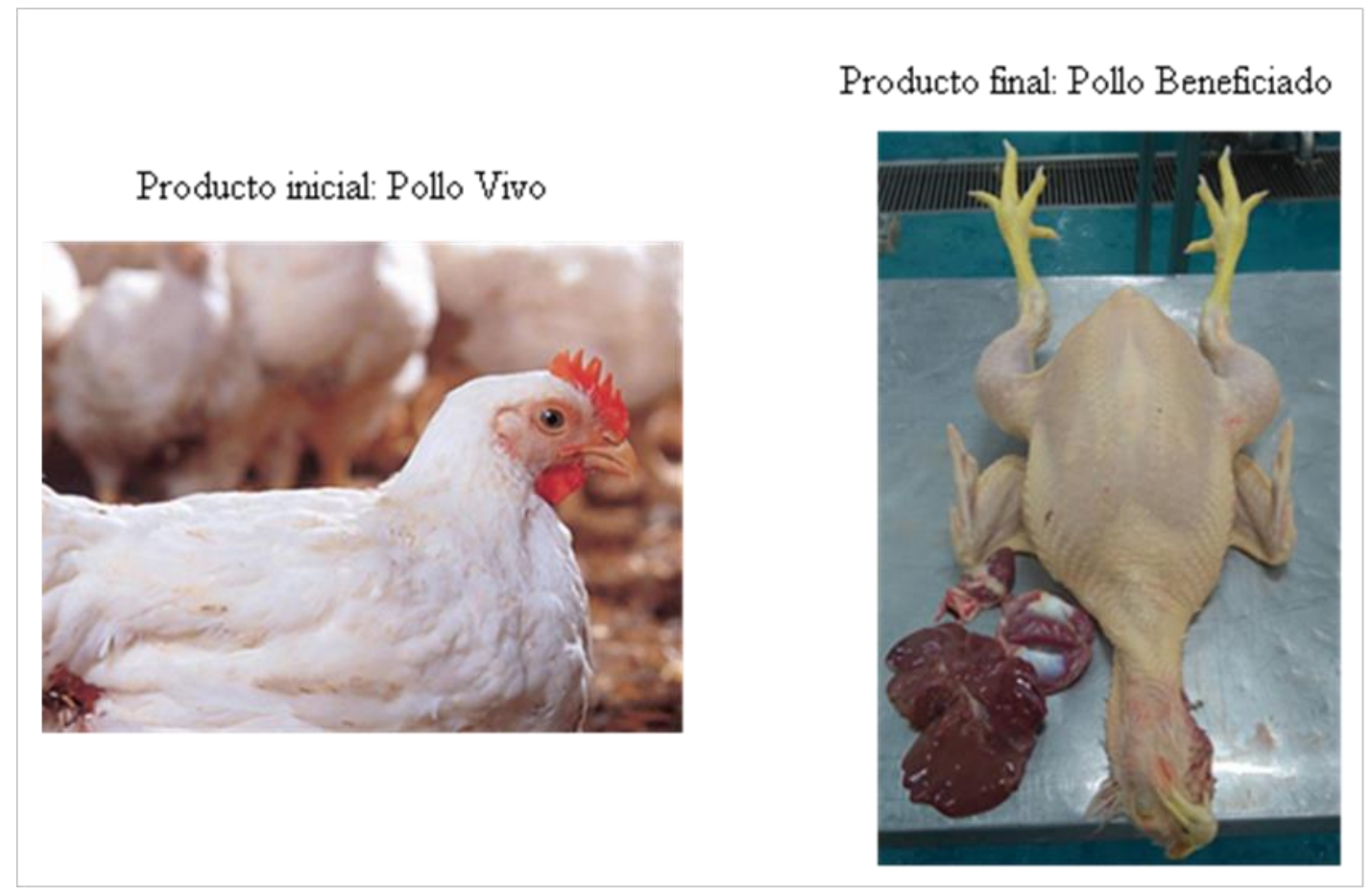

Fuente: Tomado de internet.

\section{Marca}

Se ha considerado incluir dentro de la marca el nombre de una persona, esto debido a que en la industria del pollo vivo, muchas veces se usa el diminutivo del nombre del dueño más que el nombre comercial de la empresa. Con la finalidad 
de aprovechar ello se está tomando como referencia el diminutivo del nombre Violeta para la creación de la marca.

Marca: Doña Viole.

\section{Logotipo}

El logotipo formará parte importante en la búsqueda de posicionar la marca en la mente de los clientes usuarios y consumidores. Se han considerado algunos aspectos importantes en la elaboración del logotipo entre los que se destacan los siguientes:

- Simpleza, que no tenga muchos detalles.

- Entendible, que exprese de manera visual la razón de ser del negocio.

- Único, porque las peladurías y CBA's que operan en la actualidad no realizan actividades para posicionar su marca.

- Recordable, fácil de recordar y utilizando el color amarillo que es asociado al color de la piel y pata del pollo. 


\section{Figura $N^{\circ}$ 17: Logotipo de la empresa}

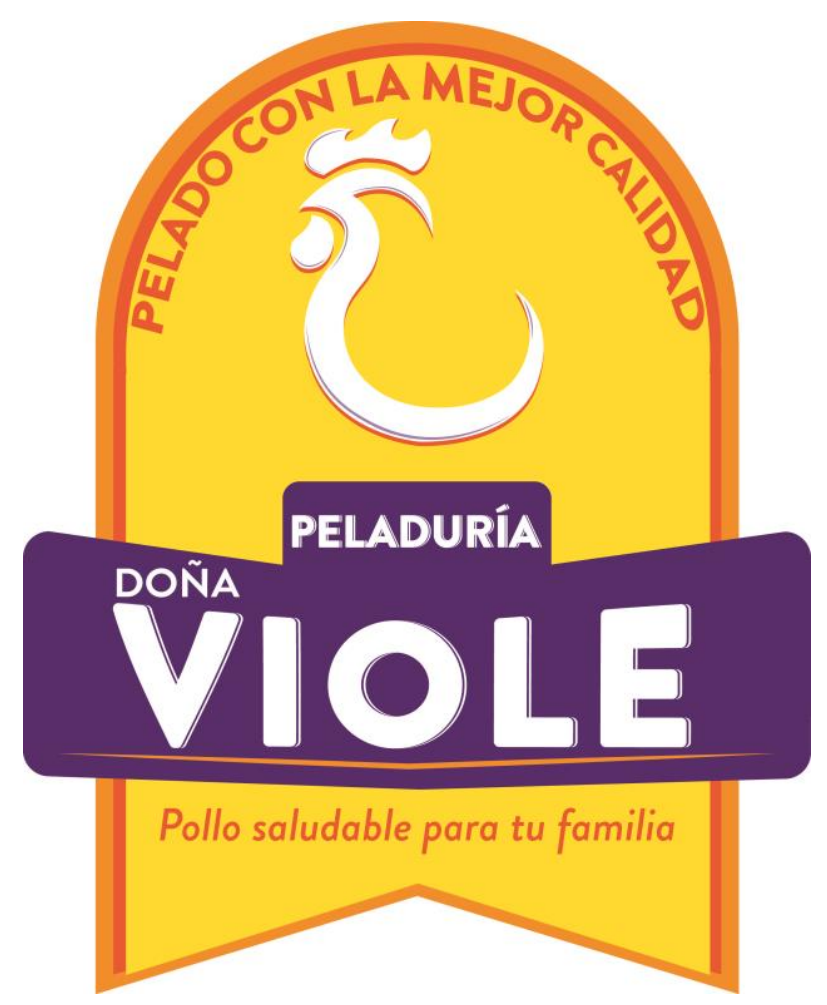

Fuente: Elaboración propia.

\section{Eslogan}

El eslogan también tendrá como finalidad conseguir el posicionamiento de la empresa en la mente de los clientes usuarios y consumidores a través de una frase que simplifique el sentido de la empresa.

Eslogan: "Pollo saludable para tu familia, pelado con la mejor calidad"

\section{Empaque}

La contratación del servicio entregado por la Peladuría Doña Viole incluirá además empaques tanto para los clientes usuarios como para los consumidores finales. 
a) Empaque para clientes usuarios del servicio: bolsas de polipropileno azules con capacidad para 10 pollos. La bolsa tendrá impreso el logo de la empresa acompañado del eslogan del servicio: "Pollo saludable para tu familia, pelado con la mejor calidad", este atributo está directamente relacionados a los dos elementos de diferenciación que se tienen: Inocuidad e higiene.

\section{Figura $\mathbf{N}^{\circ}$ 18: Modelo de empaque para clientes usuarios}

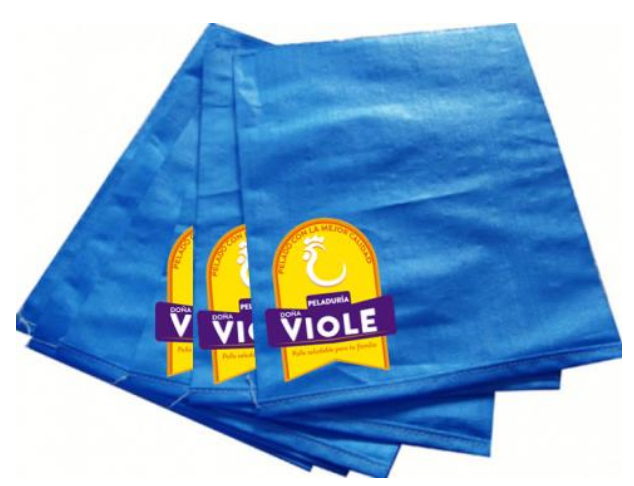

Fuente: Elaboración propia.

b) Empaque para los clientes consumidores: Se contempla entregar, junto al empaque de los clientes usuarios del servicio, paquetes de bolsas pequeñas las mismas que serán utilizadas en los puestos de mercado para despachar los pollos o piezas a los consumidores al momento de la compra. Estas bolsas tendrán impreso al frente, el logo de la empresa y por el lado posterior el eslogan y la ruta de la página web de la empresa (www.donaviole.com.pe url tentativo) donde el ama de casa encontrará información respecto al tipo de beneficio que ha 
tenido el pollo que está adquiriendo, comparado con el tipo de beneficio que se realiza en la actualidad (peladurías informales), las constancias de certificación y licencia otorgadas por las entidades correspondientes así como otras recomendaciones de compra.

\section{Figura $\mathbf{N}^{\circ}$ 19: Modelo de empaque para consumidor final}

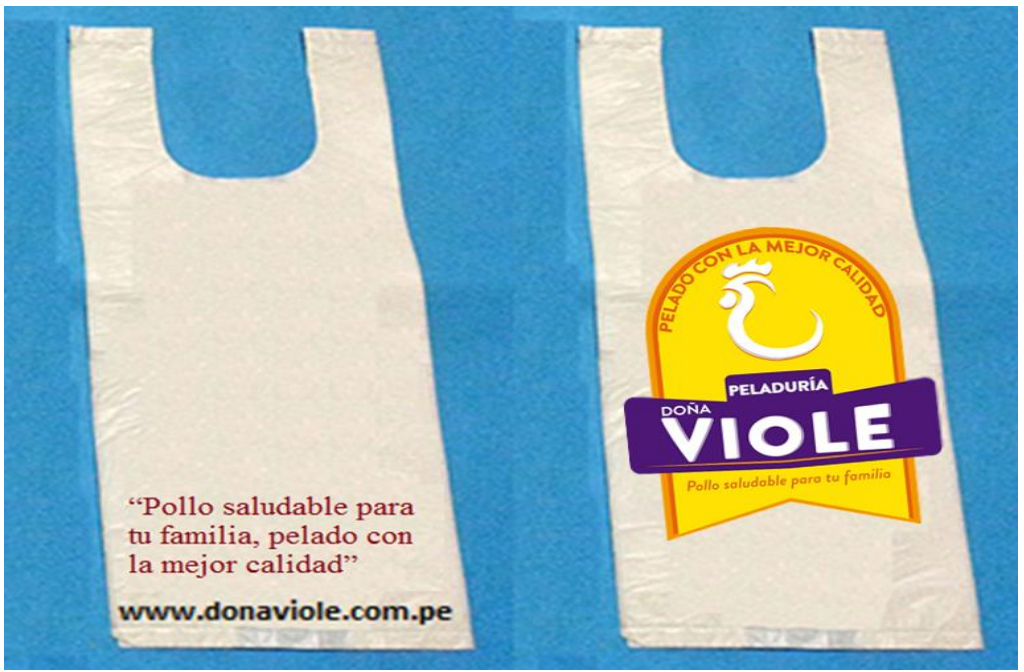

Fuente: Elaboración propia.

\subsubsection{Estrategia de Precio}

Los elementos que se incluyen en la estrategia de precio son:

\section{Mercado:}

De acuerdo a lo analizado en las encuestas y entrevistas a profundidad se contempla que el cliente está pagando en la actualidad por un servicio similar pero sin la oferta de valor contemplada, un precio con rango entre $\mathrm{S} / 0.35$ y S/ 0.60 por cada pollo beneficiado, siendo el promedio del precio un importe de S/ 0.41, este 
precio disminuye hasta $\mathrm{S} / 0.30$ en la medida que se va haciendo uso de servicios informales.

Los precios mencionados no incluyen IGV debido a que en el sector prima la informalidad y los clientes no exigen factura por el servicio.

En relación a la competencia, los precios mencionados son el reflejo de los precios que maneja la competencia ya que este dato ha sido obtenido de los clientes usuarios del servicio.

\section{Costo de la operación:}

Se plantea trabajar con el modelo de gestión de excelencia operativa que se enfoca básicamente en la obtención de costos más bajos y mejoras en la velocidad de los procesos.

Para determinar el costo de ventas unitario se han considerado todos los costos relacionados a las operaciones realizadas en la planta y a los gastos propios de la entrega del servicio tales como insumos y empaques, mano de obra, servicios básicos y costos indirectos; el detalle de estos costos se encuentran desarrollados en el capítulo $\mathrm{N}^{\circ} 9$.

\section{Condiciones de pago:}

Para este tipo de negocio el pago es al contado, manteniendo fijo el precio por unidad de pollo. 


\section{Estrategia:}

De acuerdo a lo mencionado anteriormente la estrategia de precio usada será el descreme del mercado, intentando poner un precio más alto con la finalidad de diferenciarnos del resto de competidores pero manteniendo los niveles fijos generando confiabilidad.

\section{El precio unitario del servicio asciende a S/ 0.54 sin IGV y S/ 0.64 con IGV.}

Al realizar el análisis comparativo del precio se identifica que este se encuentra S/ 0.23 por encima del precio que pagan en la actualidad las avícolas y picadores, sin embargo estas peladurías operan en condiciones actuales de informalidad y falta de inocuidad.

Es importante mencionar que en la encuesta realizada se ha determinado que el precio que estarían dispuestos a pagar los clientes asciende a $\mathrm{S} / 0.55$, por encima del precio actual con una diferencia de S/ 0.14. En los clientes cuya respuesta sobre la disposición de pago del servicio es superior, este importe se incrementa a S/ 0.66 en promedio, este valor es superior al precio definido del servicio. A continuación se detalla la Tabla $\mathrm{N}^{\circ} 32$ con los datos comparativos.

Tabla $\mathrm{N}^{\circ}$ 32: Comparativa de precio actual, precio que están dispuestos los clientes a realizar y precio definido para el servicio

\begin{tabular}{ccccc}
\hline $\begin{array}{c}\text { Precio } \\
\text { Actual }\end{array}$ & $\begin{array}{c}\text { Disposición de pago } \\
\text { por el nuevo servicio }\end{array}$ & $\begin{array}{c}\text { Disposición de pago } \\
\text { superior por el } \\
\text { nuevo servicio }\end{array}$ & $\begin{array}{c}\text { Precio definido } \\
\text { para el servicio } \\
\text { (sin IGV) }\end{array}$ & $\begin{array}{c}\text { Precio definido } \\
\text { para el servicio } \\
\text { (con IGV) }\end{array}$ \\
\hline 0.41 & 0.55 & 0.66 & 0.54 & 0.64 \\
\hline
\end{tabular}

Nota: Elaboración propia. 


\subsubsection{Estrategia de Plaza y Distribución}

La operatividad del CBA no contempla actividades de distribución debido a que tanto el ingreso como el distribución del pollo pelado a los puestos en los mercados es responsabilidad de las avícolas y picadores. La industria de pollo vivo está definida por el canal mayorista donde a través de los distribuidores de marca y mayoristas, y a través de los minoristas (avícolas y picadores) el pollo llega beneficiado al puesto de mercado. El diseño de las instalaciones del CBA contempla utilizar zonas independientes para manipular el pollo vivo y la zona de despacho del pollo ya beneficiado, de esta forma se asegura la inocuidad y durabilidad del pollo en el puesto de mercado.

En la Figura $\mathrm{N}^{\circ} 20$ se puede identificar el canal de distribución completo que inicia desde las granjas o centros de producción y que llega al consumidor final a través de los distintos canales. 
Figura $\mathbf{N}^{\circ}$ 20: Canal de distribución mayorista

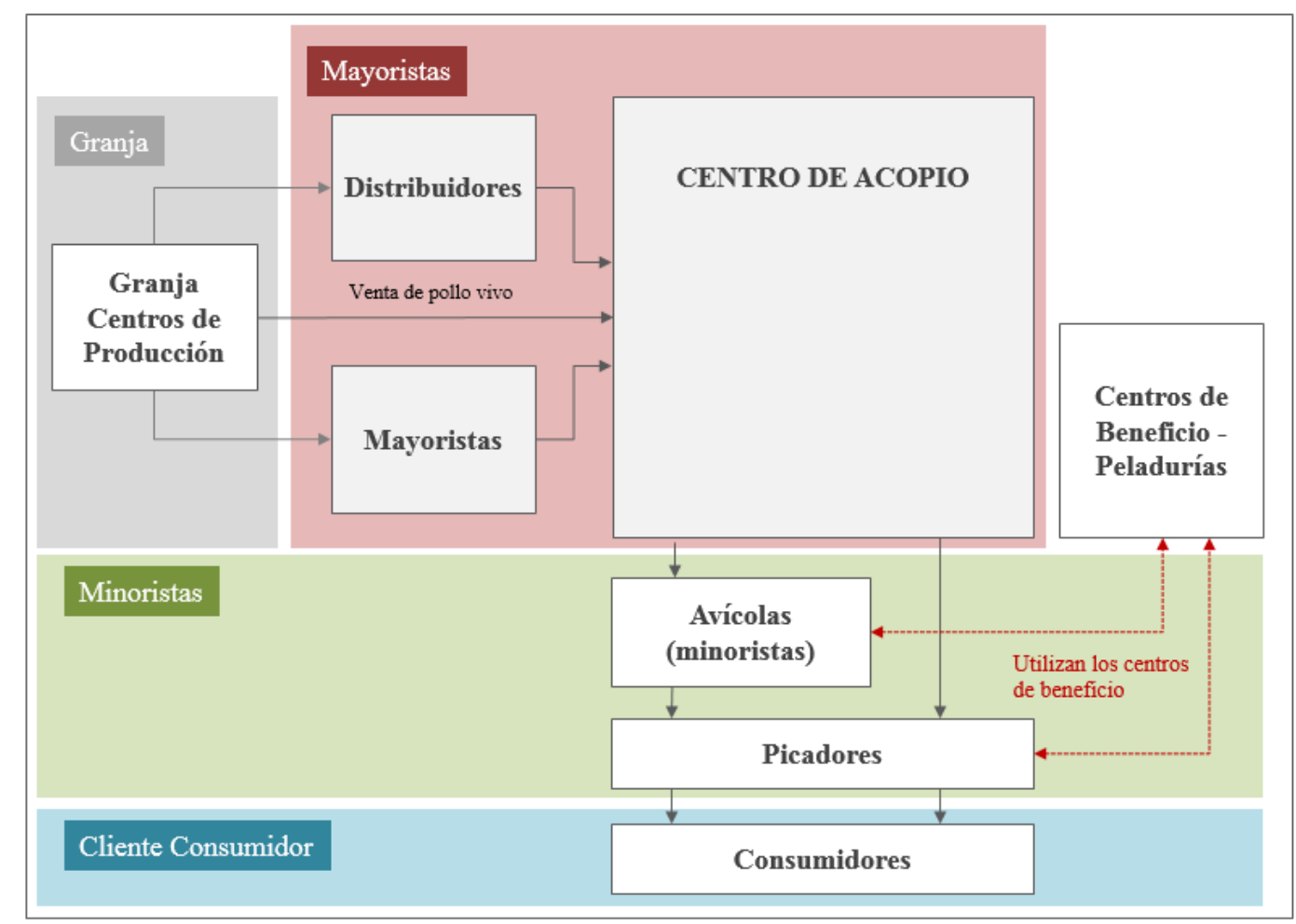

Fuente: Elaboración propia.

\subsubsection{Estrategia de promoción y publicidad}

La estrategia de comunicación y publicidad que se realizará estará enfocada a dar a conocer la forma como el negocio va a satisfacer las necesidades del mercado y posicionar el servicio en la mente de los usuarios y consumidores buscando aprovechar y atender los atributos que más valoran los mismos que han sido identificados en el proceso de investigación de mercado.

Posicionamiento deseado: Ser considerados como una empresa formal y como la mejor alternativa para el pelado o beneficio del pollo, utilizando una planta 
automatizada con buenas prácticas de manufactura que aseguren la inocuidad del producto.

Eslogan: "Pollo saludable para tu familia, pelado con la mejor calidad"

En este sentido se realizarán estrategias diferentes para los clientes usuarios del servicio y para los consumidores finales, éstos últimos cumplen un rol importante en la cadena de venta de pollo con lo cual se realizarán una serie de actividades que permitan posicionarnos rápidamente en estos consumidores.

\section{a) Publicidad en puesto de mercado:}

Está orientada a reforzar la promesa de valor a través de la recordación tanto del servicio como de la propuesta de valor. Para este caso se ha contemplado marcar los puestos de mercado que utilicen pollos provenientes de la Peladuría Doña Viole con un circulo azul que contenga el logo de la empresa y también el eslogan. En la siguiente figura se puede visualizar un ejemplo de lo que se implementará.

\section{Figura $N^{\circ}$ 21: Modelo de publicidad en puesto de mercado}

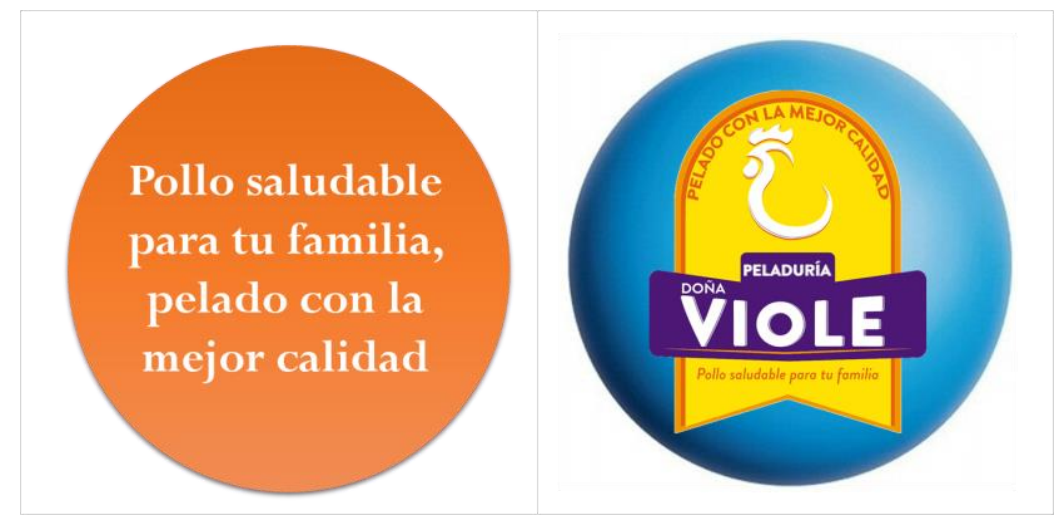

Fuente: Elaboración propia. 


\section{b) Relaciones Públicas:}

Las actividades de relaciones púbicas se realizaran con el objetivo de concientizar a los clientes usuarios de la Peladuría Doña Viole y a los clientes potenciales, la importancia de beneficiar su pollo en un centro autorizado, que cumpla con todas las exigencias requeridas por el SENASA y municipio, y que cumpla con estándares adecuados de salubridad y cuidado del pollo, para esto se concretarán reuniones con los representantes de la municipalidad de San Juan de Lurigancho, se buscará a través de la municipalidad tener presencia en los mercado y comunicar la ventaja competitiva.

Una estrategia adicional contemplada es patrocinar a la municipalidad de San Juan de Lurigancho en campañas de lucha contra la insalubridad y el consumo saludable. Estas actividades serán grabadas y comunicadas en la página web diseñada para tal fin.

\section{c) Marketing Digital:}

Se ha considerado utilizar las redes sociales y otros elementos digitales con la finalidad de conseguir un acercamiento a las amas de casa ya que representan al consumidor final, para que sean ellas las que identifiquen los beneficios de comprar un pollo proveniente de un CBA con BPM y se conviertan en una masa crítica que influyan en el resto de consumidores en la decisión de compra. 
Se creará un perfil de Facebook, ya en la actualidad la mayoría de mujeres de entre 24 y 55 años cuentan con acceso a internet y utilizan esta red social, con lo cual tenemos la oportunidad de comunicar las principales características del CBA, potenciando cuáles son los beneficios de consumir un pollo que ha sido beneficiado en dicha planta y enfocado a la salubridad y el cuidado de la familia.

Además se diseñará una página web oficial de la empresa en donde además de indicar los valores corporativos de la empresa, se incluirá toda la parte normativa relacionada al negocio en donde se pueda identificar también el modelo de gestión y compararlo con el modelo que opera en la actualidad con informalidad e insalubridad, se podrá ver videos de las noticias más relevantes sobre el cierre y decomiso que realizan el gobierno y municipalidades a las peladurías informales y en contraparte se podrá ver también videos sobre cómo se opera en la Peladuría Doña Viole.

Tanto la página web como el perfil de Facebook, estarán implementados desde el primer día de la puesta en marcha de la empresa.

\section{d) Marketing Boca a Boca:}

Los planes de marketing buscan mecanismos para fidelizar a los consumidores en línea con el mundo competitivo que se está viviendo actualmente. Para este proyecto se está considerando utilizar la ventaja competitiva de proporcionar un: "Servicio accesible, que entrega un producto de la mejor calidad, cumpliendo con las normas de inocuidad 
vigentes" como fortaleza para ofrecer la propuesta de valor: "Servicio accesible, que entrega un producto a tiempo, con la mejor calidad y cumpliendo con las normas de inocuidad vigentes" al consumidor final y lograr su fidelización.

Así, se ha considerado como plan de fidelización el marketing boca a boca que se realizará en los puestos de mercado a través de impulsadoras, quienes entrarán en contacto con las amas de casa y tendrán como función realizar la campaña de concientización sobre la importancia que tiene para la familia que el pollo sea beneficiado en ambientes que garanticen la inocuidad del producto y su salud. Con ello se busca captar clientes y convencerlos de los beneficios del servicio propuesto. Adicionalmente se entregarán trípticos donde se puedan comparar la forma de beneficio actual y el modelo de un CBA con buenas prácticas de manufactura. Se incluye además las rutas de la página web de la empresa y del Facebook. Con ello se espera que el consumidor mantenga una relación estable y duradera con el picador que le ofrece un pollo beneficiado en la Peladuría Doña Viole.

\section{Calendario de realización}

a) Fase de introducción: Por introducción se realizaran campañas de impulsación todos los domingos durante los primeros tres meses del año 2018.

b) Fase de mantenimiento: Pasado los primeros tres meses del año 2018 se realizarán campañas de impulsación dos veces por mes (días domingo) 
Los mercados que se visitarán corresponden al distrito de San Juan de Lurigancho y estarán ubicados dentro de la zona de influencia del CBA.

\subsubsection{Estrategia de Personas}

Dentro del equipo de personas que se encuentran desarrollando el presente plan de negocios se cuenta con la participación de una persona que acumula más de 27 años de experiencia en el sector avícola, trabajando en la principal empresa productora y comercializadora de carne de pollo, dicha personas participará también en la parte societaria de la empresa y estará a cargo de la implementación del equipo de trabajo necesario para la operación.

El CBA estará bajo la responsabilidad del Gerente Administrativo encontrándose las personas que conforman el equipo de trabajo de esta empresa en dos niveles:

a. Operarios, los cuales están especializados en las siguientes labores manuales:

- Desestiba del pollo vivo al CBA.

- Colocación de las aves en la línea de pelado.

- Beneficio propiamente dicho.

- Descolgado de los pollos de la línea de beneficio.

- Embolsado de pollos.

- Entrega al cliente del producto final.

b. Administrativos y ventas, los cuales están especializados en:

- Manejo de caja y emisión de boletas por el servicio prestado. 
- Back office para contabilidad, almacenes u otros.

- Administración del CBA y todas las áreas funcionales.

- Gestión de clientes y campañas de ventas, desarrollo del plan de marketing.

Todo el personal contemplado, contará con los implementos exigidos por las normas de seguridad y salud en el trabajo así como la indumentaria adecuada en cada parte del proceso en el que participen.

Se ha contemplado la ejecución de capacitaciones relacionadas al adecuado manejo de la maquinaria, del pollo en la zona sucia y limpia para evitar focos de contaminación, adecuado manejo de los residuos, y además temas relacionados a la seguridad y salud en el trabajo y prevención de accidentes.

\subsubsection{Estrategia de Procesos}

Los procesos que implican este servicio están pensados para maximizar la automatización y dejar solo algunos procesos relevantes en forma manual. Estos procesos permiten también generar satisfacción del cliente considerando que deben de ser una palanca para asegurar la promesa de valor ofrecida a los clientes, tanto por el lado de los usuarios del CBA como también de las amas de casa. Ya que este modelo se basa entre otras cosas en la oferta de valor de la duración del producto en la mesa del puesto de mercado, está contemplando un enfriamiento previo a la entrega. Esta práctica permite que la descomposición natural del producto se retrase, dándole al picador del puesto de mercado más tiempo para 
exponer a la venta su producto sin que adquiera mal olor o cambie su aspecto físico.

El CBA está diseñado para contar en todo el proceso de beneficio con agua potable e iluminación así como un sistema de recolección de desechos generados durante el proceso de beneficio. El diseño de las instalaciones contempla espacios para recepcionar a los vehículos motorizados o de transporte que utilicen los clientes para trasladar sus productos al mercado.

\subsubsection{Estrategia de Presencia Física}

Como ya se ha mencionado en los capítulos previos, la Peladuría Doña Viole estará ubicada en el distrito de San Juan de Lurigancho debido a que el mercado al cual se atenderá se encuentra en el mismo distrito y es necesario tener presencia física en una zona cercana a la operación de los clientes.

El local estará diseñado para que exista una clara diferenciación entre la zona de beneficio y pelado del pollo o también llamada zona sucia y el lugar de despacho también llamado zona limpia, con la finalidad de evitar la contaminación cruzada. Se tendrá acceso restringido a la zona de beneficio de las aves sin embargo los clientes usuarios tendrán la posibilidad de visualizar el proceso a través de ventanas con vidrio transparente.

Asimismo está contemplado el uso de mostradores para que los clientes lleguen a recoger sus bolsas.

Los espacios son diseñados de acuerdo a las normas vigentes en cuanto al aforo y otros. 


\subsection{Estrategia de ventas}

La estrategia de ventas que se utilizará estará enfocada a la implementación de una fuerza de venta B2B debido a que los clientes de la peladuría Doña Viole son avícolas y picadores quienes llegan al consumidor final.

Para ejecutar esta estrategia se realizarán ventas personales a clientes potenciales ya sea en las instalaciones de los clientes o en el centro de acopio, lugar donde llegan para comprar pollos vivos. Además estos vendedores también realizarán coordinaciones y brindarán información a través del servicio telefónico.

\subsubsection{Plan de ventas}

El plan de ventas para el negocio de la Peladuría Doña Viole considera como meta conseguir que se cumplan los pronósticos de ventas detallados en el capítulo $\mathrm{N}^{\circ} 6$.

Se trabajará con precios unitarios pactados previamente y que serán negociados a largo plazo asegurando que los usuarios puedan proyectar su flujo de caja.

Se busca que los clientes usuarios sean considerados como socios estratégicos y que sirvan de apoyo para que ellos a su vez puedan generar rentabilidad en su negocio.

A continuación se detalla el cronograma de actividades de fidelización considerado en el plan de negocios, el mismo que permitirá posicionar en la mente de los usuarios y consumidores el servicio brindado la Peladuría Doña Viole. 
Figura $N^{\circ}$ 22: Cronograma de actividades del plan de ventas - año 2018

\begin{tabular}{|c|c|c|c|c|c|c|c|c|c|c|c|c|c|c|c|c|c|c|c|c|c|c|c|c|c|c|c|}
\hline \multicolumn{7}{|c|}{ ENERO } & \multicolumn{7}{|c|}{ FEBRERO } & \multicolumn{7}{|c|}{ MARZO } & \multicolumn{7}{|c|}{ ABRIL } \\
\hline \multirow[t]{2}{*}{$\underline{\mathrm{D}}$} & $\underline{\mathbf{L}}$ & $\underline{\mathrm{M}}$ & $\underline{M}$ & $\underline{J}$ & $\underline{\mathbf{v}}$ & $\underline{\mathbf{s}}$ & \multirow[t]{2}{*}{$\underline{\mathrm{D}}$} & \multirow[t]{2}{*}{$\underline{\mathbf{L}}$} & \multirow[t]{2}{*}{$\underline{\mathrm{M}}$} & \multirow[t]{2}{*}{$\underline{\mathbf{M}}$} & \multirow{2}{*}{$\frac{\mathbf{J}}{1}$} & \multirow{2}{*}{$\frac{\mathrm{v}}{2}$} & \multirow{2}{*}{$\frac{\mathbf{s}}{3}$} & \multirow[t]{2}{*}{$\underline{\mathrm{D}}$} & \multirow[t]{2}{*}{$\underline{\underline{ }}$} & \multirow[t]{2}{*}{$\underline{\mathrm{M}}$} & \multirow[t]{2}{*}{$\underline{\mathrm{M}}$} & \multirow{2}{*}{$\frac{\mathbf{J}}{1}$} & \multirow{2}{*}{$\frac{\underline{v}}{2}$} & \multirow{2}{*}{$\frac{\mathbf{s}}{3}$} & \multirow{2}{*}{$\frac{\mathrm{D}}{1}$} & \multirow{2}{*}{$\frac{\mathrm{L}}{2}$} & \multirow{2}{*}{$\frac{\mathrm{M}}{3}$} & $\underline{\mathrm{M}}$ & $\underline{\mathbf{J}}$ & $\underline{\mathbf{v}}$ & $\underline{\mathbf{s}}$ \\
\hline & 1 & 2 & 3 & 4 & 5 & 6 & & & & & & & & & & & & & & & & & & 4 & 5 & 6 & 7 \\
\hline 7 & 8 & 9 & 10 & 11 & 12 & 13 & 4 & 5 & 6 & 7 & 8 & 9 & 10 & 4 & 5 & 6 & 7 & 8 & 9 & 10 & 8 & 9 & 10 & 11 & 12 & 13 & 14 \\
\hline 14 & 15 & 16 & 17 & 18 & 19 & 20 & 11 & 12 & 13 & 14 & 15 & 16 & 17 & 11 & 12 & 13 & 14 & 15 & 16 & 17 & 15 & 16 & 17 & 18 & 19 & 20 & 21 \\
\hline 21 & 22 & 23 & 24 & 25 & 26 & 27 & 18 & 19 & 20 & 21 & 22 & 23 & 24 & 18 & 19 & 20 & 21 & 22 & 23 & 24 & 22 & 23 & 24 & 25 & 26 & 27 & 28 \\
\hline 28 & 29 & 30 & 31 & & & & 25 & 26 & 27 & 28 & & & & 25 & 26 & 27 & 28 & 29 & 30 & 31 & 29 & 30 & & & & & \\
\hline MAY & & & & & & & JUNI & & & & & & & JULIC & & & & & & & AGO & STO & & & & & \\
\hline$\underline{\mathrm{D}}$ & $\underline{\mathbf{L}}$ & $\underline{\mathrm{M}}$ & $\underline{\mathrm{M}}$ & $\underline{J}$ & $\underline{\mathrm{v}}$ & $\underline{\mathbf{s}}$ & $\underline{\mathrm{D}}$ & $\underline{\mathbf{L}}$ & $\underline{\mathrm{M}}$ & $\underline{\mathrm{M}}$ & $\underline{J}$ & $\underline{\mathbf{v}}$ & $\underline{\mathbf{s}}$ & $\underline{\mathrm{D}}$ & $\underline{\underline{L}}$ & $\underline{\mathrm{M}}$ & $\underline{\mathrm{M}}$ & $\underline{J}$ & $\underline{\mathbf{v}}$ & $\underline{\mathbf{S}}$ & $\underline{\mathrm{D}}$ & $\underline{\mathbf{L}}$ & $\underline{\mathrm{M}}$ & $\underline{\mathrm{M}}$ & $\underline{\jmath}$ & $\underline{\mathbf{v}}$ & $\underline{\mathbf{S}}$ \\
\hline & & 1 & 2 & 3 & 4 & 5 & & & & & & 1 & 2 & 1 & 2 & 3 & 4 & 5 & 6 & 7 & & & & 1 & 2 & 3 & 4 \\
\hline 6 & 7 & 8 & 9 & 10 & 11 & 12 & 3 & 4 & 5 & 6 & 7 & 8 & 9 & 8 & 9 & 10 & 11 & 12 & 13 & 14 & 5 & 6 & 7 & 8 & 9 & 10 & 11 \\
\hline 13 & 14 & 15 & 16 & 17 & 18 & 19 & 10 & 11 & 12 & 13 & 14 & 15 & 16 & 15 & 16 & 17 & 18 & 19 & 20 & 21 & 12 & 13 & 14 & 15 & 16 & 17 & 18 \\
\hline 20 & 21 & 22 & 23 & 24 & 25 & 26 & 17 & 18 & 19 & 20 & 21 & 22 & 23 & 22 & 23 & 24 & 25 & 26 & 27 & 28 & 19 & 20 & 21 & 22 & 23 & 24 & 25 \\
\hline 27 & 28 & 29 & 30 & 31 & & & 24 & 25 & 26 & 27 & 28 & 29 & 30 & 29 & 30 & 31 & & & & & 26 & 27 & 28 & 29 & 30 & 31 & \\
\hline SETIE & EMB & & & & & & OCT & JBRE & & & & & & NOV & IEMB & & & & & & DICIE & MBR & & & & & \\
\hline$\underline{\mathrm{D}}$ & $\underline{\underline{L}}$ & $\underline{\mathrm{M}}$ & $\underline{\mathrm{M}}$ & $\underline{\mathbf{J}}$ & $\underline{\mathbf{v}}$ & $\underline{\mathbf{s}}$ & $\underline{\mathrm{D}}$ & $\underline{\mathbf{L}}$ & $\underline{\mathbf{M}}$ & $\underline{\mathbf{M}}$ & $\underline{J}$ & $\underline{\mathbf{v}}$ & $\underline{\mathbf{S}}$ & $\underline{\mathrm{D}}$ & $\underline{\mathbf{L}}$ & $\underline{\mathbf{M}}$ & $\underline{\mathbf{M}}$ & $\underline{\mathbf{J}}$ & $\underline{\mathbf{v}}$ & $\underline{\mathbf{s}}$ & $\underline{\mathrm{D}}$ & $\underline{\mathbf{L}}$ & $\underline{\mathbf{M}}$ & $\underline{\mathbf{M}}$ & $\underline{\mathbf{J}}$ & $\underline{\mathbf{v}}$ & $\underline{\mathbf{s}}$ \\
\hline & & & & & & 1 & & 1 & 2 & 3 & 4 & 5 & 6 & & & & & 1 & 2 & 3 & & & & & & & 1 \\
\hline 2 & 3 & 4 & 5 & 6 & 7 & 8 & 7 & 8 & 9 & 10 & 11 & 12 & 13 & 4 & 5 & 6 & 7 & 8 & 9 & 10 & 2 & 3 & 4 & 5 & 6 & 7 & 8 \\
\hline 9 & 10 & 11 & 12 & 13 & 14 & 15 & 14 & 15 & 16 & 17 & 18 & 19 & 20 & 11 & 12 & 13 & 14 & 15 & 16 & 17 & 9 & 10 & 11 & 12 & 13 & 14 & 15 \\
\hline 16 & 17 & 18 & 19 & 20 & 21 & 22 & 21 & 22 & 23 & 24 & 25 & 26 & 27 & 18 & 19 & 20 & 21 & 22 & 23 & 24 & 16 & 17 & 18 & 19 & 20 & 21 & 22 \\
\hline 23 & 24 & 25 & 26 & 27 & 28 & 29 & 28 & 29 & 30 & 31 & & & & 25 & 26 & 27 & 28 & 29 & 30 & & 23 & 24 & 25 & 26 & 27 & 28 & 29 \\
\hline 30 & & & & & & & & & & & & & & & & & & & & & 30 & 31 & & & & & \\
\hline Leye & nda & & & & & & & & & & & & & & & & & & & & & & & & & & \\
\hline & Publ & cidac & en pu & lesto & de $m$ & ercado & & & & & & & & & & & & & & & & & & & & & \\
\hline & Rela & ione & s públ & icas & & & & & & & & & & & & & & & & & & & & & & & \\
\hline & Marl & eting & digit & & & & & & & & & & & & & & & & & & & & & & & & \\
\hline & Marl & eting & boca & $\mathrm{a} b \mathrm{bc}$ & & & & & & & & & & & & & & & & & & & & & & & \\
\hline
\end{tabular}

Fuente: Elaboración propia.

\subsubsection{Políticas de servicios y garantías}

Para darle mayor solidez al negocio, el proceso debe operar satisfaciendo las expectativas de los cliente y garantizando una adecuada calidad de servicio, por lo cual se ha contemplado desarrollar una serie de políticas que normen la forma de cómo se debe operar este negocio de cara al cliente.

Esto nos permitirá canalizar los reclamos y sugerencias que los clientes necesiten hacer llegar para mejorar continuamente las condiciones del servicio, el objetivo es generar en el cliente la capacidad de recomendar el servicio a otros clientes potenciales. 
Se desarrollaran las siguientes políticas:

- Política de calidad, la cual normará las consideraciones básicas para operar en forma correcta los productos y contemplando la obligatoriedad de las fases de planeamiento, control y mejora de la calidad los cuales aseguran la promesa de valor al cliente de entregar un pollo sano, inocuo, con la piel en buen estado y sin mal olor, entre algunas característica.

- Procedimientos operacionales, los cuales indicarán cuales son los procesos con los que cada trabajar deberá operar en forma estandarizada y cumpliendo con todas las actividades necesarias (parámetros de operación, de tiempo entre otros) trayendo como consecuencia la entrega de un buen servicio.

- Política de Buenas prácticas de manufactura (BPM), la cual normará las operaciones asegurando que el servicio sea ejecutado cumpliendo con los estándares necesarios, las restricciones en las operaciones entre las zonas sucias (momento de ingreso del pollo vivo) y las zonas limpias (momento de salida del pollo beneficiado) del CBA entre otros. El detalle de estas políticas se consideran en el capítulo $\mathrm{N}^{\circ} 7$ del plan de negocio. 


\section{CAPÍTULO VI}

\section{Pronóstico de ventas}

En este capítulo se han especificado los pronósticos de ventas para los cinco primeros años desde la puesta en marcha del negocio. En el cuarto capítulo, se determinó que el mercado objetivo para el primer año sería de 8 clientes, esto ha sido la base o input para la generación de la proyección, además de los datos obtenidos en las encuestas sobre la cantidad de pollo beneficiado, la frecuencia y la aceptación del servicio.

Se han determinado los factores de crecimiento de la demanda del servicio para los siguientes 4 años y la propuesta es un aumento gradual de clientes iniciando con 8 para llegar a 14 clientes el año 2022 .

Se ha estudiado los factores cuyos cambios pueden poner en riesgo la operación de la planta, relacionado al incumplimiento de los pronósticos de ventas y por ende una afectación en los ingresos de la compañía.

\subsection{Fundamentos y supuestos}

La proyección ha sido fundamentada en tres principales aspectos: a) El mercado objetivo, b) La frecuencia con que se utiliza el servicio, y c) La cantidad de pollo que benefician las avícolas y picadores. 
a) Mercado objetivo, en el cuarto capítulo, se determinó que el mercado objetivo para el primer año de operación estará compuesto por 8 clientes, lo que representaría un $5.0 \%$ de participación inicial.

Se ha determinado dos factores de crecimiento de la demanda del servicio para los siguientes 4 años: el crecimiento del PBI y del sector pecuario, y el crecimiento poblacional, los cuales originan que el consumo per cápita de pollo se incremente. Estos factores, apoyados con las actividades de control que viene ejecutando el gobierno y municipios y la expectativa que pueden tener los clientes como consecuencia de las campañas de marketing que se realizarán apalancan un incremento en la demanda proyectada del servicio de pelado. Se propone un aumento gradual de clientes iniciando con 8 para llegar a 14 clientes el año 2022 logrando una participación del mercado de $8.75 \%$.

Esta información que ha sido especificada en el cuarto capítulo. En la tabla $\mathrm{N}^{\circ} 33$ se puede identificar el mercado objetivo para todo el plan de negocio.

Tabla $N^{\circ}$ 33: Evolución del mercado objetivo en años 2018 - 2022

\begin{tabular}{cccccc}
\hline Año & $\mathbf{2 0 1 8}$ & $\mathbf{2 0 1 9}$ & $\mathbf{2 0 2 0}$ & $\mathbf{2 0 2 1}$ & $\mathbf{2 0 2 2}$ \\
\hline $\mathbf{N}^{\circ}$ Clientes & 8 & 9 & 10 & 12 & 14 \\
\hline
\end{tabular}

Nota: Elaboración propia.

b) Frecuencia con que se utiliza el servicio, este fundamento ha sido tomado de la encuesta realizada y descrita en el capítulo $\mathrm{N}^{\circ} 3$, en la cual se identificó que el $100 \%$ de los clientes utilizan el servicio de forma diaria, lo significa que el nivel de utilización del servicio es de 365 veces por cada año y por cada cliente captado, sin 
embargo no se está considerando como días laborables los días 25 de diciembre y 01 de enero. Se considera el supuesto de que se mantendrá este comportamiento en los próximos dos años debido a que el consumo de pollo se realiza en los hogares de forma diaria. En la Tabla 34 se muestra el cálculo de la frecuencia de utilización del servicio, tomando como referencia la pregunta $\mathrm{N}^{\circ} 5$ de la encuesta: ¿Con qué frecuencia utiliza el servicio de beneficio de pollo?.

Tabla $N^{\circ}$ 34: Cálculo de la frecuencia de utilización del servicio

\begin{tabular}{lccrrr}
\hline \multicolumn{1}{c}{ Ítem } & $\begin{array}{c}\mathbf{N}^{\circ} \mathbf{d e} \\
\text { Respuestas }\end{array}$ & $\boldsymbol{\%}$ & $\begin{array}{c}\text { Repeticiones } \\
\text { por año }\end{array}$ & Cálculo & Cantidad \\
\hline Diaria & 74 & $100 \%$ & 363 veces & $363 \times 100 \%$ & 363 \\
Semanal & 0 & $0 \%$ & 52 veces & $52 \times 0 \%$ & 0 \\
Quincenal & 0 & $0 \%$ & 24 veces & $24 \times 0 \%$ & 0 \\
Mensual & 0 & $0 \%$ & 12 veces & $12 \times 0 \%$ & 0 \\
\hline \multicolumn{1}{c}{ Total } & $\mathbf{7 4}$ & $\mathbf{1 0 0 \%}$ & Total de repeticiones por & $\mathbf{3 6 3}$ \\
\hline
\end{tabular}

Nota: Elaboración propia.

c) Cantidad de pollo que benefician las avícolas y picadores, este fundamento ha sido tomado de la encuesta realizada y descrita en el tercer capítulo, en esta se identificó que el promedio de pollos que beneficia cada cliente es de 547 unidades cada vez que utiliza el servicio. En la Tabla $\mathrm{N}^{\circ} 35$ se muestra el cálculo de la cantidad de pollo que benefician los clientes, tomando como referencia la pregunta N 4 de la encuesta: ¿Qué cantidad de pollo beneficia aproximadamente cada vez que utiliza el servicio?. 
Tabla $\mathbf{N}^{\circ}$ 35: Cálculo de la cantidad de pollo que se beneficia al utilizar el servicio

\begin{tabular}{cccrrr}
\hline Ítem & $\begin{array}{c}\mathbf{N}^{\circ} \text { de } \\
\text { Respuestas }\end{array}$ & $\%$ & $\begin{array}{c}\text { Promedio } \\
\text { del Rango }\end{array}$ & \multicolumn{1}{c}{ Cálculo } & Cantidad \\
\hline $100-199$ & 14 & $19 \%$ & 149 & $149 \times 19 \%$ & 28 \\
$200-299$ & 4 & $5 \%$ & 255 & $255 \times 5 \%$ & 14 \\
$300-399$ & 8 & $11 \%$ & 363 & $363 \times 11 \%$ & 39 \\
$400-499$ & 15 & $20 \%$ & 413 & $413 \times 20 \%$ & 84 \\
$500-599$ & 3 & $4 \%$ & 560 & $560 \times 4 \%$ & 23 \\
$600-699$ & 9 & $12 \%$ & 632 & $632 \times 12 \%$ & 77 \\
$700-799$ & 6 & $8 \%$ & 740 & $740 \times 8 \%$ & 60 \\
$800-899$ & 3 & $4 \%$ & 895 & $895 \times 4 \%$ & 36 \\
$900-999$ & 3 & $4 \%$ & 980 & $980 \times 4 \%$ & 40 \\
$1000-1099$ & 0 & $0 \%$ & 0 & $0 \times 0 \%$ & 0 \\
$1100-1199$ & 0 & $0 \%$ & 0 & $0 \times 0 \%$ & 0 \\
$1200-1299$ & 9 & $12 \%$ & $12031203 \times 12 \%$ & 146 \\
\hline Total & $\mathbf{7 4}$ & $\mathbf{1 0 0 \%}$ & Cantidad de pollo que & $\mathbf{5 4 7}$ \\
\hline
\end{tabular}

Nota: Elaboración propia.

Este valor es inicial y válido solo en el año de evaluación del proyecto, 2017. Para los cinco periodos comprendidos en la evaluación del proyecto se trabaja con el supuesto que los clientes usuarios del CBA buscarán también incrementar sus ventas de pollo en función de la demanda proyectada para esos períodos y por ende requerirán en la misma proporción del servicio propuesto en el presente plan.

El cálculo de la evolución de la demanda del servicio se ha realizado tomando como supuesto el incremento en la demanda de pollo que se proyecta tener en base al incremento de la población e incremento de consumo per cápita tal como se indica en la Tabla $\mathrm{N}^{\circ} 36$. 
Tabla N ${ }^{\circ}$ 36: Evolución de la demanda 2016-2022

\begin{tabular}{|l|c|c|c|c|c|c|c|c|}
\hline & DATOS & $\mathbf{2 0 1 6}$ & $\mathbf{2 0 1 7}$ & $\mathbf{2 0 1 8}$ & $\mathbf{2 0 1 9}$ & $\mathbf{2 0 2 0}$ & $\mathbf{2 0 2 1}$ & $\mathbf{2 0 2 2}$ \\
\hline Demanda Pollo & MM Unid & 272 & 284 & 297 & 309 & 322 & 333 & 344 \\
\hline Poblacion & MM Hab & 10.1 & 10.2 & 10.4 & 10.5 & 10.7 & 10.8 & 11.0 \\
\hline Consumo Percapita & Kg/año Hab & 74.3 & 76.5 & 78.7 & 80.6 & 82.6 & 84.2 & 85.9 \\
\hline \% Crecimiento anual & \% Var & $5.0 \%$ & $4.5 \%$ & $4.5 \%$ & $4.0 \%$ & $4.0 \%$ & $3.5 \%$ & $3.5 \%$ \\
\hline
\end{tabular}

Nota: Adaptado de Bases de MINAGRI e INEI.

Tabla $\mathrm{N}^{\circ}$ 37: Porcentaje promedio de variación anual de la demanda del servicio 2016-2022

\begin{tabular}{cc}
\hline Año & $\begin{array}{c}\text { Demanda del servicio ( } \% \\
\text { de Variación anual) }\end{array}$ \\
\hline$[2016-2022]$ & $4.20 \%$ \\
\hline
\end{tabular}

Nota: Elaboración propia.

Con el promedio de variación de la tasa de crecimiento de la demanda indicado en la Tabla $\mathrm{N}^{\circ} 36$ se identifica la cantidad de pollo que cada cliente requerirá beneficiar por día de acuerdo a la frecuencia mencionada anteriormente y se calcula también el beneficio diario incremental de cada cliente usuario entre los años 2018 y 2022, periodo de evaluación del presente plan de negocios. Esto se detalla en la Tabla $\mathrm{N}^{\circ} 38$. 
Tabla $\mathrm{N}^{\circ}$ 38: Cantidad de pollo beneficiado por cliente 2017-2022

\begin{tabular}{lrrrrrr}
\hline \multicolumn{1}{c}{ Año } & $\mathbf{2 0 1 7}$ & $\mathbf{2 0 1 8}$ & $\mathbf{2 0 1 9}$ & $\mathbf{2 0 2 0}$ & $\mathbf{2 0 2 1}$ & $\mathbf{2 0 2 2}$ \\
\hline Factor de crecimiento & & $4.20 \%$ & $4.20 \%$ & $4.20 \%$ & $4.20 \%$ & $4.20 \%$ \\
Cantidad beneficiada por cliente & 547 & 570 & 594 & 619 & 645 & 672 \\
\hline
\end{tabular}

Nota: Elaboración propia.

\subsection{Justificación}

Tras el análisis de los fundamentos y los supuestos, se ha desarrollado el siguiente pronóstico de ventas anuales para los 5 periodos como se muestra en la Tabla $\mathrm{N}^{\circ} 39$.

En este pronóstico se detallan las ventas anuales de los periodos comprendidos entre los años 2018 y 2022 considerando las variables: número de clientes proyectado, frecuencia de uso del servicio y cantidad promedio de beneficio por cliente. Estos valores son de importancia para el proyecto ya que servirán además para proyectar los ingresos de la empresa y validar su viabilidad financiera.

Tabla $N^{\circ}$ 39: Pronóstico de ventas anuales

\begin{tabular}{lrrrrr}
\hline \multicolumn{1}{c}{ Año } & $\mathbf{2 0 1 8}$ & $\mathbf{2 0 1 9}$ & $\mathbf{2 0 2 0}$ & $\mathbf{2 0 2 1}$ & $\mathbf{2 0 2 2}$ \\
\hline $\mathrm{N}^{\circ}$ Clientes & 8 & 9 & 10 & 12 & 14 \\
Frecuencia (días) & 363 & 363 & 363 & 363 & 363 \\
Cantidad de pollo beneficiado por cliente & 570 & 594 & 619 & 645 & 672 \\
Cantidad de pollo beneficiado diariamente & 4,560 & 5,346 & 6,190 & 7,740 & 9,408 \\
\hline $\begin{array}{l}\text { Demanda del servicio expresada en } \\
\text { unidades de pollo beneficiado }\end{array}$ & $\mathbf{1 , 6 5 5 , 2 8 0}$ & $\mathbf{1 , 9 4 0 , 5 9 8}$ & $\mathbf{2 , 2 4 6 , 9 7 0}$ & $\mathbf{2 , 8 0 9 , 6 2 0}$ & $\mathbf{3 , 4 1 5 , 1 0 4}$ \\
\hline
\end{tabular}

Nota: Elaboración propia.

Para el primer año de operación (2018) el pronóstico de ventas se muestra de forma mensual. Para llevar esta información a nivel de detalle mensual, se ha elaborado 
una tabla de distribución de ventas expresada de forma porcentual que toma como referencia el comportamiento de las ventas mensuales de aves vivas en centros de acopio en Lima Metropolitana de los años 2014, 2015 y 2016.

Es importante mencionar que el detalle mensual permite la visibilidad de cualquier variación que pueda presentarse por efecto de la estacionalidad.

En la tabla $\mathrm{N}^{\circ} 40$ se puede visualizar el detalle de las ventas mensuales promedio de los últimos 3 años.

Tabla $N^{\circ}$ 40: Tabla de distribución de ventas

\begin{tabular}{|c|c|c|c|c|c|c|c|c|c|c|c|c|c|}
\hline Año & Ene & Feb & Mar & Abr & May & Jun & Jul & Ago & Sep & Oct & Nov & Dic & Total \\
\hline 2014 - millones de unid. & 19.1 & 18.2 & 21.0 & 19.3 & 21.6 & 21.0 & 21.1 & 21.6 & 20.3 & 20.5 & 20.6 & 22.3 & - \\
\hline 2015 - millones de unid. & 20.9 & 19.9 & 21.7 & 20.0 & 22.0 & 21.2 & 22.0 & 23.0 & 21.1 & 22.6 & 22.2 & 23.8 & - \\
\hline 2016p - millones de unid. & 21.7 & 21.7 & 21.8 & 21.3 & 21.9 & 20.4 & 21.9 & 21.9 & 21.1 & 21.4 & 20.1 & 21.3 & - \\
\hline Total [2014 - 2016] & 61.7 & 59.8 & 64.5 & 60.6 & 65.5 & 62.6 & 65.0 & 66.5 & 62.5 & 64.5 & 62.9 & 67.4 & 763.5 \\
\hline \% Distribución mensual & $8.1 \%$ & $7.8 \%$ & $8.4 \%$ & $7.9 \%$ & $8.6 \%$ & $8.2 \%$ & $8.5 \%$ & $8.7 \%$ & $8.2 \%$ & $8.4 \%$ & $8.2 \%$ & $8.8 \%$ & $100.0 \%$ \\
\hline
\end{tabular}

Nota: Adaptado de "Boletín estadístico mensual de la producción y comercialización avícola, diciembre 2015 - 2016".

Con esta tabla de distribución referencial se han inferido en forma mensual las ventas que se han pronosticado para el año 2018 utilizando como base la demanda del servicio requerida para el mismo año.

Esto se puede visualizar en la tabla $N^{\circ} 41$ y la información servirá de base para identificar el comportamiento mensual de las ventas y determinar los ingresos y costos necesarios. 
Tabla $N^{\circ}$ 41: Pronóstico de ventas mensual año 2018

\begin{tabular}{|c|c|c|c|c|c|c|c|c|c|c|c|c|}
\hline $\begin{array}{l}\text { Pronóstico de demanda } 2018 \\
\text { (unidades) }\end{array}$ & & $, 655,280$ & & & & & & & & & & \\
\hline Año & Ene & Feb & Mar & Abr & May & Jun & Jul & Ago & Sep & Oct & Nov & Dic \\
\hline \% Distribución mensual & $8.1 \%$ & $7.8 \%$ & $8.4 \%$ & $7.9 \%$ & $8.6 \%$ & $8.2 \%$ & $8.5 \%$ & $8.7 \%$ & $8.2 \%$ & $8.4 \%$ & $8.2 \%$ & $8.8 \%$ \\
\hline $\begin{array}{l}\text { Demanda mensual del servicio } \\
\text { expresada en unidades de } \\
\text { pollo beneficiado }\end{array}$ & 133,767 & 129,647 & 139,837 & 131,382 & 142,005 & 135,718 & 140,921 & 144,173 & 135,501 & 139,837 & 136,368 & 146,124 \\
\hline
\end{tabular}

Nota: Elaboración propia.

\subsection{Análisis de los riesgos y aspectos críticos que impactan en el pronóstico}

Existen una serie de factores que pueden impactar de forma negativa en el pronóstico de ventas realizado, los cuales deben ser revisados para identificar su status actual y determinar el nivel de riesgo que representa.

Estos factores se han divido en dos grupos, los factores internos que son controlados por la empresa, y los factores externos en los cuales la empresa no tiene influencia.

\section{Factores internos}

a) Gestión de marketing, aunque existe un entorno favorable para la puesta en marcha del plan de negocio, es importante el cumplimiento de las actividades de marketing que permitan posicionar el servicio en los clientes y consumidores, también que se comuniquen de forma eficiente los factores de diferenciación que presenta el servicio los mismos que garantizarían la aceptación de los clientes. Teniendo en cuenta que se trata de una empresa nueva el hecho de no hacer una 
eficiente campaña de marketing generaría el riesgo de no conseguir la utilización de la planta necesaria para operar en condiciones normales.

b) Gestión de operaciones, este factor es también relevante para la empresa ya que es necesario cumplir con la propuesta de valor que se le ha ofrecido a los clientes a través de un tratamiento adecuado del pollo por el lado de la calidad y la salubridad. La ventana horaria o el plazo de atención es un factor también importante ya que el pollo beneficiado debe de estar disponible en el puesto de mercado cuando este se aperture, entre las 6:00 am y 7:00 am. El incumplimiento de esto generaría el riesgo que los usuarios vuelvan a modelos de beneficio que utilizan en la actualidad disminuyendo la demanda del servicio.

c) Precio del servicio, Tomando en cuenta los resultados obtenidos en la encuesta y en las entrevistas a profundidad se ha establecido un precio competitivo y acorde al mercado y al servicio brindado. Sin embargo, para los clientes del CBA el precio del servicio representa su costo el cual cambia en función a la cantidad de pollo que benefician. Un precio demasiado alto generaría el riesgo de la no utilización del servicio y si el servicio es demasiado bajo, el servicio podría ser percibido también como de baja calidad.

\section{Factores externos}

a) Situación económica del país, el riesgo que se puede presentar desde el lado de la situación económica está relacionado a que Perú entre en un proceso de contracción de su economía, que traiga como consecuencia una desaceleración y pérdidas de ingresos para las compañías en general. Aunque para el Perú este año 
2017 ha sido un año difícil por los fenómenos naturales que se han vivido, existe una percepción favorable para los siguientes años debido a la fuerte inversión económica que se realizará como consecuencia al plan de reactivación del país, además es importante tener en cuenta que el Perú sigue siendo el país con mayor proyección de crecimiento de la región.

b) Situación de la industria, los CBA forman parte de la cadena de la industria de venta de pollo vivo con lo cual una contracción de ésta significaría un riesgo para el proyecto. Sin embargo, es importante mencionar que la industria avícola se encuentra estable en la actualidad y que además viene creciendo año a año.

c) Políticas gubernamentales, En la actualidad tanto el gobierno como los municipios han adoptado una posición restrictiva hacia la informalidad y se identifica también una fuerte decisión de luchar contra la insalubridad. Un cambio en estas decisiones políticas pueden generar restricciones que pondrían en riesgo la viabilidad del proyecto.

d) Precio del pollo, el sector avícola en general muestra una demanda inelástica en condiciones normales, esto quiere decir que los consumidores compran la misma cantidad de pollo ante subidas razonables en el precio. Sin embargo ante subidas desproporcionadas como consecuencia de alguna situación de crisis los consumidores optarían por el consumo de otras carnes como el pescado y cerdo entre otras. Ante una posible reducción del consumo de pollo, el CBA tendría el riesgo de reducción de su demanda. En los últimos años el precio del pollo no ha experimentado subidas desproporcionadas, salvo el último incremento transitorio que se generó como consecuencia del fenómeno del niño costero. Otro aspecto 
que se debe considerar es el precio de los commodities principalmente el maíz y la soya, alimento principal del pollo que pueden generar un incremento del precio del pollo. En la actualidad, se mantienen estables.

e) Preferencias del consumidor, el consumidor final es también un aspecto que se debe de tener en cuenta ya que de este depende la demanda del pollo y como consecuencia la demanda del servicio, en la actualidad el número de personas vegetarianas y veganas se encuentra en aumento pero en baja proporción y es una tendencia que se debe evaluar. Sin embargo el consumo de pollo sigue mostrando un incremento anual directamente relacionado al crecimiento de la población y sigue siendo el pollo la carne preferida por los consumidores en Lima Metropolitana. 


\section{CAPÍTULO VII}

\section{Ingeniería del proyecto}

En el presente capítulo se ha especificado todo el equipamiento e infraestructura necesarios para la implementación de la Peladuría Doña Viole. Se ha modelado el proceso de beneficio y pelado del pollo considerando principalmente actividades automatizadas. Quedarán algunos procesos que se realizarán de forma manual para mejorar el acabado.

Se ha diseñado el layout que tendrá la empresa considerando las áreas administrativas y de ventas así como el área de operaciones.

La distribución de la maquinaria y el tamaño de planta se han diseñado para conseguir un nivel de eficiencia óptimo con la finalidad de asegurar una producción inicial de 1,750 pollos por hora para pasar en el cuarto año a una producción de 2,500 pollos por hora.

\subsection{Estudio de ingeniería}

\subsubsection{Modelamiento y selección de procesos productivos}

La actividad principal de la Peladuría Doña Viole corresponde al beneficio de pollo. Este Macro Proceso consta de Procesos y sub procesos, los mismos que al interactuar dentro de la cadena de valor, transforma el ingreso de pollo vivo en pollo beneficiado y empacado para su distribución.

Como parte del modelo de procesamiento se han incluido las actividades de requemado y enfriamiento, estas actividades toman mucha importancia ya que 
garantizarán en el pollo beneficiado el color amarillo característico al que están acostumbrados los consumidores finales.

A continuación en la Figura $\mathrm{N}^{\circ} 23$ se detalla el Macro Proceso de beneficio de pollo junto a todos sus elementos.

Figura $N^{\circ}$ 23: Macro Proceso, procesos y sub procesos de beneficio de pollo

\begin{tabular}{|l|ll|l|}
\hline \multicolumn{1}{|c|}{ Proceso } & \multicolumn{2}{|c|}{ Sub proceso } & \multicolumn{1}{c|}{ Output } \\
\hline Recepción & $\begin{array}{l}\text { 1. Recepción } \\
\text { 2. Colgado }\end{array}$ & $\begin{array}{l}\text { Pollo colgado en línea listo para su } \\
\text { beneficio }\end{array}$ \\
\hline Beneficio & $\begin{array}{l}\text { 3. Aturdido } \\
\text { 4. Sacrificio }\end{array}$ & 7. Requemado & 8. Enfriado \\
5. Escaldado & 9. Eviscerado & Pollo beneficiado, y desplumado \\
6. Pelado & & para su empaque y despacho \\
\hline Despacho & $\begin{array}{l}\text { 9. Empaque } \\
\text { 10. Despacho }\end{array}$ & $\begin{array}{l}\text { Pollo empacado y listo para } \\
\text { despacho }\end{array}$ \\
\hline
\end{tabular}

Fuente: Elaboración propia.

A continuación gráficamente se muestra el macro proceso y cómo interactúan cada uno de los procesos que intervienen en él. 
Figura $\mathbf{N}^{\circ}$ 24: Macro proceso beneficio de pollo

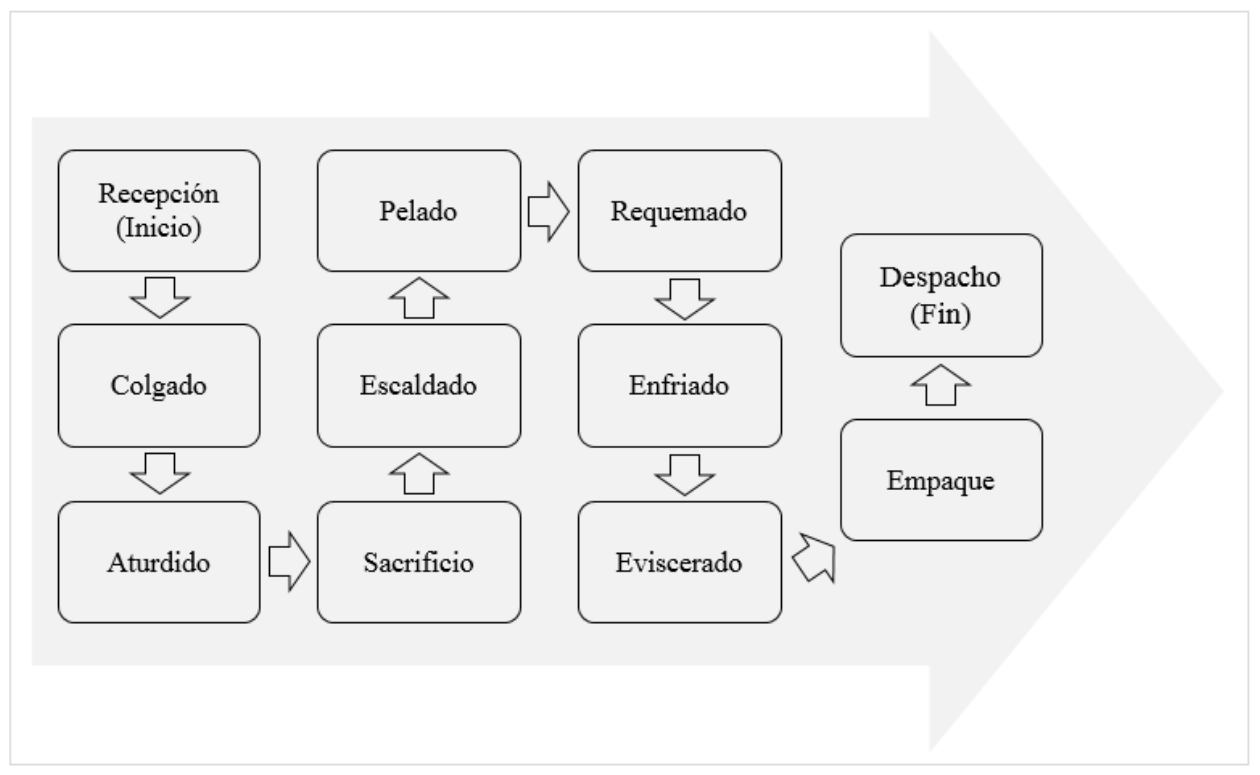

Fuente: Elaboración propia.

A continuación se detalla cada uno de los procesos, los sub procesos que lo componen, el input, la descripción del proceso y el output.

\section{$\underline{\text { Recepción }}$}

\section{1) Recepción}

\section{Input:}

Recibe de parte del cliente usuario las jabas conteniendo los pollos vivos para su beneficio.

\section{Descripción:}

- Recepción de la orden de servicio.

- Validación de la cantidad de pollo.

- Recepción de las jabas conteniendo el pollo vivo. 


\section{Output:}

Se envían al área de operaciones las jabas recepcionadas.

\section{2) Colgado}

\section{Input:}

Las jabas recepcionadas conteniendo el pollo vivo identificadas según el cliente.

\section{Descripción:}

- Los pollos se cuelgan uno a uno de las patas.

- Los pollos vivos ingresan a la línea de producción.

- Esta actividad se realiza de forma manual.

- La zona de colgado es una zona oscura, no debe de existir luz natural o eléctrica.

\section{Output:}

Los pollos vivos salen colgados hacia la línea de proceso y llegan a la máquina de aturdido. 
Figura $N^{\circ}$ 25: Fotografía del colgado de pollo vivo

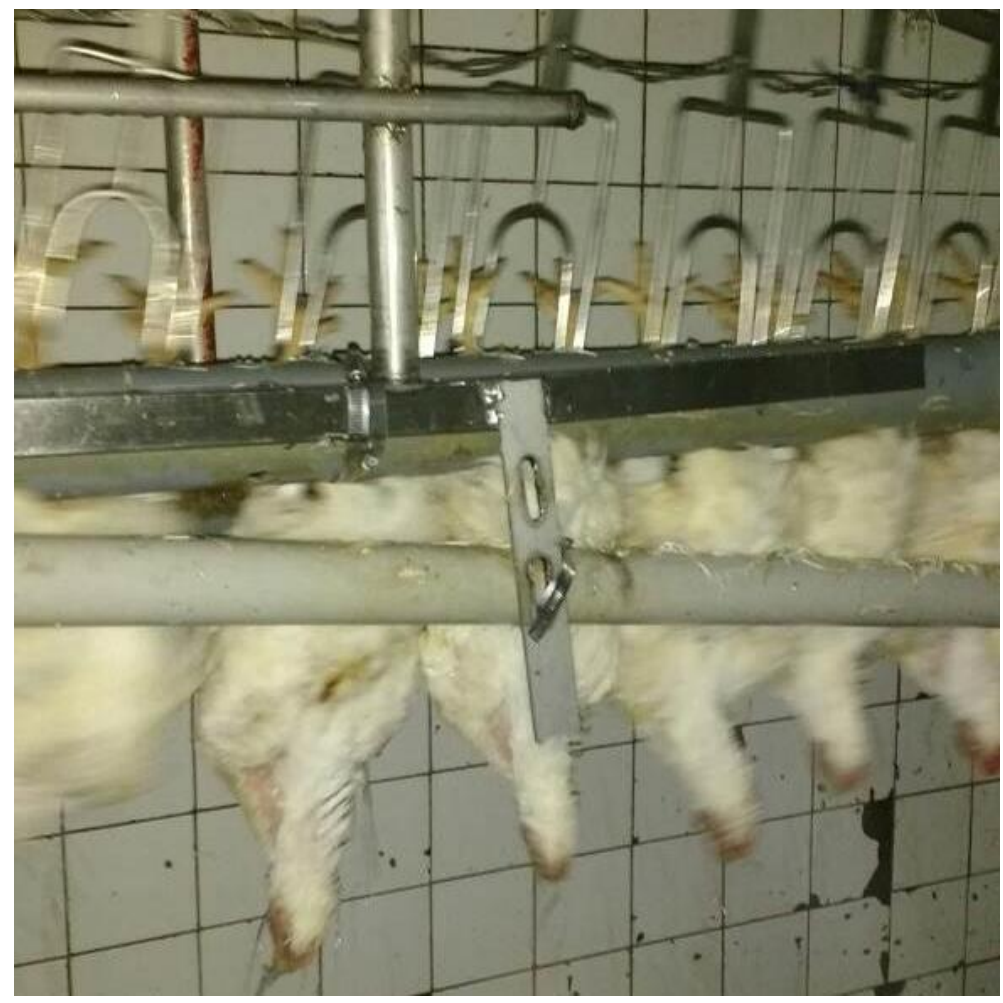

Fuente: Tomada en la planta de beneficio de la empresa San Fernando en Huaral.

\section{$\underline{\text { Beneficio }}$}

\section{3) Aturdido}

\section{Input:}

Los pollos colgados en la fase previa.

\section{Descripción:}

- Los pollos ingresan a la máquina de aturdido el mismo que contiene agua a temperatura normal.

- A través de esta máquina los pollos reciben un impulso eléctrico de 37 voltios. 
- Esta actividad se encuentra automatizada.

\section{Output:}

Los pollos aturdidos continúan la línea de proceso y llegan a la máquina de sacrificio.

Figura $\mathbf{N}^{\circ}$ 26: Fotografía de la máquina de aturdido

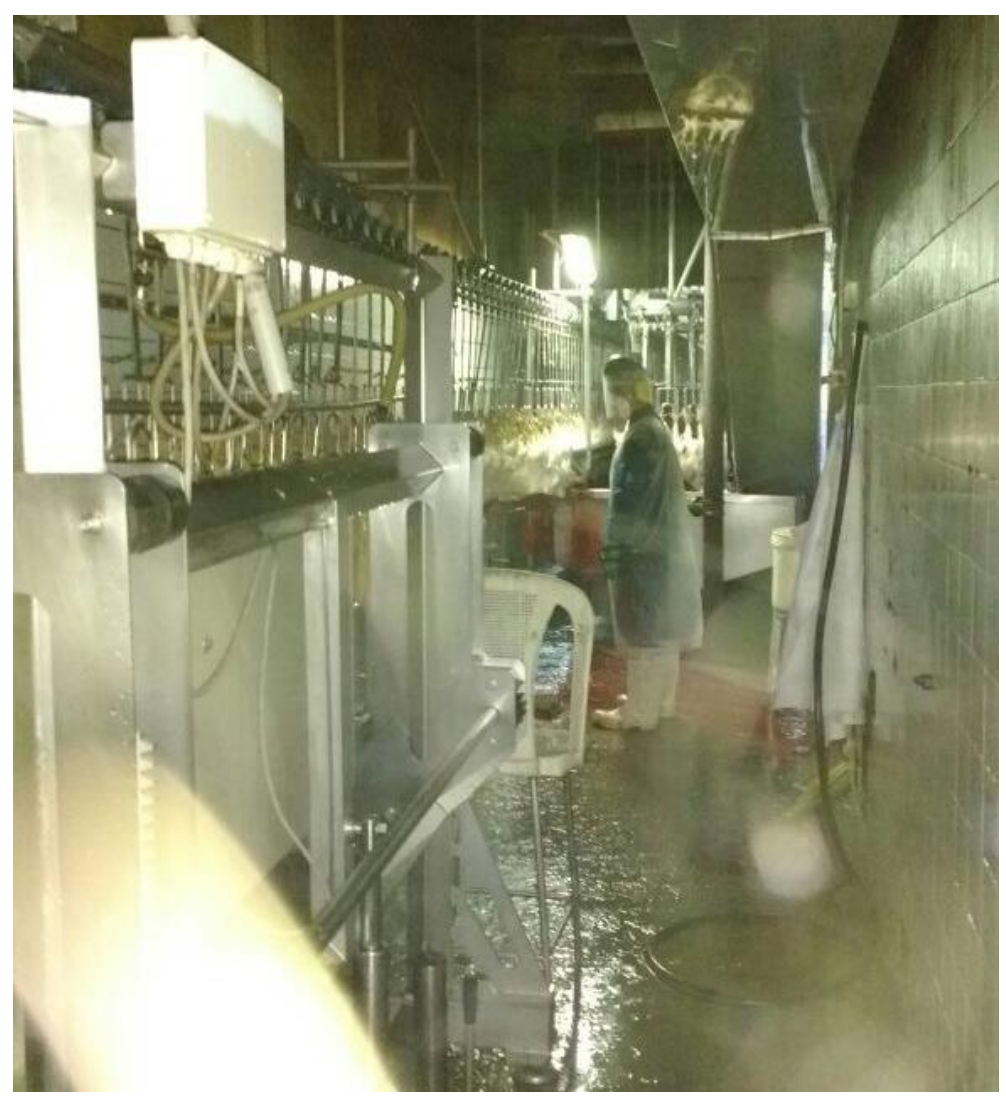

Fuente: Tomada en la planta de beneficio de la empresa San Fernando en Huaral.

\section{4) Sacrificio}

\section{Input:}

Llegan los pollos que han sido aturdidos en la fase previa. 


\section{Descripción:}

- Los pollos siguen en la línea de producción y reciben un corte en el cuello

- Inicia el proceso de desangrado con una duración no menor a 3 minutos.

- Se considera una persona validando que el corte se haya realizado de forma correcta.

- Esta actividad se encuentra automatizada.

\section{Output:}

Los pollos ya beneficiados y desangrados siguen en la línea de proceso y llegan a la máquina del escaldado. 
Figura $\mathrm{N}^{\circ}$ 27: Fotografía del proceso de sangrado

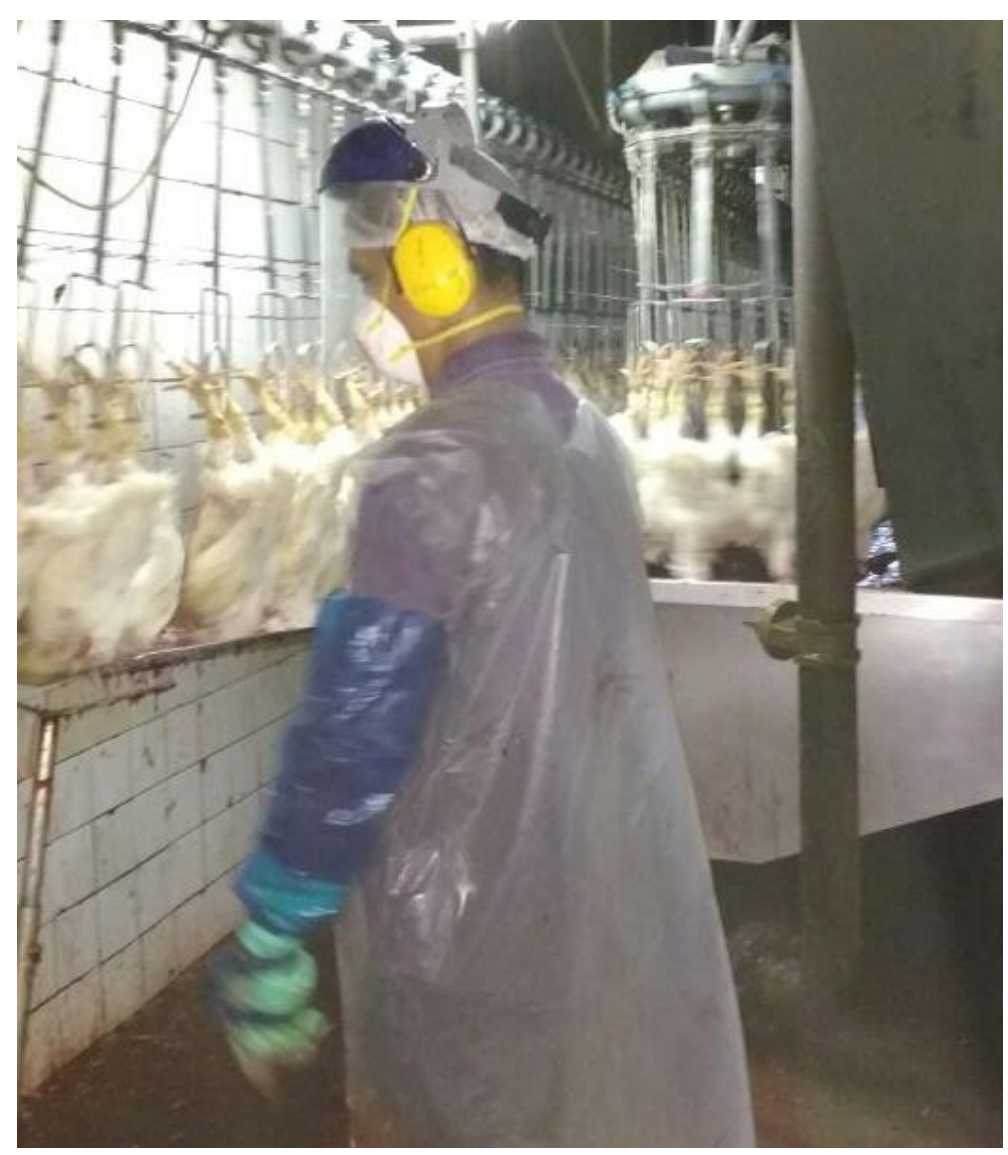

Fuente: Tomada en la planta de beneficio de la empresa San Fernando en Huaral.

\section{5) Escaldado}

\section{Input:}

Llegan los pollos beneficiados y desangrados en la fase previa.

\section{Descripción:}

- Los pollos ingresan a la máquina de escaldado la misma que contiene agua a una temperatura de $54^{\circ} \mathrm{C}$. 
- Los pollos deben permanecer dentro del agua entre 2.5 y 3.0 minutos, esto depende del tamaño del pollo pero no se debe de exceder este tiempo.

- Esta actividad se encuentra automatizada.

\section{Output:}

Los pollos escaldados siguen en la línea de proceso y llegan a la máquina del desplumado.

Figura $\mathbf{N}^{\circ}$ 28: Fotografía de la máquina del proceso de escaldado

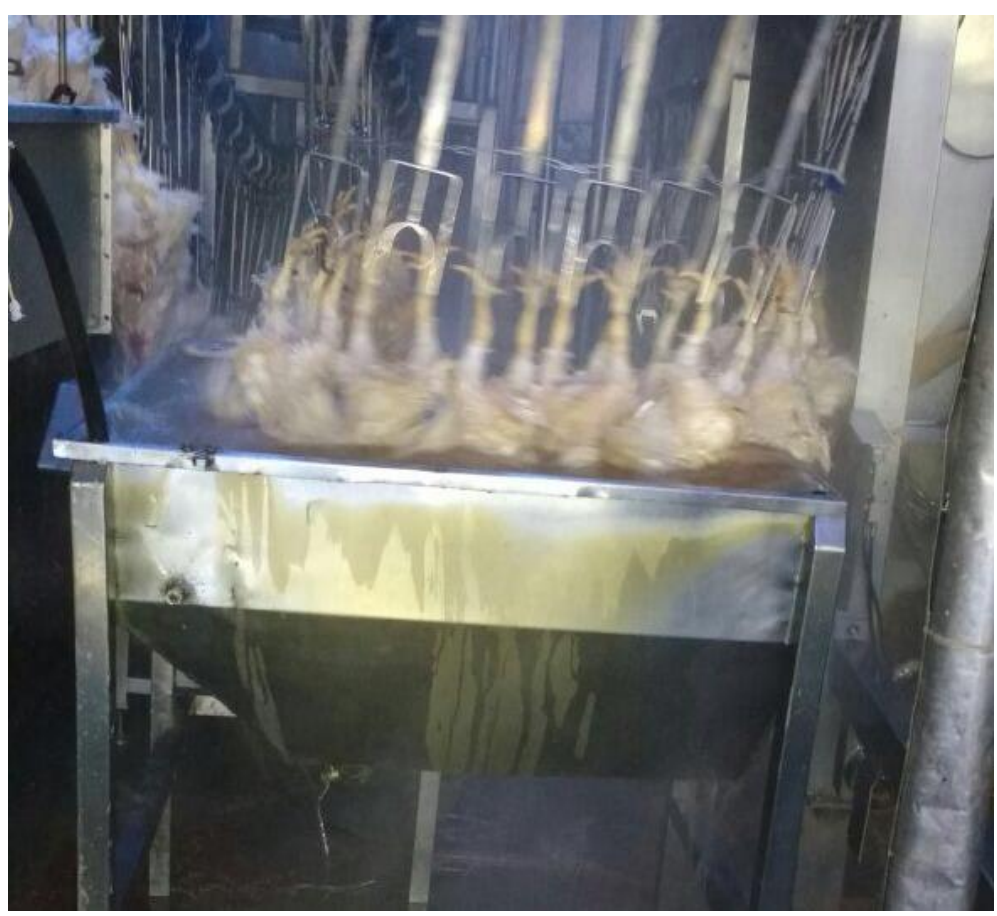

Fuente: Tomada en la planta de beneficio de la empresa San Fernando en Huaral. 


\section{6) Pelado}

\section{Input:}

Llegan los pollos que han sido escaldados en la fase previa.

\section{Descripción:}

- Los pollos ingresan a la máquina de pelado en donde a través de una tecnología de dedos mecánicos se les desprende las plumas.

- Se considera una persona validando que el pelado se haya realizado de forma correcta.

- Esta actividad se encuentra automatizada.

\section{Output:}

Los pollos pelados siguen la línea del proceso e ingresan a la máquina de requemado.

\section{Figura $\mathrm{N}^{\circ}$ 29: Fotografía exterior de la máquina del proceso de desplumado}

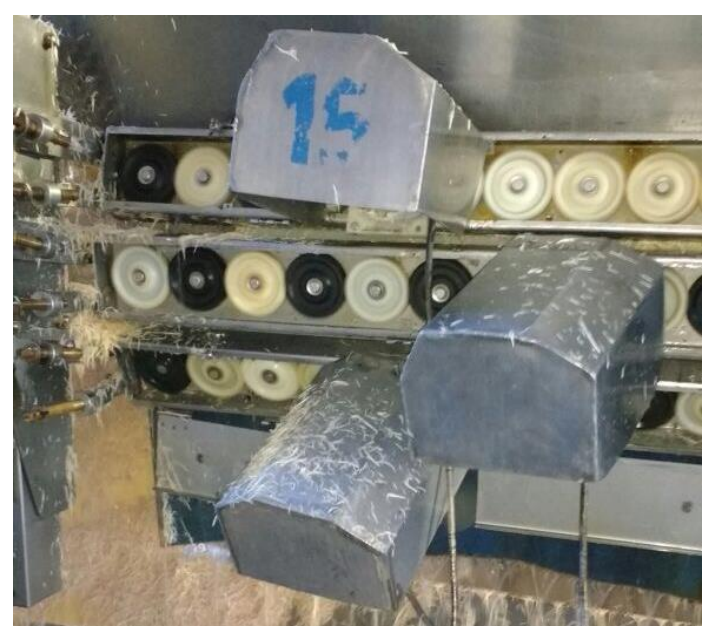

Fuente: Tomada en la planta de beneficio de la empresa San Fernando en Huaral. 
Figura $\mathrm{N}^{\circ}$ 30: Fotografía de la salida del pollo ya pelado

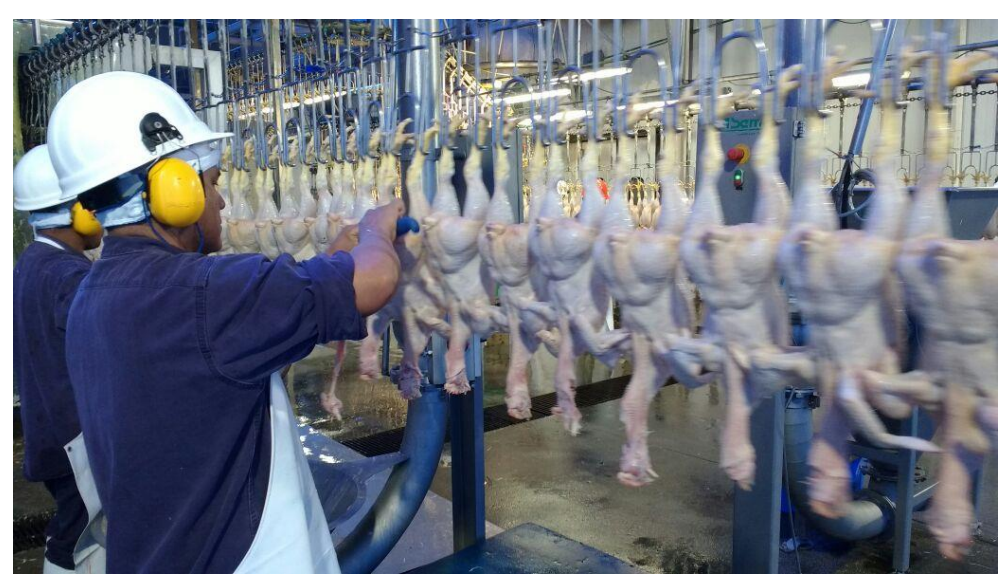

Fuente: Tomada en la planta de beneficio de la empresa San Fernando en Huaral.

\section{7) Requemado}

\section{Input:}

Llegan los pollos que han sido pelados en la fase previa.

\section{Descripción:}

- Los pollos ingresan a la máquina de repelado que contienen agua a una temperatura de $50^{\circ} \mathrm{C}$.

- Permanecen en el agua un aproximado de 1 minuto para sellar la piel y cutícula y así dar el color amarillo característico que requiere el consumidor final.

- Esta actividad se encuentra automatizada. 


\section{Output:}

Los pollos requemados siguen la línea del proceso e ingresan a la zona de enfriamiento.

Figura $N^{\circ} 31$ : Fotografía maquinaria para el requemado

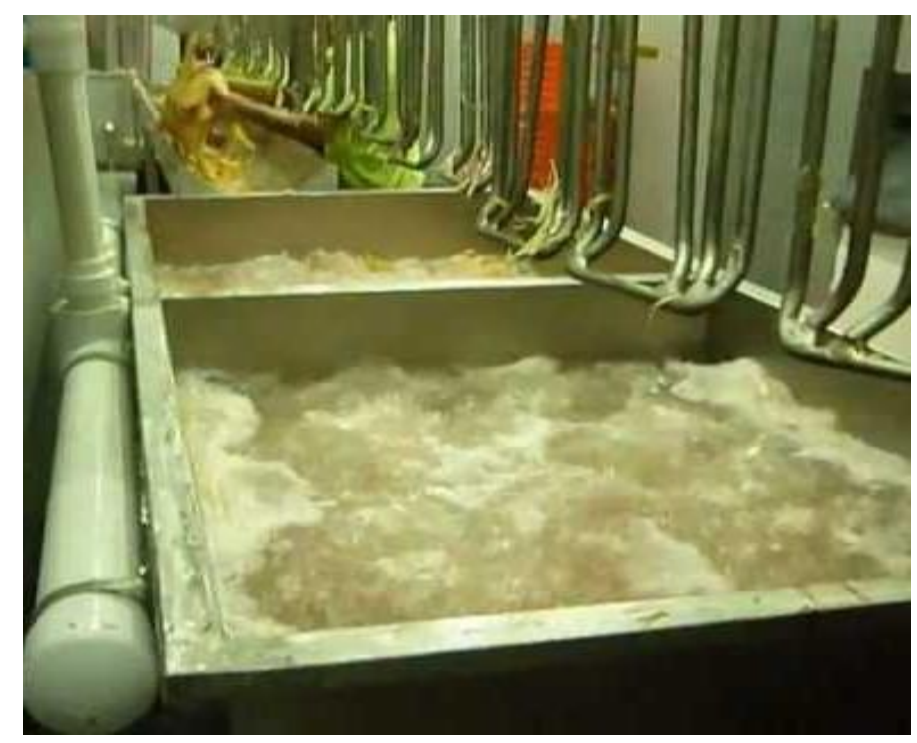

Fuente: Tomado de internet.

\section{8) Enfriado}

\section{Input:}

Llegan los pollos que han sido requemados en la fase previa.

\section{Descripción:}

- Los pollos de descuelgan de la línea e ingresan a tanques que contienen $1 \mathrm{~m}^{3}$ de agua en una temperatura de $1^{\circ} \mathrm{C}$.

- Permanecen en el agua un aproximado de 15 minutos. 
- Esta actividad es importante porque este enfriamiento permitirá alargar el tiempo de vida del producto en la mesa del picador, así como también evita la cocción de la piel del pollo y por ende su deterioro.

- Esta actividad se realiza de forma manual.

\section{Output:}

Los pollos enfriados son retirados de los tanques y son enviados a la zona de eviscerado.

\section{9) Eviscerado}

\section{Input:}

Llegan los pollos que han sido enfriados en la fase previa.

\section{Descripción:}

- Los pollos se colocan en mesas y se procede a realizar un corte en la zona abdominal.

- Se retiran los intestinos y la vesícula biliar.

- Se realiza una última limpieza del pollo con agua a temperatura normal

- Esta actividad se realiza de forma manual.

\section{Output:}

Los pollos lavados y eviscerados son enviados a la zona de empaque. 


\section{Figura $\mathbf{N}^{\circ}$ 32: Pollo eviscerado}

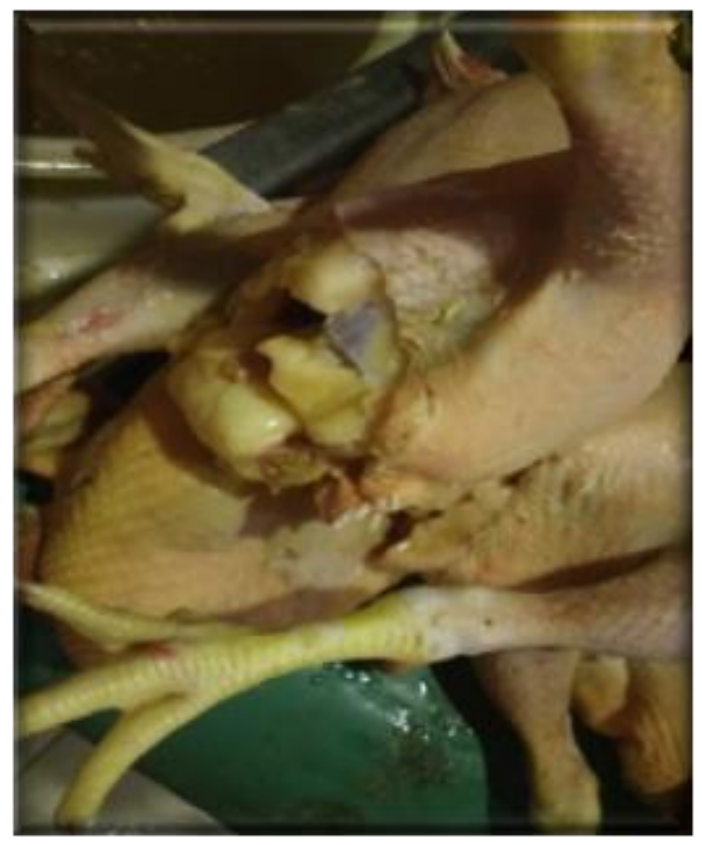

Fuente: Tomado de internet.

\section{Despacho}

\section{0) Empaque}

\section{Input:}

Llegan los pollos que han sido eviscerados y lavados en la fase previa.

\section{Descripción:}

- Los pollos son colocados en mesas y empacados en bolsas de 10 unidades.

- Cada bolsa con 10 pollos se coloca en las tinas de almacenamiento temporal.

- Esta actividad se realiza de forma manual. 


\section{Output:}

Las tinas con los pollos empacados son enviadas a la zona de despacho.

\section{1) Despacho}

\section{Input:}

Llegan las tinas con los pollos que han sido empacados en la fase previa.

\section{Descripción:}

- Se entregan los pollos empacados a los clientes de acuerdo a la orden de trabajo.

- Se sella la orden de servicio como entregada.

- Esta actividad se realiza de forma manual.

\section{Output:}

Pollos despachados.

A continuación se adjunta la Tabla $\mathrm{N}^{\circ}$ 42: Especificaciones técnicas por proceso en donde se puede observar los tiempos y condiciones necesarios para el correcto funcionamiento del proceso. 
Tabla $N^{\circ}$ 42: Especificaciones técnicas por proceso

\begin{tabular}{|c|c|c|c|c|}
\hline Proceso & Sub proceso & $\begin{array}{l}\text { Tiempo } \\
\text { estimado }\end{array}$ & Especificaciones técnicas & Output \\
\hline \multirow{2}{*}{ Recepción } & Recepción & $3 "$ & No debe existir luz natural | & \multirow{2}{*}{$\begin{array}{l}\text { Pollo colgado en la } \\
\text { línea de Beneficio }\end{array}$} \\
\hline & Colgado & $2 "$ & artificial & \\
\hline \multirow{7}{*}{ Beneficio } & Aturdido & 7" & Impulso eléctrico 37 voltios & \multirow{7}{*}{$\begin{array}{l}\text { Pollo beneficiado, } \\
\text { desplumado, } \\
\text { eviscerado y listo } \\
\text { para empaque y } \\
\text { despacho }\end{array}$} \\
\hline & Sacrificio & 3'16" & Desangrado no menor a $3 \mathrm{~min}$ & \\
\hline & Escaldado & $2^{\prime}$ & Temperatura del agua $54^{\circ} \mathrm{C}$ & \\
\hline & Pelado & $29 "$ & $\begin{array}{l}\text { Calibración correcta de los dedos } \\
\text { para impedir desgarros de la piel }\end{array}$ & \\
\hline & Requemado & 1'01" & Temperatura del agua $50^{\circ} \mathrm{C}$ & \\
\hline & Enfriado & $15^{\prime}$ & Temperatura del agua $1^{\circ} \mathrm{C}$ & \\
\hline & Eviscerado & $15^{\prime \prime}$ & $\begin{array}{l}\text { Lavado de carcasa con agua fría a } \\
\text { temperatura ambiente }\end{array}$ & \\
\hline \multirow{2}{*}{ Despacho } & Empaque & $10 "$ & $\begin{array}{l}10 \text { Pollos con patas en carcasa y } \\
\text { paquete de vísceras aparte }\end{array}$ & \multirow{2}{*}{$\begin{array}{l}\text { Pollo empacado y } \\
\text { listo para despacho }\end{array}$} \\
\hline & Despacho & $4^{\prime}$ & $\begin{array}{l}\text { De acuerdo a especificaciones } \\
\text { técnicas }\end{array}$ & \\
\hline
\end{tabular}

Nota: Adaptado de San Fernando S.A. - Jefe de operaciones de la planta de beneficio de pollos

A continuación se adjunta la Tabla $\mathrm{N}^{\circ}$ 43: Detalle de capacidad de planta en donde se puede observar las capacidades de pollo por beneficiar, mínimas y máximas por hora de la infraestructura operativa que será adquirida para el funcionamiento de planta. 
Tabla $N^{\circ}$ 43: Detalle de capacidad de planta

\begin{tabular}{cccc}
\hline $\mathbf{N}^{\circ}$ & $\begin{array}{c}\text { Área Operativa } \\
\text { - Capacidad por hora }\end{array}$ & $\begin{array}{c}\text { Capacidad } \\
\text { Mínima }\end{array}$ & $\begin{array}{c}\text { Capacidad } \\
\text { Máxima }\end{array}$ \\
\hline 11 & Transporte & 1,750 & 1,750 \\
Cadena transportadora, Curva + Reductor de & & \\
transmisión, Curva tensora, Curva de 180, & & \\
Curva de 90, Ganchos de colgado, Cadenilla & & \\
$\quad$ de arrastre de ganchos & & \\
& Equipamiento & 1,750 & 2,500 \\
$\quad$ Aturdidor & 1,750 & 2,500 \\
& Tina de sangrado & 1,750 & 2,500 \\
& Escaldador & 1,750 & 3,000 \\
& Desplumador & 1,750 & 2,500 \\
\hline & Requemador
\end{tabular}

Nota: Adaptado de San Fernando S.A. - Jefe de operaciones de la planta de beneficio de pollos y proveedor de la infraestructura.

Es importante mencionar lo siguiente:

- Para crecer en producción es necesario aumentar la cadena de transporte, el desmontaje y montaje se realiza fácilmente ya que el diseño así lo permite.

- La tecnología incluye un variador de velocidad lo que permite llegar a su máxima capacidad y recalibrase según la necesidad de producción.

En relación a las buenas prácticas de manufactura (BPM) se puede revisar en la página web del SENASA (https://www.senasa.gob.pe/) la guía de buenas prácticas avícolas (Faenamiento), para efectos del presente plan de negocio se ha realizado un extracto con sus principales características. 


\section{Guía de buenas prácticas avícolas (faenamiento)}

\begin{tabular}{|c|c|}
\hline Localización & $\begin{array}{l}\text { Los centros de faenamiento deben estar ubicados en lugares alejados } \\
\text { de cualquier foco de contaminación, que no estén expuestos a } \\
\text { inundaciones, olores desagradables, humo, polvo y/o gases; asimismo } \\
\text { su perímetro debe estar claramente delimitado. }\end{array}$ \\
\hline Vías de acceso & $\begin{array}{l}\text { Importante que estas vías tengan una superficie (piso) que no levante } \\
\text { polvo, apta para el movimiento de camiones, autos, transportes } \\
\text { internos y contenedores, para la descarga de las aves. }\end{array}$ \\
\hline $\begin{array}{l}\text { Sistema de } \\
\text { drenaje de aguas } \\
\text { residuales } \\
\text { producto de la } \\
\text { actividad }\end{array}$ & $\begin{array}{l}\text { - El establecimiento disponga de desagües y canaletas, las que } \\
\text { deben estar provistas de rejillas que sean fácilmente desmontables } \\
\text { para realizar la limpieza. } \\
\text { - Las canaletas o sistema de drenaje deben limpiarse } \\
\text { frecuentemente con agua a chorro y de manera profunda al } \\
\text { terminar cada jornada de trabajo. } \\
\text { - Las canaletas deben contar con trampas de grasa y estar cubiertas } \\
\text { con rejillas metálicas desmontables, estar limpias y en constante } \\
\text { estado de mantenimiento. } \\
\text { Implementar un sistema de disposición de residuos (plumas, } \\
\text { vísceras), mediante el uso de recipientes que permita la } \\
\text { eliminación de sus residuos líquidos, de manera que estos sean } \\
\text { fácilmente removibles del establecimiento de faenado. }\end{array}$ \\
\hline Instalaciones & $\begin{array}{l}\text { - Mantenerse en buen estado de limpieza. } \\
\text { - } \text { Mantener buena iluminación y ventilación. } \\
\text { - Estar abastecidos de agua potable en cantidad suficiente y con } \\
\text { sistemas de desagüe. } \\
\text { - Tener techos, paredes y pisos en buen estado de higiene y } \\
\text { conservación. } \\
\text { Disponer de servicios higiénicos en número suficiente y buenas } \\
\text { condiciones de operación e higiene. }\end{array}$ \\
\hline
\end{tabular}




\begin{tabular}{|c|c|}
\hline & $\begin{array}{l}\text { - Tener un área destinada a la disposición interna de los residuos } \\
\text { sólidos. } \\
\text { - Las instalaciones del centro de faenamiento deben tener una } \\
\text { distribución de zonas que evite la contaminación cruzada de los } \\
\text { productos por efecto de la circulación del personal o equipos y por } \\
\text { la proximidad de los servicios higiénicos a las salas de } \\
\text { fabricación. }\end{array}$ \\
\hline $\begin{array}{l}\text { Abastecimiento de } \\
\text { agua }\end{array}$ & $\begin{array}{l}\text { Asegurar que la calidad del agua que se usa sea potable, debiendo } \\
\text { contener niveles de } 5 \text { ppm de cloro residual a su ingreso; así mismo se } \\
\text { debe contar con una presión de flujo adecuado de agua, haciendo uso } \\
\text { de mangueras con llave de tipo pistola }\end{array}$ \\
\hline $\begin{array}{l}\text { Limpieza y } \\
\text { desinfección }\end{array}$ & $\begin{array}{l}\text { - La planta debe disponer de un programa de limpieza y } \\
\text { desinfección que será objeto de revisión y comprobación durante } \\
\text { la inspección realizada por la autoridad competente. } \\
\text { - Deben tomarse las precauciones necesarias para impedir que el } \\
\text { producto final sea contaminado cuando las áreas, equipo y } \\
\text { utensilios se limpien y desinfecten. }\end{array}$ \\
\hline $\begin{array}{l}\text { Equipos y } \\
\text { utensilios }\end{array}$ & $\begin{array}{l}\text { Los equipos deben limpiarse de manera profunda durante las } \\
\text { interrupciones principales de las operaciones y al final de la jornada. } \\
\text { Los recipientes para el depósito de sangre (canastillas, túneles u otros) } \\
\text { deben ser de material inoxidable, plástico u otro, de ser una estructura } \\
\text { de pared de concreto esta debe ser recubierta de mayólica o de algún } \\
\text { material impermeable con superficie lisa, que facilite su drenaje, y de } \\
\text { anchura suficiente para facilitar la limpieza completa. }\end{array}$ \\
\hline Capacitación & $\begin{array}{l}\text { - Los responsables de los establecimientos dedicados al } \\
\text { faenamiento de aves deben adoptar las disposiciones que sean } \\
\text { necesarias para que el personal que interviene durante las } \\
\text { actividades reciba entrenamiento adecuado y continuo sobre } \\
\text { manipulación higiénica de productos alimenticios e higiene } \\
\text { personal. }\end{array}$ \\
\hline
\end{tabular}




\begin{tabular}{|l|l|}
\hline \multirow{5}{*}{} & $\begin{array}{l}\text { Toda persona que labora en el área de faenamiento, debe lavarse } \\
\text { las manos con agua y jabón, antes de iniciar el trabajo, } \\
\text { inmediatamente después de utilizar los servicios higiénicos y de } \\
\text { manipular material sucio o contaminado así como todas las veces } \\
\text { que sea necesario. }\end{array}$ \\
\hline Contaminación & $\begin{array}{l}\text { Se entiende por contaminación cruzada, a la contaminación producida } \\
\text { cuando un proceso o producto y/o materia prima puede ser } \\
\text { contaminantes de otro proceso, producto y/o materia prima. Para } \\
\text { prevenir el riesgo de contaminación cruzada de los productos, el } \\
\text { faenamiento de las aves deberá seguir un flujo de avance en etapas } \\
\text { nítidamente separadas, desde el área sucia hacia el área limpia. }\end{array}$ \\
\hline
\end{tabular}

En relación a los requerimientos técnicos para la obtención de la licencia de funcionamiento expedida por el SENASA, esta se refiere a Autorización Sanitaria de Establecimiento de procesamiento primario que SENASA otorga (Procesamiento primario: Fase de la cadena alimenticia que se aplica a todo lo referente a una producción primaria de alimentos no sometidos a transformación. Incluye entre otros el pelado o desollado, cortado, limpiado, desgrasado) cuyo detalle puede ser observado en su página web: https://www.senasa.gob.pe/senasa/autorizacion-sanitaria/. Los requerimientos se encuentran alineados al cumplimiento de la guía de buenas prácticas avícolas (faenamiento) descritos anteriormente, es por ello que aunque la certificación se realizará en el segundo año según el plan descrito, desde el inicio de la actividad se operará con las BPM.

En relación a la política de calidad, se ha diseñado de tal forma que aseguré la inocuidad del producto final y garantice el correcto cumplimiento de la guía de BPM. 


\section{Política de calidad}

\section{Objetivo:}

La organización planifica y desarrolla los procesos necesarios para obtener productos inocuos implementando y operando para asegurar la eficacia de las actividades planificadas.

\section{Responsabilidad de gerencia y jefaturas:}

- Comprometidos para cumplir con la planificación y con los requisitos de inocuidad que requiere el producto final.

- Establecen y asignan los recursos humanos, infraestructura y ambiente de trabajo que garanticen el logro de los objetivos de calidad.

- Preparan la comunicación ante emergencias que puedan afectar la inocuidad de los productos.

- Revisan mensualmente el cumplimiento de las políticas y normas establecidas. 


\section{Tabla $N^{\circ}$ 44: Política de calidad}

\begin{tabular}{|c|c|c|}
\hline Proceso & & Normas básicas \\
\hline \multirow{3}{*}{ 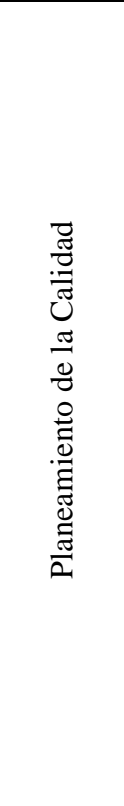 } & $\begin{array}{l}\text { Programas de Pre- } \\
\text { requisitos }\end{array}$ & $\begin{array}{l}\text { Programas y controles para cumplir con los pre- requisitos que pide la norma de BPM y } \\
\text { otras a nivel nacional. }\end{array}$ \\
\hline & $\begin{array}{c}\text { Pasos preliminares } \\
\text { para el análisis de } \\
\text { Peligros }\end{array}$ & $\begin{array}{l}\text { Formación de equipo de inocuidad con personas claves de los distintos procesos de la } \\
\text { planta que se reúne mensualmente. } \\
\text { Descripción del producto terminado, pollo beneficiado. } \\
\text { Descripción de la manipulación de acuerdo al manual BPM. } \\
\text { Diagramas de flujos de los procesos para poder analizar los peligros. }\end{array}$ \\
\hline & Análisis de peligros & $\begin{array}{l}\text { Identificación de peligros relacionados con la inocuidad y determinación de niveles } \\
\text { aceptables los mismos que estarán alineados a la guía de BPM. } \\
\text { Evaluación de peligros en función a su probabilidad y severidad. } \\
\text { Selección y evaluación de métodos de control combinando distintas medidas y evaluando } \\
\text { su eficacia. } \\
\text { Desarrollo de programa documentado (Plan HACCP análisis de peligros y puntos de } \\
\text { control) respecto a pre requisitos operativos definiendo que se controla, cuales son las } \\
\text { medidas de control, los límites críticos y acciones correctivas. } \\
\text { Actualización de información preliminar con las conclusiones de los resultados } \\
\text { obtenidos. } \\
\text { Planificación de las verificaciones y monitoreos diarios. }\end{array}$ \\
\hline Proceso & & Normas básicas \\
\hline \multirow{4}{*}{ 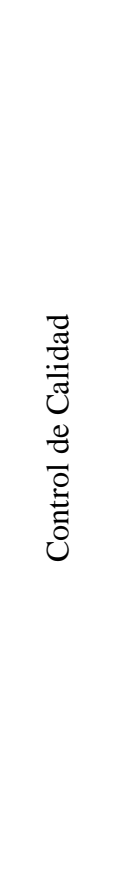 } & $\begin{array}{l}\text { Control de no } \\
\text { conformidades }\end{array}$ & $\begin{array}{l}\text { Correcciones cuando se superan los límites permitidos para el producto final se } \\
\text { identifica y se controla de acuerdo al plan. } \\
\text { Acciones correctivas establecidas cuando se superan los límites críticos del proceso o } \\
\text { cuando se pierde la conformidad. } \\
\text { Indicaciones para la manipulación de productos potencialmente no inocuos a fin de } \\
\text { impedir que lleguen al consumidor final. }\end{array}$ \\
\hline & $\begin{array}{l}\text { Validación de las } \\
\text { combinaciones de } \\
\text { medidas de control }\end{array}$ & $\begin{array}{l}\text { Que las medidas de control seleccionadas para el control son capaces de alcanzar el } \\
\text { nivel de control exigido para este proceso. } \\
\text { Las medidas de control son eficaces y permiten cuando se combinan asegurar el control } \\
\text { de peligros de inocuidad del producto final. }\end{array}$ \\
\hline & $\begin{array}{c}\text { Control de } \\
\text { seguimiento y } \\
\text { medición } \\
\end{array}$ & $\begin{array}{l}\text { Los métodos y equipos son los adecuados de acuerdo a las normas y existen controles de } \\
\text { inspección y calibración de equipos. }\end{array}$ \\
\hline & $\begin{array}{l}\text { Verificación del } \\
\text { sistema }\end{array}$ & $\begin{array}{l}\text { Auditorías Internas a intervalos planificados (cada } 2 \text { meses). } \\
\text { Evaluación de los resultados individuales y los indicadores de las verificaciones } \\
\text { planificadas. Si no alcanzan la conformidad se toman acciones para alcanzar la } \\
\text { conformidad requerida. } \\
\text { Análisis de los resultados de las verificaciones y auditorías internas. Se informa a la } \\
\text { Alta dirección respecto a ello. }\end{array}$ \\
\hline
\end{tabular}

\begin{tabular}{ccl}
\hline Proceso & & \multicolumn{1}{c}{ Normas básicas } \\
\hline & Mejora Continua & $\begin{array}{l}\text { La Alta dirección asegura que la empresa mejore continuamente sus procesos a través de } \\
\text { la comunicación, educación, revisión por la dirección y evaluación de resultados de las } \\
\text { verificaciones y auditorías. }\end{array}$ \\
\cline { 2 - 3 } & $\begin{array}{c}\text { Actualización de } \\
\text { actividades y } \\
\text { documentación }\end{array}$ & $\begin{array}{l}\text { Actualización de la guía en forma continua y cada vez que existan supuestos riesgos a } \\
\text { nivel interno así como el entorno. }\end{array}$ \\
\hline
\end{tabular}

Nota: Elaboración propia. 


\subsubsection{Selección del equipamiento}

En relación a la selección del equipamiento necesario para el inicio de las operaciones de la Peladuría Doña Viole, estos requerimientos podrán ser visualizados a detalle en el anexo $\mathrm{N}^{\circ}$ 8: Selección del equipamiento, los mismos que incluirán los siguientes ítems:

a) Infraestructura operativa.

b) Implementos para operarios.

c) Equipamiento para oficinas.

d) Utensilios para la limpieza.

e) Equipamiento para el área de despacho.

\subsubsection{Layout}

La empresa se encontrará ubicada en el distrito de San Juan de Lurigancho, el local será arrendado por el periodo de evaluación del proyecto y ya cuenta con servicios de luz, agua y desagüe, las adecuaciones adicionales serán asumidas por la empresa.

En la Figura 33, se identifica el layout de la empresa, las adaptaciones necesarias al local deberán de realizarse sobre este layout, se identifica también la infraestructura o maquinarias necesarias para la operación. 
Figura $\mathbf{N}^{\circ}$ 33: Layout de la empresa

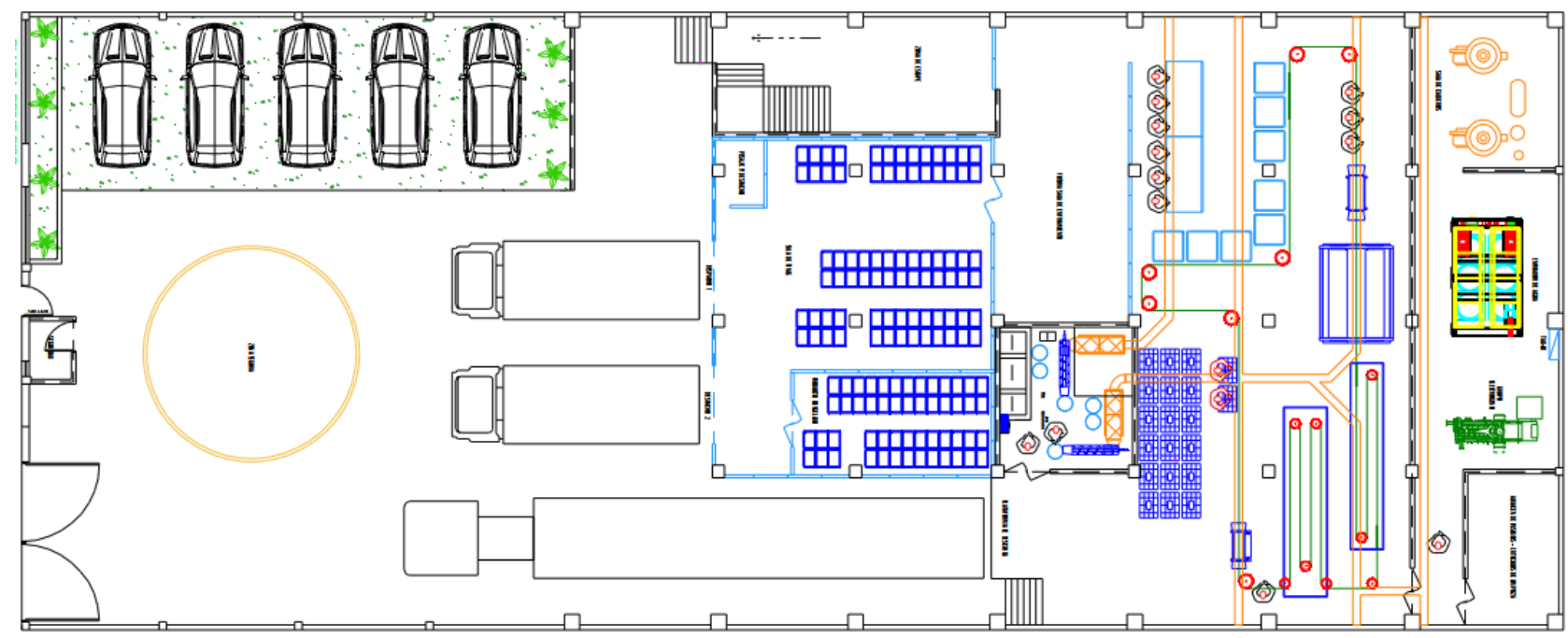

Fuente: Elaboración propia.

\subsubsection{Distribución de equipos y maquinarias}

Los equipos y maquinarias principales para el proceso de beneficio de pollo se encuentran instaladas en el área de operaciones, es aquí donde se realizan todas las actividades propias del proceso que generan como resultado final la entrega a los clientes del pollo beneficiado con BPM.

A continuación en la Figura 34 se puede identificar como se encuentra distribuida el área de operaciones y como fluye la cadena del valor del proceso desde el ingreso del pollo vivo hasta el despacho del pollo beneficiado, enfriado y empacado. 
Figura $\mathrm{N}^{\circ}$ 34: Distribución de equipos en el área de operaciones

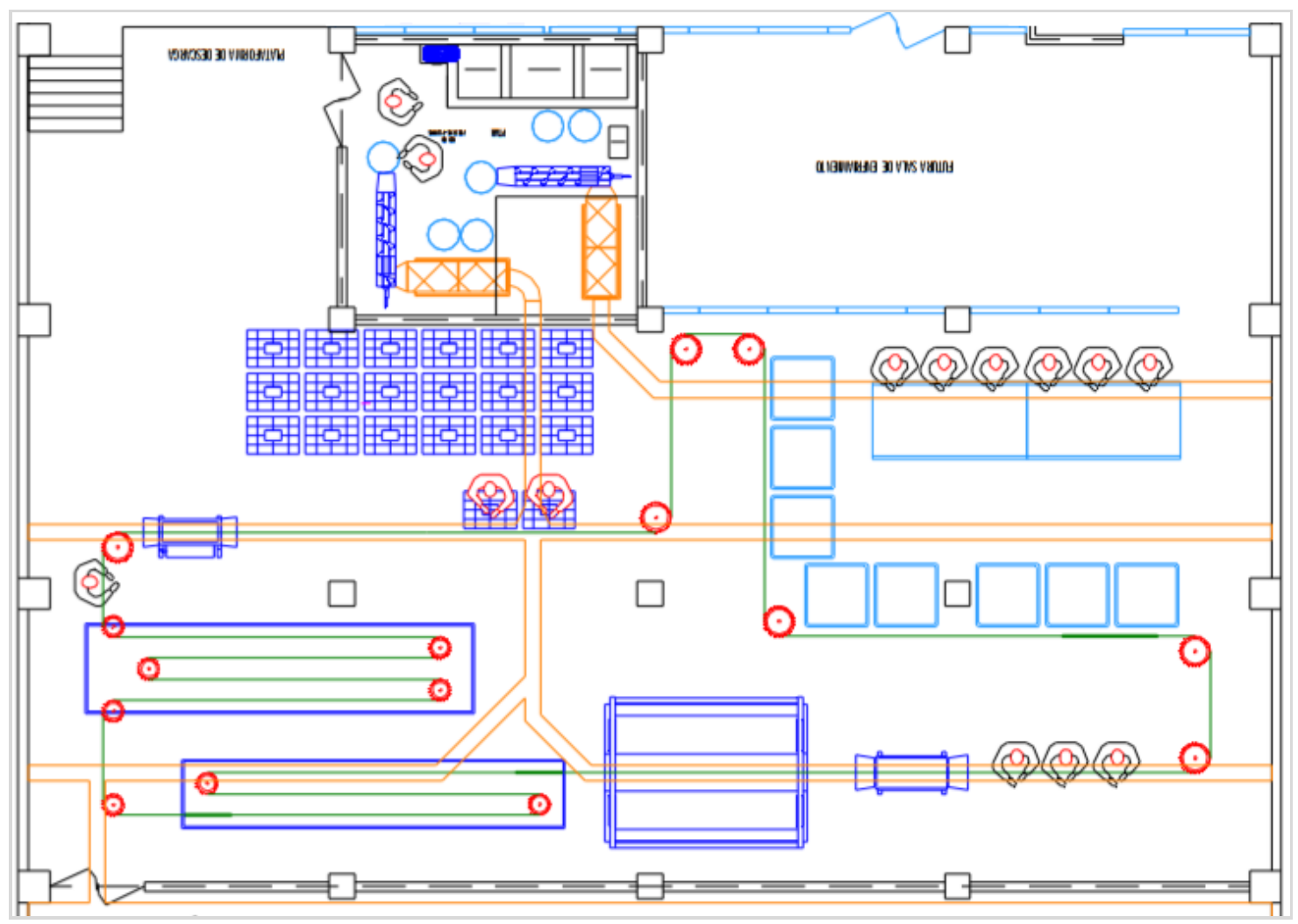

Fuente: Elaboración propia.

\subsection{Determinación del Tamaño}

\subsubsection{Proyección de crecimiento}

Para el presente plan de negocios cuyo horizonte de evaluación es de cinco años, se realizará un crecimiento en planta debido a que la demanda proyectada del servicio así lo requiere.

La planta de operaciones será aperturada con una capacidad inicial de 7,000 pollos beneficiados por día para pasar en el cuarto año a una capacidad de 10,000 pollos, este crecimiento obedece al crecimiento en la demanda del servicio y ventas, información que ha sido detallada en los capítulos Nros.4 y 6 del presente 
plan de negocios en donde se determinó tanto el mercado objetivo y su crecimiento anual, así como también los pronósticos de ventas.

\subsubsection{Recursos}

Los recursos necesarios para la operación de la Peladuría Doña Viole se han clasificado de la siguiente forma: a) Recursos para la operación, b) Recursos para el despacho, y c) Recursos para la limpieza, a continuación se realiza el detalle de estos recursos:

\section{a) Recursos para la operación}

La cantidad de recursos para la operación será proporcional a la cantidad de pollo a beneficiar de forma diaria.

\section{Tabla $N^{\circ}$ 45: Detalle de recursos para la operación}

\begin{tabular}{lrrrrr}
\hline \multicolumn{1}{c}{ Ítems / Año } & $\mathbf{2 0 1 8}$ & $\mathbf{2 0 1 9}$ & $\mathbf{2 0 2 0}$ & $\mathbf{2 0 2 1}$ & $\mathbf{2 0 2 2}$ \\
\hline Cantidad de pollo beneficiado diariamente & \multicolumn{1}{c}{4,560} & 5,346 & 6,190 & 7,740 & 9,408 \\
Corriente eléctrica (S/) - Consumo x día & 166.67 & 166.67 & 166.67 & 167.67 & 168.67 \\
Agua potable (Mts 3) - Consumo x día & 5.56 & 6.35 & 7.19 & 8.74 & 10.41 \\
Mano de obra (HH) - día & 40 & 45 & 51 & 62 & 73 \\
\hline
\end{tabular}

Nota: Elaboración propia.

La Tabla 45, ha sido elaborada tomando como referencia información proporcionada por el responsable de la empresa encargada de la venta de las maquinarias y la instalación de la misma. 


\section{b) Recursos para el despacho}

La cantidad de recursos para el despacho será proporcional a la cantidad de pollo a beneficiar de forma diaria.

Tabla $\mathbf{N}^{\circ}$ 46: Detalle de recursos para el despacho

\begin{tabular}{lrrrrr}
\hline \multicolumn{1}{c}{ Ítems / Año } & $\mathbf{2 0 1 8}$ & $\mathbf{2 0 1 9}$ & $\mathbf{2 0 2 0}$ & $\mathbf{2 0 2 1}$ & $\mathbf{2 0 2 2}$ \\
\hline Cantidad de pollo beneficiado diariamente & 4,560 & 5,346 & 6,190 & 7,740 & 9,408 \\
Bolsas para los usuarios - Conumo x día & 456 & 535 & 619 & 774 & 941 \\
Bolsas para los consumidores - Por día & 4,560 & 5,346 & 6,190 & 7,740 & 9,408 \\
Mano de obra (HH) - día & 9 & 10 & 12 & 15 & 18 \\
\hline
\end{tabular}

Nota: Elaboración propia.

\section{c) Recursos para la limpieza}

La cantidad de recursos para la limpieza son fijos, no dependen del volumen de pollos a beneficiar, En el caso de la mano de obra esta se encuentra relacionada a la actividad de operaciones.

Tabla $\mathbf{N}^{\circ}$ 47: Detalle de recursos para la limpieza

\begin{tabular}{lrrrrr}
\hline \multicolumn{1}{c}{ Ítems / Año } & $\mathbf{2 0 1 8}$ & $\mathbf{2 0 1 9}$ & $\mathbf{2 0 2 0}$ & $\mathbf{2 0 2 1}$ & $\mathbf{2 0 2 2}$ \\
\hline Cantidad de pollo beneficiado diariamente & 4,560 & 5,346 & 6,190 & 7,740 & 9,408 \\
Detergente (Kg) - Consumo x día & 6.7 & 6.7 & 6.7 & 6.7 & 6.7 \\
Desinfectante (Kg) - Consumo x día & 4.8 & 4.8 & 4.8 & 4.8 & 4.8 \\
Mano de obra (HH) - día & 29 & 34 & 40 & 49 & 60 \\
\hline
\end{tabular}

Nota: Elaboración propia. 


\subsubsection{Tecnología}

El plan de negocio no contempla programas de investigación y desarrollo tecnológico ya que la adquisición de los equipos y maquinarias necesarias para la implementación de la Peladuría Doña Viole se realizará a través de una empresa nacional relacionada al sector y que viene incursionando en este tipo de tecnología.

\subsubsection{Flexibilidad}

La flexibilidad de la Peladuría Doña Viole viene determinada por dos factores: a) Flexibilidad en el horario y b) Flexibilidad en el tipo de ave a beneficiar, a continuación se detalla cada una de ellas:

\section{a) Flexibilidad de horario de atención}

En relación a este punto, la ventana horario bajo la cual operará el CBA es de 4 horas por día, esto proporciona una capacidad instalada disponible que puede ser utilizada para asumir solicitudes adicionales que atiendan a otros mercados. Por ejemplo se podría dar cobertura a los mayoristas que tengan como clientes a las pollerías del distrito y aledaños y que cuya operación no requiera atención en horario de madrugada.

\section{b) Flexibilidad en el tipo de ave a beneficiar}

En relación a este punto, la tecnología que contempla el CBA está diseñada para beneficiar pollos. Sin embargo existe la posibilidad de cambiar 
la configuración de tiempos y temperaturas de las maquinas con la finalidad de pelar otros tipos de aves. Por ejemplo existe la alternativa de beneficiar gallinas por tratarse también de una carne muy aceptada por los consumidores limeños.

\subsubsection{Selección del tamaño ideal}

La selección del tamaño inicial de la planta ha sido realizada considerando la demanda del servicio los primeros cinco años desde la puesta en marcha del negocio.

Utilizando como referencia los hallazgos detectados en los capítulos previos se ha determinado que el tamaño ideal e inicial de planta debe permitir un beneficio diario de 7,000 pollos en una ventana horaria de 4 horas, esto significa que la línea de producción debe de procesar 1,750 pollos por hora de trabajo.

Como resultado de la evaluación cuantitativa se determinó el mercado objetivo de la Peladuría Doña Viole, y con la información relacionada a la frecuencia de utilización del servicio y la cantidad de pollo que beneficia cada cliente, se ha podido determinar el pronóstico de ventas. En la siguiente tabla se puede identificar la demanda diaria del servicio y el nivel de utilización que se tendrá entre los años 2018 y 2022. 
Tabla $N^{\circ}$ 48: Demanda diaria del servicio y nivel de utilización

\begin{tabular}{lrrrrr}
\hline \multicolumn{1}{c}{ Año } & $\mathbf{2 0 1 8}$ & $\mathbf{2 0 1 9}$ & $\mathbf{2 0 2 0}$ & $\mathbf{2 0 2 1}$ & $\mathbf{2 0 2 2}$ \\
\hline $\mathbf{N}^{\circ}$ Clientes & 8 & 9 & 10 & 12 & 14 \\
$\begin{array}{l}\text { Cantidad de pollo beneficiado } \\
\text { diariamente }\end{array}$ & 4,560 & 5,346 & 6,190 & 7,740 & 9,408 \\
$\begin{array}{l}\text { Capacidad de planta } \\
\text { Nivel de utilización de la }\end{array}$ & 7,000 & 7,000 & 7,000 & 10,000 & 10,000 \\
\hline \begin{tabular}{l} 
planta (\%) \\
\hline
\end{tabular} & $\mathbf{6 5 . 1 \%}$ & $\mathbf{7 6 . 4 \%}$ & $\mathbf{8 8 . 4 \%}$ & $\mathbf{7 7 . 4 \%}$ & $\mathbf{9 4 . 1 \%}$ \\
\hline
\end{tabular}

Nota: Elaboración propia.

Como se puede apreciar, en el año 2018 se generaría un nivel de utilización del 63.9\%, si bien es cierto este porcentaje puede considerarse bajo para una planta de beneficio automatizada, se considera aceptable en el primer año tener cierto nivel de improductividad de planta con la finalidad de atender algún tipo de demanda anormal no identificada.

En los siguientes años este nivel de utilización se incrementa llegando a 97.3\% en el quinto año, se puede observar también que en el cuarto año desde la puesta en marcha del negocio se genera un crecimiento de planta pasando de un de capacidad de 7,000 a 10,000 pollos por beneficiar diariamente.

\subsection{Estudio de localización}

Este capítulo tiene como finalidad estudiar los factores que permiten determinar la ubicación física de la Peladuría Doña Viole. En los capítulos previos se ha especificado que la empresa estará ubicada en el distrito de San Juan de Lurigancho, sin embargo es importante realizar este estudio para determinar la localización exacta dentro de éste. 


\subsubsection{Definición de factores locacionales}

Con respecto a los factores que han permitido definir la localización de la empresa, se han considerado los cinco factores más importantes:

\section{a) Accesibilidad de la zona}

Es importante estudiar el factor de accesibilidad debido a que la zona debe ser de fácil acceso al transporte, por una parte para que los empleados puedan llegar a la empresa sin inconvenientes, y por otro lado para que los clientes tengan el acceso necesario teniendo en cuenta que en muchos casos se movilizan en camiones livianos y pesados, camionetas u otros vehículos.

\section{b) Concentración de mercados}

La Peladuría Doña Viole debe de encontrarse ubicada en una zona céntrica dentro del distrito de San Juan de Lurigancho, zona que concentren una alta cantidad de mercados a su alrededor, esto debido a que las avícolas y los picadores que distribuyen el pollo beneficiado a los puestos de mercados, buscan el menor desplazamiento posible.

\section{c) Extensión del terreno/local (metros cuadrado)}

Es importante estudiar este factor debido a que la instalación de la empresa debe de realizarse sobre una superficie amplia que permita la instalación de toda la infraestructura necesaria, además se debe tener en cuenta la maniobrabilidad de los vehículos de los clientes usuarios. 


\section{d) Precio de terrenos/locales}

Es importante considerar este factor ya que el mismo tiene un impacto directo sobre los flujos económicos del proyecto, Se debe buscar la mejor alternativa de precio por metro cuadrado y cuya relación costo/beneficio sea la que más se adapte a las necesidades de la empresa.

\section{e) Seguridad de la zona}

Este factor es importante ya que impacta directamente en los empleados, en los clientes y en los activos de la empresa. De acuerdo al giro de negocio, los pagos se realizan con dinero en efectivo, con lo cual se hace necesario escoger una zona segura para reducir los riesgos por asaltos.

\section{Estudio Macro}

El CBA Doña Viole estará ubicado en el distrito de San Juan de Lurigancho. En los capítulos previos se han mencionado los motivos por el cual se ha tomado esta decisión, siendo los principales: La cantidad de pollo que se beneficia diariamente y la cantidad de personas que viven en el distrito. 


\section{Figura $\mathbf{N}^{\circ}$ 35: Plano de la macro localización de la empresa}

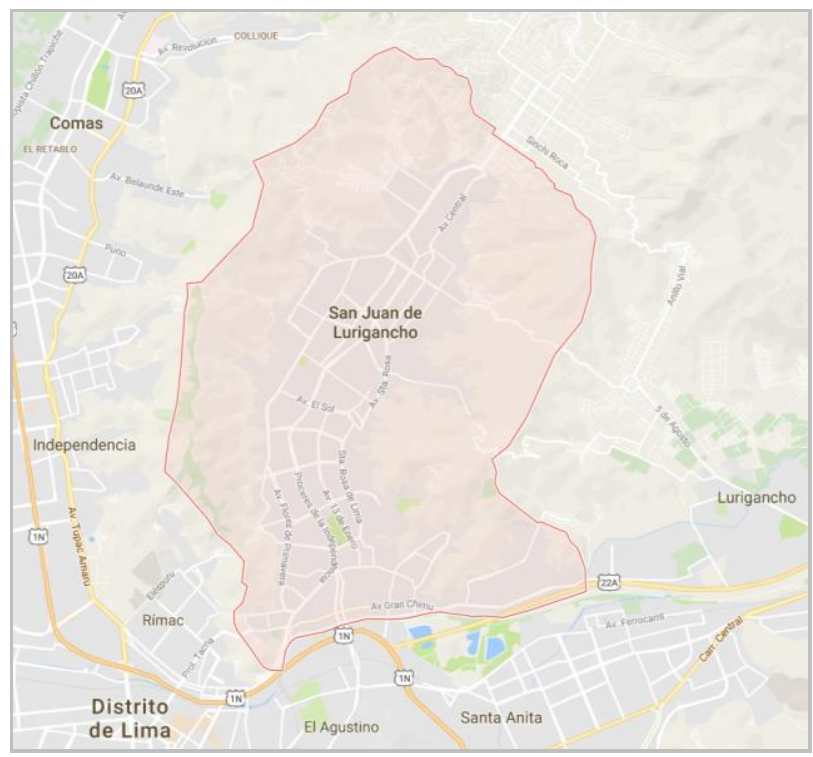

Fuente: Google Maps.

\section{Estudio Micro}

Con la finalidad de seleccionar correctamente el local donde estará ubicado la Peladuría Doña Viole, se ha utilizado el método de suma puntos, a través de este método se han evaluado los 5 factores locacionales más relevantes para el proyecto, a cada uno de ellos se le asignó un peso utilizando como referencia la experiencia de Violeta Fernandez integrante del equipo desarrollador del plan de negocio que tiene más de 27 años de experiencia en el sector.

A continuación se detallan los 5 factores locacionales más relevantes y sus respectivos pesos: 


\section{Tabla $N^{\circ}$ 49: Factores locacionales y pesos}

\begin{tabular}{clr}
\hline $\mathbf{N}^{\circ}$ & \multicolumn{1}{c}{ Factores } & Peso (\%) \\
\hline 1 & Accesibilidad de la zona & $22 \%$ \\
2 & Concentración de mercados & $33 \%$ \\
3 & Extensión del terreno/local (mt2) & $18 \%$ \\
4 & Precio del terreno/local (costo mensual) & $15 \%$ \\
5 & Seguridad de la zona & $12 \%$ \\
\hline \multicolumn{2}{c}{ Total } & $\mathbf{1 0 0 \%}$ \\
\hline
\end{tabular}

Nota: Elaboración propia.

A continuación se detallan las posibles opciones de valoración que serán asignadas a cada factor utilizando la escala de Likert siendo:

- Muy bueno: 5

- Bueno: 4

- Regula: 3

- Malo: 2

- Muy malo: 1

En la Tabla $\mathrm{N}^{\circ} 50$ se pueden identificar las tres alternativas de micro localización para la implementación de la Peladuría Doña Viole. Estas alternativas cumplen con los requisitos de ubicación y dimensiones de terreno y se encuentran disponibles en modalidad de arrendamiento.

Tabla $\mathbf{N}^{\circ}$ 50: Alternativas micro localización

\begin{tabular}{|c|c|c|c|c|}
\hline $\mathbf{N}^{\circ}$ & Factores & $\begin{array}{c}\text { Local } 1 \\
\text { Av. Los Duraznos - San } \\
\text { Juan de Lurigancho } \\
\end{array}$ & $\begin{array}{c}\text { Local 2 } \\
\text { Av. Las Lomas - Zarate }\end{array}$ & $\begin{array}{c}\text { Local 3 } \\
\text { Avenida El Sol - San } \\
\text { Juan de Lurigancho } \\
\end{array}$ \\
\hline 1 & Accesibilidad de la zona & Media & Alta & Media \\
\hline 2 & Concentración de mercados & Alta & Alta & Alta \\
\hline 3 & Extensión del terreno/local (mt2) & 2,700 & 1,410 & 1,000 \\
\hline 4 & Precio del terreno/local (costo mensual) & 34,650 & 36,886 & 17,985 \\
\hline 5 & Seguridad de la zona & Custodia del municipio & Custodia del municipio & Custodia del municipio \\
\hline
\end{tabular}

Nota: Elaboración propia. 
Con la información detallada en la Tabla $\mathrm{N}^{\circ} 49$ factores locacionales $\mathrm{y}$ pesos, se ha procedido a elaborar la matriz de localización con el método de suma puntos, esto con la finalidad de identificar el local que se ajusta más a las necesidades del CBA, ver Tabla $\mathrm{N}^{\circ} 50$.

Tabla $N^{\circ}$ 50: Matriz de localización del CBA

\begin{tabular}{|c|c|c|c|c|c|c|c|c|}
\hline \multirow[b]{2}{*}{$\mathbf{N}^{\circ}$} & \multirow[b]{2}{*}{ Factores } & \multirow[b]{2}{*}{$\begin{array}{c}\text { Peso } \\
(\%) \\
\end{array}$} & \multicolumn{2}{|c|}{ Local 1} & \multicolumn{2}{|c|}{ Local 2} & \multicolumn{2}{|c|}{ Local 3} \\
\hline & & & Valor & Pond. & Valor & Pond. & Valor & Pond. \\
\hline 1 & Accesibilidad de la zona & $22 \%$ & 3 & 0.66 & 4 & 0.88 & 3 & 0.66 \\
\hline 2 & Concentración de mercados & $33 \%$ & 4 & 1.32 & 4 & 1.32 & 4 & 1.32 \\
\hline 3 & Extensión del terreno/local (mt2) & $18 \%$ & 2 & 0.36 & 3 & 0.54 & 4 & 0.72 \\
\hline 4 & Precio del terreno/local (costo mensual) & $15 \%$ & 3 & 0.45 & 2 & 0.30 & 4 & 0.60 \\
\hline 5 & Seguridad de la zona & $12 \%$ & 3 & 0.36 & 3 & 0.36 & 3 & 0.36 \\
\hline & Total & $100 \%$ & & 3.15 & & 3.40 & & 3.66 \\
\hline
\end{tabular}

Nota: Elaboración propia.

Como se puede observar el tercer local tiene la mayor ponderación con un valor de 3.66 puntos siendo éste en donde se implementará la Peladuría Doña Viole.

\subsubsection{Consideraciones legales}

\subsubsection{Identificación del marco legal}

a) Licencias y autorizaciones

Autorización sanitaria de apertura y funcionamiento de centros de

\section{faenamiento.}


Esta autorización es emitida por SENASA y debe solicitarse completando los siguientes registros:

- REG-SCEE/PRONASA-18: Hoja de procesos para autorización sanitaria de apertura y funcionamiento de centros de acopio o faenamiento.

- REG-SCEE/PRONOSA-19: Acta de inspección de requisitos técnicos para autorización sanitaria de apertura y funcionamiento de centro de faenamiento.

- REG-SCEE/PRONASA-20: Certificado de registro de autorización sanitaria de apertura y funcionamiento de centros de faenamiento o acopio.

Los requisitos administrativos y técnicos necesarios para conseguir la autorización del SENASA se encuentran detallados y disponibles en el anexo 8: Autorización sanitaria de apertura y funcionamiento de centros de faenamiento, disponible en el presente plan de negocio.

\section{Certificado de funcionamiento de defensa civil}

Esta autorización es emitida por la municipalidad de San Juan de Lurigancho y tiene como objetivo evaluar las condiciones de seguridad existentes en los establecimientos o empresas del distrito, esto con el fin de prevenir o reducir los riesgos producidos por siniestros naturales o por causas humanas para salvaguardar la vida de las personas, y el patrimonio de las personas y el estado. 
Por el tipo de negocio, la ITSE (inspección técnica de seguridad en edificaciones) que debe solicitar el CBA corresponde a una inspección DE DETALLE, las características de esta ITSE así como los requisitos generales y específicos pueden ser revisados en el anexo 8, adjunto en al presente plan de negocio.

\section{Licencia de funcionamiento municipal}

Esta autorización es emitida por la Municipalidad de San Juan de Lurigancho y tiene como base legal la ley 28976 - Ley marco de licencias de funcionamiento, a continuación se detallan los principales requisitos exigidos:

1) Solicitud de licencia de funcionamiento, está debe de incluir:

- Número de R.U.C. y D.N.I. o carnet de extranjería del solicitante, tratándose de personas jurídicas o naturales, según corresponda.

- D.N.I. o carnet de extranjería del representante legal por tratarse de una solicitud de personas jurídica.

2) Vigencia de poder de representante legal.

3) Inspección técnica de seguridad en edificaciones, esto según corresponda (certificado de Defensa Civil).

4) Copia simple de la autorización del SENASA ya que de acuerdo a ley es necesario contar con una autorización previa al inicio de actividades. 


\section{b) Legislación laboral}

Laboralmente La Peladuría Doña Viole, estará sujeta al Régimen laboral de "Pequeña Empresa", considerando que la proyección de las ventas anuales se encuentran entre las 150 - 1700 UIT y el número de trabajadores no excederá los 100 colaboradores.

Para poder acreditarse como Pequeña Empresa, se deberá realizar la inscripción en el Registro Nacional de la Micro y Pequeña Empresa "REMYPE" a través de la página web del Ministerio de Trabajo.

Se proyecta emplear en el primer año a 30 trabajadores, quienes según la Ley MYPE tendrán los siguientes beneficios:

- Remuneración mensual.

- Jornada de 8 horas de trabajo.

- Remuneración por trabajo en sobretiempo.

- Descansos remunerados (descanso semanal, descanso vacacional de 15 días y descanso por días feriados).

- Cobertura de seguridad de salud a través de ESSALUD.

- Protección contra el despido injustificado o arbitrario (20 remuneraciones diarias por cada año completo de servicios con un máximo de 120 remuneraciones diarias).

- S.C.T.R. (Seguro complementario de trabajo de riesgo) y un Seguro de Vida a cargo del empleador (cuando corresponda).

- Derechos Colectivos. 
- Participación en las Utilidades.

- C.T.S. (15 remuneraciones diarias por año completo de servicios, hasta alcanzar un máximo de 90 remuneraciones diarias).

- Gratificaciones de Fiestas Patrias y Navidad (cada una equivalente a media remuneración).

- $\quad \mathrm{SNP}(\mathrm{ONP})$ o al SPP (AFP).

- Asignación familiar (cuando corresponda).

\section{c) Legislación tributaria}

La Peladuría Doña Viole, de acuerdo a la proyección de sus ingresos anuales, los cuales no superaran las 1,700 UIT, estará sujeta al nuevo tributario "Régimen MYPE Tributario (RMT)".

Este nuevo régimen tributario comprende:

\section{Comprobantes de pago:}

- Facturas.

- Boletas de venta.

- Todos los demás comprobantes de pago permitidos.

\section{Tributos afectos:}

- I.G.V. $18 \%$ del valor de venta, con deducción del crédito fiscal.

- Impuesto a la Renta: se aplicará la escala progresiva acumulativa 
Hasta 15 UIT $=10 \%$

Más de 15 UIT $=29.5 \%$

Se realizarán pagos a cuenta del $1.5 \%$ de los ingresos mensuales.

\section{Libros y registros contables:}

Por ingresos brutos anuales mayores a 300 UIT, se llevará la contabilidad completa, según corresponda.

- Libros, Caja y Bancos.

- Inventarios y Balances.

- Libro Diario.

- Libro Mayor.

- Registro de Compras.

- Registro de Ventas.

- Libro de retenciones (si fuese el caso).

- Libros de Registro de Activos Fijos.

- Registro de Costos.

- Registro de Inventario Permanente en unidades físicas (si fuese el caso).

- Registro de Inventario Permanente Valorizado (si fuese el caso).

- Libro de Actas.

- Libro de Matricula de Acciones (si fuese el caso). 


\subsubsection{Ordenamiento jurídico de la empresa}

Se constituirá la empresa como una Sociedad Anónima Cerrada, según la regulación en la Ley General de Sociedades 26887, con la razón social CBA Doña Viole S.A.C.

Los pasos a seguir para la constitución de la empresa son:

1) Búsqueda y reserva del nombre, verificar en SUNARP que no exista en el mercado una razón social igual o similar a la de la empresa, tras la búsqueda y verificación de la no existencia de la razón social, se procederá a realizar la reserva.

2) Elaboración de la minuta, documento en el cual se expresa ante un notario público la voluntad de los socios de constituir la empresa.

3) Apertura de cuenta bancaria a nombre de la empresa, en la cual los socios realizarán el depósito del capital social.

4) Elevar la escritura pública a SUNARP, se realiza la inscripción de la empresa en SUNARP.

Al ser inscrita la empresa como una Sociedad Anónima Cerrada, tendrá las siguientes características:

- El capital social estará compuesto por aportes en bienes dinerarios, los cuales estarán representados por acciones.

- Las acciones serán distribuidas de manera equitativa entre los socios-accionistas, personas naturales quienes también serán parte de la Junta General de Accionistas.

- El número mínimo de socios-accionistas es 2 y máximo 20. 
- Los socios no responderán personalmente por las obligaciones de la sociedad, solo se verán afectados hasta por el monto de lo que hayan aportado como capital social.

- El tiempo de duración de la empresa será indeterminado.

- No se inscribirá las acciones en el Registro Público del Mercado de Valores.

- Las acciones pueden ser vendidas de un accionista a otro sin disolver la organización empresarial.

Los órganos societarios de la empresa serán: la Junta General de Accionistas, Gerente, Sub-Gerente y el Directorio (no es obligatorio).

\subsection{Determinación de la localización óptima}

Según el estudio de micro localización realizado anteriormente, se ha determinado arrendar la tercera opción de los locales analizados, a continuación se detallan las características principales del local:

- Dirección: Avenida S/N El Sol - San Juan de Lurigancho.

- Dimensión: 1,000 mts².

- Precio mensual: S/ 17,985 inc. IGV.

- El acceso al local es el adecuado ya que este se encuentra en la zona central del distrito en donde existen varias alternativas de locales industriales. 


\section{CAPÍTULO VIII}

\section{Aspectos organizacionales}

En este capítulo se detallan los aspectos más importantes que deben considerarse para estructurar y gestionar la empresa partiendo de los aspectos culturales que la definen como son la visión, misión y los principios que la rigen para lograr comportamientos y competencias acordes a la organización.

También se formulan las estrategias de negocio y ventajas competitivas que deben guiar las operaciones de los procesos.

Se define la estructura organizacional conveniente y coherente con el modelo de gestión del negocio y los puestos y remuneraciones que acompañan a la estructura.

Finalmente se determinan las políticas adecuadas al tipo de operación que sincronicen con la cultura que se propone para esta empresa.

\subsection{Caracterización de la cultura organizacional deseada}

La Peladuría "Doña Viole" se presenta como una empresa preocupada por contar con procesos inocuos y de calidad que aseguren la salud de la familia.

Al formular la visión, se considera que el país está preocupándose cada vez más por la salud de las personas y por proporcionar una alimentación sana. Esto se evidencia en la decisión política de los organismos como SENASA y las municipalidades en decretar leyes y generar intervenciones para cerrar establecimientos que no cuenten con 
la garantía de salubridad e inocuidad en la manipulación de productos para consumo de las personas.

\subsubsection{Visión}

La visión es una declaración de lo que se quiere ser en un horizonte determinado y para ello se ha formulado lo siguiente:

"Ser reconocidos como el mejor CBA en Lima Metropolitana en el 2022, financieramente sólida, operando con las mejores prácticas de manufactura, considerado por nuestros colaboradores como un gran lugar para trabajar, preservando la inocuidad del producto final y contribuyendo al bienestar de las familias"

\subsubsection{Misión}

La misión responde a la razón de ser de la organización y atiende a los grupos de interés identificados en este proyecto:

"Brindar a las avícolas y picadores un servicio de beneficio de aves de manera rentable que permita atenderlos en los tiempos requeridos y con la calidad comprometida, con procesos y tecnología que aseguren la inocuidad del producto final y con personas que puedan desarrollarse en forma integral respetando la legislación vigente y las normas ambientales". 


\subsubsection{Principios}

Los principios con los que se pretende operar esta empresa se basan en los valores fundamentales:

\section{$\underline{\text { Valores }}$}

Honestidad: Comportarse correctamente, con honradez y siempre con la verdad.

Puntualidad: Las obligaciones y los compromisos de entrega deben ser en el tiempo acordado

Respeto: A uno mismo, a la empresa y a los demás.

Laboriosidad: Dar más allá de lo que el trabajo rutinario exige cuando sea necesario.

Compromiso: Responsabilidad en todas las actividades que se realizan, trabajando con lealtad y disciplina.

\section{$\underline{\text { Principios }}$}

Los principios con los cuales se guían las operaciones son los siguientes:

- Orientación al cliente logrando que siempre se encuentre satisfecho con lo ofrecido y excediendo sus expectativas.

- Flexibilidad adecuándose de forma rápida a los cambios que se den en los procesos propios del giro del negocio y a las innovaciones que se apliquen.

- Cumplimiento de estándares de calidad, siendo este factor no negociable en las operaciones. 


\subsection{Formulación de Estrategias del Negocio}

Los objetivos principales que se consideran para que el modelo de negocio resulte exitoso se orientan a conseguir ventajas competitivas con respecto a cualquier servicio que se presente con un modelo similar, con procesos altamente estandarizados que aseguren un servicio similar siempre y con costos competitivos logrando la combinación de la propuesta de valor de precio, calidad y entrega a tiempo.

De acuerdo a la estructura organizacional de la empresa se ha detallado la propuesta de estrategias, actividades e indicadores que aseguren el logro de los objetivos de negocio en cada gerencia de la empresa de acuerdo a la estructura organizacional propuesta.

A continuación se presenta la matriz de planificación estratégica donde se detalla lo anterior. 
Tabla $N^{\circ}$ 51: Matriz de Planificación Estratégica

\begin{tabular}{|c|c|c|c|c|c|c|}
\hline \multicolumn{7}{|c|}{ Matriz de Planificación Estratégica } \\
\hline Área & Objetivos & Estrategia & Actividades & Resultado & $\begin{array}{l}\text { Índice de } \\
\text { medición }\end{array}$ & Responsables \\
\hline \multirow[t]{4}{*}{ 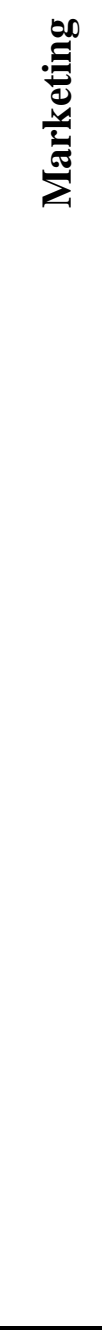 } & \multirow{4}{*}{$\begin{array}{l}\text { Conseguir } \\
\text { ventaja } \\
\text { competitiva } \\
\text { con respecto a } \\
\text { cualquier } \\
\text { servicio que se } \\
\text { presente con un } \\
\text { modelo similar }\end{array}$} & \multirow{2}{*}{$\begin{array}{l}\text { Diferenciación a } \\
\text { través de la } \\
\text { garantía e } \\
\text { inocuidad e } \\
\text { higiene durante } \\
\text { el proceso de } \\
\text { beneficio } \\
\text { contribuyendo a } \\
\text { la salud familiar }\end{array}$} & $\begin{array}{l}\text { Implementando } \\
\text { una Planta } \\
\text { automatizada y } \\
\text { certificada con } \\
\text { buenas prácticas } \\
\text { de manufactura } \\
\text { que aseguren la } \\
\text { inocuidad del } \\
\text { producto. }\end{array}$ & $\begin{array}{l}\text { Más clientes } \\
\text { que eligen } \\
\text { utilizar el } \\
\text { servicio }\end{array}$ & $\begin{array}{l}\text { Número de } \\
\text { clientes que } \\
\text { utilizan el } \\
\text { servicio }\end{array}$ & $\begin{array}{l}\text { Gerente } \\
\text { Administrativo / } \\
\text { Jefe comercial }\end{array}$ \\
\hline & & & $\begin{array}{l}\text { Obteniendo la } \\
\text { certificación de } \\
\text { BPM como } \\
\text { garantía de } \\
\text { inocuidad e } \\
\text { higiene durante el } \\
\text { proceso de } \\
\text { beneficio }\end{array}$ & $\begin{array}{l}\text { Más clientes } \\
\text { satisfechos }\end{array}$ & $\begin{array}{l}\% \text { de clientes } \\
\text { que reconocen } \\
\text { el servicio } \\
\text { diferenciado }\end{array}$ & $\begin{array}{l}\text { Gerente } \\
\text { Administrativo/ } \\
\text { Jefe Comercial }\end{array}$ \\
\hline & & \multirow{2}{*}{$\begin{array}{l}\text { Posicionamiento } \\
\text { del servicio } \\
\text { frente a la } \\
\text { competencia } \\
\text { utilizando la } \\
\text { frase: " Servicio } \\
\text { accesible, que } \\
\text { entrega un } \\
\text { producto a } \\
\text { tiempo, con la } \\
\text { mejor calidad y } \\
\text { cumpliendo con } \\
\text { las normas de } \\
\text { inocuidad } \\
\text { vigentes" }\end{array}$} & $\begin{array}{l}\text { Creando valor a } \\
\text { través de } \\
\text { atributos } \\
\text { diferenciados que } \\
\text { sean percibidos } \\
\text { como únicos: No } \\
\text { presente mal olor, } \\
\text { pollo fresco, bien } \\
\text { pelado. }\end{array}$ & \multirow{2}{*}{\begin{tabular}{|l|} 
\\
Mejor \\
recordación del \\
servicio
\end{tabular}} & $\begin{array}{l}\% \text { de Clientes } \\
\text { que } \\
\text { recomendarían } \\
\text { el servicio a sus } \\
\text { clientes finales }\end{array}$ & $\begin{array}{l}\text { Gerente } \\
\text { Administrativo / } \\
\text { Jefe comercial }\end{array}$ \\
\hline & & & \begin{tabular}{|l|} 
Implementando \\
en el proceso la \\
actividad de \\
requemado que \\
proporciona un \\
acabado similar al \\
proceso manual \\
\end{tabular} & & \begin{tabular}{|l|}
$\%$ de clientes \\
que distinguen \\
la diferencia \\
entre el acabado \\
de pollos con la \\
implementación \\
del requemado \\
\end{tabular} & Vendedores \\
\hline \multicolumn{7}{|c|}{ Matriz de Planificación Estratégica } \\
\hline \multirow[t]{2}{*}{ : } & \multirow{2}{*}{$\begin{array}{l}\text { Lograr el } \\
\text { cumplimiento } \\
\text { de las los } \\
\text { tiempos de } \\
\text { entrega del } \\
\text { servicio }\end{array}$} & $\begin{array}{l}\text { Identificar } \\
\text { principales } \\
\text { inconvenientes } \\
\text { para lograr los } \\
\text { tiempos } \\
\text { requeridos }\end{array}$ & $\begin{array}{l}\text { Revisando de todo } \\
\text { el flujo de los } \\
\text { procesos e } \\
\text { implementar } \\
\text { mejoras de } \\
\text { procesos }\end{array}$ & \multirow{2}{*}{$\begin{array}{l}\text { Cumplimiento } \\
\text { de las } \\
\text { ventanas } \\
\text { horarias } \\
\text { establecidas } \\
\text { para este } \\
\text { proceso }\end{array}$} & \multirow{2}{*}{$\begin{array}{l}\text { Número de } \\
\text { horas totales en } \\
\text { la ejecución del } \\
\text { proceso }\end{array}$} & \multirow{2}{*}{$\begin{array}{l}\text { Asistente } \\
\text { Administrativo }\end{array}$} \\
\hline & & $\begin{array}{l}\text { Diseñar los } \\
\text { nuevos } \\
\text { procesos para } \\
\text { garantizar el } \\
\text { cumplimiento } \\
\text { de las ventanas } \\
\text { horarias } \\
\end{array}$ & $\begin{array}{l}\text { Manteniendo en } \\
\text { todo el proceso } \\
\text { aquellos que } \\
\text { aseguren las } \\
\text { ventanas horarias }\end{array}$ & & & \\
\hline
\end{tabular}




\begin{tabular}{|c|c|c|c|c|c|c|}
\hline \multirow[t]{2}{*}{ 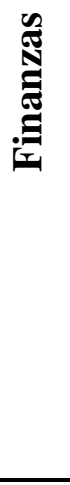 } & \multirow{2}{*}{$\begin{array}{l}\text { Garantizar la } \\
\text { sostenibilidad } \\
\text { del crecimiento } \\
\text { para el año } 2020\end{array}$} & \multirow{2}{*}{$\begin{array}{l}\text { Incrementando } \\
\text { las ventas }\end{array}$} & $\begin{array}{l}\text { Buscando nuevas } \\
\text { carteras de clientes }\end{array}$ & $\begin{array}{l}\text { Cumplimiento } \\
\text { de los } \\
\text { ingresos } \\
\text { proyectados }\end{array}$ & $\begin{array}{l}\text { Margen de } \\
\text { utilidad sobre } \\
\text { las ventas }\end{array}$ & $\begin{array}{l}\text { Gerente } \\
\text { Administrativo }\end{array}$ \\
\hline & & & $\begin{array}{l}\text { Manteniendo la } \\
\text { calidad del } \\
\text { servicio en todas } \\
\text { las partes del } \\
\text { proceso } \\
\end{array}$ & $\begin{array}{l}\text { Cumplimiento } \\
\text { de los } \\
\text { márgenes de } \\
\text { contribución y } \\
\text { flujos de caja } \\
\end{array}$ & $\begin{array}{l}\text { Flujo de caja } \\
\text { efectivo positivo }\end{array}$ & $\begin{array}{l}\text { Gerente } \\
\text { Administrativo }\end{array}$ \\
\hline \multirow[t]{3}{*}{$\underline{\underline{z}}$} & \multirow{3}{*}{$\begin{array}{l}\text { Contar con el } \\
\text { personal idóneo } \\
\text { para que cumpla } \\
\text { con el perfil de } \\
\text { acuerdo a las } \\
\text { necesidades del } \\
\text { proceso y las } \\
\text { posiciones que } \\
\text { ocupan }\end{array}$} & \multirow{3}{*}{$\begin{array}{c}\text { Asegurar la } \\
\text { especialización } \\
\text { del personal en } \\
\text { los procesos } \\
\text { diseñados }\end{array}$} & $\begin{array}{l}\text { Implementando } \\
\text { programas de } \\
\text { educación y } \\
\text { capacitación en los } \\
\text { procesos }\end{array}$ & $\begin{array}{l}\text { Mejor } \\
\text { desempeño } \\
\text { del personal a } \\
\text { todo nivel }\end{array}$ & $\begin{array}{l}\text { \% de personas } \\
\text { con desempeño } \\
\text { superior al } \\
\text { establecido }\end{array}$ & \multirow{3}{*}{$\begin{array}{l}\text { Gerente } \\
\text { Administrativo }\end{array}$} \\
\hline & & & $\begin{array}{l}\text { Relevando los } \\
\text { perfiles y } \\
\text { asegurándolos en } \\
\text { los diferentes } \\
\text { niveles }\end{array}$ & $\begin{array}{l}\text { Menor } \\
\text { rotación del } \\
\text { personal }\end{array}$ & $\begin{array}{l}\text { \% de rotación } \\
\text { semestral }\end{array}$ & \\
\hline & & & $\begin{array}{l}\text { Diseñar programa } \\
\text { de incentivos } \\
\text { grupales para } \\
\text { afianzar el trabajo } \\
\text { en equipo }\end{array}$ & $\begin{array}{l}\text { Personal } \\
\text { motivado y } \\
\text { con buen } \\
\text { clima laboral }\end{array}$ & $\begin{array}{l}\text { Índice de clima } \\
\text { laboral superior } \\
\text { al esperado }\end{array}$ & \\
\hline
\end{tabular}

Nota: Elaboración propia.

\subsection{Determinación de las ventajas competitivas críticas}

Las ventajas competitivas, como se mencionó anteriormente se basan en brindar un servicio de beneficio de aves diferenciado que materialice la estrategia.

Se ha considerado lo siguiente:

- Servicio con procesos certificados en cuanto a inocuidad del producto durante su procesamiento (BPM).

- Estándares de calidad definidos durante la manipulación del producto final.

- Enfriamiento del producto para lograr mayor durabilidad. 
- Traslado al puesto de mercado de las aves beneficiadas en forma higiénica (bolsas de polipropileno)

- Ventana horaria de 4 horas para el beneficio de las aves que asegure llegar a tiempo a los puestos de mercado.

- Flexibilidad en el servicio (capacidad de ampliar el horario de atención).

\subsection{Diseño de la estructura organizacional deseada}

El diseño organizacional define la estructura y la integración de las áreas además de la línea jerárquica lo que servirá para la definición de los roles y perfiles de los puestos.

Como lo indica Idalberto Chiavenato en su libro "Introducción a la teoría general de la administración”, el tipo de organización lineal es el indicado para una organización pequeña ya que facilita el canal de comunicación entre las áreas y delimita sus responsabilidades. Por otro lado, facilita la implementación de las estrategias planificadas mencionadas en la Matriz de Planificación Estratégica de la Figura 36 y en particular las definidas para gestión humana. Considerando ello se optará por un organigrama lineal con el fin que la interacción entre las áreas sea ágil y esto conlleve al cumplimiento de los objetivos.

Además, y tal como lo estipula el tipo de empresa (SAC), se ha determinado la composición de un Directorio integrado por los propios accionistas y contará con un Gerente Administrativo quien para esta empresa reportará al Directorio en reuniones mensuales. A continuación se presenta el siguiente organigrama: 


\section{Figura $\mathbf{N}^{\circ}$ 36: Organigrama de la Empresa}

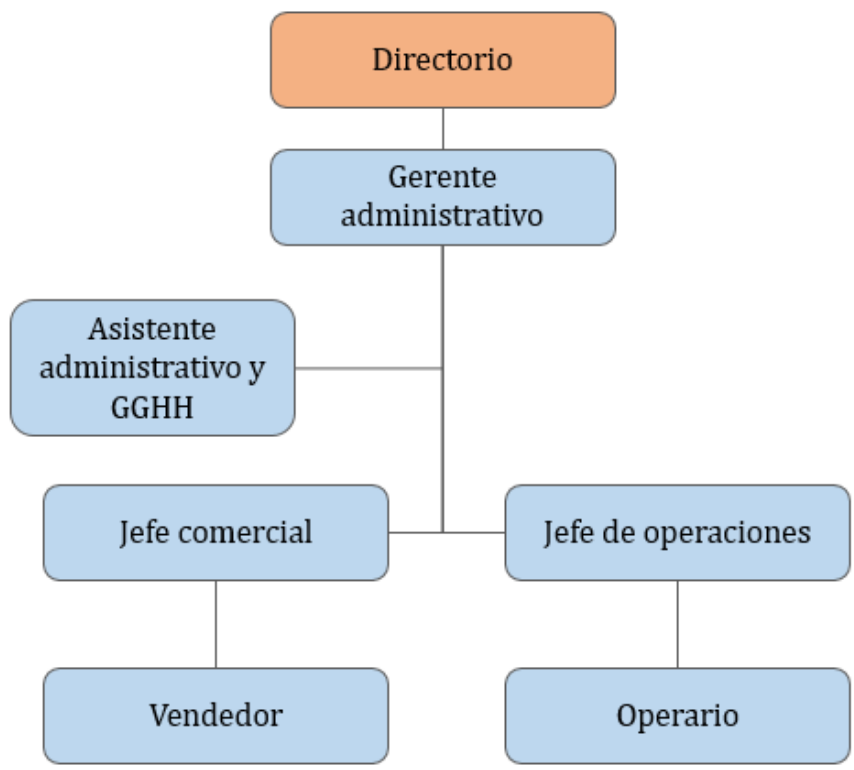

Fuente: Elaboración propia.

La empresa estará dirigida por el Gerente Administrativo quien tendrá a su cargo a los jefes del área comercial y de operaciones. Rendirá cuentas directamente a los accionistas sobre el desempeño del negocio quienes a su vez son los Directores. Adicionalmente tendrá como soporte a un asistente administrativo y de GGHH.

El Jefe del área comercial será responsable de asegurar que las estrategias comerciales se reflejen en las ventas y márgenes, logrando entre otras cosas, la fidelización de los clientes. Para ello tendrá a vendedores a su cargo con tareas comerciales específicas.

El Jefe del área de operaciones estará encargado de asegurar el correcto funcionamiento de la operación y cumplimiento de los procedimientos exigidos por las 
BPM. Tendrá a operarios a su cargo quienes estarán brindando el trabajo en toda la cadena. Este personal será la mayoría y tendrán trabajos específicos para la operación, además al tratarse de una planta de beneficio automatizada será el responsable de gestionar con los proveedores la evaluación y selección de las tendencias tecnológicas, así como las coordinaciones para los mantenimientos de planta.

El trabajo se ejecutará en la parte interna del local, cuidando las medidas de SST que sean necesarias para este rol y con los materiales e implementos necesarios para que tengan un desempeño adecuado.

Los temas contables y legales están contemplados para ser tratados con entidades terceras.

Se ha planteado un equipo de trabajo que se detalla en el cuadro adjunto para el primer año de operación, el número de operarios se incrementa en los siguientes años de forma proporcional al crecimiento de la operación:

Tabla $\mathbf{N}^{\circ}$ 52: Número de trabajadores de la empresa

\begin{tabular}{|c|c|c|c|c|c|}
\hline \multirow{2}{*}{ Descripción del puesto } & \multicolumn{5}{|c|}{$\mathbf{N}^{\circ}$ de empleados } \\
\hline & 2018 & 2019 & 2020 & 2021 & 2022 \\
\hline Gerente Administrativo & 1 & 1 & 1 & 1 & 1 \\
\hline Jefe Comercial & 1 & 1 & 1 & 1 & 1 \\
\hline Jefe de Operaciones & 1 & 1 & 1 & 1 & 1 \\
\hline Asistente Administrativo y GGHH & 1 & 1 & 1 & 1 & 1 \\
\hline Vendedores & 2 & 2 & 2 & 2 & 2 \\
\hline Operarios & 11 & 13 & 16 & 19 & 22 \\
\hline Total & 17 & 19 & 22 & 25 & 28 \\
\hline
\end{tabular}

Nota: Elaboración propia. 


\subsection{Diseño de los perfiles de puestos clave}

El perfil de los puestos claves se detalla en la ficha donde se contempla lo siguiente:

- Nombre del puesto.

- Tipo de función.

- Supervisado por.

- Supervisa a.

- Perfil del puesto.

- Funciones.

- Responsabilidades.

- Competencias.

Tabla $N^{\circ}$ 53: Perfil del Gerente Administrativo

\begin{tabular}{|l|l|}
\hline NOMBRE DEL PUESTO: & GERENTE ADMINISTRATIVO \\
\hline TIPO DE FUNCIÓN: & ADMINISTRATIVA \\
\hline SUPERVISADO POR: & DIRECTORIO \\
\hline SUPERVISA A: & JEFES COMERCIAL Y OPERACIONES \\
\hline \multicolumn{2}{|c|}{ REQUISITOS DEL PUESTO } \\
\hline
\end{tabular}

- Administrador de empresas, ingeniero industrial y afines.

- Manejo de paquetes informáticos.

- Conocimiento de legislación municipal, sanitaria.

- Alta capacidad de Liderazgo.

- Sexo masculino o femenino.

- Edad 30 años en adelante.

- Residir en la ciudad de Lima.

\section{FUNCIONES DEL PUESTO}

- Planear y desarrollar metas a corto y largo plazo junto con objetivos de desempeño y revisar las proyecciones de flujos y presupuestos.

- Administrar el flujo de caja asegurando la operatividad del negocio.

- Realizar evaluaciones periódicas acerca del cumplimiento de los indicadores de negocio y metas de los jefes comercial y de operación. 
- Revisar los estados financieros de la empresa.

- Autorizar las compras requeridas.

- Supervisar todas las actividades operativas, administrativas, contables, legales y de GGHH.

- Liderar la iniciativa para la obtención de la certificación de BPM y gestionar con las jefaturas la adaptación de las políticas.

\section{RESPONSABILIDADES DEL PUESTO}

- Será el responsable ante los entes contralores del estado, clientes y proveedores.

- Orientar a la empresa hacia el logro de sus objetivos, así como el cumplimiento de sus metas a corto y largo plazo, logrando con ello el éxito de la empresa.

- Presentar al directorio de administración los resultados obtenidos en cada periodo.

\section{COMPETENCIAS}

- Liderazgo.

- Trabajo bajo presión.

- Enfoque en resultados.

- Capacidad de negociación.

- Visión de negocio.

Nota: Elaboración propia.

Tabla $N^{\circ}$ 54: Perfil del Jefe Comercial

\begin{tabular}{|l|l|}
\hline NOMBRE DEL PUESTO: & JEFE COMERCIAL \\
\hline TIPO DE FUNCIÓN: & VENTAS \\
\hline SUPERVISADO POR: & GERENTE ADMINISTRATIVO \\
\hline SUPERVISA A: & VENDEDORES \\
\hline \multicolumn{2}{|c|}{ REQUISITOS DEL PUESTO } \\
\hline \\
- Administrador de Empresas, Marketing y carreras afines. \\
- Especialidad en Marketing o afines. \\
- Buenas relaciones interpersonales. \\
- Sexo femenino o masculino. \\
- Edad en 25 a 35 años. \\
- Experiencia mínima 2 años en puestos similares. \\
- Orientado al cumplimiento de metas. \\
- Manejo de office a nivel intermedio. \\
\hline
\end{tabular}




\section{FUNCIONES DEL PUESTO}

- Establecer objetivos y metas de ventas.

- Preparar planes para el logro de las metas.

- Administrar los recursos necesarios y disponibles para conseguir los objetivos de ventas.

- Determinar el tamaño y la estructura de la fuerza de ventas.

- Selección de vendedores.

- Elaboración de programas de recompensas a los vendedores por la consecución de las metas.

- Conocer, administrar y proponer el sistema de venta y distribución de los productos.

- Suministrar al Gerente Administrativo los informes relacionados sobre volúmenes de venta, así como cualquier inconveniente con el producto reportado por parte de los clientes.

\section{RESPONSABILIDADES DEL PUESTO}

- Responsable de la consecución de los objetivos y metas de ventas que han sido definidos en la estrategia anual.

- Responsable de todas las acciones realizadas por los vendedores del área.

- Proactividad.

- Liderazgo y trabajo en equipo.

- Orientación a la consecución de objetivos.

- Capacidad de toma de decisiones.

- Trabajo bajo presión.

- Capacidad de negociación.

Nota: Elaboración propia.

Tabla $\mathbf{N}^{\circ}$ 55: Perfil del Jefe de Operaciones

\begin{tabular}{|l|l|}
\hline NOMBRE DEL PUESTO: & JEFE DE OPERACIONES \\
\hline TIPO DE FUNCIÓN: & OPERACIONAL \\
\hline SUPERVISADO POR: & GERENTE ADMINISTRATIVO \\
\hline SUPERVISA A: & OPERARIOS \\
\hline \multicolumn{2}{|c|}{ REQUISITOS DEL PUESTO } \\
\hline \\
- Ingeniero Industrial o afines. \\
- Buenas relaciones interpersonales. \\
- Sexo femenino o masculino.
\end{tabular}


- Edad en 25 a 35 años.

- Experiencia mínima 2 años en puestos similares.

- Orientado al cumplimiento de metas.

- Manejo de office a nivel intermedio.

\section{FUNCIONES DEL PUESTO}

- Establecer objetivos y metas de producción.

- Preparar planes para el logro de las metas.

- Administrar los recursos necesarios y disponibles para conseguir los objetivos de producción.

- Determinar los puestos y funciones de los operarios.

- Selección de operarios.

- Conocer, administrar y proponer el flujo del proceso de prestación del servicio.

- Asegurar el cumplimiento de las políticas descritas en la guía de buenas prácticas avícolas (faenamiento).

- Suministrar al gerente administrativo los informes relacionados sobre volúmenes de beneficio, así como cualquier inconveniente con la calidad del servicio.

- Gestionar con los proveedores la evaluación y selección de las tendencias tecnológicas.

- Gestionar con los proveedores el mantenimiento de planta.

\section{RESPONSABILIDADES DEL PUESTO}

- Responsable de la consecución de los objetivos y metas de costos y gastos operacionales que has sido definidos en la estrategia anual.

- Responsable de todas las acciones realizadas por los operarios durante la prestación del servicio.

- Responsable de garantizar el cumplimiento de las normas que exigen los entes reguladores.

\section{COMPETENCIAS}

- Proactividad.

- Liderazgo y trabajo en equipo.

- Orientación a la consecución de objetivos.

- Capacidad de toma de decisiones.

- Trabajo bajo presión

- Capacidad de negociación

Nota: Elaboración propia. 
Tabla $N^{\circ}$ 56: Perfil del Asistente Administrativo y GGHH

\begin{tabular}{|c|c|}
\hline NOMBRE DEL PUESTO: & $\begin{array}{l}\text { ASISTENTE ADMINISTRATIVO Y } \\
\text { GGHH }\end{array}$ \\
\hline TIPO DE FUNCIÓN: & ADMINISTRATIVA \\
\hline SUPERVISADO POR: & GERENTE ADMINISTRATIVO \\
\hline SUPERVISA A: & \\
\hline \multicolumn{2}{|c|}{ REQUISITOS DEL PUESTO } \\
\hline \multicolumn{2}{|c|}{$\begin{array}{l}\text { - Sexo femenino o masculino. } \\
\text { - Edad: 20-30 años. } \\
\text { - Técnico en Administración. } \\
\text { - Manejo de Microsoft office. } \\
\text { - Excelentes relaciones humanas. } \\
\text { - Experiencia laboral mínimo } 2 \text { años. }\end{array}$} \\
\hline \multicolumn{2}{|c|}{ FUNCIONES DEL PUESTO } \\
\hline \multicolumn{2}{|c|}{$\begin{array}{l}\text { - Asistir al gerente Administrativo y a los Jefes Comercial y de Operación en } \\
\text { sus requerimientos de gestión. } \\
\text { - Elaborar reportes a la gerencia en coordinación con las Jefaturas. } \\
\text { - } \text { Recepción y envío de documentos a clientes y proveedores. } \\
\text { - Envío de comunicación interna y externa a los organismos requeridos. } \\
\text { - Llevar el control de caja chica. } \\
\text { - Brindar apoyo logístico a quien lo solicite tanto en la organización y ejecución } \\
\text { de reuniones y eventos. } \\
\text { - Convocar a las reuniones de la Gerencia Administrativa con el resto de la } \\
\text { empresa. Participa de la misma y lleva y envía el acta. } \\
\text { - Coordinación y atención de aspectos contables con proveedores. } \\
\text { - Coordinación y atención de aspectos legales con proveedores. } \\
\text { - Atender las necesidades de recursos humanos en relación a: } \\
\text { ○ Reclutamiento, selección y contratación. } \\
\text { ○ Elaboración y pago de planillas. } \\
\text { ○ Liquidaciones. } \\
\text { ○ Amonestaciones entre otros. }\end{array}$} \\
\hline \multicolumn{2}{|c|}{ RESPONSABILIDADES DEL PUESTO } \\
\hline \multicolumn{2}{|c|}{$\begin{array}{l}\text { - Responsable de dar soporte oportuno y eficiente a las distintas jefaturas de la } \\
\text { empresa. } \\
\text { - Responsable de la interacción correcta entre la gerencia de administración y el } \\
\text { resto de la empresa. }\end{array}$} \\
\hline \multicolumn{2}{|c|}{ COMPETENCIAS } \\
\hline
\end{tabular}


- Pro actividad.

- Comunicación.

- Disposición de servicio.

Nota: Elaboración propia.

Tabla $\mathbf{N}^{\circ}$ 57: Perfil del Vendedor

\begin{tabular}{|c|c|}
\hline NOMBRE DEL PUESTO: & VENDEDOR \\
\hline TIPO DE FUNCIÓN: & VENTAS \\
\hline SUPERVISADO POR: & JEFE COMERCIAL \\
\hline SUPERVISA A: & - \\
\hline \multicolumn{2}{|c|}{ REQUISITOS DEL PUESTO } \\
\hline \multicolumn{2}{|c|}{$\begin{array}{l}\text { - Carrera técnica en marketing, administración, comunicación o carreras afines. } \\
\text { - Buen nivel de comunicación. } \\
\text { - Sexo femenino o masculino. } \\
\text { - Edad en } 20 \text { a } 30 \text { años. } \\
\text { - Experiencia mínima } 1 \text { año. } \\
\text { - Orientado al cumplimiento de metas. }\end{array}$} \\
\hline \multicolumn{2}{|c|}{ FUNCIONES DEL PUESTO } \\
\hline \multicolumn{2}{|c|}{$\begin{array}{l}\text { - Captar nuevos clientes. } \\
\text { - } \text { Retener a los clientes actuales. } \\
\text { - Lograr determinados volúmenes de venta. } \\
\text { - } \text { Generar una determinada utilidad o beneficio. }\end{array}$} \\
\hline \multicolumn{2}{|c|}{ RESPONSABILIDADES DEL PUESTO } \\
\hline \multicolumn{2}{|c|}{$\begin{array}{l}\text { - Responsable de cumplir sus objetivos y metas de ventas diarias, semanales y } \\
\text { mensuales. }\end{array}$} \\
\hline \multicolumn{2}{|c|}{ COMPETENCIAS } \\
\hline \multicolumn{2}{|c|}{$\begin{array}{l}\text { - Orientación a la consecución de objetivos. } \\
\text { - Trabajo bajo presión. } \\
\text { - Proactividad } \\
\text { - Capacidad para trabajo en equipo }\end{array}$} \\
\hline
\end{tabular}

Nota: Elaboración propia. 
Tabla $\mathbf{N}^{\circ}$ 58: Perfil del Operario

\begin{tabular}{|c|c|}
\hline NOMBRE DEL PUESTO: & OPERARIOS \\
\hline TIPO DE FUNCIÓN: & OPERACIONES \\
\hline SUPERVISADO POR: & JEFE DE OPERACIONES \\
\hline SUPERVISA A: & \\
\hline \multicolumn{2}{|c|}{ REQUISITOS DEL PUESTO } \\
\hline \multicolumn{2}{|c|}{$\begin{array}{l}\text { - Haber finalizado la educación secundaria. } \\
\text { - Edad entre 19-25 años. } \\
\text { - Sexo masculino. } \\
\text { - De preferencia con experiencia en peladurías de pollos. } \\
\text { - Capacidad para trabajar bajo presión. } \\
\text { - Disponibilidad para trabajar en horario nocturno. }\end{array}$} \\
\hline \multicolumn{2}{|c|}{ FUNCIONES DEL PUESTO } \\
\hline \multicolumn{2}{|c|}{$\begin{array}{l}\text { - Encargados directos de las distintas fases de producción. } \\
\text { - Aseo y limpieza de su área de trabajo después de la jornada de labores. } \\
\text { - Reporte de problemas con la maquinaria y equipos. } \\
\text { - Identificación de oportunidades de mejora }\end{array}$} \\
\hline \multicolumn{2}{|c|}{ RESPONSABILIDADES DEL PUESTO } \\
\hline \multicolumn{2}{|c|}{$\begin{array}{l}\text { - Cumplir con las tareas encomendadas con los estándares definidos por el jefe } \\
\text { de operaciones. }\end{array}$} \\
\hline \multicolumn{2}{|c|}{ COMPETENCIAS } \\
\hline $\begin{array}{l}\text { - Responsabilidad. } \\
\text { - Comunicación. } \\
\text { - Trabajo en equipo. } \\
\text { - Flexibilidad. }\end{array}$ & \\
\hline
\end{tabular}

Nota: Elaboración propia.

\subsection{Remuneraciones, compensaciones e incentivos}

De acuerdo a la estructura propuesta se ha elaborado una escala de sueldos que van de acuerdo a la industria y al perfil que se está solicitando:

- La remuneración anual del Gerente Administrativo está prevista ser de: 
S/ 48,000.

- La remuneración anual de las Jefaturas Comercial y de Operaciones están previstas ser de: S/ 36,000.

- La remuneración anual del Asistente Administrativo y GGHH está prevista ser de: S/ 15,600.

- La remuneración anual de los vendedores está prevista ser de: S/ 12,000.

- $\quad$ La remuneración anual de los operarios está previstas ser de: S/ 13,770.

En el caso de las compensaciones, se aplicarán las legales tales como: CTS, horas extras cuando sean necesarias, remuneración extra por trabajo nocturno etc.

Los incentivos son definidos por incrementos de productividad en operarios y por mejoras comerciales en el caso de vendedores.

\subsection{Política de recursos humanos}

La política de Recursos Humanos está diseñada de acuerdo a lo permitido por ley y adicionalmente considerando que se busca tener una gestión eficaz de los recursos y ventas.

Esta política contempla lo siguiente:

\section{a. Jornada laboral}

- $\quad$ Horario laboral: son 48 horas semanales de acuerdo a ley y $35 \%$ adicionales por trabajo nocturno.

- $\quad$ Después de esas horas, se considera horas extras. 
- La jornada laboral considera los siete días de la semana y el día de descanso semanal será rotativo cada mes.

- Se llevará un control de asistencia que permita registrar los ingresos, salidas y permisos entre otros.

- $\quad$ Se contemplará la hora de refrigerio de 45 minutos.

- $\quad$ Las inasistencias serán justificadas de acuerdo a ley.

- Las vacaciones serán de acuerdo a ley y la naturaleza del negocio correspondiéndoles 15 días por año previa coordinación con las jefaturas y consensuadas entre ambas partes.

\section{b. Horario de trabajo}

Los horarios de trabajo son de acuerdo a la naturaleza del negocio y es el siguiente:

- De lunes a domingo: 2am a 10am.

\section{c. Indumentaria y materiales de trabajo}

- La empresa, de acuerdo a lo indicado por ley, proporciona la indumentaria y los EPP que se requieren para este giro de negocio.

- $\quad$ La indumentaria contempla tres juegos de uniformes. 


\section{CAPÍTULO IX}

\section{Planificación financiera}

En este capítulo se identifican y analizan las inversiones que son necesarias para poner en marcha el presente plan de negocio, se ha calculado la inversión total, la misma que ha sido desagregada en inversión pre operativa (activos tangibles e intangibles) y en capital de trabajo. Con esta información se ha calculado el costo del proyecto y si se contemplarán inversiones futuras.

Por otro lado, se ha determinado el tipo de financiamiento en el que se incurrirá y los presupuestos que lo sustentan. Finalmente, utilizando los estados financieros proyectados con un horizonte de evaluación de cinco años, tales como el balance general, el estado de pérdidas y ganancias y el flujo de caja se sustenta la factibilidad del plan de negocio.

Los montos en todos los casos están calculados en soles corrientes.

\subsection{La Inversión}

La inversión que se requiere para implementar el plan de negocio asciende a S/ 617,072 y el detalle de la misma será explicada en los puntos que siguen. A continuación se detalla la estructura de capital en donde se puede apreciar los aportes de los socios considerando que el proyecto no contempla la posibilidad de financiamiento bancario. 
Tabla $N^{\circ}$ 59: Estructura de Capital

\begin{tabular}{clccr}
\hline \multicolumn{5}{c}{ Financiamiento de la Inversión } \\
\hline $\mathbf{N}^{\circ}$ & \multicolumn{1}{c}{ Descripción } & \multicolumn{2}{c}{ Monto (S/) } & Peso (\%) \\
\hline 1 & Aporte propio & S/. & 617,072 & $100 \%$ \\
2 & Financiamiento bancario & S/. & - & $0 \%$ \\
\hline & Total & S/. & $\mathbf{6 1 7 , 0 7 2}$ & $\mathbf{1 0 0 \%}$ \\
\hline
\end{tabular}

Nota: Elaboración propia.

Como se puede observar el $100 \%$ de la estructura de capital estará comprendida por el aporte de la sociedad la cual estará conformada por 3 accionistas los mismos que tendrán el mismo nivel de participación. A continuación se detalla la distribución:

Tabla $\mathbf{N}^{\circ}$ 60: Distribución del Accionariado

\begin{tabular}{|c|c|c|c|c|}
\hline \multicolumn{5}{|c|}{ Distribución de Accionariado } \\
\hline $\mathbf{N}^{\circ}$ & Descripción & & $\mathbf{0}(\mathbf{S} /)$ & $\operatorname{Peso}(\%)$ \\
\hline 1 & Violeta Fernandez & $\mathrm{S} /$. & 205,691 & $33.3 \%$ \\
\hline 2 & Christian Gago & $\mathrm{S} /$. & 205,691 & $33.3 \%$ \\
\hline 3 & Luis Cerro & $\mathrm{S} /$. & 205,691 & $33.3 \%$ \\
\hline & Total & S/. & 617,072 & $100.0 \%$ \\
\hline
\end{tabular}

Nota: Elaboración propia.

\subsubsection{Inversión pre-operativa}

Para la puesta en marcha del plan de negocio se ha calculado incurrir en una inversión pre operativa que contempla tanto la inversión en activos tangibles como en intangibles. 
Los requerimientos que han sido contemplados en la inversión, se obtuvieron del estudio de ingeniería detallado en el capítulo $\mathrm{N}^{\circ} 7$, así como también se encuentran incluidos todos los costos que serán asumidos de manera previa al inicio de actividad, tales como las licencias de funcionamiento, constitución de la empresa, arrendamiento previo del local y sus adaptaciones, entre otros, y cuyo detalle se puede apreciar en el anexo $\mathrm{N}^{\circ} 10$ : Detalle de la inversión.

El monto total de la inversión pre operativa asciende a S/. 567,676 y se detalla en la siguiente tabla.

\section{Tabla $N^{\circ}$ 61: Inversión Pre Operativa}

\begin{tabular}{|c|c|c|c|c|c|}
\hline \multicolumn{6}{|c|}{ Estructura de Inversión } \\
\hline $\mathbf{N}^{\circ}$ & Tipo de Inversión & & to $(*)$ & $\operatorname{Peso}(\%)$ & IGV \\
\hline 1 & Activos Fijos & $\mathrm{S} /$. & 343,422 & $60 \% \mathrm{~S} /$. & 52,386 \\
\hline 2 & Activos Intangibles & $\mathrm{S} /$. & 224,254 & $40 \% \mathrm{~S} /$ & 32,154 \\
\hline & Total & $\mathrm{S} /$. & 567,676 & $100 \% \mathrm{~S} /$. & 84,541 \\
\hline
\end{tabular}

(*) Incluido el IGV

Nota: Elaboración propia.

\subsubsection{Inversión en capital de trabajo}

El giro de negocio en donde operará la empresa, es un sector de alta liquidez como consecuencia de cobrar los servicios al contado y desembolsar los costos y gastos a finales de cada mes, sin embargo considerando que se trata de una empresa nueva en donde existe una curva de aprendizaje propia del proyecto, se ha utilizado el método de máximo déficit acumulado para poder identificar las necesidades de capital de trabajo. 
El monto de la inversión en capital de trabajo asciende a $\mathbf{S}$ / 49,396 y formará parte de la inversión inicial necesaria para el proyecto.

Tabla $N^{\circ}$ 62: Detalle del Capital de Trabajo

\begin{tabular}{|c|c|c|c|c|c|c|c|c|c|c|c|c|}
\hline & Ene & Feb & Mar & Abr & May & Jun & Jul & Ago & Sep & Oct & Nov & Dic \\
\hline \multicolumn{13}{|l|}{ INGRESOS } \\
\hline Ingreso por Ventas (S/) & 32,688 & 61,018 & 90,075 & 87,169 & 90,075 & 87,169 & 90,075 & 90,075 & 87,169 & 90,075 & 87,169 & 87,169 \\
\hline Total de Ingresos (S/) & 32,688 & 61,018 & 90,075 & 87,169 & 90,075 & 87,169 & 90,075 & 90,075 & 87,169 & 90,075 & 87,169 & 87,169 \\
\hline \multicolumn{13}{|l|}{ EGRESOS } \\
\hline Costos de Producción & 49,028 & 55,088 & 55,724 & 55,253 & 55,884 & 55,556 & 60,795 & 56,104 & 55,559 & 55,776 & 55,582 & 56,190 \\
\hline Gastos Administrativos & 7,096 & 7,413 & 7,413 & 7,413 & 7,413 & 7,413 & 7,413 & 7,413 & 7,413 & 7,413 & 7,413 & 7,909 \\
\hline Gastos de Ventas & 10,815 & 12,257 & 12,216 & 12,318 & 12,233 & 12,340 & 12,277 & 12,329 & 12,361 & 12,274 & 12,318 & 12,283 \\
\hline Liquidación del IGV & 0 & 0 & 0 & 0 & 0 & 0 & 0 & 0 & 0 & 0 & 0 & 0 \\
\hline Impuesto a la Renta $1.5 \%$ & 490 & 915 & 1,351 & 1,308 & 1,351 & 1,308 & 1,351 & 1,351 & 1,308 & 1,351 & 1,308 & 1,308 \\
\hline Total de Egresos & 67,429 & 75,673 & 76,704 & 76,292 & 76,882 & 76,617 & 81,836 & 77,197 & 76,641 & 76,815 & 76,621 & 77,689 \\
\hline Saldo del Mes & $-34,741$ & $-14,655$ & 13,370 & 10,877 & 13,193 & 10,552 & 8,239 & 12,877 & 10,528 & 13,260 & 10,548 & 9,480 \\
\hline Saldo del Mes Acumulado & $-34,741$ & $-49,396$ & $-36,026$ & $-25,149$ & $-11,956$ & $-1,404$ & 6,835 & 19,712 & 30,239 & 43,499 & 54,048 & 63,527 \\
\hline
\end{tabular}

\begin{tabular}{|l|l|}
\hline Máximo déficit acumulado & $-49,396$ \\
\hline
\end{tabular}

Nota: Elaboración propia.

El detalle de las partidas que forman parte de los costos y gastos del presente proyecto son detallados en el anexo $\mathrm{N}^{\circ} 14$ : Detalle de costos y gastos. Se considera el $1.5 \%$ de las ventas como pago del impuesto a la renta y la liquidación del IGV considera el escudo fiscal generado por la inversión inicial.

\subsubsection{Costo del proyecto}

El costo del proyecto está determinado por la sumatoria de los montos en inversión pre operativa (activos tangibles e intangibles) más la inversión en capital de trabajo. La inversión total del proyecto asciende a la suma de S/ 617,072 y el resumen se puede apreciar en el siguiente cuadro. 
Tabla $N^{\circ}$ 63: Costo Total del Proyecto

\begin{tabular}{|c|c|c|c|c|c|}
\hline \multicolumn{6}{|c|}{ Estructura de Inversión } \\
\hline $\mathbf{N}^{\circ}$ & Tipo de Inversión & & to $(*)$ & Peso $(\%)$ & IGV \\
\hline 1 & Activos Fijos & $\mathrm{S} /$. & 343,422 & $56 \% \mathrm{~S} /$ & 52,386 \\
\hline 2 & Activos Intangibles & $\mathrm{S} /$. & 224,254 & $36 \% \mathrm{~S} /$ & 32,154 \\
\hline 3 & Capital de Trabajo & $\mathrm{S} /$. & 49,396 & $8 \%$ & \\
\hline & Total & $\mathrm{S} /$. & 617,072 & $100 \% \mathrm{~S} /$. & 84,541 \\
\hline
\end{tabular}

Nota: Elaboración propia.

Es importante tener en cuenta que esta inversión inicial le da al negocio un importe de S/ 84,541 de escudo fiscal por pago del IGV, este importe será utilizado en las liquidaciones y pagos futuros del IGV e incluidos en los flujos futuros.

\subsubsection{Inversiones futuras}

El presente plan de negocio contempla inversiones futuras en los años 2021 y 2022. Las inversiones adicionales se realizan en función a dos factores:

- Ampliación de planta como consecuencia del crecimiento de la demanda del servicio, en el año 2021 la planta aumenta su capacidad de beneficio de pollo diario, pasando de 7,000 a 10,000 unidades.

- Renovación de equipos de cómputo, equipos telefónicos y activos menores cuyos periodos de depreciación han finalizado

En el anexo $\mathrm{N}^{\circ} 12$ se puede identificar el detalle de la reinversión. Como se puede apreciar en la Tabla $\mathrm{N}^{\circ} 64$ se detallan los importes de las inversiones futuras. 
Tabla $N^{\circ}$ 64: Reinversiones Futuras

\begin{tabular}{cccrrrrr}
\hline \multicolumn{7}{c}{ Reinversión } \\
\hline $\mathbf{N}^{\circ}$ & Año & \multicolumn{2}{c}{ Importe } & \multicolumn{2}{c}{ IGV } & \multicolumn{2}{c}{ Total } \\
\hline 1 & 2021 & & S/. & 61,195 & S/. 11,015 & S/. & 72,210 \\
2 & 2022 & S/. & 10,351 & S/. 1,863 & S/. & 12,214 \\
\hline & Total & S/. & $\mathbf{7 1 , 5 4 6}$ & S/. & $\mathbf{1 2 , 8 7 8}$ & S/. & $\mathbf{8 4 , 4 2 4}$
\end{tabular}

Nota: Elaboración propia.

\subsection{Financiamiento}

El financiamiento considera el análisis de las condiciones del endeudamiento en el que se está incurriendo y cuál es el costo de oportunidad del capital invertido por los accionistas.

\subsubsection{Endeudamiento y condiciones}

De acuerdo a la estructura de capital mostrada anteriormente, el 100\% del capital necesario para invertir corresponde a endeudamiento que la empresa asumirá con los accionistas del proyecto. Debido a ello el presente plan no considera la posibilidad de financiamiento bancario. Esto se puede identificar en la Tabla $\mathrm{N}^{\circ}$ 60: Distribución del Accionariado.

\subsubsection{Capital y costo de oportunidad}

El costo de oportunidad del capital COK (Costo de oportunidad) se calcula para asegurar a los accionistas que la inversión ejecutada para este plan tendrá un rendimiento mínimo esperado. 
Para este cálculo se ha usado el modelo de CAPM (Capital Asset Pricing Model), cuya ecuación se basa en los rendimientos que pueden obtenerse de valores similares en el mercado de capitales y utiliza la siguiente fórmula:

$$
C O K=r f+(r m-r f) \times \beta
$$

Donde:

La tasa libre de riesgo (rf) considera el bono americano a 10 años en los periodos comprendidos entre los años [1967-2016] cuyo valor es de $\mathbf{7 . 0 8 \%}$ y la información ha sido obtenida en la página web de Damodaran disponible en: http://pages.stern.nyu.edu/ adamodar/New_Home_Page/datafile/histretSP.html

El rendimiento del mercado $(\mathrm{rm})$ considera los índices bursátiles de S\&P 500 comprendidos entre los años [1967-2016] cuyo valor es de $\mathbf{1 1 . 4 5 \%}$ y la información ha sido obtenida en la página web de Damodaran disponible en: http://pages.stern.nyu.edu/ adamodar/New_Home_Page/datafile/histretSP.html

La Beta desapalancada $(\beta)$ utiliza la referencia del sector Business \& Consumer Services, cuyo valor es de $\mathbf{0 . 8 5}$ y la información ha sido obtenida en la página web de Damodaran disponible en el siguiente enlace:

http://pages.stern.nyu.edu/ adamodar/New_Home_Page/datafile/Betas.html

Primero se calcula con la fórmula anterior el COK corriente USA.

El COK corriente USA es: $\mathbf{1 0 . 7 9 \%}$ 
Como se requiere calcular el COK real USA, se incorpora en el cálculo la inflación USA cuyo promedio de los últimos 10 años ha sido de $\mathbf{1 . 8 2 \%}$ y cuya información fue obtenida de la siguiente fuente:

http://www.es.global-rates.com/estadisticas-economicas/inflacion/indice-deprecios-al-consumo/IPC/estados-unidos.aspx

\section{EI COK real USA es: $\mathbf{8 . 8 1 \%}$}

Obtenido el COK real USA, se ajusta a Perú calculando primero el COK real Perú. Este cálculo incluye el riesgo país, se ha considerado el promedio de los últimos 4 años dando como resultado el valor de $\mathbf{1 . 7 7}$ y cuya información se ha obtenida de la siguiente fuente:

http://www.bcrp.gob.pe/estadisticas/cuadros-de-la-nota-semanal.html

\section{El COK real Perú es: $\mathbf{1 0 . 5 8 \%}$}

Para efectos del presente plan de negocio y considerando que existen diversos factores de riesgo propios del mercado, la competencia y la aceptación del servicio, se ha sumado un 6\% al COK Real Perú como parte de las exigencias de los inversionistas.

\section{El COK del proyecto es: $16.58 \%$}

Este indicador será utilizado para identificar la viabilidad económica del proyecto, a continuación se adjunta el cuadro resumen con el cálculo del COK del proyecto. 
Tabla N 64: Cálculo del COK del Proyecto

\begin{tabular}{lr}
\hline Cálculo del COK & \\
\hline Beta del proyecto (desapalancado): & 0.85 \\
COK Corriente USA: & $10.79 \%$ \\
COK Real USA: & $8.81 \%$ \\
COK Real Perú: & $10.58 \%$ \\
Riesgo del proyecto & $\mathbf{6 . 0 0 \%}$ \\
COK del proyecto & $\mathbf{1 6 . 5 8 \%}$ \\
\hline
\end{tabular}

Nota: Elaboración propia.

Se adjunta el cuadro con los datos relevantes para el cálculo del COK del proyecto.

Tabla $\mathbf{N}^{\circ}$ 65: Indicadores para cálculo del COK

\begin{tabular}{lr}
\hline \multicolumn{1}{c}{ Indicadores } & \multicolumn{1}{c}{ Dato } \\
\hline Tasa libre de riesgo $(\mathrm{rf})$ & $7.08 \%$ \\
Rendimiento del mercado $(\mathrm{rm})$ & $11.45 \%$ \\
Beta desapalancado $(\beta)$ & 0.85 \\
Riesgo país & 1.77 \\
Inflacion USA & $1.82 \%$ \\
\hline
\end{tabular}

Nota: Elaboración propia.

\subsubsection{Costo de capital promedio ponderado}

La medición del WACC no será necesaria debido a que la inversión del proyecto será asumida en un 100\% por aporte de los socios. 


\subsection{Presupuestos Base}

La formulación de los presupuestos se han realizado en base a los estudios y distintos análisis elaborados en los capítulos anteriores considerándose entre ellos el precio del servicio, los pronósticos de ventas anuales, los costos y gastos necesarios para la operación de la planta, los gastos administrativos y de ventas y otros menores.

\subsubsection{Presupuesto de ventas}

En base al estudio de mercado realizado y validando la tendencia de crecimiento del mercado a través de las entrevistas a profundidad, se ha calculado el presupuesto de ventas que considera el precio y demanda del servicio.

De acuerdo a ello los ingresos por ventas para los cinco años proyectados asciende al importe de $\mathbf{S} / \mathbf{6 , 4 5 3 , 8 4 0}$ (no incluye IGV) considerando un valor de venta unitario del servicio de $\mathbf{S}$ / $\mathbf{0 . 5 4}$ sin IGV. El detalle por año se observa en el siguiente cuadro.

Tabla $N^{\circ}$ 66: Presupuesto de Ventas

\begin{tabular}{lrrrrr}
\hline \multicolumn{1}{c}{ Servicio CBA } & \multicolumn{1}{c}{$\mathbf{2 0 1 8}$} & \multicolumn{1}{c}{$\mathbf{2 0 1 9}$} & \multicolumn{1}{c}{$\mathbf{2 0 2 0}$} & \multicolumn{1}{c}{$\mathbf{2 0 2 1}$} & \multicolumn{1}{c}{$\mathbf{2 0 2 2}$} \\
\hline Pollo beneficiado & $1,539,264$ & $1,940,596$ & $2,246,972$ & $2,809,620$ & $3,415,104$ \\
(Unid.) & 831,203 & $1,047,922$ & $1,213,365$ & $1,517,195$ & $1,844,156$ \\
\hline Ingresos por venta (S/) & 149,616 & 188,626 & 218,406 & 273,095 & 331,948 \\
IGV (S/) & 980,819 & $1,236,548$ & $1,431,771$ & $1,790,290$ & $2,176,104$ \\
Total de ingresos (S/) & & & & & \\
\hline
\end{tabular}

Nota: Elaboración propia.

Las ventas proyectadas en el primer año de operación ascienden a S/ 831,203 (sin IGV), la proyección incluye la curva de aprendizaje de los primeros 
meses ya que al tratarse de un negocio nuevo existe un periodo de adaptación que debe ser cubierto. En la tabla $\mathrm{N}^{\circ}$ 67: Presupuesto de ventas del primer año, se puede identificar dichas proyecciones en donde se visualiza el crecimiento en ventas mes a mes.

La distribución de las ventas ha sido calculadas en función al número de clientes que se captan de forma mensual, la cantidad de pollo que beneficia en promedio cada cliente y la distribución mensual de las ventas cuyo análisis ha sido realizado en el capítulo $\mathrm{N}^{\circ} 6$.

\section{Tabla $N^{\circ}$ 67: Presupuesto de ventas del primer año}

\begin{tabular}{|c|c|c|c|c|c|c|c|c|c|c|c|c|}
\hline Servicio CBA & ene-18 & feb-18 & mar-18 & abr-18 & may-18 & jun-18 & jul-18 & ago-18 & sep-18 & oct-18 & nov-18 & dic-18 \\
\hline $\mathrm{N}^{\circ}$ Clientes captados & 3 & 6 & 8 & 8 & 8 & 8 & 8 & 8 & 8 & 8 & 8 & 8 \\
\hline \% Captación de clientes & $37.5 \%$ & $75.0 \%$ & $100.0 \%$ & $100.0 \%$ & $100.0 \%$ & $100.0 \%$ & $100.0 \%$ & $100.0 \%$ & $100.0 \%$ & $100.0 \%$ & $100.0 \%$ & $100.0 \%$ \\
\hline \% Distribución de ventas & $8.1 \%$ & $7.8 \%$ & $8.4 \%$ & $7.9 \%$ & $8.6 \%$ & $8.2 \%$ & $8.5 \%$ & $8.7 \%$ & $8.2 \%$ & $8.4 \%$ & $8.2 \%$ & $8.8 \%$ \\
\hline $\begin{array}{l}\text { Pollo beneficiado } \\
\text { (Unid.) }\end{array}$ & 50,162 & 97,236 & 139,837 & 131,382 & 142,005 & 135,718 & 140,921 & 144,173 & 135,501 & 139,837 & 136,368 & 146,124 \\
\hline Ingresos por venta $(\mathrm{S} /)$ & 27,702 & 51,710 & 76,334 & 73,872 & 76,334 & 73,872 & 76,334 & 76,334 & 73,872 & 76,334 & 73,872 & 73,872 \\
\hline $\mathrm{IGV}(\mathrm{S} /)$ & 4,986 & 9,308 & 13,740 & 13,297 & 13,740 & 13,297 & 13,740 & 13,740 & 13,297 & 13,740 & 13,297 & 13,297 \\
\hline Total de ingresos $(\mathrm{S} /)$ & 32,688 & 61,018 & 90,075 & 87,169 & 90,075 & 87,169 & 90,075 & 90,075 & 87,169 & 90,075 & 87,169 & 87,169 \\
\hline \multicolumn{2}{|c|}{ Ventas primer año } & \multicolumn{2}{|c|}{ Cant. } & \% Cump. & & & & & & & & \\
\hline \multicolumn{2}{|c|}{ Ventas anuales sin curva de aprendizaje } & \multicolumn{2}{|c|}{$1,655,280$} & $100 \%$ & & & & & & & & \\
\hline \multicolumn{2}{|c|}{ Ventas anuales con curva de aprendizaje } & \multicolumn{2}{|c|}{$1,539,264$} & $93 \%$ & & & & & & & & \\
\hline
\end{tabular}

Nota: Elaboración propia.

\subsubsection{Presupuesto de costos de producción}

Para calcular los costos de producción no se contempla el costo de Materia Prima debido a que este plan es para la implementación de un servicio. Sí considera la mano de obra directa y los costos indirectos que son asociados a la entrega del servicio y cuyas características del proceso productivo han sido detallados en el Capítulo $\mathrm{N}^{\circ}$ 7. El presupuesto incluye también las depreciaciones 
(estas no generan desembolso monetario pero impactan en los estados financieros) de cada periodo relacionadas a los activos del área de operaciones, el detalle se puede ver en el anexo $\mathrm{N}^{\circ} 11$ : Detalle de depreciaciones y amortizaciones.

El costo unitario se obtiene al dividir el costo total entre la demanda del servicio. Los valores obtenidos son de S/ 0.41 y disminuye hasta S/ 0.28 en el año 2022. En el siguiente cuadro se identifica el detalle de los costos de producción,

\section{Tabla $\mathbf{N}^{\circ}$ 68: Presupuesto de Costos de Producción}

\begin{tabular}{lrrrrr}
\hline \multicolumn{7}{c}{ Proyección de Costos de producción } \\
\multicolumn{1}{c}{ Servicio CBA } & $\mathbf{2 0 1 8}$ & $\mathbf{2 0 1 9}$ & $\mathbf{2 0 2 0}$ & $\mathbf{2 0 2 1}$ & \multicolumn{1}{c}{$\mathbf{2 0 2 2}$} \\
\hline Costo de materia prima & & & & & \\
Costo de mano de obra directa & 190,347 & 224,956 & 276,869 & 328,782 & 380,695 \\
Costos indirectos de fabricación & & & & & \\
Materia prima indirecta & 92,356 & 116,436 & 134,818 & 168,577 & 204,906 \\
Mano de obra indirecta & 45,240 & 45,240 & 45,240 & 45,240 & 45,240 \\
Otros CIF & 278,303 & 288,671 & 290,897 & 294,170 & 299,403 \\
Depreciaciones del periodo & 29,522 & 29,522 & 29,522 & 34,721 & 34,721 \\
\hline Total & $\mathbf{6 3 5 , 7 6 8}$ & $\mathbf{7 0 4 , 8 2 4}$ & $\mathbf{7 7 7 , 3 4 6}$ & $\mathbf{8 7 1 , 4 9 1}$ & $\mathbf{9 6 4 , 9 6 5}$ \\
\hline Demanda del servicio (Unid.) & $1,539,264$ & $1,940,596$ & $2,246,972$ & $2,809,620$ & $3,415,104$ \\
\hline Costo unitario & $\mathbf{0 . 4 1}$ & $\mathbf{0 . 3 6}$ & $\mathbf{0 . 3 5}$ & $\mathbf{0 . 3 1}$ & $\mathbf{0 . 2 8}$ \\
\hline
\end{tabular}

Nota: Elaboración propia.

El detalle de los costos de producción se pueden visualizar en el anexo

$\mathrm{N}^{\circ}$ 14: Detalle de costos y gastos.

\subsubsection{Presupuesto de compras}

Para el cálculo del presupuesto de compras se han considerado las adquisiciones de todos los insumos necesarios para la operación de la planta y para atender la demanda del servicio, las adquisiciones realizadas son empaques y 
utensilios menores necesarios para la operación, con lo cual las compras y los pagos se realizan en el mes en curso.

En el siguiente cuadro se identifica el presupuesto monetario de las compras a realizarse en los cinco años de evaluación del proyecto.

\section{Tabla N 69: Presupuesto de Compras}

\begin{tabular}{lrrrrr}
\hline \multicolumn{7}{c}{ Proyección del Presupuesto de Compras } & & & \\
\hline \multicolumn{1}{c}{ Servicio CBA } & $\mathbf{2 0 1 8}$ & $\mathbf{2 0 1 9}$ & $\mathbf{2 0 2 0}$ & $\mathbf{2 0 2 1}$ & $\mathbf{2 0 2 2}$ \\
\hline $\begin{array}{l}\text { Materia prima indirecta } \\
\text { Otras compras necesarias para la } \\
\text { operación }\end{array}$ & 92,356 & 116,436 & 134,818 & 168,577 & 204,906 \\
\hline Total & 10,336 & 17,808 & 17,808 & 16,962 & 17,808 \\
IGV & $\mathbf{1 0 2 , 6 9 2}$ & $\mathbf{1 3 4 , 2 4 3}$ & $\mathbf{1 5 2 , 6 2 6}$ & $\mathbf{1 8 5 , 5 3 9}$ & $\mathbf{2 2 2 , 7 1 4}$ \\
\hline Presupuesto total & 18,485 & 24,164 & 27,473 & 33,397 & 40,088 \\
\hline
\end{tabular}

Nota: Elaboración propia.

\subsubsection{Presupuesto de costo de ventas}

De acuerdo al giro de negocio que es el servicio de beneficio diario de aves vivas, no se cuenta con stocks iniciales ni finales de productos, por lo tanto se está considerando que el costo de ventas es igual al costo de producción, esto se muestra en la Tabla $\mathrm{N}^{\circ} 69$, mencionada anteriormente.

\subsubsection{Presupuesto de gastos administrativos}

Los gastos administrativos han sido considerados en forma anual e incluyen los gastos realizados por el área de administración en materiales de oficina, servicios administrativos y gastos concernientes a las planillas administrativas entre otros, además se están incluyendo las depreciaciones (activos del área 
administrativa) acumuladas en los periodos evaluados (estas no generan desembolso monetario pero impactan en los estados financieros), el detalle de esto se puede visualizar en el anexo $\mathrm{N}^{\circ}$ 11: Detalle de depreciaciones $\mathrm{y}$ amortizaciones.

En la siguiente tabla se puede visualizar los importes de forma anualizada.

Tabla $N^{\circ}$ 70: Presupuesto de Gastos Administrativos

\begin{tabular}{lrrrrr}
\hline \multicolumn{1}{c}{ Servicio CBA } & $\mathbf{2 0 1 8}$ & $\mathbf{2 0 1 9}$ & $\mathbf{2 0 2 0}$ & $\mathbf{2 0 2 1}$ & $\mathbf{2 0 2 2}$ \\
\hline Planilla administrativa & 79,924 & 79,924 & 79,924 & 79,924 & 79,924 \\
Otras gastos & 8,078 & 8,078 & 8,078 & 8,078 & 8,078 \\
Depreciación & 1,696 & 1,696 & 1,696 & 1,696 & 1,696 \\
\hline Total & $\mathbf{8 9 , 6 9 7}$ & $\mathbf{8 9 , 6 9 7}$ & $\mathbf{8 9 , 6 9 7}$ & $\mathbf{8 9 , 6 9 7}$ & $\mathbf{8 9 , 6 9 7}$ \\
\hline
\end{tabular}

Nota: Elaboración propia.

El detalle de los gastos administrativos se pueden visualizar en el anexo $\mathrm{N}^{\circ}$ 14: Detalle de costos y gastos.

\subsubsection{Presupuesto de marketing y ventas}

Los gastos de marketing y ventas involucran tanto al personal asignado al área comercial (inclusive las comisiones por ventas) así como también a los gastos correspondientes a las estrategias de mercadeo utilizadas para dar a conocer la empresa e impulsar este negocio dentro de los mercados entre otros, además se están incluyendo las depreciaciones (activos del área de ventas) acumuladas en los periodos evaluados (estas no generan desembolso monetario pero impactan en los 
estados financieros), el detalle de esto se puede visualizar en el anexo $\mathrm{N}^{\circ} 11$ : Detalle de depreciaciones y amortizaciones.

En el siguiente cuadro se pueden visualizar los importes de forma anualizada.

\section{Tabla $N^{\circ}$ 71: Presupuesto de Marketing y Ventas}

\begin{tabular}{lrrrrr}
\hline \multicolumn{1}{c}{ Servicio CBA } & $\mathbf{2 0 1 8}$ & $\mathbf{2 0 1 9}$ & $\mathbf{2 0 2 0}$ & $\mathbf{2 0 2 1}$ & $\mathbf{2 0 2 2}$ \\
\hline Planilla Ventas & 92,024 & 96,358 & 99,667 & 105,744 & 112,283 \\
Plan de Marketing $\left(^{*}\right)$ & 46,080 & 46,080 & 46,080 & 46,080 & 46,080 \\
Otras gastos $\left(^{*}\right)$ & 1,007 & 1,007 & 1,007 & 1,007 & 1,007 \\
Depreciación & 1,484 & 1,484 & 1,484 & 1,484 & 1,484 \\
\hline Total & $\mathbf{1 4 0 , 5 9 5}$ & $\mathbf{1 4 4 , 9 2 9}$ & $\mathbf{1 4 8 , 2 3 8}$ & $\mathbf{1 5 4 , 3 1 5}$ & $\mathbf{1 6 0 , 8 5 4}$ \\
\hline
\end{tabular}

(*) Los importes no incluyen el IGV

Nota: Elaboración propia.

El detalle de los gastos administrativos se pueden visualizar en el anexo $\mathrm{N}^{\circ}$ 14: Detalle de costos y gastos.

\subsubsection{Presupuesto de gastos financieros}

No se desarrolla el presupuesto financiero debido a que la inversión del proyecto será asumida en un $100 \%$ por capital de los socios.

\subsection{Presupuestos de Resultados}

Los resultados financieros se han proyectado para los cinco años de evaluación del proyecto y se muestra el estado de resultados y la rentabilidad que se espera obtener, el balance general y la posición financiera que tendrá la empresa producto de la gestión 
propia del negocio, así como también el flujo de caja proyectado que permitirá identificar a los inversionistas el nivel de rentabilidad que generará el negocio.

Los resultados obtenidos son el producto de los ingresos conseguidos por las ventas que han sido proyectadas en el presente plan y los costos operativos que resultan de la operación (costos de producción) y que corresponden a la generación del flujo del proceso detallada en el capítulo $\mathrm{N}^{\circ} 7$.

Se consideran además los gastos administrativos y de ventas que generan la operación de la empresa, el detalle de los costos y gastos pueden ser visualizados en el anexo $\mathrm{N}^{\circ} 14$.

\subsubsection{Estado de ganancias y pérdidas proyectado}

El estado de ganancias y pérdidas proyectado muestra resultados positivos desde el segundo año del presente plan de negocios, se han considerado los siguientes aspectos:

- Se cumplen todos los presupuestos detallados anteriormente.

- Las depreciaciones de cada periodo están incluidas en los costos de ventas y gastos de administración y ventas.

- Se amortizan las inversiones en intangibles en el mismo periodo de evaluación del proyecto por tratarse en general de gastos pre operativos.

- El impuesto a la renta es de $29.5 \%$, porcentaje exigido por la SUNAT y se encuentra en función a los ingresos por las ventas de la empresa 
- Se generan inversiones adicionales en los años 2021 y 2022 pero no es necesario conseguir un préstamo bancario ya que el costo es asumido con los ingresos de la empresa.

En el siguiente cuadro se puede identificar el estado de ganancias y pérdidas proyectado.

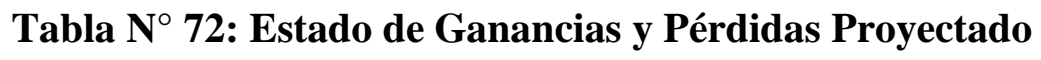

ESTADO DE GANANCIAS Y PÉRDIDAS PROYECTADO

Doña Viole SAC

Año 2018 al 2020

\begin{tabular}{lccccc} 
& $\mathbf{2 0 1 8}$ & $\mathbf{2 0 1 9}$ & $\mathbf{2 0 2 0}$ & $\mathbf{2 0 2 1}$ & $\mathbf{2 0 2 2}$ \\
\hline Ventas & 831,203 & $1,047,922$ & $1,213,365$ & $1,517,195$ & $1,844,156$ \\
Costo de ventas & $(635,768)$ & $(704,824)$ & $(777,346)$ & $(871,491)$ & $(964,965)$ \\
\hline Utilidad bruta & 195,434 & 343,098 & 436,019 & 645,704 & 879,191 \\
Gastos administrativos & $(89,697)$ & $(89,697)$ & $(89,697)$ & $(89,697)$ & $(89,697)$ \\
Gastos de ventas & $(140,595)$ & $(144,929)$ & $(148,238)$ & $(154,315)$ & $(160,854)$ \\
Amortizaciones & $(38,420)$ & $(38,420)$ & $(38,420)$ & $(38,420)$ & $(38,420)$ \\
\hline Utilidad operativa & $(73,278)$ & 70,051 & 159,663 & 363,272 & 590,220 \\
\hline Resultado antes de participaciones & $(73,278)$ & 70,051 & 159,663 & 363,272 & 590,220 \\
Distribución legal de la renta & - & $(3,503)$ & $(7,983)$ & $(18,164)$ & $(29,511)$ \\
\hline Resultados antes de impuesto & $(73,278)$ & 66,548 & 151,680 & 345,109 & 560,709 \\
Impuesto a la renta & - & $(19,632)$ & $(44,746)$ & $(101,807)$ & $(165,409)$ \\
\hline Resultado del ejercicio (Utilidad Neta) & $\mathbf{( 7 3 , 2 7 8 )}$ & $\mathbf{4 6 , 9 1 7}$ & $\mathbf{1 0 6 , 9 3 4}$ & $\mathbf{2 4 3 , 3 0 2}$ & $\mathbf{3 9 5 , 3 0 0}$ \\
\hline
\end{tabular}

Nota: Elaboración propia.

Se puede observar en la tabla anterior que el resultado obtenido el primer año es negativo debido a que los costos y gastos incluyen las depreciaciones de cada periodo, además los costos fijos son altos en comparación a los niveles de ventas proyectados en dicho periodo. 


\subsubsection{Balance proyectado}

El balance general muestra los activos o inversión de la empresa y en contraparte los pasivos y el patrimonio, siendo estos 2 últimos las fuentes de financiamiento.

Se puede identificar que la empresa viene generando valor año a año como consecuencia de la acumulación de la utilidad neta, para el presente plan de negocio no se contempla el pago de dividendos a los accionistas debido a la política empresarial derivada de una práctica para negocios de este sector, sin embargo el reparto de utilidades a los empleados se realizará desde el segundo año y se distribuirá el 5\% de la utilidad operativa según el rubro del negocio.

En el siguiente cuadro se puede identificar el balance general en los cinco años de evaluación del proyecto. 


\section{Tabla $N^{\circ}$ 73: Balance General Proyectado}

BALANCE GENERAL PROYECTADO

Doña Viole SAC

Año 2018 al 2022

dic-18 dic-19

dic-20

dic-21

dic-22

\begin{tabular}{|c|c|c|c|c|c|}
\hline Activo & & & & & \\
\hline \multicolumn{6}{|l|}{ Activo Corriente } \\
\hline Caja y banco & 128,517 & 250,829 & 428,895 & 687,779 & $1,149,369$ \\
\hline Total de Activo Corriente & $\mathbf{1 2 8 , 5 1 7}$ & 250,829 & 428,895 & 687,779 & $1,149,369$ \\
\hline \multicolumn{6}{|l|}{ Activo No Corriente } \\
\hline Activo Fijo & 291,035 & 291,035 & 291,035 & 352,231 & 362,581 \\
\hline Activo Intangible & 192,100 & 192,100 & 192,100 & 192,100 & 192,100 \\
\hline Depreciación Acumulada & $-32,702$ & $-65,403$ & $-98,105$ & $-136,006$ & $-173,907$ \\
\hline Amortización Acumulada & $-38,420$ & $-76,840$ & $-115,260$ & $-153,680$ & $-192,100$ \\
\hline Credito Fiscal del IGV & 11,572 & 7,990 & 8,504 & 9,014 & 9,726 \\
\hline Total Activo No Corriente & 423,586 & $\mathbf{3 4 8 , 8 8 2}$ & 278,274 & 263,658 & 198,400 \\
\hline Total Activo & 552,103 & 599,711 & 707,169 & $\mathbf{9 5 1 , 4 3 7}$ & $1,347,769$ \\
\hline \multicolumn{6}{|l|}{ Pasivo } \\
\hline \multicolumn{6}{|l|}{ Pasivo Corriente } \\
\hline $\begin{array}{l}\text { Cuentas por pagar } \\
\text { Impuestos Diferidos }\end{array}$ & 8,309 & 9,000 & 9,524 & 10,490 & 11,522 \\
\hline Total de Pasivo Corriente & 8,309 & 9,000 & 9,524 & 10,490 & $\mathbf{1 1 , 5 2 2}$ \\
\hline Total Pasivo & 8,309 & 9,000 & 9,524 & 10,490 & 11,522 \\
\hline \multicolumn{6}{|l|}{ Patrimonio } \\
\hline Capital Social & 617,072 & 617,072 & 617,072 & 617,072 & 617,072 \\
\hline Resultados del Ejercicio & $-73,278$ & 46,917 & 106,934 & 243,302 & 395,300 \\
\hline Resultados Acumulados & & $-73,278$ & $-26,361$ & 80,573 & 323,875 \\
\hline Total Patrimonio & 543,794 & 590,711 & 697,645 & 940,947 & $1,336,246$ \\
\hline Total Pasivo y Patrimonio & 552,103 & 599,711 & 707,169 & $\mathbf{9 5 1 , 4 3 7}$ & $1,347,769$ \\
\hline
\end{tabular}

Nota: Elaboración propia.

\subsubsection{Flujo de caja proyectado}

El flujo de caja indica los saldos disponibles de efectivo que genera la empresa una vez que asume todas sus obligaciones. Los flujos obtenidos son flujos corrientes y serán utilizados para el análisis de los indicadores de rentabilidad del proyecto. 
Para efectos de la evaluación de proyecto se han considerado dos flujos de caja, el primero que únicamente incluye las transacciones económicas y cuyo fin es identificar el importe en efectivo que será trasladado a la cuenta de caja y banco como saldo al balance general y un segundo flujo en donde se incluyen los valores de rescate y la recuperación del capital de trabajo, con la finalidad de identificar los flujos para el análisis de los ratios e indicadores de rentabilidad.

En el siguiente cuadro se puede identificar el primero de ellos que es el flujo de caja proyectado en soles corrientes, flujo económico sin considerar la recuperación del capital de trabajo y los valores de rescate de los activos.

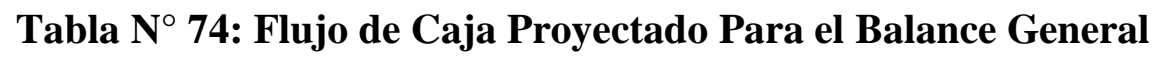

\begin{tabular}{|c|c|c|c|c|c|c|}
\hline & & 2018 & 2019 & 2020 & 2021 & 2022 \\
\hline Ingreso por Ventas & & 980,819 & $1,236,548$ & $1,431,771$ & $1,790,290$ & $2,176,104$ \\
\hline Total de Ingresos & & 980,819 & $1,236,548$ & $1,431,771$ & $1,790,290$ & $2,176,104$ \\
\hline Costos de Producción & & 666,540 & 747,913 & 824,221 & 919,634 & $1,020,564$ \\
\hline Gastos Administrativos & & 89,139 & 89,456 & 89,456 & 89,456 & 89,456 \\
\hline Gastos de Ventas & & 146,020 & 151,538 & 154,938 & 160,770 & 167,268 \\
\hline Pago del IGV & & 0 & 102,195 & 132,361 & 169,366 & 230,092 \\
\hline Reparto de utilidades a empleados & & 0 & 3,503 & 7,983 & 18,164 & 29,511 \\
\hline Impuesto a la Renta & & 0 & 19,632 & 44,746 & 101,807 & 165,409 \\
\hline Total de Egresos & & 901,698 & $1,114,235$ & $1,253,704$ & $1,459,196$ & $1,702,300$ \\
\hline Flujo de Caja Operativo & & 79,121 & 122,312 & 178,066 & 331,094 & $\overline{473,804}$ \\
\hline $\begin{array}{l}\text { Activo Tangible } \\
\text { Activo Intangible } \\
\text { Capital de Trabajo } \\
\text { Recuperación del Capital de Trabajo } \\
\text { Valor de Rescate }\end{array}$ & $\begin{array}{r}-343,422 \\
-224,254 \\
-49,396\end{array}$ & & & & $-72,210$ & $-12,214$ \\
\hline Flujo de Caja de Inversión & $-617,072$ & $\mathbf{0}$ & $\mathbf{0}$ & $\mathbf{0}$ & $-72,210$ & $-12,214$ \\
\hline Flujo de Caja Económico & $-617,072$ & 79,121 & 122,312 & 178,066 & 258,883 & 461,590 \\
\hline
\end{tabular}

Nota: Elaboración propia. 
En la siguiente tabla se puede identificar el flujo de caja proyectado en soles corrientes, flujo económico considerando la recuperación del capital de trabajo y los valores de rescate de los activos.

\section{Tabla ${ }^{\circ}$ 75: Flujo de Caja Proyectado Para Ratios de Rentabilidad}

\begin{tabular}{|c|c|c|c|c|c|c|}
\hline & & 2018 & 2019 & 2020 & 2021 & 2022 \\
\hline Ingreso por Ventas & & 980,819 & $1,236,548$ & $1,431,771$ & $1,790,290$ & $2,176,104$ \\
\hline Total de Ingresos & & 980,819 & $1,236,548$ & $1,431,771$ & $1,790,290$ & $2,176,104$ \\
\hline Costos de Producción & & 666,540 & 747,913 & 824,221 & 919,634 & $1,020,564$ \\
\hline Gastos Administrativos & & 89,139 & 89,456 & 89,456 & 89,456 & 89,456 \\
\hline Gastos de Ventas & & 146,020 & 151,538 & 154,938 & 160,770 & 167,268 \\
\hline Pago del IGV & & 0 & 102,195 & 132,361 & 169,366 & 230,092 \\
\hline Distribución Legal de Renta & & 0 & 3,503 & 7,983 & 18,164 & 29,511 \\
\hline Impuesto a la Renta & & 0 & 19,632 & 44,746 & 101,807 & 165,409 \\
\hline Total de Egresos & & 901,698 & $1,114,235$ & $1,253,704$ & $1,459,196$ & $1,702,300$ \\
\hline Flujo de Caja Operativo & & 79,121 & 122,312 & 178,066 & 331,094 & 473,804 \\
\hline Activo Tangible & $-343,422$ & & & & $-72,210$ & $-12,214$ \\
\hline Activo Intangible & $-224,254$ & & & & & \\
\hline Capital de Trabajo & $-49,396$ & & & & & \\
\hline Recuperación del Capital de Trabajo & & & & & & 49,396 \\
\hline Valor de Rescate & & & & & & 222,636 \\
\hline Flujo de Caja de Inversión & $-617,072$ & $\mathbf{0}$ & $\mathbf{0}$ & $\mathbf{0}$ & $-72,210$ & 259,818 \\
\hline Flujo de Caja Económico & $-617,072$ & 79,121 & 122,312 & 178,066 & 258,883 & 733,622 \\
\hline
\end{tabular}

Nota: Elaboración propia.

\section{Consideraciones:}

- Para efectos de la evaluación del proyecto se ha considerado método de año de liquidación y no el de negocio en marcha ya que los inversionistas así lo han decidido con la finalidad de ser más conservadores al momento de analizar los flujos puesto que al realizar una comparación utilizando la perpetuidad en el flujo del quinto año se puede identificar un flujo más alto.

- Solo se consideran los movimientos económicos, no se incluyen las depreciaciones y amortizaciones de los intangibles. 
- Se incluyen los importes según periodo de desembolso.

- En la liquidación del IGV se considera a favor el crédito fiscal por IGV generado por la inversión inicial.

- En el quinto año se venden los activos tangibles a su valor en libros.

- En el último año de evaluación se recupera el capital de trabajo.

El pago del IGV forma parte de los flujos de caja y debido a ello es importante gestionarlos de forma eficiente, en la Tabla $\mathrm{N}^{\circ}$ 76: Liquidación del IGV se puede identificar los pagos a realizar en cada año resultado de la diferencia que existe entre el IGV que generan los ingresos y el IGV que generan los egresos. Este proyecto generó un escudo fiscal por el IGV de la inversión inicial de S/ 84,541 que impacta favorablemente al proyecto.

\section{Tabla $N^{\circ}$ 76: Liquidación del IGV}

\begin{tabular}{lrrrrrrr}
\multicolumn{1}{c}{ LIQUIDACIÓN DEL IGV } & $\mathbf{2 , 0 1 7}$ & $\mathbf{2 , 0 1 8}$ & $\mathbf{2 , 0 1 9}$ & $\mathbf{2 , 0 2 0}$ & $\mathbf{2 , 0 2 1}$ & $\mathbf{2 , 0 2 2}$ & $\mathbf{2 , 0 2 3}$ \\
\hline IGV DE INGRESOS DE VENTAS & & 149,616 & 188,626 & 218,406 & 273,095 & 331,948 & \\
\hline IGV INVERSIONES & $-84,541$ & & & & $-11,015$ & $-1,863$ & \\
\hline IGV ÁREA DE OPERACIONES & & $-60,162$ & $-72,446$ & $-76,115$ & $-82,785$ & $-90,063$ & $-8,766$ \\
IGV ÁRE DE ADMINISTRACIÓN & $-1,215$ & $-1,454$ & $-1,454$ & $-1,454$ & $-1,454$ & -239 \\
IGV ÁREA DE VENTAS & $-7,754$ & $-8,476$ & $-8,476$ & $-8,476$ & $-8,476$ & -721 \\
TOTAL IGV GASTOS Y COSTOS & & $\mathbf{- 6 9 , 1 3 1}$ & $\mathbf{- 8 2 , 3 7 6}$ & $\mathbf{- 8 6 , 0 4 5}$ & $\mathbf{- 9 2 , 7 1 4}$ & $\mathbf{- 9 9 , 9 9 3}$ & $\mathbf{- 9 , 7 2 6}$ \\
\hline DIFERENCIA & $-84,541$ & 80,485 & 106,250 & 132,361 & 169,366 & 230,092 & $-9,726$ \\
CREDITO TRIBUTARIO & $-84,541$ & $-84,541$ & $-4,055$ & 0 & 0 & 0 & \\
\hline TOTAL IGV A PAGAR & $\mathbf{0}$ & $\mathbf{1 0 2 , 1 9 5}$ & $\mathbf{1 3 2 , 3 6 1}$ & $\mathbf{1 6 9 , 3 6 6}$ & $\mathbf{2 3 0 , 0 9 2}$ & $\mathbf{- 9 , 7 2 6}$ \\
\hline
\end{tabular}

Nota: Elaboración propia. 


\section{CAPÍTULO X}

\section{Evaluación económico financiera}

En este capítulo se evalúa desde el punto de vista financiero la factibilidad del plan de negocio en base a indicadores que consideran el efecto del financiamiento.

Se calculan los ratios más importantes que dan mejor visibilidad al desempeño esperado del plan y se obtiene también el punto de equilibro que sirve como referencia a los ingresos y producciones mínimas necesarias.

Finalmente se evalúan los riesgos y su impacto en base a escenarios que consideran supuestos inherentes a un proyecto de esta naturaleza.

\subsection{Evaluación Financiera}

Se han identificado y analizado los indicadores de rentabilidad que generaría la empresa y además los ratios de desempeño a lo largo de los cinco años de evaluación del proyecto.

\subsubsection{TIR}

La TIR es la tasa de interés o rentabilidad que ofrece la inversión en este plan. Se expresa en porcentaje e indica los soles que se pueden ganar o perder por efecto de la operación del negocio.

Se ha calculado la TIR con los flujos de caja económicos considerando que no existe flujo financiero. 
Como se visualiza en el siguiente cuadro, el valor de la TIR supera la tasa de descuento mínima que los accionistas exigen de retorno por su inversión realizada, con un resultado de $22.86 \%$ la misma que supera el COK del proyecto que es de $16.58 \%$.

\section{Tabla $\mathbf{N}^{\circ}$ 77: TIR Económica}

\begin{tabular}{|c|c|c|c|c|c|c|}
\hline Flujos & $\begin{array}{c}\text { Inversión } \\
\text { Inicial } \\
\end{array}$ & 2018 & 2019 & 2020 & 2021 & 2022 \\
\hline Flujo de Caja Económico & $-617,072$ & 79,121 & 122,312 & 178,066 & 258,883 & 733,622 \\
\hline Cálculo & & \multicolumn{3}{|c|}{ Comparación } & & \\
\hline TIRE: & $22.86 \%$ & \multicolumn{2}{|c|}{ COK: } & $16.58 \%$ & & \\
\hline
\end{tabular}

Nota: Elaboración propia.

\subsubsection{VAN}

El VAN es el valor actual neto y expresa la rentabilidad del plan presentado en soles, permite analizar los flujos futuros descontándolos con la tasa de descuento mínima que el accionista espera por su inversión.

Este cálculo sirve para evaluar si la inversión es factible o si genera ganancia o pérdida y si la tasa de descuento esperada genera beneficios futuros. Se ha calculado el VAN Económico con los flujos de caja económicos descontados con el COK.

En el siguiente cuadro se pueden identificar los resultados obtenidos tras el cálculo realizado. 
Tabla $N^{\circ}$ 78: VAN Económico

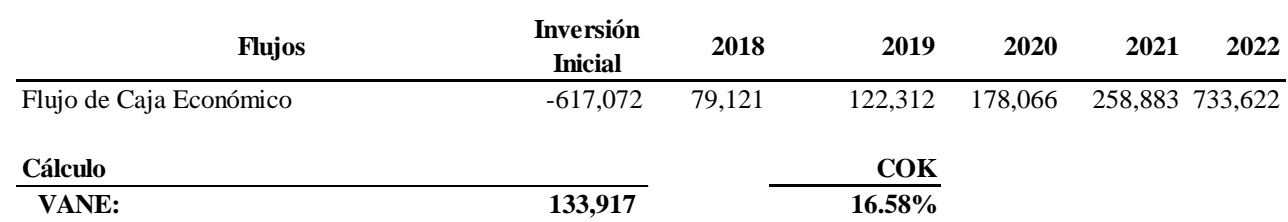

Nota: Elaboración propia.

Como se puede identificar el valor obtenido genera beneficios y valor para los accionistas a la tasa de descuento mínima que está dispuesto a obtener por su inversión.

Finalmente se ha evaluado el Payback o periodo de recuperación de la inversión, resultando en un período de recuperación descontado de 4 años y 7 meses. Los flujos han sido descontados con el COK identificado para el proyecto, en la tabla adjunta el detalle.

Tabla N $N^{\circ}$ 79: Periodo de Recuperación

\begin{tabular}{lcrrrrr}
\multicolumn{1}{c}{ Flujos } & $\begin{array}{c}\text { Inversión } \\
\text { Inicial }\end{array}$ & $\mathbf{2 0 1 8}$ & $\mathbf{2 0 1 9}$ & $\mathbf{2 0 2 0}$ & $\mathbf{2 0 2 1}$ & $\mathbf{2 0 2 2}$ \\
\hline Flujo de Caja Económico & $-617,072$ & 79,121 & 122,312 & 178,066 & 258,883 & 733,622 \\
Flujo de C. E. Descontado & $-617,072$ & 67,866 & 89,989 & 112,373 & 140,135 & 340,625 \\
F. C. E. Descontado Acumulado & & 67,866 & 157,855 & 270,229 & 410,364 & 750,988 \\
& & & & & & \\
Flujo acumulado 4to. año (año 2021) & 410,364 & & & & \\
Por Recuperar (-618,450 + 495,886) & $-206,708$ & & & & \\
Años & 4 & & & & & \\
Meses & 7 & & & & &
\end{tabular}

Nota: Elaboración propia. 


\subsubsection{ROE}

Se utiliza el ROE como un indicador de rentabilidad que permite identificar el porcentaje de rentabilidad que genera la empresa sobre el patrimonio de la misma, en la siguiente tabla se puede identificar los resultados obtenidos en los cinco años de evaluación del proyecto.

Como se puede visualizar, se obtienen resultados positivos desde el segundo año de la operación consiguiendo los mejores resultados los últimos dos años incrementando así el patrimonio de la empresa, sin embargo los flujos obtenidos por el proyecto son positivos desde el primer año, esto se ha identificado en el capítulo anterior y se detalla en la Tabla $\mathrm{N}^{\circ} 80$.

\section{Tabla $\mathbf{N}^{\circ}$ 80: Tabla de ROE del Proyecto}

\begin{tabular}{|c|c|c|c|c|c|}
\hline & 2018 & 2019 & 2020 & 2021 & 2022 \\
\hline Utilidad Neta del Periodo & $-73,278$ & 46,917 & 106,934 & 243,302 & 395,300 \\
\hline Patrimonio & 543,794 & 590,711 & 697,645 & 940,947 & $1,336,246$ \\
\hline
\end{tabular}

Nota: Elaboración propia.

\subsubsection{Ratios}

\section{Ratio de Liquidez}

La empresa presenta en los cinco años de evaluación del proyecto una alta liquidez, esto debido a que cobra por sus servicios al contado y paga sus obligaciones al final de cada mes o al siguiente mes en el caso de los servicios básicos. Esto significa que la empresa se encuentra en la 
capacidad de afrontar sus obligaciones de corto plazo sin inconvenientes.

El detalle de los resultados se puede visualizar en la siguiente tabla.

\section{Tabla $\mathbf{N}^{\circ}$ 81: Ratio de Liquidez}

\begin{tabular}{lrrrrr} 
Liquidez & $\mathbf{2 0 1 8}$ & $\mathbf{2 0 1 9}$ & $\mathbf{2 0 2 0}$ & $\mathbf{2 0 2 1}$ & $\mathbf{2 0 2 2}$ \\
\hline Activo Corriente & 128,517 & 250,829 & 428,895 & 687,779 & $1,149,369$ \\
Pasivo Corriente & 8,309 & 9,000 & 9,524 & 10,490 & 11,522 \\
\hline Razón de liquidez corriente & $\mathbf{1 5}$ & $\mathbf{2 8}$ & $\mathbf{4 5}$ & $\mathbf{6 6}$ & $\mathbf{1 0 0}$
\end{tabular}

Nota: Elaboración propia.

\section{Ratio de Solvencia}

Se ha analizado la razón de endeudamiento, dando como resultado que el nivel de endeudamiento es prácticamente nulo, lo que significa que la empresa cuenta con el patrimonio necesario afrontar nuevas inversiones con capital propio, teniendo en cuenta que no se ha adquirido deuda de largo plazo en el momento de la inversión inicial.

En el siguiente cuadro se pueden identificar los resultados por cada año de evaluación.

\section{Tabla $\mathbf{N}^{\circ}$ 82: Razón de Endeudamiento}

\begin{tabular}{lrrrrr} 
Solvencia & $\mathbf{2 0 1 8}$ & $\mathbf{2 0 1 9}$ & $\mathbf{2 0 2 0}$ & $\mathbf{2 0 2 1}$ & $\mathbf{2 0 2 2}$ \\
\hline Activos Totales & 552,103 & 599,711 & 707,169 & 951,437 & $1,347,769$ \\
Patrimonio & 543,794 & 590,711 & 697,645 & 940,947 & $1,336,246$ \\
\hline Razón de endeudamiento & $\mathbf{0 . 0 2}$ & $\mathbf{0 . 0 2}$ & $\mathbf{0 . 0 1}$ & $\mathbf{0 . 0 1}$ & $\mathbf{0 . 0 1}$
\end{tabular}

Nota: Elaboración propia. 


\section{Ratios de Rentabilidad}

Los ratios de rentabilidad han sido calculados para identificar los niveles de rentabilidad que generaría la empresa en los cinco años de evaluación del proyecto, como se puede identificar en el siguiente cuadro, estos indicadores muestran una mejora año a año, identificándose mayores porcentajes en los años 2021 y 2022.

Esto demuestra que la empresa se encontrará estable en los siguientes años, lo que genera una mayor confianza tanto para inversores o entidades financieras lo que permitiría expandir el negocio.

\section{Tabla $N^{\circ}$ 83: Ratios de Rentabilidad}

\begin{tabular}{lrrrrr} 
Rentabilidad & $\mathbf{2 0 1 8}$ & $\mathbf{2 0 1 9}$ & $\mathbf{2 0 2 0}$ & $\mathbf{2 0 2 1}$ & $\mathbf{2 0 2 2}$ \\
\hline Ingresos & 831,203 & $1,047,922$ & $1,213,365$ & $1,517,195$ & $1,844,156$ \\
Margen Bruto & 195,434 & 343,098 & 436,019 & 645,704 & 879,191 \\
Margen Operativo & $-73,278$ & 70,051 & 159,663 & 363,272 & 590,220 \\
Margen Neto & $-73,278$ & 46,917 & 106,934 & 243,302 & 395,300 \\
\hline \% Margen bruto & $\mathbf{2 3 . 5 \%}$ & $\mathbf{3 2 . 7 \%}$ & $\mathbf{3 5 . 9 \%}$ & $\mathbf{4 2 . 6 \%}$ & $\mathbf{4 7 . 7 \%}$ \\
\% Margen operativo & $\mathbf{- 8 . 8 \%}$ & $\mathbf{6 . 7 \%}$ & $\mathbf{1 3 . 2 \%}$ & $\mathbf{2 3 . 9 \%}$ & $\mathbf{3 2 . 0 \%}$ \\
\% Margen neto & $\mathbf{- 8 . 8 \%}$ & $\mathbf{4 . 5 \%}$ & $\mathbf{8 . 8 \%}$ & $\mathbf{1 6 . 0 \%}$ & $\mathbf{2 1 . 4 \%}$ \\
ROA & $\mathbf{- 1 3 . 3 \%}$ & $\mathbf{7 . 8 \%}$ & $\mathbf{1 5 . 1 \%}$ & $\mathbf{2 5 . 6 \%}$ & $\mathbf{2 9 . 3 \%}$
\end{tabular}

Nota: Elaboración propia.

\subsection{Análisis de Riesgo}

Se ha realizado el análisis de riesgo con la finalidad de identificar la variación de los resultados económicos - financieros ante cambios en las condiciones que se han planteado inicialmente, y así poder determinar si ante estos cambios la rentabilidad planteada sufriría cambios radicales poniendo en riesgo el negocio. 


\subsubsection{Análisis del punto de equilibrio}

El análisis del punto de equilibrio permite identificar la cantidad mínima de producción que necesita realizar la empresa para no generar rentabilidad negativa, es decir, cuando los ingresos totales son iguales a los costos totales.

Para poder calcular el punto de equilibro se han clasificado los costos y gastos como variables y fijos, identificándose que para el primer año del proyecto el punto de equilibrio asciende a 1,543,950 unidades de pollo beneficiado, resultado obtenido de la división de los costos fijos entre el margen de contribución unitario.

En la siguiente tabla, se puede identificar los puntos de equilibrio en los cinco años de evaluación del proyecto. Según lo proyectado en el plan de negocio, los volúmenes considerados se encuentran en un promedio del $34.4 \%$ sobre el punto de equilibrio en los años evaluados.

Tabla $N^{\circ}$ 84: Punto de Equilibrio

\begin{tabular}{lrrrrr} 
& $\mathbf{2 0 1 8}$ & $\mathbf{2 0 1 9}$ & $\mathbf{2 0 2 0}$ & $\mathbf{2 0 2 1}$ & $\mathbf{2 0 2 2}$ \\
\hline Cant. de pollo beneficiado & $1,539,264$ & $1,940,596$ & $2,246,972$ & $2,809,620$ & $3,415,104$ \\
Valor de venta unitario & 0.54 & 0.54 & 0.54 & 0.54 & 0.54 \\
Costo variable unitario & 0.08 & 0.08 & 0.08 & 0.08 & 0.08 \\
\hline Margen de contribución unitario & $\mathbf{0 . 4 6}$ & $\mathbf{0 . 4 6}$ & $\mathbf{0 . 4 6}$ & $\mathbf{0 . 4 6}$ & $\mathbf{0 . 4 6}$ \\
Costo Fijo & 710,496 & 752,577 & 804,490 & 855,557 & 908,315 \\
\hline & & & & & \\
Punto de equilibrio (cant.) & $\mathbf{1 , 5 4 3 , 9 5 0}$ & $\mathbf{1 , 6 3 4 , 0 6 8}$ & $\mathbf{1 , 7 4 6 , 0 7 4}$ & $\mathbf{1 , 8 5 5 , 9 9 3}$ & $\mathbf{1 , 9 6 9 , 6 9 8}$ \\
Punto de equilibrio (S/) & $\mathbf{8 3 3 , 7 3 3}$ & $\mathbf{8 8 2 , 3 9 7}$ & $\mathbf{9 4 2 , 8 8 0}$ & $\mathbf{1 , 0 0 2 , 2 3 6}$ & $\mathbf{1 , 0 6 3 , 6 3 7}$ \\
\hline
\end{tabular}

Nota: Elaboración propia. 


\subsubsection{Análisis de sensibilidad}

El análisis de sensibilidad permite identificar las variables que pueden ser sensibles y críticas para el proyecto, sobre ello se han tomado como referencia algunos supuestos que serán analizados a continuación y cuyo objetivo es identificar la variación que generan en los flujos de caja y en las tasas de retorno.

\section{Variables:}

a) Reducción en la demanda del servicio, este aspecto es considerado debido a que existe la posibilidad que el servicio no genere la aceptación que inicialmente se ha planteado por tratarse de una empresa nueva con un modelo de negocio con el que no se opera actualmente.

Supuesto 1: Reducción del $10 \%$ de la demanda que trae como consecuencia los siguientes flujos y tasas de retorno.

Tabla $N^{\circ}$ 85: Flujos y TIR con $-10 \%$ de Ingresos

\begin{tabular}{lrrrrrr} 
& Año 0 & Año 1 & Año 2 & Año 3 & Año 4 & Año 5 \\
\hline Flujo de Caja Económico & $-616,873$ & $-5,312$ & 69,055 & 108,529 & 171,939 & 627,741 \\
Rentabilidad & & & & & \\
\cline { 1 - 2 } TIRE: & $\mathbf{1 1 . 0 \%}$ & & & &
\end{tabular}

Nota: Elaboración propia.

Supuesto 2: Reducción del $5 \%$ de la demanda que trae como consecuencia los siguientes flujos y tasas de retorno. 
Tabla $N^{\circ}$ 86: Flujos y TIR con $-5 \%$ de Ingresos

\begin{tabular}{lrrrrrr} 
& Año 0 & Año 1 & Año 2 & Año 3 & Año 4 & Año 5 \\
\hline Flujo de Caja Económico & $-617,867$ & 36,915 & 98,915 & 143,296 & 215,420 & 681,565 \\
Rentabilidad & & & & & \\
\hline TIRE: & $\mathbf{1 7 . 1 \%}$ & & & &
\end{tabular}

Nota: Elaboración propia.

b) Incremento en los costos de operación, este aspecto es tomado en consideración debido a que por tratarse de un negocio nuevo existe la posibilidad que la empresa deba realizar gastos operativos adicionales no considerados para asegurar la continuidad de la prestación del servicio.

Supuesto: Incremento de los costos de operación en un 10\% sin consideran aumento en los costos de planilla, trae como consecuencia los siguientes flujos y tasas de retorno.

Tabla $N^{\circ}$ 87: Flujos y TIR con $+\mathbf{1 0 \%}$ de Costos de Operación

\begin{tabular}{lrrrrrr} 
& Año 0 & Año 1 & Año 2 & Año 3 & Año 4 & Año 5 \\
\hline Flujo de Caja Económico & $-630,734$ & 36,025 & 102,305 & 149,828 & 228,185 & 708,389 \\
Rentabilidad & & & & & \\
\cline { 1 - 2 } TIRE: & $\mathbf{1 7 . 6 \%}$ & & & &
\end{tabular}

Nota: Elaboración propia.

c) Reducción del precio del servicio, este aspecto es tomado en consideración debido a que por tratarse de un negocio nuevo existe la posibilidad que los competidores ejerzan un alto nivel de competencia que obligue a una reducción en el precio del servicio 
Supuesto: Reducción del precio unitario del servicio en un $15 \%$, trae como consecuencia los siguientes flujos y tasas de retorno.

Tabla N N $^{\circ}$ : Flujos y TIR con -15\% del Precio del Servicio

\begin{tabular}{lrrrrrr} 
& Año 0 & Año 1 & Año 2 & Año 3 & Año 4 & Año 5 \\
\hline Flujo de Caja Económico & $-662,492$ & $-65,729$ & 13,787 & 52,387 & 109,430 & 597,392 \\
Rentabilidad & & & & & & \\
\cline { 1 - 2 } TIRE: & $\mathbf{1 . 3 \%}$ & & & &
\end{tabular}

Nota: Elaboración propia.

\subsubsection{Análisis de escenarios}

El análisis de los escenarios se realiza utilizando como referencia las variables analizadas anteriormente. En este análisis previo se identificaron 4 supuestos y sus respectivas variaciones en flujos y tasas de retorno, estos supuestos han tomado escenarios pesimistas para que la empresa para tener mejor visibilidad del impacto en situaciones de desventaja.

A cada uno de los supuestos planteados se le asignó su respectivo peso o porcentaje de probabilidad, estas probabilidades han sido identificadas tomando como referencia las opiniones de dos de los inversionistas debido al conocimiento que tienen en el sector ya que cuentan con más de 27 años de experiencia en el rubro. A continuación se detalla cada escenario y su probabilidad de ocurrencia:

- Escenario Normal, con un $40 \%$ de probabilidad. A este supuesto se le asignó la mayor probabilidad ya que las proyecciones de este escenario se encuentran sustentadas en todo el análisis previo 
realizado en el presente plan de negocio en donde se analizó el sector, la competencia, se realizaron entrevistas a profundidad y encuentras a los posibles clientes. Además no se han considerado escenarios optimistas con la finalidad de obtener un dato más ácido.

- Reducción en la demanda del servicio del -10\%, con un $15 \%$ de probabilidad. A este supuesto se le brinda una probabilidad media.

- Reducción en la demanda del servicio del $\mathbf{- 5 \%}$, con un $15 \%$ de probabilidad. A este supuesto se le brinda una probabilidad media.

- Incremento en los costos de operación, con un $20 \%$ de probabilidad. A este supuesto se le asignó una probabilidad levemente por encima de la media debido a que la gestión eficiente de los costos depende de la empresa en donde se han definido claramente las funciones y responsabilidades de cada puesto, sin embargo al tratarse de un negocio nuevo existe la posibilidad de incurrir en costos ocultos no identificados previamente.

- Reducción del precio del servicio, con un $10 \%$ de probabilidad. A este supuesto se le brinda una probabilidad baja debido a que en el análisis del mercado objetivo no se ha considerado al porcentaje de clientes cuya disposición de pago por el servicio se encontraba por debajo de la media, esto con la finalidad de ser más precisos en las proyecciones. 
En el siguiente cuadro se identifica el análisis de escenarios en donde se puede visualizar el nuevo valor esperado de TIR resultado de su aplicación. Lo que se observa es que la tasa de retorno disminuye en comparación al escenario normal pero que aun así y siendo conservadores con las proyecciones, se consigue una tasa de retorno que se encuentra por encima de lo que exigen los inversionistas. La TIR ponderada con escenarios pesimistas asciende a $17.01 \%$.

Tabla N 89: Análisis de Escenarios

\begin{tabular}{llrrrr} 
& & & & \multicolumn{2}{r}{ Factor de } \\
$\mathbf{N}^{\circ}$ & Escenarios & TIR & Probabil. & Ponderac. & Desv. \\
\hline E1 & Normal & $22.9 \%$ & $40 \%$ & $9.1 \%$ & 0.0014 \\
E2 & Demanda del Servicio (-10\%) & $11.0 \%$ & $15 \%$ & $1.6 \%$ & 0.0005 \\
E3 & Demanda del Servicio (-5\%) & $17.1 \%$ & $15 \%$ & $2.6 \%$ & 0.0000 \\
E4 & Incremento de Costos de Operación (+10\%) & $17.6 \%$ & $20 \%$ & $3.5 \%$ & 0.0000 \\
E5 & Reducción en el Precio del Servicio (-15\%) & $1.3 \%$ & $10 \%$ & $0.1 \%$ & 0.0025 \\
\hline & Valor Esperado (TIR) & $\mathbf{1 7 . 0 1 \%}$ & & & \\
& Comparación COK: & $\mathbf{1 6 . 5 8 \%}$ & & &
\end{tabular}

Nota: Elaboración propia. 


\section{CONCLUSIONES Y RECOMENDACIONES}

\section{Conclusiones}

El sector avícola en el Perú ha sido uno de los más dinámicos en los últimos años con tendencias crecientes que conducen a un incremento cada vez mayor del consumo per cápita de carne de pollo. Esto se da, entre otros factores, porque el pollo forma parte importante de la canasta familiar $\mathrm{y}$ es reconocido como un alimento saludable $\mathrm{y}$ beneficioso para la salud, de fácil preparación y disponible en todos los lugares del país.

El cambio en las normas sanitarias para la comercialización de pollos vivos que prohíbe que las aves vivas compradas por los dueños de los puestos del mercado de abasto (picadores) sean beneficiadas dentro de los centros de acopio o de los mercados exigiendo que las operaciones se ejecuten en centros de beneficio formales que cuenten con las condiciones higiénicas básicas, ha encontrado al sector sin capacidad para afrontar esta decisión política y cumplir con las normas y estándares de calidad necesarios originando la proliferación de distintos modelos de peladurías informales donde los las avícolas y los

propios picadores benefician y pelan pollos con pobres condiciones sanitarias y de higiene.

El plan de negocio que se propone es implementar un Centro de Beneficio de Aves certificado con Buenas Prácticas de Manufactura (BPM), que cumpla con las normas legales de salubridad, higiene e impacto ambiental vigentes que garantice la calidad e inocuidad del producto final, creando así una solución a la situación de informalidad existente, sin perjudicar el medio ambiente, impactando positivamente en los pobladores aledaños y proporcionando una oferta de valor para las avícolas y picadores que podrán 
trasladarla a su puesto del mercado y que será reconocida y preferida por el consumidor final.

Esta propuesta está orientada a la dirección y ejecución de los procesos en el marco de la excelencia operacional considerando para la administración del centro de Beneficio a un grupo humano estructurado de tal forma que cuente con la capacidad suficiente para poder mantener estos procesos en control.

Teniendo en cuenta la alta demanda actual y potencial de este servicio y además las consideraciones legales, sanitarias, técnicas y de impacto ambiental que implica esta propuesta, se ha realizado la evaluación económica y financiera con una proyección a cinco años concluyendo que se trata de un plan de negocio rentable y factible de implementar.

Se ha estimado una inversión total de S/ 617,072 con un VAN positivo de S/. 133,917 que asegura el retorno de la inversión y una TIR de $22.86 \%$ mayor al COK de 16.58\%. Esta propuesta estima beneficiar 3,415,104 pollos a partir del quinto año $(9,408$ pollos por día), con un valor de venta de servicio de S/. 0.64 (incluye IGV) por pollo, con una utilidad operativa anual del $32.0 \%$ de las ventas, manteniendo un margen bruto para el año 2022 de $47.7 \%$ y con flujos de caja positivos desde el primer año por tratarse de un modelo con pago al contado.

Se considera un crecimiento potencial de este servicio el mismo que puede ser operado bajo la modalidad de franquicias, que permita atomizar el modelo y llegar a los diferentes mercados.

Se trata de una propuesta de negocio única e innovadora ya que hasta la fecha no existen modelos similares implementados y se encuentra en medio de una oportunidad 
también única donde la coyuntura gubernamental, los temas vinculados a la salud e inocuidad de los productos, las cada vez más rigurosas políticas de cuidado al medio ambiente entre otras cosas son cubiertas en este plan de negocio.

\section{Recomendaciones}

Los inversionistas potenciales que encuentren en este plan de negocio una oportunidad única para desarrollar una alternativa que propone una oferta de valor que sea reconocida y preferida por el cliente, deben considerar que este modelo se encuentra en medio de un entorno favorable impulsado por el gobierno y los propios distritos a través de las normas de salubridad que exigen las municipalidades para que los picadores lleguen a los consumidores finales con productos que no pongan en riesgo su salud al momento de su consumo.

Es por ello que se recomienda lo siguiente:

- Implementar al más corto plazo el CBA propuesto para lograr una ventaja competitiva sostenible en el tiempo frente al resto de inversores.

- Este modelo de un Centro de Beneficio Avícola (CBA) operado con altos estándares de calidad y certificado con buenas prácticas de manufactura (BPM) está diseñado con tecnología innovadora adecuada a las necesidades de los clientes lo cual requiere trabajar en forma estrecha con los picadores para que entiendan la nueva forma de operar y establecer relaciones estratégicas duraderas.

- Ampliar la cadena de valor hacia atrás creando alianzas estratégicas con empresas que se dedican a la crianza de pollos y que cuenten a su vez con certificaciones de calidad pero que terminan perdiendo esa oferta de valor al momento del beneficio 
de las aves ya que en la actualidad no existen centros de beneficio de pollos que se preocupen por asegurar la preservación de procesos de calidad hasta la llegada del producto al consumidor final.

- Un centro de beneficio de esta naturaleza puede explotar opciones adicionales en las ventanas horarias que no son utilizadas. Se pueden beneficiar gallinas durante el día y ser conservadas en la zona de refrigeración para ser vendidas junto con los pollos beneficiados en su horario de despacho. Igualmente pueden comercializarse productos relacionados tales como huevos frescos, pavita trozada congelada y cerdo congelado.

- Mantener una relación estrecha con la municipalidad y las asociaciones de los mercados de abasto para promover a través de ellos la formalización de este proceso y que cuenten con la alternativa de recomendar a las avícolas y picadores el uso de CBA formales y certificados.

- Utilizar como elemento principal la estrategia de marketing de fidelización boca a boca a través de impulsadoras en los puestos de mercado contemplado en el plan de negocio a largo plazo para que concienticen al consumidor final sobre las bondades del servicio e identifiquen nuevas necesidades que puedan ser materializadas rápidamente en el negocio.

- Monitorear y mantener actualizada la página web con las últimas intervenciones municipales a centros de pelado locales clandestinos, así como los cambios en la legislación vigente respecto al negocio avícola. 


\section{ANEXOS}

\section{Anexo $N^{\circ} 1$ : Entrevista a profundidad $N^{\circ} 01$ - Especialista del sector.}

\section{Ficha Técnica - Estudio Exploratorio}

Perfil: Experto en el sector, con experiencia en el comportamiento de la demanda y con conocimiento de las nuevas tendencias en el mercado objetivo.

Objetivo: Conocer, desde el punto de vista de un experto cuales son los comportamientos de la demanda que deben servir de base para enfocar el negocio y recoger las sugerencias que ayuden a afinar la propuesta de negocio.

Método: El tipo de técnica usada fue la entrevista a profundidad.

Fecha y lugar: La entrevista se llevó a cabo el día martes 09 de mayo del 2017 en las instalaciones de la empresa San Fernando y tuvo una duración de 58 minutos.

Responsable: La persona responsable de ejecutar la entrevista fue Violeta Fernández Locatelli, miembro del equipo de la Maestría en Administración de empresas (MBA) de la Escuela de Postgrado de la Universidad San Ignacio de Loyola.

Entrevistado: Cesar Padilla, Jefe de Planeamiento de la Demanda de San Fernando S.A.

\section{Ejecución de la entrevista:}

1. En su experiencia en el sector avícola y sobre todo en el rubro de la venta de pollo vivo, ¿cómo describiría la tendencia de este sector? ¿porque?

Este sector se encuentra posesionado en la venta de pollo vivo. Perú, México y Guatemala (en muy poca escala) son los tres únicos países que continúan con esta práctica. Se prevé que será permanente en la medida que el pollo forma parte de la canasta familiar por un 
lado pero más relevante es por la cultura del país con una población acostumbrada a este tipo de comercialización. Las principales empresas del sector dan trabajo a muchas familias que literalmente viven de este negocio.

2. ¿Usted cree que las acciones gubernamentales del estado peruano con respecto a la comercialización de aves vivas tiene una tendencia a disminuir? si no fuera así, ¿cuáles serían las oportunidades que se presenta al respecto?

No. Por el contrario, cada vez más el gobierno y las municipalidades inciden en formalizar las peladurías, interviniéndolas y exigiendo mejores condiciones sanitarias. Al inicio no se podía trabajar porque no había ninguna planta que pudiera soportar todo el volumen que se requería beneficiar.

Esta es una gran oportunidad porque por ejemplo, en San Fernando estamos enfocados en tener procesos con certificaciones BPM, HACPP, ISO que finalmente pierden su valor al ingresar a esas peladurías informales donde la inocuidad es nula. Cualquier empresa avícola, por el tipo de negocio debe tener prácticas sanitarias adecuadas. La reglamentación debe ser informada y hacerse cumplir.

3. Ud. es un profesional que tiene muchos años desempeñándose en el sector avícola. ¿Cuáles considera que serían ventajas y desventajas que podrían presentarse para aquellos inversionistas potenciales que quisieran invertir en este sector? ¿Podrían ser superadas con mayor apoyo del gobierno?

Una ventaja competitiva es que estas peladurías son nuevos actores dentro de esta cadena de valor. San Fernando lo ha incorporado al flujo de distribuidores pero definitivamente puede hacerse con mayoristas y otros clientes. Como desventaja es que compite con informales que pueden sentirse amenazados con la aparición de estos centros formales. 
También recordar que este negocio es trabajado de noche con una ventana horaria corta y la necesidad de cercanía a los mercados hace que los locales para implementar estos negocios sean cada vez más escasos y con restricciones propias del negocio. Esto se puede superar si el gobierno enfatiza en la necesidad de contar con centros de beneficios formales, higiénicos y que se preocupen por los impactos ambientales. Es un negocio interesante porque puedes marcar diferencia pudiendo tener mayores clientes que de todas formas estarían dispuestos a pagar unos centavos más por un mejor servicio.

4. ¿Qué propuestas de valor considera que podrían ser clave y que serían apreciadas por los usuarios? ¿Por qué? ¿Cómo piensa Ud. que estas ofertas de valor pueden ser reconocidas por los clientes finales?

Las propuestas de valor que reconocen los clientes son la duración del producto, que cumplan con las ventanas horarias de atención que ellos requieren y que tenga una duración en tabla importante ya que algunos clientes dejan hasta el día siguiente su producto en conservadoras. Estos son temas de calidad que los clientes pueden fácilmente reconocer si es que las amas de casa logran comparara cómo es un beneficio informal contra las bondades de uno formal. Esto haría que ellas mismas fueran las que solicitarían a los propios picadores que el origen de sus productos sea de calidad.

5. ¿Cómo describiría la demanda actual de servicios de beneficio y pelado de aves, teniendo en cuenta la informalidad presentada en el sector? ¿Cree que podría ser una oportunidad?

Hoy entre el $5 \%$ y $7 \%$ de los empresas que realizan la actividad de pelado son picadores y la diferencia son avícolas entre medianas y grandes (75\% avícolas medianas y $19.5 \%$ avícolas grandes), esta información es aproximada ya que no existe información estadística 
que se pueda analizar. Existe una demanda insatisfecha producto de las regulaciones propias del gobierno y de las municipalidades. Además el crecimiento de la industria viene acompañado de esta necesidad. Es una oportunidad interesante ya que al haber tanta informalidad, se pierde la oferta y garantía de valor.

Pueden reconocer las marcas y esto es una oportunidad interesante para que se le permita culminar con la cadena de valor y que los clientes reciban el producto con las buenas prácticas desde la manufactura.

6. ¿Cuáles son de los sistemas de operación de los CBA considera Ud. que son las más representativas del sector? ¿pueden ser diferenciadas por el cliente? ¿Por qué?

Los sistemas que más se usan en este proceso son sistemas manuales con poco cuidado en la higiene. Podemos ubicar en promedio más de 160 avícolas y picadores de las cuales el 93\% son avícolas, ellos hacen uso de peladurías por cada grupo de mercados periféricos en un distrito como san Juan de Lurigancho donde se comercializan algo de 75,000 pollos diarios.

7. ¿Cuál cree Ud. que deberían ser las consideraciones a tomar dentro de un estudio de riesgos respecto a la implementación de un CBA? ¿Por qué los considera así?

Los riesgos asociados a la operación no son tan relevantes. Más habría que estar atentos a los temas de distribución que podrían darse al momento de tener picadores acumulados en las puertas de las peladurías. Hoy las casas trabajan como peladurías y pueden ser intervenidos por la municipalidad.

Los riesgos de estar manejando dinero en la noche pueden darse por la situación de inseguridad que viene atravesando el país. Pero pueden manejarse líneas de crédito u otros mecanismos que aseguren los pagos previos. 


\section{8. ¿Qué recomendaciones adicionales podría dar a los inversionistas de este rubro?}

Que se empapen bien de las normas regulatorias para poder sacarle el máximo provecho. Además el hecho de que la gente vaya viendo como los locales informales se van cerrando invita a tener un pollo grande para entrar al sistema.

La ventana horaria es lo más importante a considerar como propuesta de valor y sobre esta característica deberíamos dimensionar las operaciones.

9. En relación a las peladurías que existen en la actualidad, ¿Considera que existe información estadística que podamos revisar? y ¿En dónde podemos conseguir esta información?

Existe muy poca información relacionada a la industria de las peladurías, en general esta información es nula en los mercados de venta de pollo vivo. Prácticamente el 100\% de las empresas que se dedican a esta actividad lo hace de manera informal lo que hace muy difícil de cuantificar sus ventas u otra información que sea necesaria para su trabajo de investigación.

10. En relación al acceso a las avícolas y picadores en los centros de acopio, ¿Considera que la disposición de las personas para ser entrevistadas o encuestadas es fácil?, ¿Por qué?

No, como lo comente en la pregunta anterior estas empresas conviven con la informalidad, además considerando que trabajan de noche y por el riesgo que corren ya que cuentan con mucho dinero en el bolsillo para el pago del pollo vivo, estas empresas no son accesibles a entrevistas o encuestas, en el caso que lo hagan lo hacen con preguntas muy cortas o puntuales. 
11. Desde su experiencia en el sector y consideran que se trata de un proyecto nuevo, ¿Qué cantidad de clientes y demanda podría tener el servicio?

La cantidad de clientes va a depender de la capacidad de planta que implementen, considero que el servicio tendrá una muy buena aceptación. Lamentablemente no se cuenta con información de las peladurías actuales para tomar como referencia, pero para empezar una planta que beneficie 10,000 pollos puede ser fácilmente cubierta en las condiciones actuales de la industria. 


\section{Anexo $N^{\circ}$ 2: Entrevista a profundidad $N^{\circ} 02$ - Especialista del sector.}

\section{Ficha Técnica - Estudio Exploratorio}

Perfil: Experto en el sector, con experiencia en el comportamiento de la demanda y con conocimiento de las nuevas tendencias en el mercado objetivo.

Objetivo: Conocer, desde el punto de vista de un experto cuales son los comportamientos de la demanda que deben servir de base para enfocar el negocio y recoger las sugerencias que ayuden a afinar la propuesta de negocio.

Método: El tipo de técnica usada fue la entrevista a profundidad.

Fecha y lugar: La entrevista se llevó a cabo el día lunes 08 de mayo en las instalaciones de la USIL y tuvo una duración de 55 minutos.

Responsable: La persona responsable de ejecutar la entrevista fue Violeta Fernández Locatelli, miembro del equipo de la Maestría en Administración de empresas (MBA) de la Escuela de Postgrado de la Universidad San Ignacio de Loyola.

Entrevistado: Eduardo Parodi Macedo, Gerente de Operaciones y Desarrollos de Phartec. Hasta hace dos meses se desempeñó como Gerente de Planeamiento de la Producción en San Fernando S.A.

\section{Ejecución de la entrevista:}

1. En su experiencia en el sector avícola y sobre todo en el rubro de la venta de pollo vivo, ¿cómo describiría la tendencia de este sector? ¿porque?

Es un sector que en los últimos años se encuentra en proceso de formalización. Si recordamos como era la comercialización hace 10 años donde las aves llegaban vivas al mismo puesto del minorista hoy esto ya no es posible tienen que llegar ya beneficiadas lo que 
ha ocasionado que se incluya en la cadena de comercialización un proceso más antes de llegar al puesto del minorista que es el beneficio de las mismas.

2. ¿Usted cree que las acciones gubernamentales del estado peruano con respecto a la comercialización de aves vivas tiene una tendencia a disminuir? si no fuera así, ¿cuáles serían las oportunidades que se presenta al respecto?

Todo lo contrario, estas irán aumentando, presentándose una gran oportunidad para las empresas o personas que la identifiquen la necesidad que se tiene de entregar un producto de calidad y con la salubridad que hoy exige el consumidor. Recordemos que hoy los consumidores son más exigentes solo recodemos lo que está sucediendo en restaurantes de Lima cerrados como 2 do muelle.

3. Ud. es un profesional que tiene muchos años desempeñándose en el sector avícola. ¿Cuáles considera que serían ventajas y desventajas que podrían presentarse para aquellos inversionistas potenciales que quisieran invertir en este sector? ¿Podrían ser superadas con mayor apoyo del gobierno?

Ventajas:

Primero que se convierte en un negocio donde además de generar un ingreso estamos contribuyendo a proporcionar un producto saludable para el consumidor.

Un problema es tener establecimientos que cuenten con todas las condiciones para operar y dedicarse al beneficio de aves. Para ello es importante la intervención del estado para impedir que informales puedan seguir trabajando sin las autorizaciones respectivas sin cumplir las normas de buenas prácticas de manufactura.

Cuando habla de problemas para tener establecimientos que cuenten con todas las condiciones me refiero a que el estado debería definir determinadas zonas donde deben 
operar para no convivir la población con estos centros de beneficio que deben cumplir las normas de salubridad hoy vigentes.

Recordemos que somos uno de los pocos países a nivel latinoamericano por no decir los únicos donde aún el pollo llega vivo a la ciudad donde es beneficiado antes de ser vendido en los puestos de mercado.

El gobierno debe permitir por ser el pollo un alimento base de la canasta familiar el ingreso de equipos de beneficio sin impuestos para incentivar el aumento de este tipo de mataderos semi industriales que cumpliendo las buenas practicas se garantiza un producto libre de patógenos que pueden afectar al consumidor.

4. ¿Qué propuestas de valor considera que podrían ser clave y que serían apreciadas por los usuarios? ¿Porque? ¿Cómo piensa Ud. que estas ofertas de valor pueden ser reconocidas por los clientes finales?

Que se proporciona un producto (pollo) beneficiado en mataderos donde se cumplen las buenas prácticas de manufactura que garantizan un producto libre de patógenos, saludables para el consumo humano y que además cumplen con la normativa medio ambiental. El mayor valor es pensando en el consumidor en este caso la familia peruana.

5. ¿Cómo describiría la demanda actual de servicios de beneficio y pelado de aves, teniendo en cuenta la informalidad presentada en el sector? ¿Cree que podría ser una oportunidad?

Si es una oportunidad, la demanda existe el problema es que aún se está manejando sin un efectivo control del estado, donde verifique la calidad de estos procesos y verificando que se cumplan las normas adecuadas de salubridad. Quien inicie este proceso de formalización es decir el inicio de este tipo de Beneficio tiene el éxito garantizado ya que sin duda tendrá el 
apoyo de los consumidores que hoy están muy interesados en consumir alimentos que no se conviertan en un riesgo para su salud.

6. ¿Cuáles son de los sistemas de operación de los CBA considera Ud. que son las más representativas del sector y pueden ser diferenciadas por el cliente? ¿Porque?

Primero que es un sistema que garantiza que el beneficio de los pollos se realiza cumpliendo las buenas prácticas lo que garantiza al consumidor que el producto obtenido de este proceso cuida la salud del consumidor. Cumple con las normativas establecidas por el gobierno.

7. ¿Cuál cree Ud. que deberían ser las consideraciones a tomar dentro de un estudio de riesgos respecto a la implementación de un CBA? ¿Porque los considera así?

Principal tema es la ubicación del centro de beneficio de aves, es importante que este en una zona donde no complique a las personas que viven en los alrededores

Ubicado cerca del mercado para facilitar la comercialización del producto. Estos permitirías que el mismo minorista recoja el producto o que se los lleven a su puesto.

No descuidar el tema del tratamiento de las aguas residuales, esto tiene que ser bien manejado de lo contrario se convierte en un problema.

Automatizar todo lo que sea posible para no incrementar los costos de beneficio (definir que automatizar y que no)

Vender bien la oferta de valor, bien direccionada será de rápida aceptación por los minoristas ya que puede ser un valor adicional apreciado por el consumidor. Si se le comunica al consumidor las condiciones en las que fue beneficiado el pollo y con ello garantizamos un producto saludable al consumidor. 
8. ¿Qué recomendaciones adicionales podría dar a los inversionistas de este rubro?

Que un alimento tan importante como el pollo necesita ser ofrecido al consumidor en las mejores condiciones de salubridad y este negocio además de generar un ingreso interesante contribuye a garantizar al consumidor productos saludables. Es una excelente oportunidad ya que podemos ir mejoramos la calidad de vida de los peruanos.

9. En relación a las peladurías que existen en la actualidad, ¿Considera que existe información estadística que podamos revisar? y ¿En dónde podemos conseguir esta información?

Pienso que no, es muy difícil conseguir información incluso para las empresas grandes que necesitarían invertir una buena cantidad de dinero para realizar un estudio de mercado. La informalidad ha hecho de esta parte del sector muy cerrado y solo conocido por las personas que opera en él. Pienso que para conseguir información deben recurrir a otros especializas ya que de otra forma les va a resultar muy costoso y difícil de acceder.

10. En relación al acceso a las avícolas y picadores en los centros de acopio, ¿Considera que la disposición de las personas para ser entrevistadas o encuestadas es fácil?, ¿Por qué? Es muy complicado por la informalidad con que operan, si no te conocen no tienes acceso a ellos, el horario es un problema porque trabajan de noche y eso hace que sientan un poco de temor.

11. Desde su experiencia en el sector y consideran que se trata de un proyecto nuevo, ¿Qué cantidad de clientes y demanda podría tener el servicio?

Primero deben de encontrar la cantidad de pollo que benefician sus futuros clientes, el servicio es muy bueno y se ajusta a las regulaciones que exige el gobierno en la actualidad, 
sobre ello es mejor que piensen en su capacidad de planta. Una capacidad mínima de 12,000 pollo estaría bien para empezar. 


\section{Anexo $N^{\circ}$ 3: Entrevista a profundidad $N^{\circ} 03$ - Cliente potencial.}

\section{Ficha Técnica - Estudio Exploratorio}

Perfil: Personas que no usan el servicio de peladurías de terceros porque esa actividad la realizan ellos mismos.

Objetivo: Entender cuáles son las oportunidades que se presentan y como deberían ser enfocadas para ser reconocidas como una oferta de valor y si coinciden con lo planificado para el negocio

Método: La técnica utilizada fue a través de entrevista a profundidad Fecha y lugar: La entrevista se llevó a cabo el 23 de mayo en el puesto de mercado del picador y tuvo una duración de 35 minutos.

Responsable: La persona responsable de ejecutar la entrevista fue Christian Gago, miembro del equipo de la Maestría en Administración de empresas (MBA) de la Escuela de Postgrado de la Universidad San Ignacio de Loyola.

Entrevistado: Picador que beneficia pollos en su puesto de mercado o en su casa.

\section{Ejecución de la entrevista:}

1. ¿Cuál es su nombre o el de su empresa y a que se dedica?

Mi nombre es Rolando Salvatierra, dueño de AVICOLA VICRA. Dejo mi teléfono: 956460185.

2. ¿Cuáles son los problemas que observa actualmente en los modelos de beneficio y pelado de pollo? ¿Porque?

Yo decidí pelar por mi propia cuenta los pollos porque los locales son muy sucios, no tienen agua potable y a veces hasta ni luz tienen. La municipalidad siempre está cerrando los locales 
y peladurías informales y como son cierres de sorpresa en ese momento es difícil encontrar otro lugar, eso demora que llegue a tiempo al mercado.

3. ¿Piensa que los clientes finales están siendo cada vez más exigentes en cuanto a la calidad del servicio de pelado?

Bueno ahora en mi local, las clientas si se dan cuenta cuando el pollo está demasiado sancochado, o medio aceitoso y grasoso. También nos afecta cuando viene con la piel desgarrada y se ve la carne del pollo. Se siente mal olor cuando están metidos mucho tiempo en las bolsas y las clientas reclaman.

4. Cada vez son más los establecimientos informales que se vienen siendo clausurados en cumplimiento con las leyes municipales. ¿Esto puede perjudicar su negocio actual?

Bueno actualmente en mi local cuento con permisos para pelar pollos pero no es tan formal porque no solo la municipalidad da los permisos. Hay otras oficinas que también tienen que aceptar

5. ¿Cree Ud. que sería una buena alternativa contar con un CBA regulado y certificado? ¿Qué beneficios le podría traer a su negocio? ¿Porque?

Si sería una buena alternativa y que se encuentre cerca de mi local.

El beneficio seria que dejaría de pelar y no dependería de mis trabajadores. A veces faltan, también me quitan tiempo. 
6. ¿Es importante para Ud. contar productos que provengan de un CBA regulado y certificado? ¿Cree Ud. que sus ventas aumentarían si los clientes se enteraran que está beneficiando su pollo en un CBA autorizado? ¿Porque?

Por ahora mis clientes confían en la pelada que realizo, y saben que mi local es limpio. Más bien si yo veo beneficios como que mi pollo dure más en la mesa o que tenga mejor acabado si podría decirle a las clientas eso y capaz aumenten las ventas.

7. ¿Le paga a alguien por este servicio? ¿El precio que paga le parece el adecuado?

Si le pago a mis peladores 60 soles el día. Eso me sale más o menos 0.30 céntimos por pollo.

8. ¿Cuánto estaría dispuesto a pagar como máximo con un CBA?

En un centro de pelado podría pagar hasta 0.35 céntimos por pollo.

9. En su experiencia, ¿Cuál debería ser una propuesta de valor que sería apreciada por Ud. o su cliente final? ¿Porque?

Se encuentre cerca de local, que llegue a tiempo y que me dure más.

10. ¿Cómo describiría la demanda actual de los servicios de centros de pelado y su relación con la oferta de pollo diaria?

Por la zona ha aumentado porque en algunos mercados ya no se puede pelar. Acá ingresa mucho pollo y se necesita ese servicio.

11. ¿Qué tipos de peladurías conoce que operan actualmente? ¿Considera que su operación es adecuada para lo que necesita su negocio?

Una que es la de Chicho, la de Elisa pero están muy lejos de mi local, a veces no hay cupo y no llegan puntuales por eso decidí pelar. 
12. ¿Cuánto tiempo es la demora de atención de una peladuría? ¿Cuál sería el ideal? ¿Qué considera clave?

Normalmente beneficio de 4 a 6 am una cantidad de 200 jabas. Es clave salir temprano de allí para poder repartir el pollo a los puestos.

13. ¿Cuáles son las recomendaciones que haría para las empresas que desean incursionar en el negocio de operar un CBA con buenas prácticas de manufactura?

Que tengan una buena pelada y un buen sangrado. 


\section{Anexo $N^{\circ}$ 4: Entrevista a profundidad $N^{\circ} 04$ - Cliente Actual.}

\section{Ficha Técnica - Estudio Exploratorio}

Perfil: Clientes que compran pollo vivo y utilizan los servicios de una peladuría.

Objetivo: Conocer cuáles son los factores que influyen en la decisión del cliente de elegir una peladuría sobre otra para la ejecución de los procesos de beneficio y pelado de pollos antes de su entrega al cliente final. Clarificar la oferta de valor, nivel de aceptación modelar el negocio

Método: La técnica utilizada fue a través de entrevista a profundidad.

Fecha y lugar: La entrevista se llevó a cabo el 25 de mayo en el mercado de San Luis y tuvo una duración de 29 minutos.

Responsable: La persona responsable de ejecutar la entrevista fue Christian Gago, miembro del equipo de la Maestría en Administración de empresas (MBA) de la Escuela de Postgrado de la Universidad San Ignacio de Loyola.

Entrevistado: Avícolas y picadores que usan peladurías.

\section{Ejecución de la Entrevista}

1. ¿Cuál es su nombre o el de su empresa? y ¿a qué rubro se dedica? Mi nombre es Juan Leonardo Chavez y mi empresa se llama Avícola Richard

\section{2. ¿Con qué frecuencia utiliza una peladuría? ¿Porque?}

Todos los días voy a comprar Pollo al centro de acopio de San Luis. Por ejemplo hoy 25/05 he comprado el Kg de pollo Vivo a S/. 5.35 por Kg a Laura, 40 jabas (20 jabas: de macho (15) y de hembra (4) con un peso de $2.659 \mathrm{~kg}$ promedio por pollo.

Los he recogido a las 4 am y he pagado 0.30 centavos por pollo pelado. 
3. ¿Qué tan importante es para su negocio el contar con una peladuría? ¿Conoce otra forma de cómo podría hacer este proceso?

No he considerado pelar, porque no tengo local y es muy sacrificado. Prefiero pagar por ese servicio además que no es muy caro. En cambio para mí sería buscar gente, ollas, agua. No.

4. ¿Cuáles son aquellos aspectos que considera negativos de la actual forma de funcionamiento de las peladurías? ¿Estos aspectos podrían cambiar la decisión de compra de su cliente? ¿Porque?

A veces están mal sangrados, los pollos vienen verdes y el personal que pela a veces llega tarde o simplemente hay ausencia de personal. Mis clientes no saben dónde pelo el pollo, pero sí reconocen algunas cosas que quieren del pollo.

5. ¿Cuáles son las cosas más importantes que una peladuría debe ofrecerle a Ud. como cliente?

Que tenga un buen sangrado. La pelada debe ser limpia. El tiempo que aproximadamente se necesita para pelar seria 50 jabas en 15 minutos, no remojar en agua estancada, esto le quita duración y huele feo.

6. ¿Cuánto es el tiempo que demora el proceso de beneficio de los pollos que Ud. comercializa diariamente? ¿Cuál considera que debe ser el tiempo más adecuado? ¿Porque?

Consideran ideal el tiempo actual es de 50 jabas x 15 minutos, considero que el tiempo actual sería el adecuado. 
7. ¿Cómo elige a qué lugar lleva a beneficiar a sus pollos? ¿Qué criterios considera para ello?

Me voy por la cercanía de donde me venden los pollos vivos, pero siempre estoy buscando sitios donde no los pelen con agua sucia ni estancada.

8. ¿Qué opina de la ventana horaria de atención? ¿Cuál debería ser, en su opinión esa ventana? ¿Porque?

El horario ideal para que me permitan repartir los pollos en los puestos de mercado es a las 5:30am, eso quiere decir que el pollo debe llegar entre la 1 am hasta las 2 am y tener el pollo listo para repartir a las 5:30am para llegar a más tardar a las 9am.

Yo compro bolsas para llevar el pollo pelado (10 pollos por bolsa) y la peladuría se queda con las tripas.

9. ¿Considera que el tiempo de vida útil de pollo desde que se le es entregado ya beneficiado es importante? ¿Porque? ¿Cuántas horas deberían durar los pollos en mesa?

Claro, el pollo debe durar hasta la 1 pm y de allí si me sobra lo puedo guardar en la congeladora.

10. ¿Considera Ud. que un servicio con mejores condiciones de sanidad y limpieza le puede dar un valor adicional a su producto?

En el mercado si porque la calidad y limpieza si las pide el ama de casa. Y si consigo pollo barato, puedo pagar algo adicional por esa calidad. 
11. ¿Considera que es importante que un servicio con buenas prácticas sanitarias lo deberían conocer sus clientes directos? ¿Porque?

Sí, es importante pues me exigirían más, y me pueden preferir a mí más que al resto para comprarme pollo.

12. ¿Cómo transporta sus pollos a los clientes o a los puestos de mercado una vez pelados?

En su carro y en bolsas que yo mismo compro.

13. ¿Estaría conforme con llevarse los pollos en bolsa de polipropileno con un logo que diga que han sido pelados con prácticas "Limpias”? ¿Porque?

Sí, sería factible así identificamos de donde vienen sobre todo los fines de semana donde van más clientes.

14. ¿Ud. que tiene contacto directo con los consumidores finales?, ¿cuál es la condición que más reclaman al momento de realizar la compra?

Lo que las amas de casa reclaman más es cuando los pollos tienen mal olor. Esto les da la sensación de que el pollo está contaminado o no es saludable. Es característica es la más importante porque siempre están pensando en llevar lo mejor para sus familias.

15. ¿Qué otras características son observadas por las amas de casa cuando eligen un pollo sobre otro ya en tabla?

Hay muchas clientas que, como compran todos los días, ya conocen como son los pollos de buena calidad. Se fijan en que no estén golpeados ni con la piel desgarrada. También miran el acabado de la piel, que esté lisa, húmeda y que no tengan restos de plumas o cañones ni manchas oscuras. 
16. ¿Qué opinan las amas de casa del color del pollo?, ¿Les sugiere alguna cualidad positiva?

Las clientas piden un pollo con un color uniforme. No les gusta el color moteado ni muy blanco ni muy amarillo. Cuando tocan el pollo se aseguran también que la carne sea firme y los muslos musculosos. 


\section{Anexo $N^{\circ}$ 5: Entrevista a profundidad $N^{\circ} 05$ - Competidor Relacionado}

\section{Ficha Técnica - Estudio Exploratorio}

Perfil: Distribuidores que hayan incorporado dentro de su modelo de negocio principal un CBA (Centro de beneficio de aves) como parte de su cadena de valor

Objetivo: Conocer, en base a las experiencias desarrolladas durante su operación, cuales son los factores de éxito del negocio.

Método: La técnica utilizada fue a través de entrevista a profundidad.

Fecha y lugar: La entrevista se llevó a cabo el 25 de mayo en local del distribuidor localizado en Lurín y tuvo una duración de 35 minutos.

Responsable: La persona responsable de ejecutar la entrevista fue Christian Gago, miembro del equipo de la Maestría en Administración de empresas (MBA) de la Escuela de Postgrado de la Universidad San Ignacio de Loyola.

Entrevistado: Distribuidor con CBA. Jorge Huascupe.

\section{Ejecución de la entrevista:}

1. De acuerdo a como viene operando, ¿Cuáles son las ventajas o beneficios identificados al contar con un CBA dentro de su cadena de valor? ¿Por qué?

Un CBA permite atender directamente a los clientes minorista, reduciendo la intermediación del mayorista de pollo beneficiado, diversificando la cartera se reduce la dependencia de mayoristas, que son muy sensibles al precio.

Agregando a la comercialización de pollo vivo el beneficio de aves, logramos una mayor rentabilidad y una reducción del riesgo de cobranza. 
Asimismo, se tiene la oportunidad de incursionar en otros negocios anexos como la venta a hoteles, restaurantes y negocios de comidas y la comercialización de productos adicionales como huevo, pavita, menudencias, cortes especiales y pollo brasa.

2. ¿Quiénes considera que son sus principales competidores con respecto al CBA? ¿Identifica alguna ventaja que puedan tener sobre Ud. sobre el resto al tener este proceso en su cadena de valor? ¿Cree Ud. que esa ventaja impacta en sus ventas?

El sector avícola está saturado de mayoristas grandes, medianos y pequeños, la principal competencia son los grandes mayoristas de pollo vivo que por su volumen de compra manejan precios más bajos, que les sirve para captar a los mayoristas medianos y pequeños de pollo beneficiado, muy sensibles al precio de venta.

El CBA ofrece al mayorista un lugar de beneficio adecuado con precio de volumen (agrupado) y prestación del servicio de administración del local a menor costo que el que tendrían de forma individual.

Esta reducción de costos permite tener un producto final a precios muy competitivos.

3. ¿Cuáles son las principales dificultades que ha tenido al implementar un CBA en su local? ¿Esta actividad está regulada por la municipalidad o las entidades pertinentes? ¿Cómo maneja estas situaciones?

Es muy complejo (y costoso) lograr las licencias municipales y Defensa Civil. El local debe adecuarse a los requerimientos mínimos de sanidad, que pueden llegar a ser onerosos según las circunstancias. La regulación de estos locales corresponde a SENASA que tiene requisitos muy estrictos para obtener los permisos, los cuales demoran en gestionarse de 2 a 3 meses. Esto pasa porque SENASA, dentro de su modelo de operación sigue las referencias de las certificaciones de BPM las cuales son difíciles de implementar si no se 
tiene considerado como objetivo estratégico. Es por ello la gran mayoría de CBA opera sin la licencia de SENASA, solo con la licencia municipal.

Además, periódicamente se recibe visitas de la Policía Fiscal, Medio Ambiente Municipal, Fiscalización Municipal, Seguridad del Estado y SENASA, que obligan a tener un presupuesto para solventar las observaciones que realizan a la operación de CBA.

Otro factor importante es lograr hacer atractiva y sostenible la oferta de valor al mayorista que beneficia en el CBA, a fin de fidelizarlo.

4. ¿Cómo define Ud. la demanda actual de un CBA para clientes que compran pollos? ¿Por qué lo considera así?

La tendencia actual es la comercialización directa del pollo beneficiado a los clientes minoristas, y aunque la mayoría de estos mayoristas usan sus propios camales ya existen CBA que permiten al mayorista trasladar todos los temas sanitarios y de licencia a la Administración del CBA, asimismo se obtiene un precio competitivo si se negocia el precio menor por el volumen total de CBA. Sin embargo el incremento de CBA aún es muy lento, pues los grandes mayoristas prefieren tener sus camales propios, y los pequeños son muy renuentes a la formalización.

5. ¿Cree que se produzca un crecimiento mucho mayor de la necesidad de CBA a través de los años? Con los modelos actuales de operación, ¿Considera que podrán ser cubiertas estas necesidades? ¿Cuáles son sus sugerencias para el tratamiento de estos CBA?

El crecimiento de los CBA se limita por la formalización y regulaciones que se requiere cumplir. 
Actualmente existen muchos camales clandestinos, muchos de ellos con la anuencia de las autoridades municipales, esto permite que los mayoristas pequeños se sientan cómodos con su situación actual de informalidad.

Convencer a los mayoristas de usar los CBA sería más eficiente si las regulaciones sanitarias de los camales se aplicaran.

6. ¿Cree Ud. que este servicio es uno de los que más se valoran o generan mayor impacto en el mercado? ¿Cómo cree Ud. que sean reconocidos por sus clientes?

El consumidor final difícilmente se percata si el pollo que compra proviene de un camal clandestino o un CBA, básicamente la diferencia la observa el cliente minorista que percibe la calidad del producto y su precio, siendo esto último lo que más le importa.

7. ¿Cree Ud. que una propuesta de CBA con buenas prácticas en su operación tenga aceptación en los clientes? ¿Por qué? ¿Podría tener algún impacto en la rentabilidad del negocio? ¿Cómo?

El mayorista valora su rentabilidad, si estas buenas practicas incrementan demasiado el costo del servicio de beneficio pueden optar por mantenerse en la informalidad. Solo si las regulaciones hicieran más costoso ser informal, se obtendría un impulso mayor para la CBA.

8. ¿Considera que automatizar el proceso de beneficio de aves puede considerarse ventajoso para Ud.? ¿Y para sus clientes?

Actualmente la automatización ha tenido bastante aceptación en el pollo brasa, para el pollo carne no ha sido tan eficiente pues los clientes finales prefieren el pelado manual, que logra un pelado que no daña la cutícula del ave manteniéndose el color amarillo característico del pollo de mercado y preferido por las amas de casa. 


\section{9. ¿Cuáles serían las desventajas de esta nueva propuesta de CBA automatizado?}

$\mathrm{Su}$ principal problema es que actualmente no logra el beneficio de las aves con el característico color amarillo que solicita el mercado. Cualquier modelo que se piense implementar debe considerar las características que el público busca. Asimismo por el volumen que se requiere y sus costo la automatización del CBA está más para el perfil de los grandes mayoristas.

10. ¿Tendría alguna sugerencia que añadir a un modelo de CBA certificado?

El éxito del modelo CBA certificado se lograría si las regulaciones y medidas contra la informalidad de los actuales camales fueran más estrictas, básicamente se requiere alinear temas políticos muy sensibles. 


\section{Anexo $N^{\circ}$ 6: Ficha técnica de la Encuesta}

\begin{tabular}{|l|l|}
\hline \multirow{4}{*}{ Universo de Estudio } & $\begin{array}{l}\text { - Personas naturales con negocio } \\
\text { - Personas jurídicas }\end{array}$ \\
\cline { 2 - 2 } & $\begin{array}{l}\text { Empresas que utilizan centros de beneficio de pollo } \\
\text { Avícolas (minoristas) y picadores }\end{array}$ \\
\cline { 2 - 2 } & Formales e informales \\
\hline Cobertura geográfica & Distrito de San Juan de Lurigancho \\
\hline Recolección de la información & Encuesta presencial \\
\hline Tamaño de la muestra & 74 empresas \\
\hline Tipo de muestreo & No Probabilístico por conveniencia \\
\hline Nivel de Confianza & $90.0 \%$ \\
\hline Error muestral & $7.0 \%$ \\
\hline Fecha de campo & Entre el 8 y 12 de mayo del 2017 \\
\hline
\end{tabular}


Anexo $\mathbf{N}^{\circ}$ 7: Modelo de encuesta para avícolas y picadores

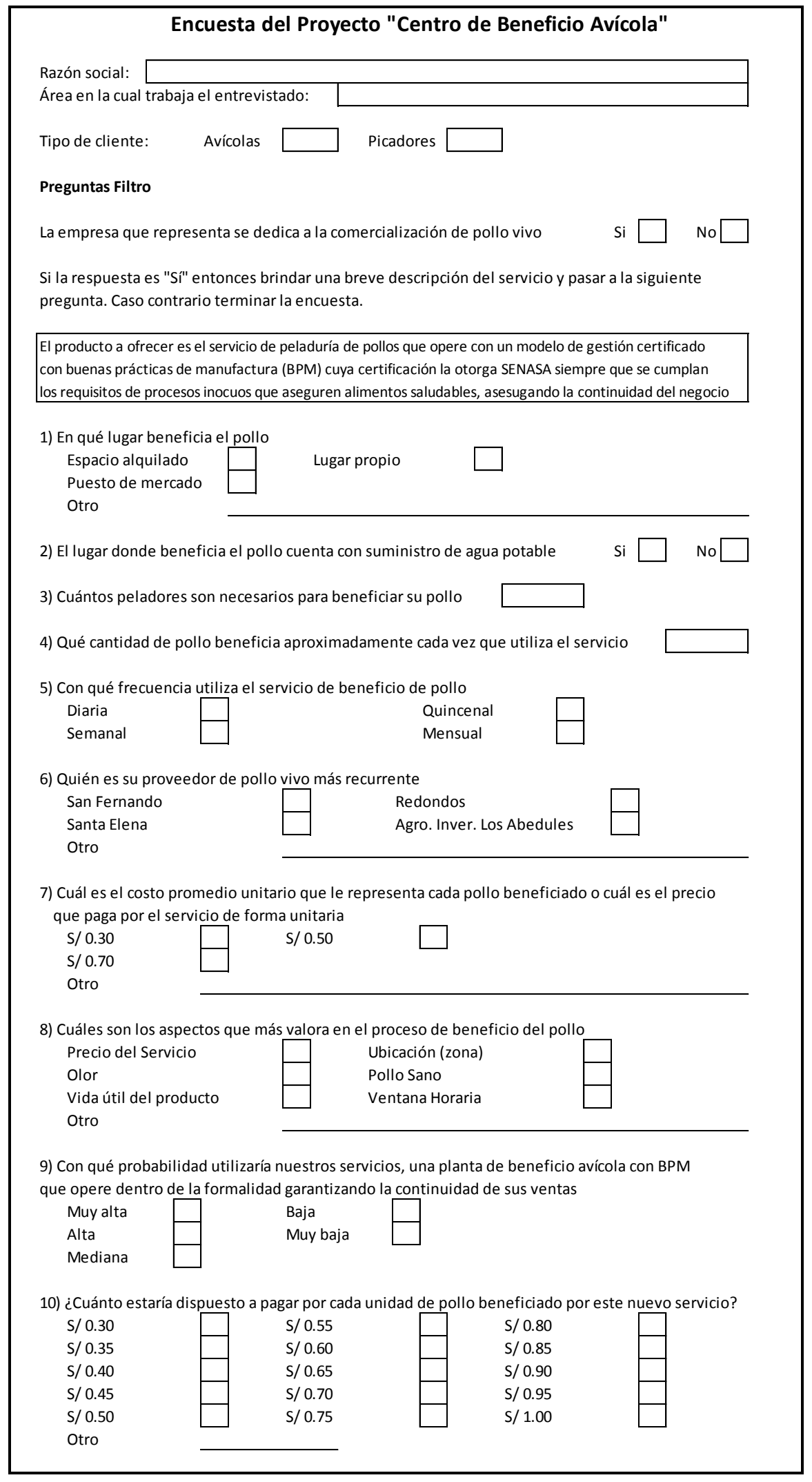




\section{Anexo $\mathbf{N}^{\circ}$ 8: Selección de equipamiento.}

En los cuadros adjuntos se encuentra en detalle los requerimientos necesarios e imágenes tentativas de cada recurso:

a) Infraestructura operativa

İtem Imagen referencial

\begin{tabular}{|c|c|}
\hline Ítem & Imagen referencial \\
\hline Aturdidor & \\
\hline
\end{tabular}

Ítem Imagen referencial

\begin{tabular}{|r|r|}
\hline İtem & Imagen referencial \\
\hline Zona de sangrado & \\
\hline
\end{tabular}

\begin{tabular}{|l|c|}
\hline Ítem & Imagen referencial \\
\hline Escaldador & \\
\hline & \\
\hline
\end{tabular}




Ítem Imagen referencial

Ítem

\begin{tabular}{|l|l|}
\hline \multicolumn{1}{|c|}{ Ítem } & Imagen referencial \\
\hline $\begin{array}{l}\text { Mesa de eviscerado, lavado y } \\
\text { empaque }\end{array}$
\end{tabular}

\begin{tabular}{|c|c|}
\hline Ítem & Imagen referencial \\
\hline Mangueras de limpieza
\end{tabular}

\begin{tabular}{|c|c|}
\hline Ítem & Imagen referencial \\
\hline Tinas limpia botas & \\
\hline
\end{tabular}


b) Implementos para operarios

\begin{tabular}{|l|l|}
\hline & Ítem \\
\hline Botas & Imagen referencial \\
\hline
\end{tabular}

\begin{tabular}{|l|c|}
\hline \multicolumn{1}{|c|}{ Ítem } & Imagen referencial \\
\hline Cuchillos & \\
\hline & \\
\hline
\end{tabular}

\begin{tabular}{|l|l|}
\hline & Ítem \\
\hline Guantes & Imagen referencial \\
\hline
\end{tabular}

\begin{tabular}{|l|l|}
\hline İtem & Imagen referencial \\
\hline Cascos & \\
\hline
\end{tabular}

\begin{tabular}{|l|l|}
\hline & Ítem \\
\hline & Imagen referencial \\
\hline Orejeras & \\
\hline
\end{tabular}

\begin{tabular}{|l|l|}
\hline \multicolumn{1}{|c|}{ Ítem } & Imagen referencial \\
\hline Mascarillas & \\
\hline & \\
\hline
\end{tabular}




\begin{tabular}{|l|c|}
\hline Ítem & Imagen referencial \\
\hline Mamelucos & \\
\hline & \\
\hline
\end{tabular}

\begin{tabular}{|l|c|}
\hline Ítem & Imagen referencial \\
\hline Gorras & \\
\hline
\end{tabular}

\begin{tabular}{|l|l|}
\hline Ítem & Imagen referencial \\
\hline Pinzas & \\
\hline
\end{tabular}

\begin{tabular}{|c|c|}
\hline Ítem & Imagen referencial \\
\hline Protectores plásticos & \\
\hline
\end{tabular}

\section{c) Equipamiento para oficinas}

\begin{tabular}{|l|l|}
\hline & Ítem \\
\hline Escritorio & Imagen referencial \\
\hline
\end{tabular}




\begin{tabular}{|l|l|}
\hline Ítem & Imagen referencial \\
\hline Sillas & \\
\hline
\end{tabular}

\begin{tabular}{|l|l|}
\hline & Ítem \\
\hline & Imagen referencial \\
\hline Laptop & \\
\hline
\end{tabular}

\begin{tabular}{|l|l|}
\hline Ítem & Imagen referencial \\
\hline Teléfonos & \\
\hline
\end{tabular}

\begin{tabular}{|c|c|}
\hline Ítem & Imagen referencial \\
\hline Tachos de basura & \\
\hline
\end{tabular}

\begin{tabular}{|c|c|}
\hline Ítem & \multicolumn{1}{|c|}{ Imagen referencial } \\
\hline Muebles archivadores & \multicolumn{1}{|c|}{} \\
\hline & \\
\hline & \\
\hline
\end{tabular}


d) Utensilios para la limpieza

\begin{tabular}{|l|l|}
\hline Ítem & Imagen referencial \\
\hline Escobas & \\
\hline
\end{tabular}

\begin{tabular}{|l|l|}
\hline & Ítem \\
\hline Baldes & Imagen referencial \\
\hline
\end{tabular}

\begin{tabular}{|l|l|}
\hline Ítem & Imagen referencial \\
\hline Escobillas & \\
\hline
\end{tabular}

\begin{tabular}{|l|l|}
\hline İtem & Imagen referencial \\
\hline Mangueras & \\
\hline
\end{tabular}

e) Equipamiento para el área de despacho

\begin{tabular}{|l|l|}
\hline Ítem & Imagen referencial \\
\hline Parihuela & \\
\hline
\end{tabular}


291

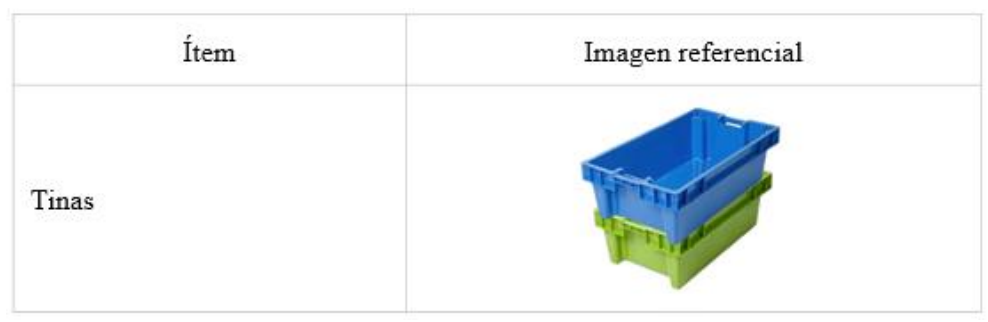




\section{Anexo $\mathbf{N}^{\circ}$ 9: Autorización sanitaria de apertura y funcionamiento de centros}

\section{de faenamiento.}

\begin{tabular}{|c|c|c|c|}
\hline \multirow[t]{2}{*}{ 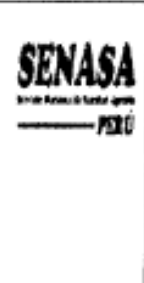 } & DIRECCIÓN DE SANIDAD ANIMAL & \multicolumn{2}{|c|}{$\begin{array}{c}\text { SUBDIRECCION DE } \\
\text { CONTROL Y } \\
\text { ERRADICACION DE } \\
\text { ENFERMEDADES } \\
\text { PRO-SCEE-06 }\end{array}$} \\
\hline & $\begin{array}{l}\text { PROCEDIMIENTO: AUTORIZACIÓN SANITARIA } \\
\text { DE APERTURA Y FUNCIONAMIENTO DE } \\
\text { CENTROS DE FAENAMIENTO. }\end{array}$ & $\begin{array}{c}\text { Revisión: } \\
00\end{array}$ & Página: 11 de 17 \\
\hline
\end{tabular}

\section{Anexo 1: \\ CARTILLA INFORMATIVA $N^{\circ} 4$}

Estimado Sr. Usuario, antes de presentar su solicitud para la autorización sanitaria de apertura y funcionamiento de Centros de Faenamiento considere los siguientes requisitos:

1. Luego de obtener la autorización de construcción, presentar a la Dirección Ejecutiva del SENASA de su jurisdicción, una solicitud indicando:

a) Nombre y dirección domiciliaria del propietario del establecimiento, quien deberá suscribir la solicitud.

b) Dirección, actividad o giro principal, número de teléfono y del fax (opcional). del establecimiento avicola.

c) Nombre, número de documento de identidad y número de colegiatura del profesional responsable.

Deberá adjuntar los siguientes documentos:

d) Copia de Registro Único de Contribuyente.

e) Copia del Título profesional, certificado de habilidad y documento de identidad del profesional responsable.

f) Copia simple de la licencia de construcción otorgada por la Municipalidad respectiva.

g) Copia del distintivo o logotipo de la empresa (opcional).

2. Los siguientes requisitos técnicos serán evaluados durante la inspección sanitaria del Centro de Faenamiento:

a) Profesional responsable que deberá ser médico veterinario, colegiado y habilitado, cualquier cambio será informado inmediatamente al SENASA.

b) Disponibilidad de agua potable

c) Sistema que garantice una adecuada limpieza.

d) El sistema de lavado de vehículos, jabas u otros elementos para el transporte, podrá estar ubicado dentro o fuera del establecimiento.

e) Servicios higiénicos completos, ubicados en una zona que permita el fácil acceso al personal que opera en el establecimiento, estos serán proporcionales a la afluencia de personas y deberán mantenerse permanentemente limpios

f) Una zona de despacho que deberá mantener las condiciones higiénicas que garanticen la inocuidad de las carcasas. Un sistema adecuado de recolección y eliminación de la basura y el estiércol.

g) Un sistema que asegure la destrucción de las aves desechadas, pudiendo ser realizada en el establecimiento o por terceros y sin que represente riesgo de escape de agentes patógenos para la avicultura o salud pública. 


\begin{tabular}{|c|c|c|c|}
\hline \multirow[t]{2}{*}{ SENASA } & DIRECCIÓN DE SANIDAD ANIMAL & \multicolumn{2}{|c|}{$\begin{array}{c}\text { SUBDIRECCION DE } \\
\text { CONTROLY } \\
\text { ERRADICACION DE } \\
\text { ENFERMEDADES } \\
\text { PRO-SCEE-06 }\end{array}$} \\
\hline & $\begin{array}{l}\text { PROCEDIMIENTO: AUTORIZACIÓN SANITARIA } \\
\text { DE APERTURA Y FUNCIONAMIENTO DE } \\
\text { CENTROS DE FAENAMIENTO. }\end{array}$ & $\begin{array}{l}\text { Revisión: } \\
00\end{array}$ & Página: 12 de 17 \\
\hline
\end{tabular}

h) El establecimiento debe realizar una adecuada eliminación, disposición y tratamiento de las aguas producto de las actividades de comercialización o faenamiento.

i) Instalaciones que permitan una fácil higienización y desinfección

j) Disponer de suficiente agua a una temperatura mayor de $60^{\circ} \mathrm{C}$ y/o vapor de agua.

k) Los Centros de faenamiento que presten servicio de congelación, deberán contar con la infraestructura que permita un adecuado proceso de enfriamiento y posterior almacenamiento de carcasas y menudencias a temperaturas óptimas.

I) La iluminación deberá tener una intensidad igual o mayor de:

i. 325 lux ( 30 bujias - pie) en los ambientes en general

ii. 540 lux ( 50 bujias - pie) en la sección de inspección sanitaria.

m) La iluminación no deberá afectar los colores y estará dirigida sobre el ave, en forma apropiada.

n) El flujo de aire debe ser de áreas limpias a áreas sucias y no al revés. No se deben concentrar gases ni malos olores.

o) Un sistema que asegure la destrucción de lo condenado, pudiendo ser realizada en el establecimiento o por terceros y sin que represente riesgo de escape de agentes patógenos para la avicultura o salud pública.

p) Las mesas de trabajo, el equipo de sangrado y los recipientes para recolectar la sangre serán de material impermeable, inoxidable, de fácil higienización y no contaminante. 


\section{Anexo $N^{\circ}$ 10: Detalle de la inversión inicial.}

\section{Tangibles}

\begin{tabular}{|c|c|c|c|c|c|c|}
\hline $\mathbf{N}^{\circ}$ & Área Operativa & Cant. & Pr. Unit. & Total S/ & IGV & Pr. Total \\
\hline \multirow[t]{10}{*}{1} & Transporte & & & & & \\
\hline & Cadena transportadora & 96 & 112 & 10,775 & 1,940 & 12,715 \\
\hline & Curva + Reductor de transmisión & 1 & 5,212 & 5,212 & 938 & 6,150 \\
\hline & Curva tensora & 1 & 3,178 & 3,178 & 572 & 3,750 \\
\hline & Curva de 180 & 3 & 1,620 & 4,861 & 875 & 5,736 \\
\hline & Curva de 90 & 9 & 1,406 & 12,650 & 2,277 & 14,927 \\
\hline & Ganchos de colgado & 475 & 30 & 14,041 & 2,527 & 16,568 \\
\hline & Cadenilla de arrastre de ganchos & 96 & 13 & 1,291 & 232 & 1,524 \\
\hline & Tubo de riel $11 / 4$ acero inox + platina $6 \mathrm{~mm}$ & 96 & 27 & 2,562 & 461 & 3,023 \\
\hline & Variador de velocidad & 1 & 657 & 657 & 118 & 775 \\
\hline \multirow[t]{6}{*}{2} & Equipamiento & 1 & & & & \\
\hline & Aturdidor & 1 & 14,796 & 14,796 & 2,663 & 17,459 \\
\hline & Tina de sangrado & 1 & 5,792 & 5,792 & 1,043 & 6,834 \\
\hline & Escaldador & 1 & 46,987 & 46,987 & 8,458 & 55,444 \\
\hline & Desplumador & 1 & 75,504 & 75,504 & 13,591 & 89,094 \\
\hline & Requemador & 1 & 10,476 & 10,476 & 1,886 & 12,362 \\
\hline 3 & Tablero electrico fuerza y control & 1 & 11,688 & 11,688 & 2,104 & 13,792 \\
\hline 4 & Estructuras & 1 & 20,509 & 20,509 & 3,692 & 24,201 \\
\hline 5 & Línea electrica, agua, aire y vapor & 1 & 8,294 & 8,294 & 1,493 & 9,787 \\
\hline 6 & Instalación y puesta en marcha de caldera & 1 & 5,744 & 5,744 & 1,034 & 6,777 \\
\hline 7 & Instalación general & 1 & 10,982 & 10,982 & 1,977 & 12,959 \\
\hline 8 & Mesas de trabajo & 3 & 900 & 2,700 & 486 & 3,186 \\
\hline 9 & Parihuelas & 18 & 64 & 1,144 & 206 & 1,350 \\
\hline \multirow[t]{2}{*}{10} & Tinas & 88 & 56 & 4,922 & 886 & 5,808 \\
\hline & Total & & & 274,764 & 49,458 & 324,222 \\
\hline $\mathbf{N}^{\circ}$ & Área Administrativa & Cant. & Pr. Unit. & Total S/ & IGV & Pr. Total \\
\hline 1 & Escritorio de oficina & 3 & 508 & 1,523 & 274 & 1,797 \\
\hline 2 & Sillas de oficina & 3 & 253 & 760 & 137 & 897 \\
\hline 3 & Laptop & 3 & 1,499 & 4,497 & 810 & 5,307 \\
\hline 4 & Equipos telefónicos & 2 & 254 & 508 & 92 & 600 \\
\hline 5 & Muebles archivadores & 1 & 677 & 677 & 122 & 799 \\
\hline 6 & Impresora Matricial & 1 & 297 & 297 & 53 & 350 \\
\hline \multirow[t]{2}{*}{7} & Impresora Láser & 1 & 297 & 297 & 53 & 350 \\
\hline & Total & & & 8,559 & 1,541 & 10,100 \\
\hline $\mathbf{N}^{\circ}$ & Área de Ventas & Cant. & Pr. Unit. & Total S/ & IGV & Pr. Total \\
\hline 1 & Escritorio de oficina & 3 & 508 & 1,523 & 274 & 1,797 \\
\hline 2 & Sillas de oficina & 3 & 253 & 760 & 137 & 897 \\
\hline 3 & Laptop & 3 & 1,499 & 4,497 & 810 & 5,307 \\
\hline 4 & Equipos telefónicos & 1 & 254 & 254 & 46 & 300 \\
\hline 5 & Muebles archivadores & 1 & 677 & 677 & 122 & 799 \\
\hline & $\begin{array}{cc}\text { Total } \\
\end{array}$ & & & 7,712 & 1,388 & 9,100 \\
\hline
\end{tabular}




\section{Intangibles}

\begin{tabular}{|c|c|c|c|c|c|c|}
\hline $\mathbf{N}^{\circ}$ & $\begin{array}{l}\text { Gastos de Constitución de la empresa } \\
\end{array}$ & Cant. & Pr. Unit. & Total S/ & IGV & Pr. Total \\
\hline 1 & Licencia de funcionamiento & 1 & 353 & 353 & 63 & 416 \\
\hline 2 & Elaboración de la minuta de constitución & 1 & 237 & 237 & 43 & 280 \\
\hline 3 & Escritura pública & 1 & 212 & 212 & 38 & 250 \\
\hline 4 & Incripción en registros públicos & 1 & 169 & 169 & 31 & 200 \\
\hline 5 & Derecho de trámite y derecho de inscripción en RR.PP & 1 & 4 & 4 & 1 & 5 \\
\hline 6 & Impresión de facturas & 1 & 212 & 212 & 38 & 250 \\
\hline 7 & Libros contables & 6 & 17 & 102 & 18 & 120 \\
\hline 8 & Legalización de libros contables & 6 & 25 & 153 & 27 & 180 \\
\hline 9 & Certificado de defensa civil & 1 & 1,422 & 1,422 & 256 & 1,678 \\
\hline 10 & Certificado de busqueda de marca en INDECOPI & 1 & 447 & 447 & 80 & 527 \\
\hline \multicolumn{3}{|c|}{$\begin{array}{ll} & \text { Total } \\
\end{array}$} & \multicolumn{2}{|r|}{$\mathbf{3 , 3 1 0}$} & 596 & 3,906 \\
\hline $\mathbf{N}^{\circ}$ & Arrendamiento y mejoras al local & Cant. & Pr. Unit. & Total S/ & IGV & Pr. Total \\
\hline \multirow[t]{7}{*}{1} & $\begin{array}{l}\text { Mejoras y adecuaciones del inmueble arrendado, incluye } \\
\text { los sistemas de tratamientos de residuos }\end{array}$ & 1 & 111,810 & 111,810 & 20,126 & 131,936 \\
\hline & Extintores de 6 Kilos & 20 & 60 & 1,200 & 216 & 1,416 \\
\hline & Sensores de humo & 12 & 30 & 360 & 65 & 425 \\
\hline & Luces de emergencia & 12 & 40 & 480 & 86 & 566 \\
\hline & Botiquín & 1 & 50 & 50 & 9 & 59 \\
\hline & Señaléticas & 50 & 2 & 100 & 18 & 118 \\
\hline & Piso antideslizante en zonas de alto transito & 1 & 2,000 & 2,000 & 360 & 2,360 \\
\hline 2 & Arrendamiento pre operativo & 2 & 15,242 & 30,483 & 5,487 & 35,970 \\
\hline 3 & Garantia & 1 & 15,242 & 15,242 & 2,743 & 17,985 \\
\hline \multicolumn{2}{|r|}{ Total } & \multicolumn{3}{|r|}{161,725} & 29,110 & $\mathbf{1 9 0 , 8 3 5}$ \\
\hline $\mathbf{N}^{\circ}$ & \multicolumn{2}{|l|}{ Capacitación de Recursos Humanos } & \multicolumn{2}{|c|}{$\begin{array}{c}\mathbf{N}^{\circ} \text { de } \\
\text { personas }\end{array}$} & $\begin{array}{c}\text { Costo } \\
\text { mensual S/ }\end{array}$ & $\begin{array}{l}\text { Costo } \\
\text { total }\end{array}$ \\
\hline 4 & \multicolumn{2}{|l|}{ Gerente Administrativo } & \multicolumn{2}{|c|}{1} & 5,027 & 5,027 \\
\hline 5 & \multicolumn{2}{|l|}{ Jefe Comercial } & \multicolumn{2}{|l|}{15} & 3,770 & 1,885 \\
\hline 6 & \multicolumn{2}{|l|}{ Jefe de Operaciones } & \multicolumn{2}{|l|}{15} & 3,770 & 1,885 \\
\hline 7 & \multicolumn{2}{|l|}{ Asistente Administrativo y GGHH } & \multicolumn{2}{|r|}{1} & 1,634 & 381 \\
\hline 8 & Vendedores & & \multicolumn{2}{|c|}{2} & 2,513 & 586 \\
\hline 9 & Operarios & & \multicolumn{2}{|c|}{11} & 15,862 & 3,701 \\
\hline \multicolumn{3}{|c|}{ Total } & \multicolumn{4}{|r|}{13,465} \\
\hline $\mathbf{N}^{\circ}$ & $\begin{array}{r}\text { Otros Activos Intangibles } \\
\end{array}$ & Cant. & \multicolumn{2}{|r|}{ Total S/ } & IGV & Pr. Total \\
\hline 10 & Diseño de página web & 1 & 1,271 & 1,271 & 229 & 1,500 \\
\hline 11 & Compra de dominio & 1 & 415 & 415 & 75 & 490 \\
\hline 12 & Marketing pre operativo & 1 & 3,000 & 3,000 & 540 & 3,540 \\
\hline & Total & & & 4,686 & 844 & $\mathbf{5 , 5 3 0}$ \\
\hline
\end{tabular}




\begin{tabular}{rlcrrrr}
\hline $\mathbf{N}^{\circ}$ & \multicolumn{1}{c}{ Gastos Pre-operativos } & Cant. & Pr. Unit. & Total S/ & IGV & Pr. Total \\
\hline 1 & Manguera de limpieza de pollo & 5 & 190 & 950 & 171 & 1,121 \\
2 & Tinas limpia botas & 2 & 100 & 200 & 36 & 236 \\
3 & Botas & 25 & 30 & 761 & 137 & 897 \\
4 & Cuchillos & 8 & 13 & 108 & 19 & 127 \\
5 & Guantes & 25 & 15 & 379 & 68 & 448 \\
6 & Cascos & 25 & 34 & 845 & 152 & 997 \\
7 & Orejeras & 25 & 34 & 845 & 152 & 997 \\
8 & Mascarillas (pack 50) & 4 & 19 & 74 & 13 & 88 \\
9 & Mamelucos & 75 & 38 & 2,854 & 514 & 3,367 \\
10 & Gorras (pack 25) & 4 & 85 & 339 & 61 & 400 \\
11 & Pinzas & 2 & 21 & 42 & 8 & 50 \\
12 & Protectores plásticos & 50 & 11 & 547 & 98 & 645 \\
13 & Escobas & 10 & 19 & 194 & 35 & 229 \\
14 & Baldes & 10 & 13 & 126 & 23 \\
15 & Escobillas & 10 & 8 & 84 & 149 \\
16 & Mangueras de limpieza del local & 5 & 85 & 423 & 15 \\
17 & Tachos de basura & 6 & 24 & 142 & 76 \\
\hline
\end{tabular}




\section{Anexo $\mathbf{N}^{\circ}$ 11: Detalle de depreciaciones y amortizaciones.}

\section{Depreciaciones}

\begin{tabular}{|c|c|c|c|c|c|c|c|c|c|c|}
\hline $\mathbf{N}^{\circ}$ & Área Operativa - Inversión Inicial & $\begin{array}{c}\text { Valor del } \\
\text { activo }\end{array}$ & $\begin{array}{l}\text { Vida } \\
\text { útil } \\
\end{array}$ & $\begin{array}{c}\text { Depreciación } \\
\text { año } 1 \\
\end{array}$ & $\begin{array}{c}\text { Depreciación } \\
\text { año } 2 \\
\end{array}$ & $\begin{array}{c}\text { Depreciación } \\
\text { año } 3 \\
\end{array}$ & $\begin{array}{c}\text { Depreciación } \\
\text { año } 4 \\
\end{array}$ & $\begin{array}{c}\text { Depreciación } \\
\text { año } 5 \\
\end{array}$ & $\begin{array}{c}\text { Valor en } \\
\text { libros }\end{array}$ & $\begin{array}{c}\text { Valor } \\
\text { Residual }\end{array}$ \\
\hline 1 & Transporte & 55,227 & 10 & 5,523 & 5,523 & 5,523 & 5,523 & 5,523 & 27,613 & 27,613 \\
\hline 2 & Equipamiento & 153,554 & 10 & 15,355 & 15,355 & 15,355 & 15,355 & 15,355 & 76,777 & 76,777 \\
\hline 3 & Tablero electrico fuerza y control & 11,688 & 10 & 1,169 & 1,169 & 1,169 & 1,169 & 1,169 & 5,844 & 5,844 \\
\hline 4 & Estructuras & 20,509 & 10 & 2,051 & 2,051 & 2,051 & 2,051 & 2,051 & 10,255 & 10,255 \\
\hline 5 & Línea electrica, agua, aire y vapor & 8,294 & 10 & 829 & 829 & 829 & 829 & 829 & 4,147 & 4,147 \\
\hline 6 & Instalación y puesta en marcha de caldera & 5,744 & 10 & 574 & 574 & 574 & 574 & 574 & 2,872 & 2,872 \\
\hline 7 & Instalación general & 10,982 & 10 & 1,098 & 1,098 & 1,098 & 1,098 & 1,098 & 5,491 & 5,491 \\
\hline 8 & Mesas de trabajo & 2,700 & 3 & 900 & 900 & 900 & & & 0 & 0 \\
\hline 9 & Parihuelas & 1,144 & 3 & 381 & 381 & 381 & & & 0 & 0 \\
\hline \multirow{2}{*}{10} & Tinas & 4,922 & 3 & 1,641 & 1,641 & 1,641 & & & 0 & 0 \\
\hline & Total & 274,764 & & 29,522 & 29,522 & 29,522 & 26,600 & 26,600 & 132,999 & 132,999 \\
\hline $\mathbf{N}^{\circ}$ & Área Operativa - Reinversión & $\begin{array}{c}\text { Valor del } \\
\text { activo }\end{array}$ & $\begin{array}{l}\text { Vida } \\
\text { útil } \\
\end{array}$ & $\begin{array}{c}\text { Depreciación } \\
\text { año } 1 \\
\end{array}$ & $\begin{array}{c}\text { Depreciación } \\
\text { año } 2 \\
\end{array}$ & $\begin{array}{c}\text { Depreciación } \\
\text { año } 3 \\
\end{array}$ & $\begin{array}{c}\text { Depreciación } \\
\text { año } 4 \\
\end{array}$ & $\begin{array}{l}\text { Depreciación } \\
\text { año } 5 \\
\end{array}$ & $\begin{array}{c}\text { Valor en } \\
\text { libros }\end{array}$ & $\begin{array}{c}\text { Valor } \\
\text { Residual }\end{array}$ \\
\hline 1 & Transporte & 19,318 & 10 & & & & 1,932 & 1,932 & 15,454 & 15,454 \\
\hline 2 & Estructuras & 8,790 & 10 & & & & 879 & 879 & 7,032 & 7,032 \\
\hline 3 & Instalación y puesta en marcha de caldera & 7,180 & 10 & & & & 718 & 718 & 5,744 & 5,744 \\
\hline 4 & Instalación general & 13,728 & 10 & & & & 1,373 & 1,373 & 10,982 & 10,982 \\
\hline 5 & Mesas de trabajo & 3,600 & 10 & & & & 360 & 360 & 2,880 & 2,880 \\
\hline 6 & Parihuelas & 1,589 & 3 & & & & 530 & 530 & 530 & 530 \\
\hline \multirow[t]{2}{*}{7} & Tinas & 6,992 & 3 & & & & 2,331 & 2,331 & 2,331 & 2,331 \\
\hline & Total & 61,195 & & $\mathbf{0}$ & $\mathbf{0}$ & $\mathbf{0}$ & 8,122 & 8,122 & 44,952 & 44,952 \\
\hline $\mathbf{N}^{\circ}$ & Área Administrativa - Inversión Inicial & $\begin{array}{c}\text { Valor del } \\
\text { activo }\end{array}$ & $\begin{array}{l}\text { Vida } \\
\text { útil } \\
\end{array}$ & $\begin{array}{c}\text { Depreciación } \\
\text { año } 1 \\
\end{array}$ & $\begin{array}{c}\text { Depreciación } \\
\text { año } 2 \\
\end{array}$ & $\begin{array}{c}\text { Depreciación } \\
\text { año } 3 \\
\end{array}$ & $\begin{array}{c}\text { Depreciación } \\
\text { año } 4 \\
\end{array}$ & $\begin{array}{l}\text { Depreciación } \\
\text { año } 5 \\
\end{array}$ & $\begin{array}{c}\text { Valor en } \\
\text { libros }\end{array}$ & $\begin{array}{c}\text { Valor } \\
\text { Residual } \\
\end{array}$ \\
\hline 1 & Escritorio de oficina & 1,523 & 10 & 152 & 152 & 152 & 152 & 152 & 761 & 761 \\
\hline 2 & Sillas de oficina & 760 & 10 & 76 & 76 & 76 & 76 & 76 & 380 & 380 \\
\hline 3 & Laptop & 4,497 & 4 & 1,124 & 1,124 & 1,124 & 1,124 & & 0 & 0 \\
\hline 4 & Equipos telefónicos & 508 & 4 & 127 & 127 & 127 & 127 & & 0 & 0 \\
\hline 5 & Muebles archivadores & 677 & 10 & 68 & 68 & 68 & 68 & 68 & 339 & 339 \\
\hline 6 & Impresora Matricial & 297 & 4 & 74 & 74 & 74 & 74 & & 0 & 0 \\
\hline \multirow[t]{2}{*}{7} & Impresora Láser & 297 & 4 & 74 & 74 & 74 & 74 & & 0 & 0 \\
\hline & Total & 8,559 & & 1,696 & 1,696 & 1,696 & 1,696 & 296 & 1,480 & 1,480 \\
\hline $\mathbf{N}^{\circ}$ & Área Administrativa - Reinversión & $\begin{array}{c}\text { Valor del } \\
\text { activo }\end{array}$ & $\begin{array}{l}\text { Vida } \\
\text { útil }\end{array}$ & $\begin{array}{c}\text { Depreciación } \\
\text { año } 1 \\
\end{array}$ & $\begin{array}{c}\text { Depreciación } \\
\text { año } 2 \\
\end{array}$ & $\begin{array}{c}\text { Depreciación } \\
\text { año } 3 \\
\end{array}$ & $\begin{array}{c}\text { Depreciación } \\
\text { año } 4 \\
\end{array}$ & $\begin{array}{c}\text { Depreciación } \\
\text { año } 5 \\
\end{array}$ & $\begin{array}{l}\text { Valor en } \\
\text { libros }\end{array}$ & $\begin{array}{c}\text { Valor } \\
\text { Residual } \\
\end{array}$ \\
\hline 1 & Laptop & 4,497 & 4 & & & & & 1,124 & 3,373 & 3,373 \\
\hline 2 & Equipos telefónicos & 508 & 4 & & & & & 127 & 381 & 381 \\
\hline 3 & Impresora Matricial & 297 & 4 & & & & & 74 & 222 & 222 \\
\hline \multirow[t]{2}{*}{4} & Impresora Láser & 297 & 4 & & & & & 74 & 222 & 222 \\
\hline & Total & 5,599 & & $\mathbf{0}$ & $\mathbf{0}$ & $\mathbf{0}$ & $\mathbf{0}$ & 1,400 & 4,199 & 4,199 \\
\hline $\mathbf{N}^{\circ}$ & Área de Ventas - Inversión Inicial & $\begin{array}{l}\text { Valor del } \\
\text { activo }\end{array}$ & $\begin{array}{l}\text { Vida } \\
\text { útil }\end{array}$ & $\begin{array}{c}\text { Depreciación } \\
\text { año } 1\end{array}$ & $\begin{array}{l}\text { Depreciación } \\
\text { año } 2\end{array}$ & $\begin{array}{l}\text { Depreciación } \\
\text { año } 3\end{array}$ & $\begin{array}{c}\text { Depreciación } \\
\text { año } 4\end{array}$ & $\begin{array}{l}\text { Depreciación } \\
\text { año } 5\end{array}$ & $\begin{array}{c}\text { Valor en } \\
\text { libros }\end{array}$ & $\begin{array}{c}\text { Valor } \\
\text { Residual }\end{array}$ \\
\hline 1 & Escritorio de oficina & 1,523 & 10 & 152 & 152 & 152 & 152 & 152 & 761 & 761 \\
\hline 2 & Sillas de oficina & 760 & 10 & 76 & 76 & 76 & 76 & 76 & 380 & 380 \\
\hline 3 & Laptop & 4,497 & 4 & 1,124 & 1,124 & 1,124 & 1,124 & & 0 & 0 \\
\hline 4 & Equipos telefónicos & 254 & 4 & 64 & 64 & 64 & 64 & & 0 & 0 \\
\hline \multirow[t]{2}{*}{5} & Muebles archivadores & 677 & 10 & 68 & 68 & 68 & 68 & 68 & 339 & 339 \\
\hline & $\begin{array}{r}\text { Total } \\
\end{array}$ & 7,712 & & 1,484 & 1,484 & 1,484 & 1,484 & 296 & 1,480 & 1,480 \\
\hline $\mathbf{N}^{\circ}$ & Área de Ventas - Reinversión & $\begin{array}{l}\text { Valor del } \\
\text { activo }\end{array}$ & $\begin{array}{l}\text { Vida } \\
\text { útil }\end{array}$ & $\begin{array}{c}\text { Depreciación } \\
\text { año } 1\end{array}$ & $\begin{array}{c}\text { Depreciación } \\
\text { año } 2\end{array}$ & $\begin{array}{c}\text { Depreciación } \\
\text { año } 3\end{array}$ & $\begin{array}{c}\text { Depreciación } \\
\text { año } 4\end{array}$ & $\begin{array}{c}\text { Depreciación } \\
\text { año } 5\end{array}$ & $\begin{array}{c}\text { Valor en } \\
\text { libros }\end{array}$ & $\begin{array}{c}\text { Valor } \\
\text { Residual }\end{array}$ \\
\hline 1 & Laptop & 4,497 & 4 & & & & & 1,124 & 3,373 & 3,373 \\
\hline \multirow[t]{2}{*}{2} & Equipos telefónicos & 254 & 4 & & & & & 64 & 191 & 191 \\
\hline & Total & 4,752 & & $\mathbf{0}$ & $\mathbf{0}$ & $\mathbf{0}$ & $\mathbf{0}$ & 1,188 & 3,564 & 3,564 \\
\hline
\end{tabular}


Valor de Rescate de Activos

\begin{tabular}{lrr}
\hline \multicolumn{1}{c}{ Activos } & \multicolumn{1}{c}{$\begin{array}{c}\text { Valor en } \\
\text { libros }\end{array}$} & $\begin{array}{c}\text { Valor de } \\
\text { Salvamento }\end{array}$ \\
\hline Área Operativa & 177,951 & 177,951 \\
Área Administrativa & 5,679 & 5,679 \\
Área de Ventas & 5,044 & 5,044 \\
\hline & 188,674 & 188,674 \\
& & \\
Utilidad/Perdida & 0 & \\
Impuesto a la Renta & 0 & \\
\hline Valor Neto & 188,674 & \\
IGV & 33,961 & \\
\hline Valor Neto + IGV & 222,636 \\
\hline
\end{tabular}

\section{Amortizaciones}

\begin{tabular}{|c|c|c|c|c|c|c|c|c|c|c|}
\hline $\mathbf{N}^{\circ}$ & Amorrizaciones & $\begin{array}{c}\text { Valor del } \\
\text { activo }\end{array}$ & Vida útil & $\begin{array}{c}\text { Depreciación } \\
\text { año } 1\end{array}$ & $\begin{array}{c}\text { Depreciación } \\
\text { año } 2\end{array}$ & $\begin{array}{c}\text { Depreciación } \\
\text { año } 3 \\
\end{array}$ & $\begin{array}{c}\text { Depreciación } \\
\text { año } 4\end{array}$ & $\begin{array}{c}\text { Depreciación } \\
\text { año } 5\end{array}$ & $\begin{array}{c}\text { Valor en } \\
\text { libros }\end{array}$ & $\begin{array}{c}\text { Valor } \\
\text { Residual }\end{array}$ \\
\hline 1 & Gastos de Constitución de la empresa & 3,310 & 5 & 662 & 662 & 662 & 662 & 662 & 0 & 0 \\
\hline 2 & Arrendamiento y mejoras al local & 161,725 & 5 & 32,345 & 32,345 & 32,345 & 32,345 & 32,345 & 0 & 0 \\
\hline 3 & Recursos Humanos & 13,465 & 5 & 2,693 & 2,693 & 2,693 & 2,693 & 2,693 & 0 & 0 \\
\hline 4 & Otros Activos Intangibles & 4,686 & 5 & 937 & 937 & 937 & 937 & 937 & 0 & 0 \\
\hline 5 & Gastos Pre-operativos & 8,913 & 5 & 1,783 & 1,783 & 1,783 & 1,783 & 1,783 & 0 & 0 \\
\hline & Total & 192,100 & & 38,420 & 38,420 & 38,420 & 38,420 & 38,420 & $\mathbf{0}$ & $\mathbf{0}$ \\
\hline
\end{tabular}




\section{Anexo $N^{\circ}$ 12: Detalle de la reinversión.}

\section{REINVERSIÓN AÑO 4}

\begin{tabular}{|c|c|c|c|c|c|c|}
\hline $\mathbf{N}^{\circ}$ & Área Operativa & Cant. & Pr. Unit. & Total S/ & IGV & Pr. Total \\
\hline \multirow[t]{7}{*}{1} & Transporte & & & & & \\
\hline & Cadena transportadora & 42 & 112 & 4,714 & 849 & 5,563 \\
\hline & Curva de 180 & 1 & 1,620 & 1,620 & 292 & 1,912 \\
\hline & Curva de 90 & 4 & 1,406 & 5,622 & 1,012 & 6,634 \\
\hline & Ganchos de colgado & 192 & 30 & 5,675 & 1,022 & 6,697 \\
\hline & Cadenilla de arrastre de ganchos & 42 & 13 & 565 & 102 & 667 \\
\hline & Tubo de riel 1 1/4 acero inox + platina $6 \mathrm{~mm}$ & 42 & 27 & 1,121 & 202 & 1,322 \\
\hline 2 & Estructuras & 1 & 8,790 & 8,790 & 1,582 & 10,372 \\
\hline 3 & Instalación y puesta en marcha de caldera & 1 & 7,180 & 7,180 & 1,292 & 8,472 \\
\hline 4 & Instalación general & 1 & 13,728 & 13,728 & 2,471 & 16,199 \\
\hline 5 & Mesas de trabajo & 4 & 900 & 3,600 & 648 & 4,248 \\
\hline 6 & Parihuelas & 25 & 64 & 1,589 & 286 & 1,875 \\
\hline 7 & Tinas & 125 & 56 & 6,992 & 1,258 & 8,250 \\
\hline \multicolumn{2}{|r|}{ Total } & & & 61,195 & 11,015 & 72,210 \\
\hline
\end{tabular}

\section{REINVERSIÓN AÑO 5}

\begin{tabular}{|c|c|c|c|c|c|c|}
\hline $\mathbf{N}^{\circ}$ & Área Administrativa & Cant. & Pr. Unit. & Total S/ & IGV & Pr. Total \\
\hline 1 & Laptop & 3 & 1,499 & 4,497 & 810 & 5,307 \\
\hline 2 & Equipos telefónicos & 2 & 254 & 508 & 92 & 600 \\
\hline 3 & Impresora Matricial & 1 & 297 & 297 & 53 & 350 \\
\hline 4 & Impresora Láser & 1 & 297 & 297 & 53 & 350 \\
\hline \multicolumn{2}{|r|}{ Total } & & & 5,599 & 1,008 & 6,607 \\
\hline $\mathbf{N}^{\circ}$ & Área de Ventas & Cant. & Pr. Unit. & Total S/ & IGV & Pr. Total \\
\hline 1 & Laptop & 3 & 1,499 & 4,497 & 810 & 5,307 \\
\hline 2 & Equipos telefónicos & 1 & 254 & 254 & 46 & 300 \\
\hline \multicolumn{2}{|r|}{ Total } & & & 4,752 & 855 & $\mathbf{5 , 6 0 7}$ \\
\hline
\end{tabular}




\section{Anexo $N^{\circ}$ 13: Tabulación de la encuesta.}

\begin{tabular}{|c|c|c|c|c|c|c|c|c|c|c|c|c|c|c|c|c|c|c|}
\hline $\mathrm{N}^{\circ}$ & $\begin{array}{l}\text { a) Tipo de } \\
\text { Cliente }\end{array}$ & $\begin{array}{l}\text { b) Pregunta } \\
\text { Filtro }\end{array}$ & Pregunta 1.- & $\begin{array}{r}\text { Pregunta 2.- } \\
-7\end{array}$ & Pregunta 3.- & Pregunta 4.- & Pregunta 5.- & Pregunta 6.- & Pregunta 7.- & $\begin{array}{r}\text { 8.1- Precio } \\
\text { del Servicio }\end{array}$ & 8.2. olor & $\begin{array}{l}\text { 8.3.- Vida útil } \\
\text { del producto }\end{array}$ & $\begin{array}{c}\text { 8.4.- } \\
\text { Ubicación } \\
\text { (zonaa }\end{array}$ & $\begin{array}{c}\text { 8.5. Pollo } \\
\text { Sano }\end{array}$ & $\begin{array}{c}\text { 8.6.- Ventana } \\
\text { Horaria }\end{array}$ & 8.7. otro & Pregunta 9.- & Pregunta 10. \\
\hline & AVÍ́COLA & SI & Espacio alquilado & SI & 6 & 1250 & DIARIA & SAN FERNANDO & 0.35 & \begin{tabular}{|l|l}
$x$ \\
\end{tabular} & & $\mathrm{x}$ & & $x$ & $\mathrm{x}$ & & \begin{tabular}{|l|l|} 
MUY ALTA \\
\end{tabular} & 0.50 \\
\hline & AVÍCOLA & SI & Puesto de mercado & $\mathrm{SI}$ & 6 & 1200 & DIARIA & SAN FERNANDO & 0.35 & $\mathrm{x}$ & $x$ & $x$ & $x$ & $x$ & $x$ & & & 0.50 \\
\hline & AVÍCOLA & SI & Puesto de mercado & No & 7 & 1200 & DIARIA & OTROS & 0.35 & $\mathrm{x}$ & $x$ & $\mathrm{x}$ & $x$ & $x$ & $\mathrm{x}$ & & MUY BAJA & 0.50 \\
\hline & AVIÍCOLA & SI & \begin{tabular}{|l} 
Espacio alquilado \\
Spai aldo
\end{tabular} & $\mathrm{SI}$ & 7 & 980 & DIARIA & AGRO. INVER. LOS ABEDULES & 0.45 & & $x$ & $\mathrm{x}$ & $x$ & & $\mathrm{x}$ & & & 0.60 \\
\hline & AVÍCOLA & SI & Espacio alquilado & SI & 4 & 850 & & & 0.40 & $\mathrm{x}$ & $x$ & $x$ & $x$ & $x$ & $x$ & & MEDIANA & \\
\hline$\frac{6}{7}$ & AVÍ́COLA & SI & Local propio & SI & 4 & 780 & DIARIA & \begin{tabular}{|l} 
REDONDOS \\
CANA IIN
\end{tabular} & 0.35 & $\mathrm{x}$ & $\mathrm{x}$ & $\mathrm{x}$ & $\mathrm{x}$ & $\mathrm{x}$ & $\mathrm{x}$ & & MEDIANA & 0.50 \\
\hline$\frac{7}{8}$ & \begin{tabular}{|l|} 
AVÍCOLALA \\
AVICOLA \\
\end{tabular} & $\frac{\text { SI }}{\text { SI }}$ & \begin{tabular}{|l} 
Espacioi alquilado \\
Espacio alquilado
\end{tabular} & $\frac{\mathrm{NO}}{\mathrm{SI}}$ & $\frac{3}{3}$ & $\frac{720}{690}$ & DIARIA & \begin{tabular}{|l} 
SANTA ELENA \\
SAN FRNANDO
\end{tabular} & 0.40 & $x$ & $\frac{x}{x}$ & $\frac{x}{x}$ & $\frac{x}{x}$ & $\frac{x}{x}$ & & & & \\
\hline & \begin{tabular}{|l|} 
PICADOR \\
\end{tabular} & $\frac{\mathrm{SI}}{\mathrm{SI}}$ & \begin{tabular}{|l} 
Sopacio alquilaco \\
Local propio
\end{tabular} & $\frac{S I}{S I}$ & $\frac{3}{4}$ & $\frac{690}{410}$ & $\begin{array}{l}\text { DIARRA } \\
\text { DIARIA }\end{array}$ & \begin{tabular}{|l|} 
SAN FERNANDO \\
REDONDOS
\end{tabular} & 0.50 & $\frac{x}{x}$ & $x$ & $\frac{x}{x}$ & $\frac{x}{x}$ & $\frac{x}{x}$ & $\frac{x}{x}$ & & $\frac{\text { MUY ALTA }}{\text { MEDANA }}$ & 0.65 \\
\hline 10 & AVÍCOLA & SI & Espacio alquilado & SI & 4 & 600 & DIARIA & AGRO. INVER. LOS ABEDULES & 0.50 & $\mathrm{x}$ & $x$ & $\mathrm{x}$ & $\mathrm{x}$ & $\mathrm{C}_{\mathrm{s}}$ & $\frac{n}{x}$ & & BA]A & 0.50 \\
\hline 11 & AVÍCOLA & SI & Espacio alquilado & SI & 3 & 590 & DIARIA & SAN FERNANDO & 0.50 & & $\mathrm{x}$ & $\mathrm{x}$ & $\mathrm{x}$ & $\mathrm{x}$ & $\mathrm{x}$ & & ALTA & 0.65 \\
\hline 12 & AVÍCOLA & SI & Puesto de mercado & No & 3 & 420 & DIARIA & OTROS & 0.35 & $\mathrm{x}$ & $x$ & $x$ & $x$ & $\mathrm{x}$ & $\mathrm{x}$ & & MUY BAJA & 0.50 \\
\hline 13 & AVÍCOLA & SI & Espacio alquilado & $\mathrm{SI}$ & 3 & 420 & DIARIA & REDONDOS & 0.50 & $\mathrm{x}$ & $\mathrm{x}$ & $x$ & $x$ & $x$ & $\mathrm{x}$ & & ALTA & \\
\hline 14 & AVÍCOLA & SI & Puesto de mercado & No & 3 & 410 & & OTROS & 0.35 & $\mathrm{x}$ & $\mathrm{x}$ & & & $x$ & $\mathrm{x}$ & & MUY BAJA & 0.50 \\
\hline 15 & AVÍCOLA & SI & Local acondicionado fuera de su casa & SI & 2 & 400 & & SAN FERNANDO & 0.35 & $\mathrm{x}$ & $x$ & $\mathrm{x}$ & $\mathrm{x}$ & & $\mathrm{x}$ & & MUY ALTA & 0.50 \\
\hline$\frac{16}{17}$ & \begin{tabular}{l|} 
AVÍ́COLA \\
AVícOLA
\end{tabular} & $\frac{\mathrm{SI}}{\mathrm{SI}}$ & $\begin{array}{l}\text { Puesto de mercado } \\
\text { Local ropio }\end{array}$ & $\frac{\mathrm{NO}}{\mathrm{SI}}$ & $\frac{2}{2}$ & $\begin{array}{r}400 \\
380\end{array}$ & & & 0.35 & $\mathrm{x}$ & $\frac{x}{x}$ & $\frac{x}{x}$ & $\frac{x}{x}$ & $\frac{x}{x}$ & $\mathrm{x}$ & & ALTA & 0.50 \\
\hline$\frac{17}{18}$ & \begin{tabular}{|l|} 
AVVICOLA \\
AVICOAA
\end{tabular} & $\frac{S I}{S I}$ & $\mid \frac{\mid \text { Local propio }}{\text { Espacio alquilado }}$ & $\frac{\mathrm{SI}}{\mathrm{SI}}$ & $\frac{2}{4}$ & $\frac{380}{370}$ & & $\begin{array}{l}\text { SANTAELENA } \\
\text { BEDONDOS S }\end{array}$ & 0.35 & & $\frac{x}{x}$ & $\frac{x}{x}$ & $\frac{x}{x}$ & $\frac{x}{x}$ & $\frac{x}{x}$ & & MEDIANA & 0.55 \\
\hline 19 & AVÍCOLA & SI & \begin{tabular}{|l} 
Sopacio alquilaco \\
Local propio
\end{tabular} & $\frac{S_{1}}{\mathrm{SI}}$ & 3 & $\frac{350}{340}$ & $\frac{\mathrm{DIA}}{\mathrm{DIA}]}$ & \begin{tabular}{|l|} 
KAEUN FERNASANDO \\
\end{tabular} & 0.30 & $\frac{x}{x}$ & $\frac{x}{x}$ & $\frac{x}{x}$ & $\frac{x}{x}$ & $\frac{x}{x}$ & $\frac{x}{x}$ & & \begin{tabular}{|l} 
AIIA A ALTA \\
\end{tabular} & $\frac{0.65}{0.55}$ \\
\hline & AVÍCOLA & SI & Local propio & SI & 3 & 410 & DIARIA & SAN FERNANDO & 0.35 & $\mathrm{x}$ & $\mathrm{x}$ & $\mathrm{x}$ & $\mathrm{x}$ & $\mathrm{x}$ & & & MUY ALTA & 0.50 \\
\hline 21 & AVÍCOLA & SI & Espacio alquilado & SI & 2 & 290 & & SAN FERNANDO & 0.50 & $x$ & $x$ & $x$ & $x$ & $x$ & $x$ & & & \\
\hline & $\begin{array}{l}\text { PICADOR } \\
\end{array}$ & SI & Local propio & SI & 3 & 270 & & SANTA ELENA & 0.35 & $\mathrm{x}$ & $\mathrm{x}$ & $x$ & $\mathrm{x}$ & $\mathrm{x}$ & $x$ & & MEDIANA & \\
\hline 23 & AVÍCOLA & SI & Espacio alquilado & NO & 3 & 190 & & RNANDO & 0.60 & $x$ & $x$ & $x$ & $\mathrm{x}$ & & $x$ & & MUY ALTA & \\
\hline 24 & AVÍ́COLA & SI & Espacio alquilado & SI & 2 & 160 & & ERNANDO & 0.60 & $x$ & $x$ & $x$ & $x$ & $x$ & $\mathrm{x}$ & & MUY & 0.70 \\
\hline 25 & AVÍ́COLA & SI & Puesto de mercado & No & 2 & 160 & & OTR & 0.35 & & $\mathrm{x}$ & $\mathrm{x}$ & $x$ & $x$ & $x$ & & MUY BAJA & 0.50 \\
\hline$\frac{26}{27}$ & \begin{tabular}{|l|} 
AVÍ́́COLA \\
Aví́OLA
\end{tabular} & $\frac{S I}{S I}$ & Local pro & $\frac{S I}{S I}$ & $\frac{2}{2}$ & 150 & & NANDO & 0.35 & $x$ & & $\frac{x}{x}$ & $\mathrm{x}$ & $\mathrm{x}$ & $x$ & & MUY ALTA & 0.50 \\
\hline$\frac{27}{28}$ & \begin{tabular}{|l|} 
AVVICOLA A \\
AVICOA
\end{tabular} & $\frac{\mathrm{SI}}{\mathrm{SI}}$ & $\frac{\text { Locala pro }}{\text { Espacio a }}$ & $\frac{S I}{S I}$ & $\frac{2}{2}$ & $\frac{140}{120}$ & & & 0.35 & $\frac{x}{x}$ & $\frac{x}{x}$ & $\frac{x}{x}$ & $\frac{x}{x}$ & $\frac{x}{x}$ & $\frac{x}{x}$ & & \begin{tabular}{|l|} 
ALTA \\
MUY ALTA
\end{tabular} & \\
\hline 29 & \begin{tabular}{|l|} 
AVÍCOLA A \\
\end{tabular} & $\frac{11}{S I}$ & Local propio & $\frac{\mathrm{II}}{\mathrm{SI}}$ & $\frac{2}{2}$ & 120 & & \begin{tabular}{|l} 
ANFENDA \\
REDONDOS
\end{tabular} & 0.000 & $\frac{x}{x}$ & $\frac{x}{x}$ & $\frac{x}{x}$ & & $\frac{x}{x}$ & $\frac{x}{x}$ & & \begin{tabular}{|l|l|} 
MUTA \\
ALTA
\end{tabular} & $\frac{0.70}{0.50}$ \\
\hline 30 & \begin{tabular}{|l|} 
AVÍCOLAA \\
\end{tabular} & SI & Espacio alquilado & SI & 6 & 1280 & DIARIA & SAN FERNANDO & 0.35 & & & $\frac{x}{x}$ & $x$ & $\frac{x}{x}$ & & & MUY ALTA & 0.50 \\
\hline 31 & AVÍCOLA & SI & Puesto de $n$ & SI & 6 & 1200 & & SAN FERNANDO & 0.35 & $x$ & $x$ & $x$ & $\mathrm{x}$ & $\mathrm{x}$ & $x$ & & ALTA & 0.50 \\
\hline 32 & AVÍCOLA & SI & Puesto de mer & No & 7 & 1200 & & & 0.35 & $x$ & $\mathrm{x}$ & $x$ & $\mathrm{x}$ & $\mathrm{x}$ & $\mathrm{x}$ & & MUY BAJA & \\
\hline & AVÍCOLA & SI & Espacio alquilado & SI & 7 & 950 & & INVER. LOS ABEDULES & 0.40 & $\mathrm{x}$ & $x$ & $x$ & $x$ & $x$ & $x$ & & BA]A & \\
\hline & AVICOLA & SI & Espacio alquilado & $S I$ & 4 & 890 & DIARIA & REDONDOS & 0.40 & & $\mathrm{x}$ & & $x$ & $x$ & $\mathrm{x}$ & & MEDIANA & 0.55 \\
\hline
\end{tabular}




\begin{tabular}{|c|c|c|c|c|c|c|c|c|c|c|c|c|c|c|c|c|c|c|}
\hline $\mathrm{N}^{\circ}$ & $\begin{array}{l}\text { a) Tipo de } \\
\text { Cliente }\end{array}$ & $\begin{array}{l}\text { b) Pregunta } \\
\text { Filtro }\end{array}$ & Pregunta 1.- & Pregunta 2.- & Pregunta 3.- & Pregunta 4.- & Pregunta 5.- & Pregunta 6.- & Pregunta 7.- & $\begin{array}{l}\text { 8.1- Precio } \\
\text { del Servicio }\end{array}$ & 8.2. - Olor & $\begin{array}{l}\text { 8.3.- Vida útil } \\
\text { del producto }\end{array}$ & \begin{tabular}{|c|}
$8.4 .-$ \\
buicación \\
(zona)
\end{tabular} & $\begin{array}{l}\text { 8.5. Pollo } \\
\text { Sano }\end{array}$ & $\begin{array}{l}\text { 8.6. - Ventana } \\
\text { Horaria }\end{array}$ & 8.7. otro & Pregunta 9.- & Pregunta 10.- \\
\hline 35 & AVí́coLA & $\mathrm{SI}$ & \begin{tabular}{|l} 
Local propio \\
\end{tabular} & $\mathrm{SI}$ & 4 & 780 & DIARIA & REDONDOS & $\begin{array}{ll}0.35 \\
\end{array}$ & \begin{tabular}{l|l}
$x$ \\
$x$
\end{tabular} & $\mathrm{x}$ & $\mathrm{x}$ & $\mathrm{x}$ & & $\mathrm{x}$ & & MEDIANA & 0.50 \\
\hline 36 & \begin{tabular}{|l|l|} 
AVÍCOLA \\
AVÍCOIA
\end{tabular} & $\frac{\text { SI }}{\text { st }}$ & Espacio alquilado & No & 3 & 740 & DIARIA & SANTA ELENA & 0.50 & & $x$ & $x$ & $x$ & $\mathrm{x}$ & $\mathrm{x}$ & & MEDIANA & 0.65 \\
\hline$\frac{37}{38}$ & \begin{tabular}{|l|} 
AVICOLA \\
PICADOR \\
\end{tabular} & $\frac{\mathrm{SI}}{\mathrm{SI}}$ & Espacio alquilado & $\frac{S I}{S t}$ & $\frac{3}{4}$ & 660 & $\begin{array}{c}\text { DIARIA } \\
\text { DAPRA }\end{array}$ & SAN FERNANDO & 0.50 & $\frac{x}{x}$ & $\frac{x}{x}$ & $\frac{x}{x}$ & $\frac{x}{x}$ & $\frac{x}{x}$ & $\frac{x}{x}$ & & MUY ALTA & 0.60 \\
\hline 39 & AVÍCOLA & SI & Espacio alquilado & SI & 4 & 600 & $\begin{array}{l}\text { DIALRIA } \\
\text { DIAIA }\end{array}$ & AGRO. INVER LOS ABEDULES & 0.55 & $\frac{x}{x}$ & $\frac{x}{x}$ & $\frac{x}{x}$ & $\frac{x}{x}$ & $\mathrm{x}$ & $\frac{x}{x}$ & & \begin{tabular}{|l} 
MEDDANA \\
BAIA
\end{tabular} & 0.505 \\
\hline 40 & AVÍCOLA & st & Espacio alquilado & SI & 3 & 580 & DIARIA & SAN FERNANDO & 0.50 & $x$ & $x$ & $\frac{A}{x}$ & $\frac{A}{x}$ & $\mathrm{x}$ & $\frac{A}{x}$ & & ALTA & 0.65 \\
\hline 41 & AVÍCOLA & SI & Puesto de mercado & NO & 3 & 440 & DIARIA & OTROS & 0.35 & $\frac{1}{x}$ & $\frac{1}{x}$ & $\frac{A}{x}$ & $\frac{1}{x}$ & $\mathrm{x}$ & $\frac{4}{x}$ & & MUY BAJA & 0.50 \\
\hline 42 & \begin{tabular}{|l|l|l|} 
AVÍCOLA \\
\end{tabular} & SI & Espacio alquilado & $\mathrm{SI}$ & 3 & 410 & DIARIA & REDONDOS & 0.50 & $\mathrm{x}$ & $\mathrm{x}$ & $\mathrm{x}$ & $\mathrm{x}$ & $\mathrm{x}$ & $\mathrm{x}$ & & ALTA & 0.65 \\
\hline 43 & \begin{tabular}{|l|} 
AVÍCOLA \\
\end{tabular} & $\mathrm{SI}$ & Puesto de mercado & NO & 3 & 410 & DIARIA & OTROS & 0.35 & $\mathrm{x}$ & $\mathrm{x}$ & $\mathrm{x}$ & & $\mathrm{x}$ & $x$ & & MUY BAJA & 0.55 \\
\hline 44 & \begin{tabular}{|l|} 
AVÍCOLA \\
\end{tabular} & SI & Local acondicionado fuera de su casa & $\mathrm{SI}$ & 2 & 400 & DIARIA & SAN FERNANDO & 0.35 & $\mathrm{x}$ & $\mathrm{x}$ & $\mathrm{x}$ & $\mathrm{x}$ & $\mathrm{x}$ & $\mathrm{x}$ & & MUY ALTA & 0.50 \\
\hline 45 & \begin{tabular}{|l|} 
AVÍCOLA \\
\end{tabular} & SI & Puesto de mercado & No & 2 & 400 & DIARIA & REDONDOS & 0.35 & $\mathrm{x}$ & $\mathrm{x}$ & & $\mathrm{x}$ & $\mathrm{x}$ & $\mathrm{x}$ & & ALTA & 0.50 \\
\hline 46 & \begin{tabular}{|l|} 
AVÍCOLA \\
\end{tabular} & SI & Local propio & SI & 2 & 370 & DIARIA & SANTA ELENA & 0.35 & & $\mathrm{x}$ & $\mathrm{x}$ & $\mathrm{x}$ & & $\mathrm{x}$ & & MEDIANA & 0.50 \\
\hline 47 & \begin{tabular}{|l|l|} 
AVÍCOLA \\
\end{tabular} & SI & Espacio alquilado & SI & 4 & 380 & & REDONDOS & 0.50 & $x$ & $\mathrm{x}$ & $\mathrm{x}$ & $\mathrm{x}$ & $\mathrm{x}$ & $\mathrm{x}$ & & & 0.60 \\
\hline 48 & AVÍCOLA & SI & Local propio & SI & 3 & 390 & DIARIA & SAN FERNANDO & 0.30 & $\mathrm{x}$ & $\mathrm{x}$ & $\mathrm{x}$ & $\mathrm{x}$ & $\mathrm{x}$ & $\mathrm{x}$ & & MUY ALTA & 0.40 \\
\hline 49 & AVÍCOLA & SI & Local propio & $\mathrm{SI}$ & 3 & 370 & DIARIA & SAN FERNANDO & 0.35 & $\mathrm{x}$ & $\mathrm{x}$ & $\mathrm{x}$ & $\mathrm{x}$ & $\mathrm{x}$ & $x$ & & MUY ALTA & 0.50 \\
\hline 50 & \begin{tabular}{|l|l|} 
AVÍCOLA \\
PICADOP
\end{tabular} & $\frac{S I}{S t}$ & Espacio alquilado & $\frac{S I}{S I}$ & 2 & 280 & DIARIA & SAN FERNANDO & 0.50 & $\mathrm{x}$ & $\mathrm{x}$ & $x$ & $x$ & $x$ & $x$ & & BAJA & 0.65 \\
\hline$\frac{51}{52}$ & \begin{tabular}{|l|} 
PICADOR \\
AVICOLA \\
\end{tabular} & $\frac{S I}{S I}$ & \begin{tabular}{|l|} 
Local propio \\
Espacio alauilado
\end{tabular} & $\frac{\mathrm{SI}}{\mathrm{NO}}$ & $\frac{3}{3}$ & 360 & DIARIA & \begin{tabular}{|l} 
SANTA ELENA \\
SANERNAND
\end{tabular} & 0.35 & $\frac{x}{x}$ & $\frac{x}{x}$ & $\frac{x}{x}$ & $\frac{x}{x}$ & $\mathrm{x}$ & $\mathrm{x}$ & & MEDIANA & 0.50 \\
\hline 52 & \begin{tabular}{|l|} 
AVIIEOLA \\
AVICOLA \\
\end{tabular} & $\frac{\mathrm{st}}{\mathrm{st}}$ & $\begin{array}{l}\text { Espacio a } \\
\text { Espacio a }\end{array}$ & $\frac{\mathrm{NO}}{\mathrm{SI}}$ & $\frac{3}{2}$ & $\frac{190}{160}$ & $\begin{array}{c}\text { DIARIA } \\
\text { DASRA }\end{array}$ & $\begin{array}{l}\text { SAN FERNANDO } \\
\text { SNN FERNANDO }\end{array}$ & 0.60 & $\frac{x}{x}$ & $\frac{x}{x}$ & $\frac{x}{x}$ & $\frac{x}{x}$ & $\frac{x}{x}$ & $\frac{x}{x}$ & & MUY ALTA & 0.70 \\
\hline 54 & AVÍCOLA & SI & $\begin{array}{l}\text { Puesto de mercado } \\
\end{array}$ & NO & 2 & 150 & DIARIA & \begin{tabular}{|l} 
OTROS \\
\end{tabular} & 0.50 & & $\frac{x}{x}$ & $\frac{x}{x}$ & $\mathrm{x}$ & $\frac{x}{x}$ & $\mathrm{x}$ & & MUY ALTA & 0.65 \\
\hline & \begin{tabular}{|l|l|l|l|l|l} 
AVICOLA & \\
\end{tabular} & SI & Local propio & SI & 2 & 190 & $\begin{array}{l}\text { DIARIA } \\
\text { DIARIA }\end{array}$ & SAN FERNANDO & 0.35 & $x$ & $\frac{A}{x}$ & $\frac{A}{x}$ & $x$ & $\frac{A}{x}$ & $\mathrm{x}$ & & MUY ALTA & $\frac{0.50}{0.50}$ \\
\hline 56 & \begin{tabular}{|l|} 
AVÍCOLA \\
\end{tabular} & $\mathrm{SI}$ & Local propio & $\mathrm{SI}$ & 2 & 150 & DIARIA & REDONDOS & 0.35 & $\mathrm{x}$ & $\mathrm{x}$ & $\mathrm{x}$ & $\mathrm{x}$ & & $\mathrm{x}$ & & & 0.50 \\
\hline & \begin{tabular}{|l|} 
AVÍCOLA \\
\end{tabular} & $\mathrm{SI}$ & Espacio alquilado & SI & 2 & 120 & DIARIA & SAN FERNANDO & 0.50 & $\mathrm{x}$ & $x$ & $x$ & $x$ & $x$ & $\mathrm{x}$ & & MUY ALTA & \\
\hline 58 & \begin{tabular}{|l|} 
AVÍCOLA \\
\end{tabular} & SI & Local propio & SI & 2 & 180 & DIARIA & REDONDOS & 0.35 & $x$ & $\frac{x}{x}$ & $x$ & & $\mathrm{x}$ & $\mathrm{x}$ & & ALTA & 0.50 \\
\hline & \begin{tabular}{|l|} 
AVÍCOLA \\
\end{tabular} & $\mathrm{SI}$ & Espacio alquilado & SI & 6 & 1260 & DIARIA & ERNANDO & 0.45 & $\mathrm{x}$ & & $\mathrm{x}$ & & $\mathrm{x}$ & & & MUY ALTA & 0.60 \\
\hline 60 & \begin{tabular}{|l|l|l|} 
AVÍCOLA \\
\end{tabular} & SI & Puesto de & SI & 6 & 120 & DIA & ERNANDO & 0.35 & & $\mathrm{x}$ & $\mathrm{x}$ & $\mathrm{x}$ & $\mathrm{x}$ & $\mathrm{x}$ & & ALTA & 0.50 \\
\hline 61 & \begin{tabular}{|l|} 
AVÍCOLA \\
\end{tabular} & SI & Puesto de mercado & No & 7 & 1200 & & & 0.3 & $\mathrm{x}$ & $\mathrm{x}$ & $\mathrm{x}$ & $\mathrm{x}$ & $\mathrm{x}$ & $\mathrm{x}$ & & MUY BAJA & 0.50 \\
\hline 62 & \begin{tabular}{|l|l|l|} 
AVÍCOLA \\
\end{tabular} & SI & Espacio alquilado & SI & 7 & & & INVER. LOS ABEDULES & 0.40 & $\mathrm{x}$ & $\mathrm{x}$ & $\mathrm{x}$ & $\mathrm{x}$ & $\mathrm{x}$ & $\mathrm{x}$ & & & 0.55 \\
\hline 63 & AVÍCOLA & SI & Espacio alquilado & SI & 4 & 980 & DIARIA & REDO & 0.40 & $\mathrm{x}$ & $\mathrm{x}$ & & $\mathrm{x}$ & $x$ & $x$ & & MEDIANA & 0.55 \\
\hline 64 & AVÍCOLA & SI & Local pro & SI & 4 & & & REDO & 0.35 & $\mathrm{x}$ & $\mathrm{x}$ & $x$ & $\mathrm{x}$ & $\mathrm{x}$ & $\mathrm{x}$ & & MEDIANA & 0.50 \\
\hline 65 & \begin{tabular}{|l|l|} 
AVÍ́COLA \\
AV́́OII
\end{tabular} & $\frac{\text { SI }}{\text { st }}$ & Espacio alquilado & $\frac{\mathrm{NO}}{\mathrm{SI}}$ & 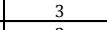 & 750 & DIARIA & & 0.50 & $x$ & $\mathrm{x}$ & $\mathrm{x}$ & $\mathrm{x}$ & $\mathrm{x}$ & & & MEDIANA & 0.60 \\
\hline$\frac{66}{67}$ & \begin{tabular}{|l|} 
AVÍCOLA \\
PIIADOR
\end{tabular} & $\frac{S I}{S I}$ & \begin{tabular}{|l} 
Espacio alquilado \\
Incl nronio
\end{tabular} & $\frac{\text { SI }}{\text { SI }}$ & 3 & 650 & DIARIA & SAN FERNANDO & 0.50 & $\frac{x}{x}$ & $\frac{x}{x}$ & $\frac{x}{x}$ & $\frac{x}{x}$ & $\frac{x}{x}$ & $x$ & & MUY ALTA & 0.55 \\
\hline$\frac{67}{68}$ & \begin{tabular}{|l|} 
IVICADORA \\
AVOCOA \\
\end{tabular} & $\frac{\mathrm{St}}{\mathrm{St}}$ & $\frac{\text { Local prop }}{\text { Espacio alc }}$ & $\frac{\mathrm{SI}}{\mathrm{SI}}$ & $\frac{4}{4}$ & $\frac{380}{600}$ & DIARIA & ER LOS ABEDULFS & 0.30 & $\frac{\mathrm{x}}{\mathrm{x}}$ & $\frac{x}{x}$ & $\frac{x}{x}$ & $\frac{x}{x}$ & & $x$ & & MEDIANA & 0.40 \\
\hline 69 & AVÍCOLA & SI & Espacio alquilado & $\mathrm{SI}$ & $\frac{4}{3}$ & 660 & DIAI & SAN FERNANDO & 0.50 & $\frac{A}{x}$ & $\frac{A}{x}$ & $\frac{A}{x}$ & $\frac{A}{x}$ & $\mathrm{x}$ & $\frac{1}{x}$ & & $\frac{\mid A L T A}{A L T A}$ & 0.70 \\
\hline 70 & AVÍCOLA & SI & Puesto de mercado & NO & 3 & 430 & DIAP & OTRO & 0.3 & $\mathrm{x}$ & $\mathrm{x}$ & $\mathrm{x}$ & & $\mathrm{x}$ & $\mathrm{x}$ & & MUY BAJA & 0.50 \\
\hline 71 & AVIíco & $\mathrm{SI}$ & Espacio alqui & $\mathrm{SI}$ & 3 & 450 & & NDOS & 0. & $\mathrm{x}$ & $\mathrm{x}$ & $\mathrm{x}$ & $\mathrm{x}$ & $\mathrm{x}$ & $\mathrm{x}$ & & ALTA & 0.55 \\
\hline 72 & AVÍCOLA & SI & Puesto de merca & NO & 3 & 410 & & & & $\mathrm{x}$ & $\mathrm{x}$ & $\mathrm{x}$ & & $\mathrm{x}$ & $\mathrm{x}$ & & & 0.50 \\
\hline 73 & AVÍCOLA & $\mathrm{SI}$ & Local acondicionado fuera de su casa & $\mathrm{SI}$ & & 410 & DIARIA & SAN FERNANDO & 35 & $x$ & $\mathrm{x}$ & $x$ & $x$ & $x$ & $x$ & & MUY ALTA & 0.50 \\
\hline & AVÍCOLA & & Puesto de mercado & NO & & 400 & DIARIA & REDONDOS & & & & & & & $\bar{x}$ & & & \\
\hline
\end{tabular}




\section{Anexo $\mathrm{N}^{\circ}$ 14: Detalle de costos y gastos.}

\section{Costos de Producción}

\begin{tabular}{|l|r|r|r|r|r|}
\hline \multicolumn{1}{|c|}{ Ítems } & $\mathbf{2 , 0 1 8}$ & $\mathbf{2 , 0 1 9}$ & $\mathbf{2 , 0 2 0}$ & $\mathbf{2 , 0 2 1}$ & $\mathbf{2 , 0 2 2}$ \\
\hline Planilla de operarios & 190,347 & 224,956 & 276,869 & 328,782 & 380,695 \\
\hline Planilla de Jefe de Operaciones & 45,240 & 45,240 & 45,240 & 45,240 & 45,240 \\
\hline Arrendamiento del local & 182,898 & 182,898 & 182,898 & 182,898 & 182,898 \\
\hline Corriente eléctrica & 50,847 & 50,847 & 50,847 & 50,847 & 50,847 \\
\hline Agua potable & 13,643 & 17,739 & 21,144 & 24,666 & 28,355 \\
\hline Empaque para usuario & 15,082 & 20,727 & 25,395 & 30,238 & 35,313 \\
\hline Empaque para consumidor & 75,409 & 103,636 & 126,977 & 151,190 & 176,563 \\
\hline Mantenimiento de planta & 13,139 & 13,139 & 13,139 & 13,139 & 13,139 \\
\hline Asesoría para certificación BPM & 4,800 & 4,800 & 4,800 & 4,800 & 4,800 \\
\hline Asesoría en desarrollo tecnológico & 2,400 & 2,400 & 2,400 & 2,400 & 2,400 \\
\hline Detergente & 3,456 & 3,456 & 3,456 & 3,456 & 3,456 \\
\hline Desinfectante & 2,687 & 2,687 & 2,687 & 2,687 & 2,687 \\
\hline Botas & 0 & 761 & 761 & 761 & 761 \\
\hline Guantes & 379 & 758 & 758 & 758 & 758 \\
\hline Cascos & 0 & 845 & 845 & 0 & 845 \\
\hline Orejeras & 0 & 845 & 845 & 845 & 845 \\
\hline Mascarillas (pack 50) & 74 & 148 & 148 & 148 & 148 \\
\hline Mamelucos & 2,854 & 5,708 & 5,708 & 5,708 & 5,708 \\
\hline Gorras (pack 25) & 339 & 678 & 678 & 678 & 678 \\
\hline Protectores plásticos & 547 & 1,093 & 1,093 & 1,093 & 1,093 \\
\hline Escobas & 0 & 194 & 194 & 194 & 194 \\
\hline Baldes & 0 & 126 & 126 & 126 & 126 \\
\hline Escobillas & 0 & 84 & 84 & 84 & 84 \\
\hline Mangueras de limpieza del local & 0 & 423 & 423 & 423 & 423 \\
\hline & $\mathbf{6 0 4 , 1 4 1}$ & $\mathbf{6 8 4 , 1 9 1}$ & $\mathbf{7 6 7 , 5 1 8}$ & $\mathbf{8 5 1 , 1 6 2}$ & $\mathbf{9 3 8 , 0 5 7}$ \\
\hline
\end{tabular}

\section{Gastos administrativos}

\begin{tabular}{|c|c|c|c|c|c|}
\hline Ítems & 2,018 & 2,019 & 2,020 & 2,021 & 2,022 \\
\hline Servicio de internet & 1,210 & 1,210 & 1,210 & 1,210 & 1,210 \\
\hline Lineas telefónicas & 2,014 & 2,014 & 2,014 & 2,014 & 2,014 \\
\hline Útiles de aseo personal & 1,017 & 1,017 & 1,017 & 1,017 & 1,017 \\
\hline Materiales de oficina & 1,017 & 1,017 & 1,017 & 1,017 & 1,017 \\
\hline Gerente Administrativo & 60,320 & 60,320 & 60,320 & 60,320 & 60,320 \\
\hline Asistente Administrativo y RRHH & 19,604 & 19,604 & 19,604 & 19,604 & 19,604 \\
\hline Servicio contables & 2,400 & 2,400 & 2,400 & 2,400 & 2,400 \\
\hline Impresión de facturas (millar) & 420 & 420 & 420 & 420 & 420 \\
\hline Total & 88,002 & 88,002 & 88,002 & 88,002 & 88,002 \\
\hline
\end{tabular}




\section{Gastos de ventas}

\begin{tabular}{|l|r|r|r|r|r|}
\hline \multicolumn{1}{|c|}{ Ítems } & $\mathbf{2 , 0 1 8}$ & $\mathbf{2 , 0 1 9}$ & $\mathbf{2 , 0 2 0}$ & $\mathbf{2 , 0 2 1}$ & $\mathbf{2 , 0 2 2}$ \\
\hline Lineas telefónicas & 1,007 & 1,007 & 1,007 & 1,007 & 1,007 \\
\hline Jefe Comercial & 45,240 & 45,240 & 45,240 & 45,240 & 45,240 \\
\hline Vendedores & 30,160 & 30,160 & 30,160 & 30,160 & 30,160 \\
\hline $\begin{array}{l}\text { Transporte para gestiones de } \\
\text { marketing }\end{array}$ & 1,920 & 1,920 & 1,920 & 1,920 & 1,920 \\
\hline Gastos en decoración del puesto & 1,440 & 1,440 & 1,440 & 1,440 & 1,440 \\
\hline Gastos en relaciones públicas & 24,000 & 24,000 & 24,000 & 24,000 & 24,000 \\
\hline Gastos en marketing digital & 2,400 & 2,400 & 2,400 & 2,400 & 2,400 \\
\hline Contratación de impulsadoras & 11,520 & 11,520 & 11,520 & 11,520 & 11,520 \\
\hline Elaboración de trípticos (Mll) & 4,800 & 4,800 & 4,800 & 4,800 & 4,800 \\
\hline Comisiones (2\%) & 16,288 & 22,385 & 27,427 & 32,657 & 38,138 \\
\hline Total & $\mathbf{1 3 8 , 7 7 5}$ & $\mathbf{1 4 4 , 8 7 2}$ & $\mathbf{1 4 9 , 9 1 4}$ & $\mathbf{1 5 5 , 1 4 4}$ & $\mathbf{1 6 0 , 6 2 4}$ \\
\hline
\end{tabular}

Nota: No se incluyen las depreciaciones. 


\section{BIBLIOGRAFÍA}

Arbaiza Fernandini, Lydia (2015). Cómo elaborar un plan de negocio. Lima: Universidad ESAN.

Malhotra, Naresh K. (2008). Investigación de mercados. México: Pearson Educación.

Kotler, Philip \& Keller, Kevin (2012). Dirección de marketing. México: Pearson Educación.

Nassir Sapag Chain (2011). Proyectos de inversión. Formulación y evaluación. Santiago de Chile: Pearson Educación.

Carabalí Ocoró, Victor (2013). Producción de proteína para consumo animal mediante hidrólisis de plumas de pollo en agua subcrítica [Trabajo de grado]. pp 3. Recuperado de: http://bibliotecadigital.univalle.edu.co/bitstream/10893/7896/1/CB-0481030.pdf 


\section{REFERENCIAS ELECTRÓNICAS}

Transparency International. “CORRUPTION PERCEPTIONS INDEX 2016”. En:

www.transparency.org [en línea]. Enero 2017 [Citado 01 de mayo del 2017]. Microsoft HTML.

Disponible en: https://www.transparency.org/news/feature/corruption_perceptions_index_2016

APEIM. "NIVELES SOCIOECONÓMICOS 2014”. En: http://www.apeim.com.pe [en línea] Lima. Agosto 2014. [Citado 01 abril 2017]. Microsoft HTML. Disponible en: http://www.apeim.com.pe/wp-content/themes/apeim/docs/nse/APEIM-NSE-2014.pdf

APEIM. "NIVELES SOCIOECONÓMICOS 2015". En: http://www.apeim.com.pe [en línea] Lima. Julio 2015. [Citado 01 abril 2017]. Microsoft HTML. Disponible en: http://www.apeim.com.pe/wp-content/themes/apeim/docs/nse/APEIM-NSE-2015.pdf

APEIM. "NIVELES SOCIOECONÓMICOS 2016". En: http://www.apeim.com.pe [en línea] Lima. Agosto 2016. [Citado 01 abril 2017]. Microsoft HTML. Disponible en: http://www.apeim.com.pe/wp-content/themes/apeim/docs/nse/APEIM-NSE-2016.pdf

La República. "17 millones de peruanos están en Facebook”. En: www.larepublica.pe [en línea] Lima. Junio 2016. [Citado 05 abril 2017]. Microsoft HTML. Disponible en: http://arepublica.pe/impresa/economia/780202-17-millones-de-peruanos-estan-en-facebook 
BCRP. "Encuesta de Expectativas Macroeconómicas del PBI”. En: www.bcrp.gob.pe [en línea] Lima. Junio 2017. [Citado 01 julio 2017]. Microsoft HTML. Disponible en: http://www.bcrp.gob.pe/docs/Estadisticas/Encuestas/Expectativas-PBI.xls

BCRP. "Encuesta de Expectativas Macroeconómicas de Inflación”. En: www.bcrp.gob.pe [en línea] Lima. Junio 2017. [Citado 01 julio 2017]. Microsoft HTML. Disponible en: http://www.bcrp.gob.pe/docs/Estadisticas/Encuestas/Expectativas-Inflacion.xls

BCRP. "Encuesta de Expectativas Macroeconómicas de Tipo de Cambio". En: www.bcrp.gob.pe [en línea] Lima. Junio 2017. [Citado 01 julio 2017]. Microsoft HTML. Disponible en: http://www.bcrp.gob.pe/docs/Estadisticas/Encuestas/Expectativas-Tipo-de-Cambio.xls

MINISTERIO DE AGRICULTURA Y RIEGO. "Boletín Estadístico Mensual de la Producción y Comercialización Avícola”. En: www.minagri.gob.pe [en línea] Lima. Julio 2017. [Citado 01 julio 2017]. Microsoft HTML. Disponible en:

http://siea.minagri.gob.pe/siea/?q=publicaciones/boletin-estadistico-mensual-de-la-produccion-y$\underline{\text { comercializacion-avicola }}$

INEI. “ESTIMACIONES Y PROYECCIONES DE POBLACIÓN". En: www.inei.gob.pe [en línea] Lima. [Citado 20 abril 2017]. Microsoft HTML. Disponible en:

http://www.inei.gob.pe/media/MenuRecursivo/Cap03020.xls 
INEI. "POBLACIÓN TOTAL AL 30 DE JUNIO, POR GRUPOS QUINQUENALES DE EDAD, SEGÚN DEPARTAMENTO, PROVINCIA Y DISTRITO”. En: www.inei.gob.pe [en línea] Lima. [Citado 20 abril 2017]. Microsoft HTML. Disponible en:

http://www.inei.gob.pe/media/MenuRecursivo/indices_tematicos/cuadro001_1.xls 